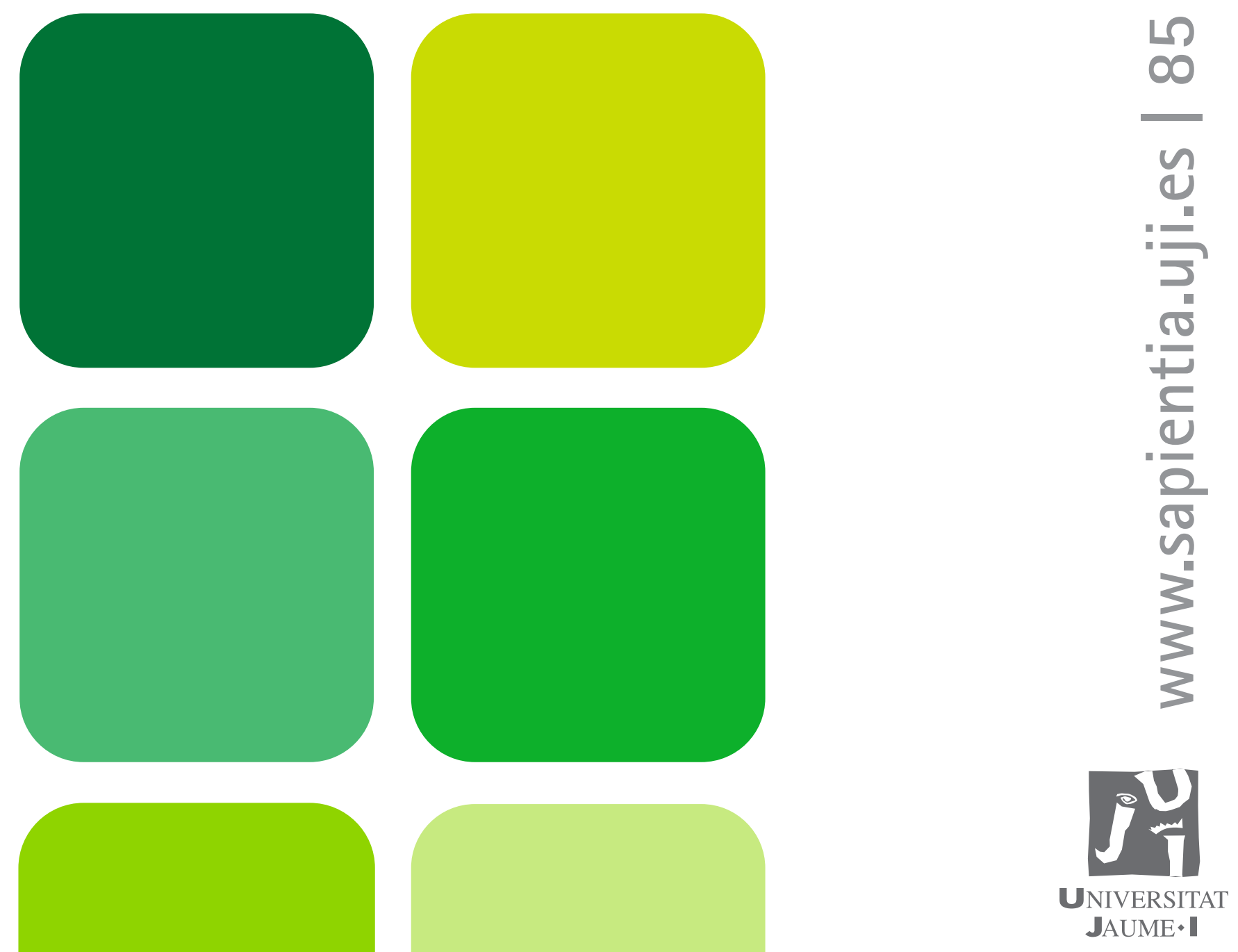

\title{
Cuaderno de prácticas de dibujo para la presentación de diseños de producto
}

Julia Galán Serrano Amelia Muñoz Torre María del Carmen Pesudo Carlos García García 


\section{Cuaderno \\ de prácticas de dibujo para la presentación de diseños de producto}

Julia Galán Serrano

Amelia Muñoz Torre

María del Carmen Pesudo

Carlos García García

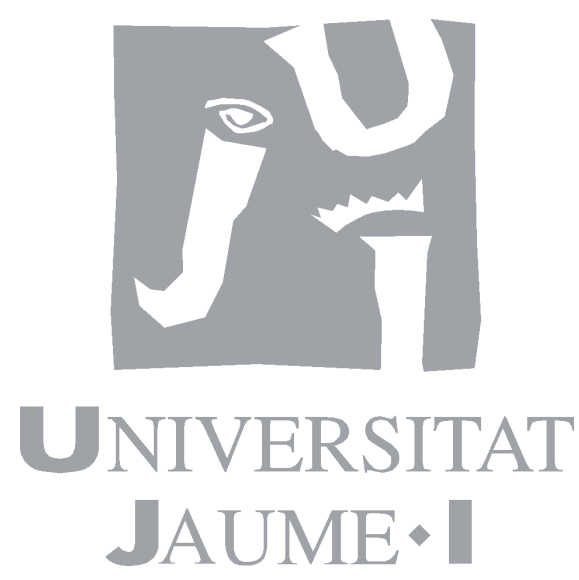

Departament d'Enginyeria de Sistemes INDUSTRIALS I DISSENY

- Codi d'assignatura DI1008 
Edita: Publicacions de la Universitat Jaume I. Servei de Comunicació i Publicacions Campus del Riu Sec. Edifici Rectorat i Serveis Centrals. 12071 Castelló de la Plana http://www.tenda.uji.es e-mail: publicacions@uji.es

(C) Compilació de totes les pràctiques i referències: Arecia Aguirre

Col·lecció Sapientia 83

www.sapientia.uji.es

Primera edició, 2013

ISBN: 978-84-695-8869-7

17 Publicacions de la Universitat Jaume I és una editorial membre de l'UNE, cosa que en garanteix la difusió de les obres en els àmbits nacional i inter-

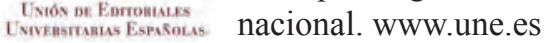

\section{(c) (i) (2)}

Reconeixement-CompartirIgual

\section{BY-SA}

Aquest text està subjecte a una llicència Reconeixement-CompartirIgual de Creative Commons, que permet copiar, distribuir i comunicar públicament l'obra sempre que s'especifique l'autor i el nom de la publicació fins i tot amb objectius comercials i també permet crear obres derivades, sempre que siguen distribuïdes amb aquesta mateixa llicència.

http://creativecommons.org/licenses/by-sa/3.0/legalcode 


\section{ÍNDICE}

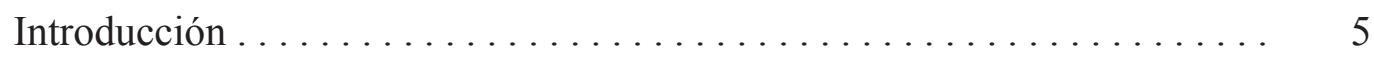

Bloque 1.

«Dibujar con el lado derecho del cerebro»

Compuesto de una serie de prácticas de dibujo de formas y contornos . . . . 7

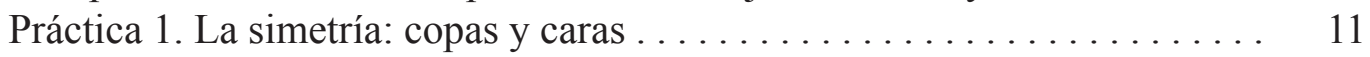

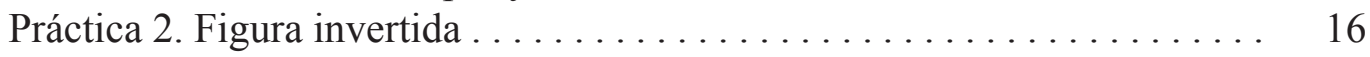

Práctica 3. Dibujo de contornos escuetos . .............. 20

Práctica 4. Dibujo de un modelo al natural: «Dibujo de contornos

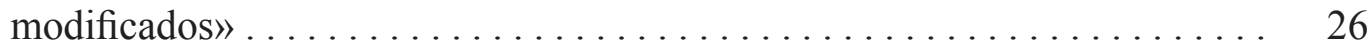

Bloque 2.

Diversas prácticas para la visualización de la forma, encajado de cuerpos geométricos, método de cajas, eje de simetría, método mixto . . . . . . . . Práctica 5. Encajado de cuerpos geométricos en diferentes posiciones y puntos de vista: cubos, prismas con diferentes bases poligonales, cilindros, conos y pirámides . . . . . . . . . . . 36

Práctica 6. Encajado de un objeto por el método de las cajas. Brick...... 50

Práctica 7. Encajado de un objeto por el método del eje de simetría. Lata de

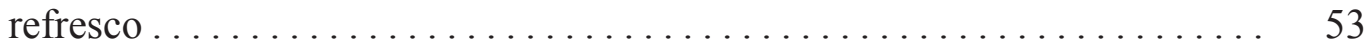

Práctica 8. Encajado de un objeto por el método mixto. Cacerola . . . . . . 56

Bloque 3.

Prácticas para el claroscuro y el color, escalas de valor, claroscuro de una composición, de un objeto sencillo, círculo cromático, escalas cromáticas .. Práctica 9. Escalas de valor . . . . . . . . . . . . . . . . . . . 67

Práctica 10. Claroscuro de una composición de volúmenes geométricos . . 70

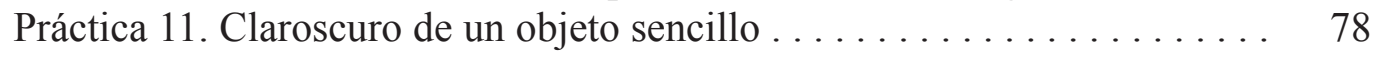

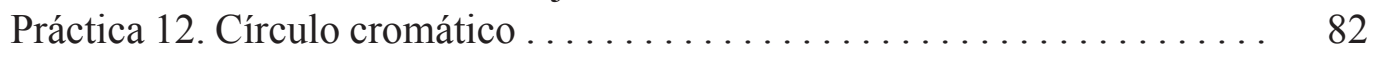

Práctica 13. Escalas cromáticas. Gama cálida y gama fría . . . . . . . . 86

Bloque 4.

Prácticas para la simulación de materiales, escalas de valor y renderizados

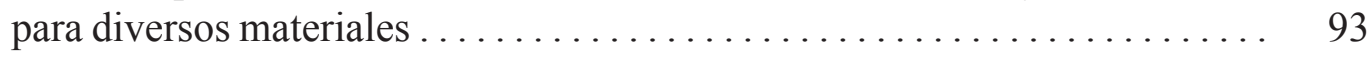

Práctica 14. Escala de valor para plástico mate .............. 96

Práctica 15. Encajado de un objeto para plástico mate ............. 99

Práctica 16. Renderizado a color con simulación de plástico mate ......... 102

Práctica 17. Escala de valor para plástico brillante . . . . . . . . . . 107 
Práctica 18. Encajado de un objeto para plástico brillante . . . . . . . . 111

Práctica 19. Renderizado a color con simulación de plástico brillante....... 114

Práctica 20. Escala de valor para metal . . . . . . . . . . . . . . 117

Práctica 21. Encajado de un objeto para metal . . . . . . . . . . 120

Práctica 22. Renderizado a color con simulación de metal .............. 123

Práctica 23. Escala de valor para madera . . . . . . . . . . . . 128

Práctica 24. Renderizado a color con simulación de madera .............. 131

Práctica 25. Escala de valor para material transparente. . . . . . . . . 136

Práctica 26. Renderizado a color con simulación de material transparente...... 138

Bloque 5.

La figura humana en el diseño industrial . . . . . . . . . . . . . 143

Práctica 27. La anatomía humana y el canon de proporción ........ . . 148

Práctica 28. Representación elemental de la figura humana ......... . 155

Práctica 29. El factor humano en el producto . . . . . . . . . . . . . 159

Práctica 30. Las manos . . . . . . . . . . . . . . . . . . . . . 170

Bibliografía .............................. 177

Selección de títulos comentados . . . . . . . . . . . . . . . . . . . 180 


\section{Introducción}

Este cuaderno de prácticas de dibujo para la representación de diseños de producto está enfocado hacia todos aquellos estudiantes de diseño que necesiten mejorar su competencia artística. Esta publicación se ha realizado concretamente para la asignatura de Expresión Artística I y tiene como objetivo fundamental aprender a realizar un renderizado o representación gráfica de un objeto industrial. Con esta colección de ejercicios prácticos que presentamos, los estudiantes adquirirán las habilidades procedimentales adecuadas para un diseñador o diseñadora industrial; habilidades que le permitirán ser capaz de realizar buenos dibujos de renderización. Al mismo tiempo, aprenderán a manejar las diferentes técnicas gráficas como medio de expresión para representar, captar y determinar la forma de un objeto industrial.

Aunque la capacidad para dibujar todos la poseemos, muchos de nuestros alumnos de diseño llegan a las aulas sin tener las destrezas mínimas con relación a la visualización y representación de la forma, ni tampoco saben cómo emplear y seleccionar las diferentes técnicas gráfico-plásticas según las intenciones expresivas pretendidas en sus trabajos.

Si un diseñador no sabe dibujar no conseguirá buenos resultados en sus creaciones. Por tanto, cuanto mejor dibujen nuestros estudiantes de diseño más aumentará su capacidad comunicativa y mejor transmitirán sus propias ideas. Si se consigue comunicar a través de los renderizados toda la información sobre el producto, el diseñador tiene garantizado el éxito de proyecto y su diseño será más efectivo.

Realizar las prácticas que este cuaderno propone, garantiza un dominio básico de los métodos y del proceso de dibujo que se emplean en las diferentes etapas de ejecución de diseño de productos.

El cuaderno posee un formato útil y práctico para el estudiante, ya que aporta una gran variedad de prácticas que están organizadas por temas y por diferentes niveles de complejidad; de forma que cada estudiante puede seleccionarlas según sus propias necesidades de aprendizaje.

A lo largo de la publicación se van tratando de forma práctica los contenidos de la asignatura Expresión Artística I relacionados a continuación: composición y análisis de formas, forma y color, análisis de las formas y sus proporciones, medios y funciones del dibujo, expresión gráfico-analítica, formas, materiales, texturas y color, análisis de diferentes soportes, técnicas y medios de representación gráfica. Asimismo, también se estudia la relación y presentación entre el producto diseñado y la figura humana.

El carácter procedimental de la asignatura requiere que el estudiantado dedique un tiempo al dibujo de forma regular y constante en casa. En este libro, el alumnado 
encontrará un conjunto de ejercicios gráficos que guiarán su estudio y complementarán los contenidos y prácticas que se le plantean en las clases. Por ello, esta publicación está formulada como un manual de autoaprendizaje que permite al alumnado comprobar progresivamente la corrección de sus dibujos.

Las prácticas propuestas están ordenadas según el grado de dificultad, por ello se aconseja realizarlas según el orden que se propone en el índice. Se comienza con la adquisición de destrezas y conceptos básicos del dibujo, para seguir con la aplicación del claroscuro, se introduce la teoría y la aplicación del color y se continúa con la simulación gráfica de materiales, para finalizar con la representación del cuerpo humano.

Cada una de las prácticas está planteada bajo el siguiente esquema:

a) Los objetivos que se deben alcanzar con la resolución de los problemas gráficos propuestos.

b) La relación de materiales necesarios para su ejecución.

c) La guía de ejecución donde se describe el planteamiento de la práctica y los pasos que se deben seguir para su correcta realización.

d) Una guía de autocorrección en la cual se relaciona una serie de consejos para representar con éxito los modelos propuestos, se describen además, unos errores habituales que el alumno no debe cometer en lo concerniente a la visualización de la forma, la representación de las texturas de los materiales y acabados de objetos, o también posibles fallos en los sistemas de aplicación de las técnicas de expresión gráfico-plásticas. Con este material, el estudiante puede evaluar el resultado de sus trabajos y adquirir así la capacidad de análisis crítico de su propio aprendizaje.

e) Ejemplos resueltos

El cuaderno contiene numerosas imágenes que muestran paso a paso la realización de las prácticas y ofrece también una numerosa colección de trabajos de estudiantes que ejemplifican las propuestas de cada práctica y marcan el nivel de ejecución, calidad y resultado que debe adquirir con la práctica del cuaderno. 
BLOQUE 1

"Dibujar con el lado derecho
del cerebro».
Compuesto de una serie
de prácticas de dibujos
de formas y contornos 
Este bloque reúne un conjunto de prácticas extraídas del libro Aprender a dibujar con el lado derecho del cerebro, escrito por Betty Edwards, y que han sido adaptadas a los objetivos de esta asignatura. Con el empleo de este método los estudiantes asumen la importancia de saber mirar el modelo para poder dibujarlo posteriormente. Para la realización de las prácticas de este bloque se recomienda la lectura de los capítulos 3 y 4 del mencionado libro.
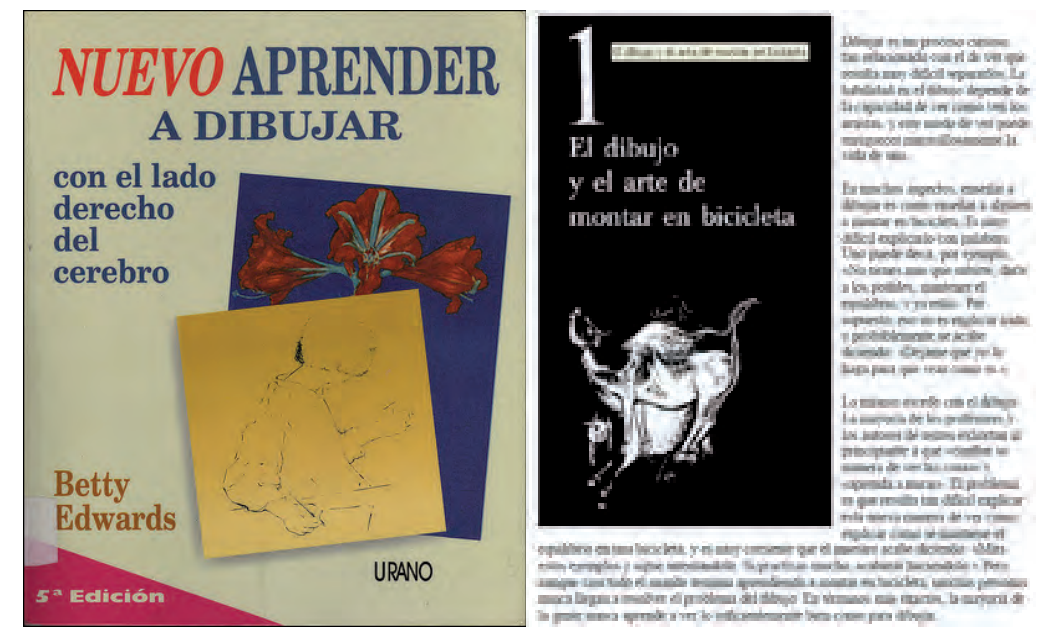

EDWARDs, Betty, Aprender a dibujar con el lado derecho del cerebro, Ed. Urano

Gracias a la realización de estos ejercicios se consigue educar la percepción para saber captar la identidad formal, estructural, espacial y matérica de los objetos que se van a representar.

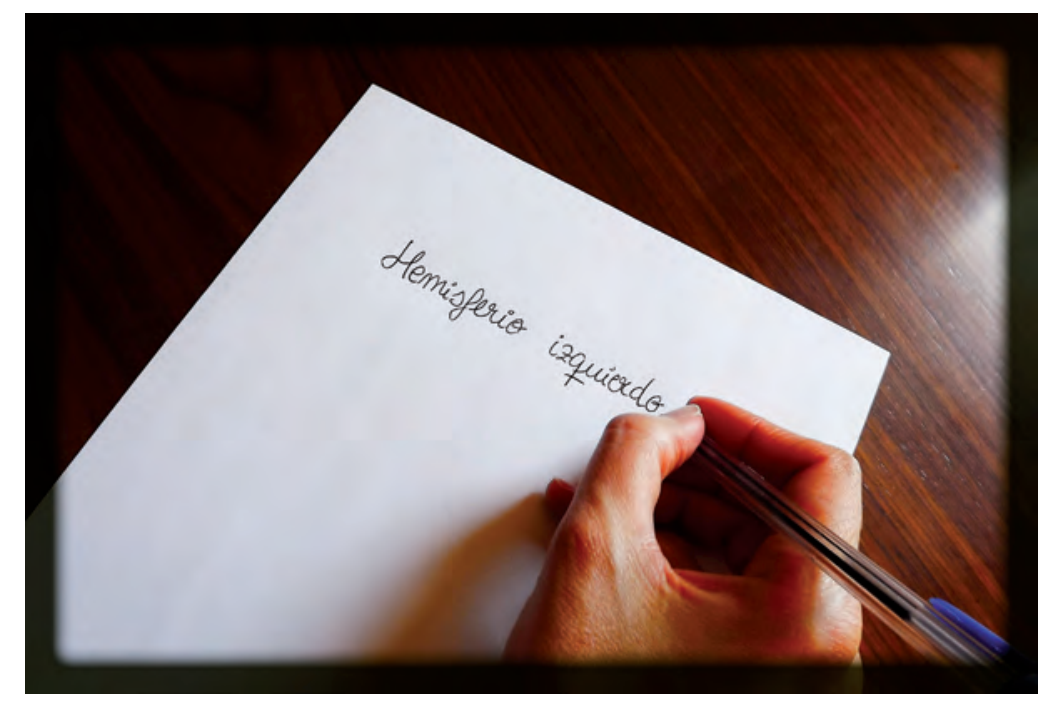

Los hemisferios tienen las funciones cruzadas: el hemisferio derecho controla la parte izquierda del cuerpo y el hemisferio izquierdo, la derecha. La comunicación entre los hemisferios permite utilizar sus funciones específicas según precise nuestra actividad. Fotografía realizada por Lucía Ribelles Santos

Este método de dibujo está basado en los diferentes procesos cognitivos de ambos hemisferios cerebrales y el paso del lado izquierdo al derecho es fundamental para la actividad del dibujante. 
- El cerebro: funciones de los dos hemisferios.

- Hemisferio izquierdo: verbal y analítico.

- Hemisferio derecho: visual y espacial.

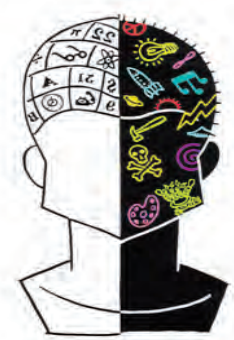

\section{Hemisferio Izquierdo}

Esquema visual sobre las cualidades funcionales de cada hemisferio del cerebro

- Características cognitivas del hemisferio izquierdo:

- verbal (palabras)

- analítico (desglosa)

- simbólico (dibujos esquemáticos)

- temporal

- numérico

- racional
- Características cognitivas del hemisferio derecho: - no verbal (imágenes) - sintético (compone) - analógico (dibuja lo que ve)

- atemporal

- espacial

- intuitivo

Este método está basado en la percepción y la concentración que permite conectar con el hemisferio derecho del cerebro que es el que controla la percepción espacial, ayuda a medir las magnitudes y las distancias, permite observar detenidamente los detalles, y con él se consigue dibujar estrictamente lo que vemos sin dejarnos influir por las imágenes esquemáticas que tenemos formadas desde la infancia.
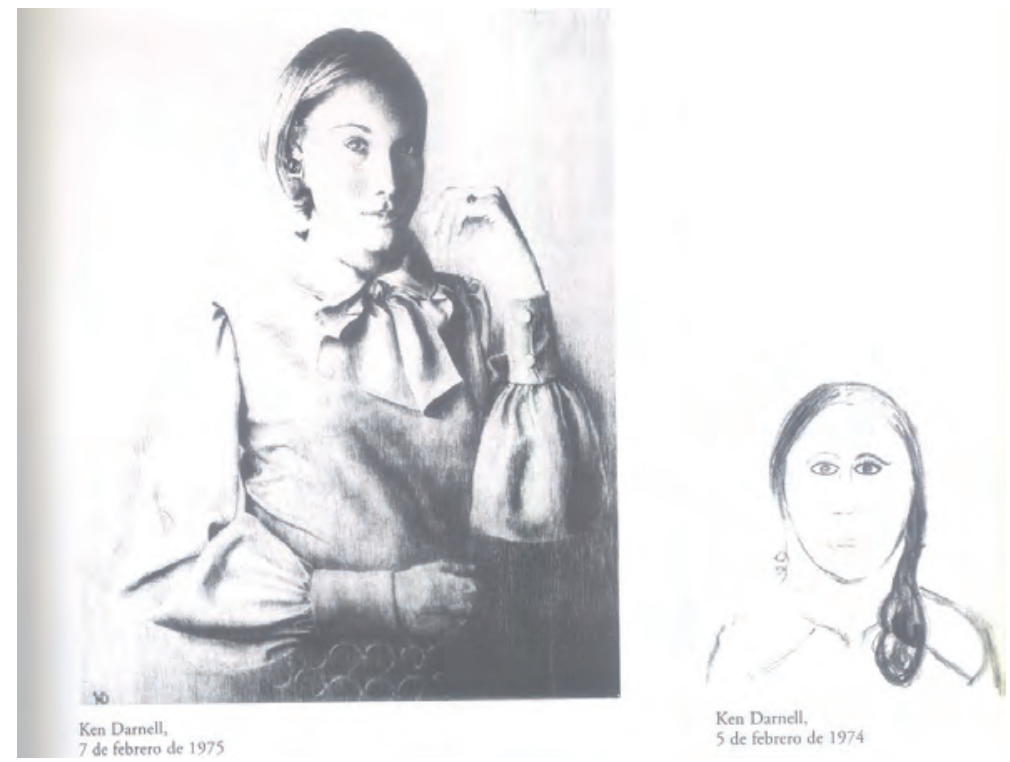

Resultados gráficos obtenidos por el método que propone el libro de EDwARDS, Betty, Aprender a dibujar con el lado derecho del cerebro, Ed. Urano 


\section{Práctica 1}

\section{La simetría: copas y caras}

Esta práctica nos hace reflexionar sobre el complejo mundo de la representación simétrica. La mayoría de objetos y seres vivos de nuestro entorno tienen formas simétricas, por ello es de suma importancia saber captar las distancias entre los espacios simétricos.

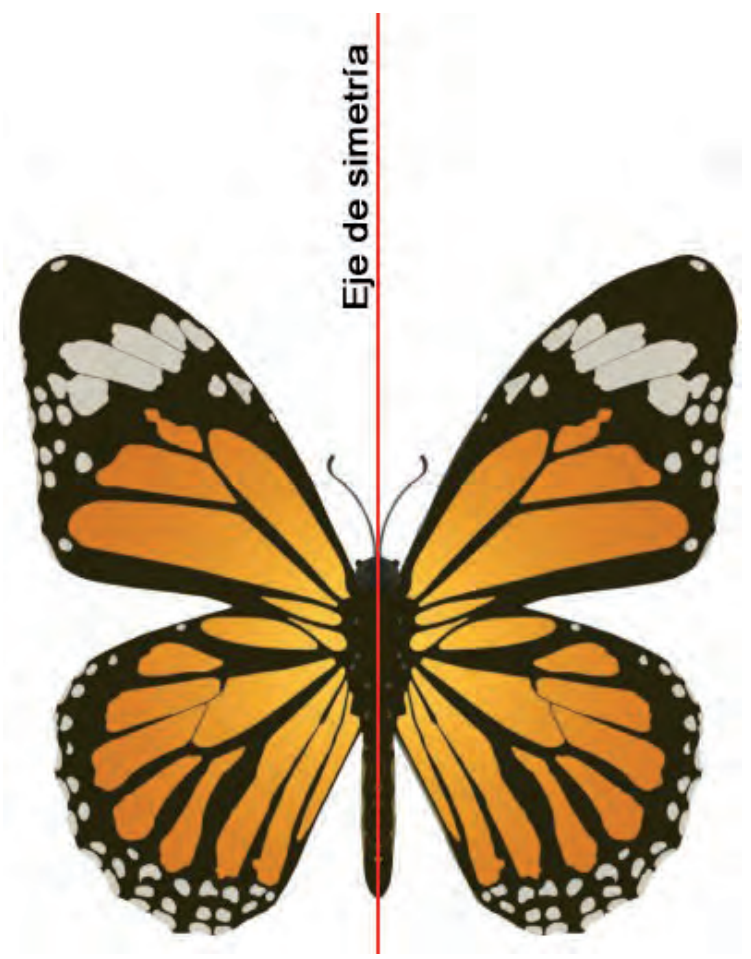

Ejemplo de simetría en la naturaleza

\section{A. Objetivos}

Esta práctica tiene una doble finalidad: conectar con el hemisferio derecho del cerebro para controlar nuestra percepción espacial y captar los bordes de los contornos simétricos. Los objetivos que se deben alcanzar con esta práctica son:

- Desarrollar la capacidad de observación.

- Experimentar el paso de la modalidad de trabajo del modo izquierdo al derecho.

- Comenzar a dibujar midiendo distancias, direcciones y ángulos. 


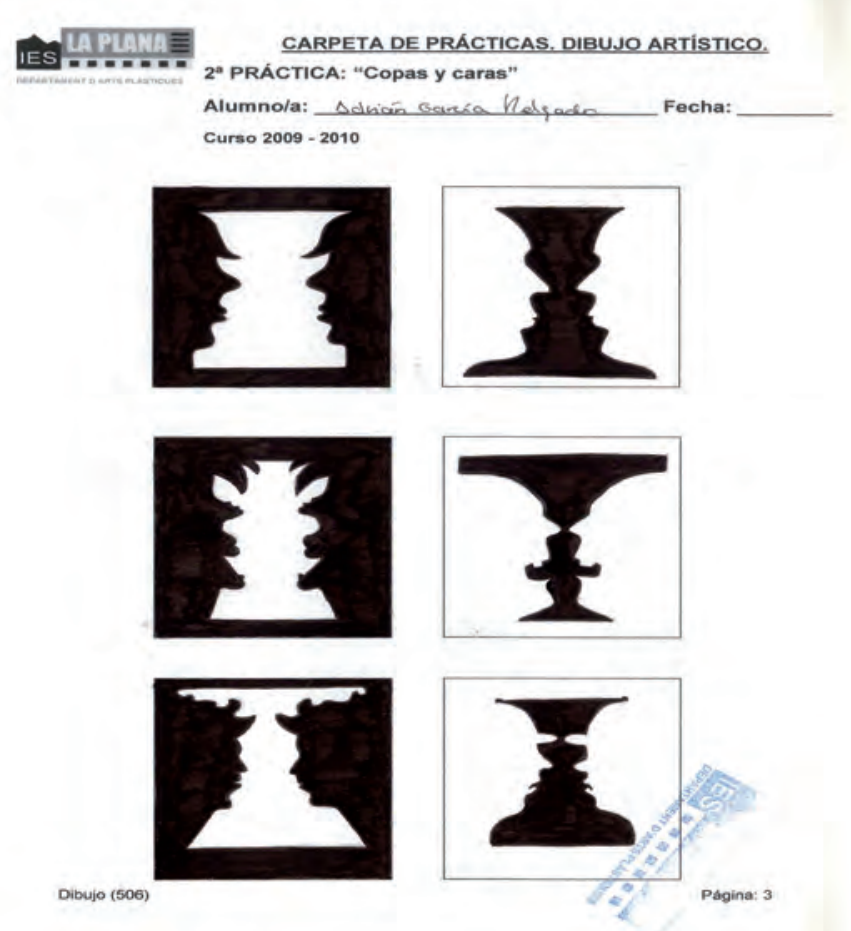

Realizado por Adrián García Delgado

\section{B. Materiales}

- Papel formato DIN A4

- Lápiz de dureza HB

- Goma de lápiz

\section{Guía de ejecución}

\section{Planteamiento}

- La práctica consistirá en realizar un dibujo de la imagen ambigua de las copas y las caras siguiendo el proceso de dibujo del hemisferio derecho del cerebro.

- Se trazarán en el papel seis pequeños rectángulos. En cada uno de ellos se ensayará el trazado de diversos perfiles confrontados, buscando cada vez mayor complejidad formal imaginando que vamos transformando el rostro al ir cambiando sus proporciones.

- Es aconsejable analizar nuestra capacidad de concentración y exactitud en los resultados que obtenemos, a medida que vamos realizando los primeros dibujos. 
- Finalmente, para poner a prueba nuestro aprendizaje, realizaremos un dibujo a mayor tamaño en otro papel. Esta vez, el rectángulo será de 14 x $22 \mathrm{~cm}$. Al trabajar a mayor tamaño, la medición de las distancias resulta más difícil y por tanto, la representación de la simetría se complica. Además, el perfil de partida debe ser mucho más complejo, por ejemplo puede servirnos el perfil de una bruja, de un monstruo, etc.

\section{Proceso de ejecución del dibujo}

$1 .^{\circ}$ En el lado izquierdo del papel (o en el derecho si es zurdo) se dibuja el perfil de una persona mirando hacia el centro.

2. ${ }^{\circ}$ Dibujar dos líneas horizontales arriba y abajo del perfil.

3. ${ }^{\circ}$ Repasar con el lápiz el perfil dibujado nombrando los rasgos al mismo tiempo que se desplaza el lápiz.

4. ${ }^{\circ}$ Comenzar a dibujar el otro perfil enfrentado sin pensar la palabra o significado de lo que vamos representando, según el modo derecho del cerebro. Solo nos preocuparemos de captar las direcciones, las distancias, las longitudes, los ángulos. Comprobaremos que únicamente así seremos capaces de dibujar exclusivamente lo que vemos.

5. ${ }^{\circ}$ Comenzaremos el dibujo por arriba. Comprobando cada borde que vamos trazando con el simétrico e intentando encontrar errores para borrarlos y rectificar hasta obtener el perfil simétrico correcto.

Figura 4.3. Para diestros.

Figura 4.4. Para zurdos.

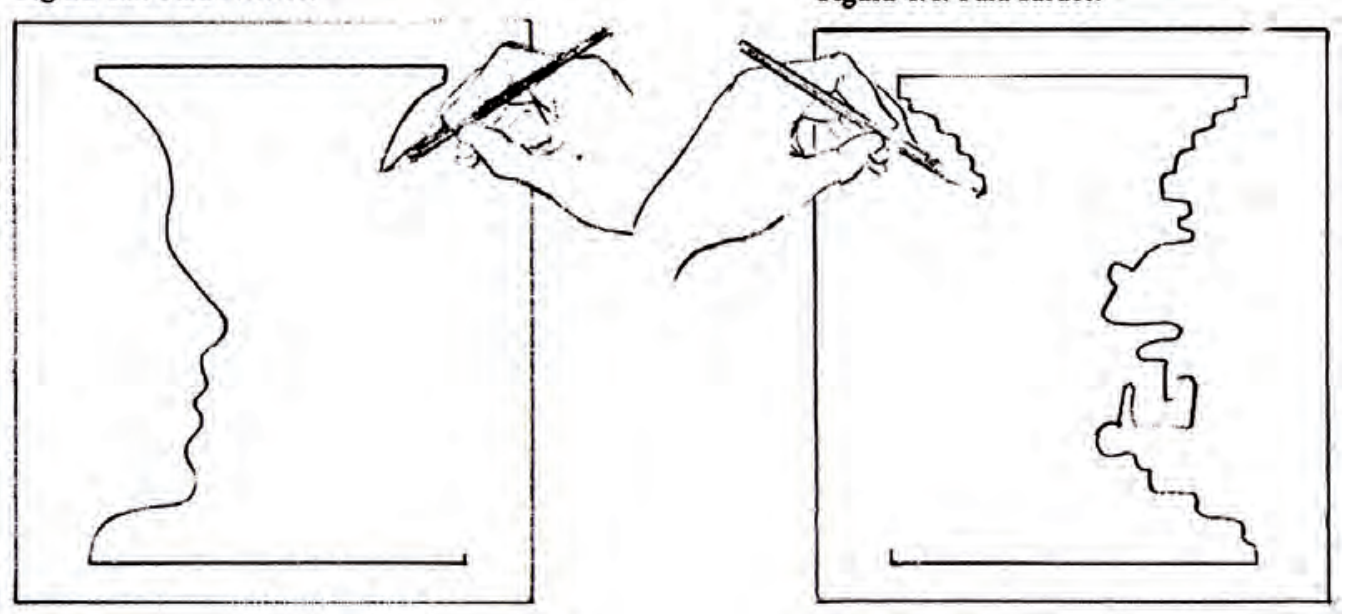

Dibujos extraídos del libro de EdwaRds, BETTy, Aprender a dibujar con el lado derecho del cerebro, Ed. Urano 


\section{Guía de autocorrección}

- Una vez realizados los dibujos conviene reflexionar sobre las diferentes sensaciones que hemos experimentado en el momento de dibujar el primer perfil respecto al segundo. Mientras dibujábamos el primero con el hemisferio izquierdo íbamos nombrando con palabras cada parte del rostro sin preocuparnos demasiado de la forma, pero al representar el segundo, es normal sentir la necesidad de dejar de verbalizar para poder concentrarnos en las distancias y así poder medir correctamente el cambio simétrico que experimenta la forma.

- Es aconsejable pintar de negro el fondo de algunos rectángulos y dejar en blanco la copa para poder comprobar con mayor facilidad los errores de simetría que hayamos podido cometer.

- Normalmente, cada persona tiene una tendencia a desviar las direcciones, a estirar o comprimir determinadas distancias... Si somos capaces de encontrar nuestros defectos, seremos capaces de rectificar y mejorar la calidad de nuestras representaciones.

- Para encontrar esos errores en nuestros dibujos de simetría debemos formularnos las siguientes cuestiones:

- Respecto al eje de simetría de referencia: ¿Está perpendicular a la base del rectángulo o por el contrario se nos ha torcido?

- En el segundo perfil: ¿Se van estirando las alturas de cada cambio formal a medida que descendemos en el dibujo?, ¿se van acortando excesivamente las anchuras respecto al primer perfil a medida que avanzamos en el trazado de la simetría?, ¿existe desnivel entre los puntos más próximos de la copa? 
E. Ejemplos resueltos

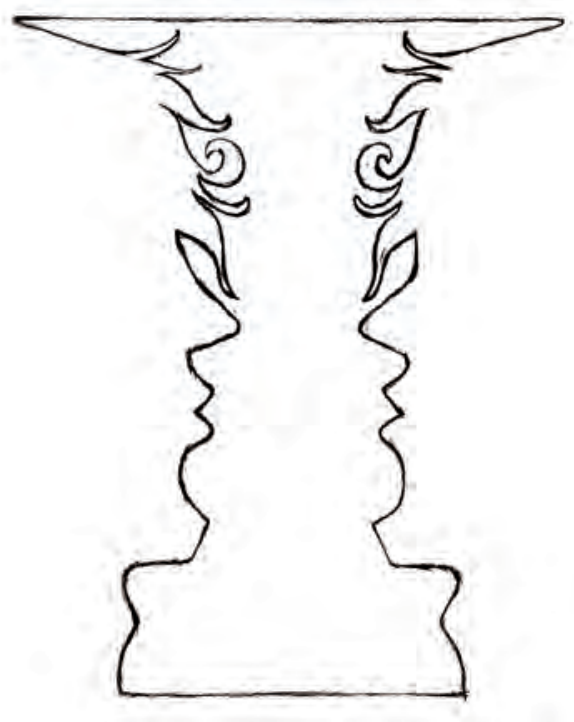

Realizado por Sara Gómez Tirado
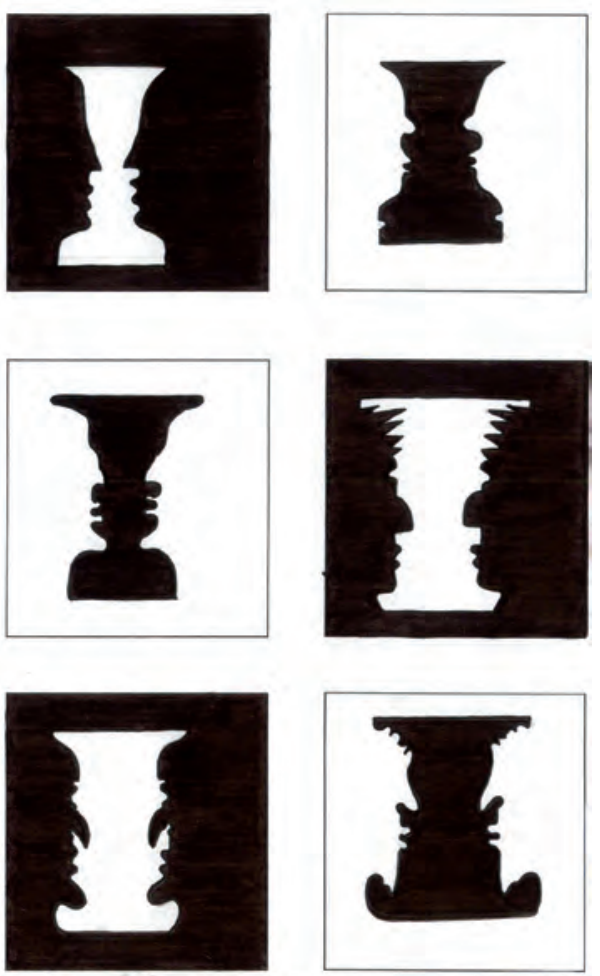

Realizado por Lara Ordóñez Aguilar

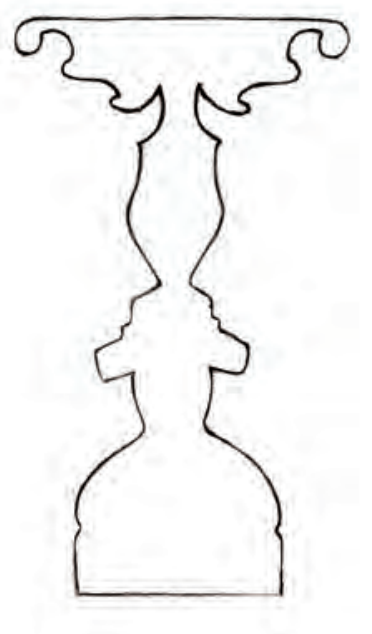

Realizado por Carlos Bellés Bastán
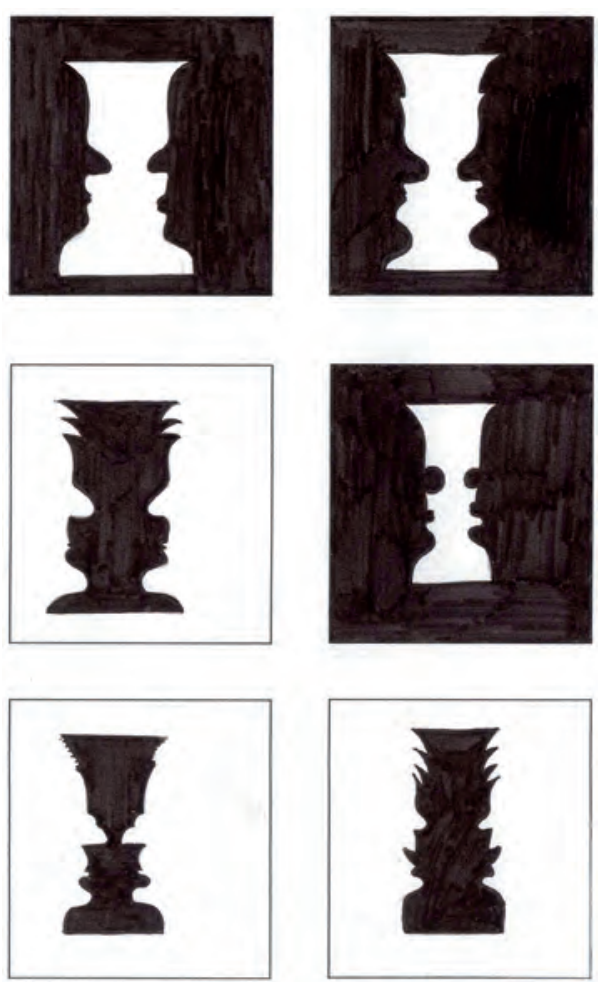

Realizado por Aitana Agulló Ribera 


\title{
Práctica 2 \\ Figura invertida
}

\begin{abstract}
A. Objetivos
El procesamiento y análisis de las imágenes invertidas es mucho más complejo, nos cuesta más reconocer todo aquello que se nos muestra. El hemisferio izquierdo (que necesita procesar la información con rapidez) no reconoce de inmediato la imagen que le mostramos, por ello se impacienta, necesita clasificar y ordenar la información de inmediato. Por tanto, vamos a mostrarle el modelo en posición invertida para que deje paso al hemisferio derecho, que es precisamente el que nos ayuda a dibujar las cosas tal y como las vemos.
\end{abstract}
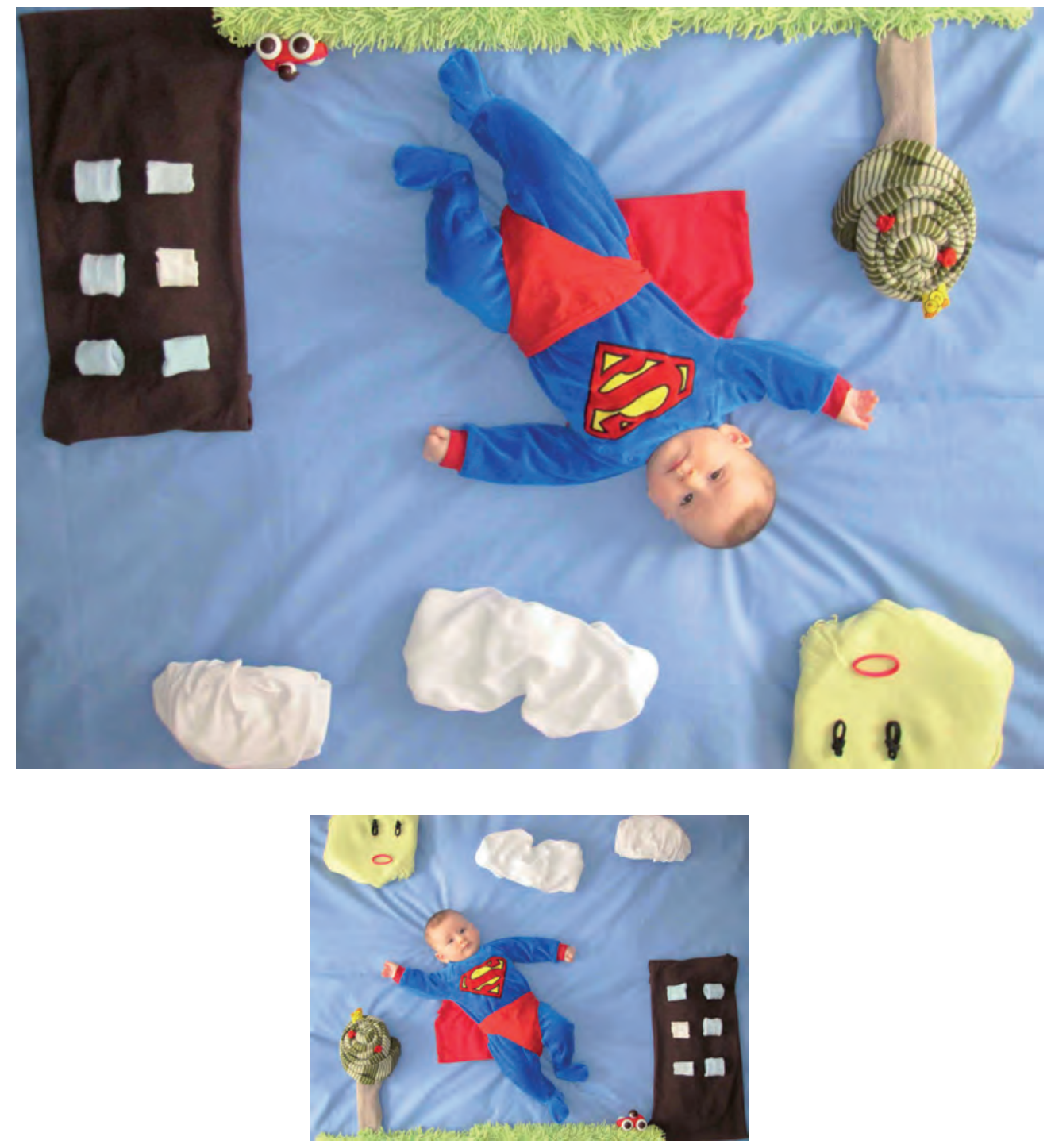

Fotografía realizada por Mercé Guillem Durà y Javier Ribelles Santos 
Los objetivos que se deben alcanzar en esta práctica continúan siendo los mismos que en el ejercicio anterior:

- Desarrollar la capacidad de observación.

- Experimentar el paso de la modalidad de trabajo del modo izquierdo al derecho.

- Comenzar a dibujar midiendo distancias, direcciones y ángulos.

\section{B. Materiales}

- Papel formato DIN A4

- Lápiz de dureza HB

- Goma de lápiz

- Imagen invertida de modelo y hoja de papel A4 con un rectángulo trazado del mismo tamaño que el del modelo propuesto.

\section{Guía de ejecución}

\section{Planteamiento}

- La práctica consistirá en realizar un dibujo de la imagen invertida propuesta conectando con el hemisferio derecho del cerebro.

- Durante una sesión de 30 a 40 min. Se ha dibujar la imagen invertida propuesta en un papel DIN A4 con un área de dibujo rectangular del mismo tamaño que el modelo.

- En ningún momento podemos dar la vuelta a la imagen ni a nuestro dibujo hasta que este acabado.

\section{Proceso de ejecución del dibujo}

1. $\quad$ Mirar el dibujo invertido durante un minuto. Observar los ángulos, los espacios, analizar dónde comienza y acaba cada línea con relación a las contiguas.

2. ${ }^{\circ}$ Dibujar sin interrupciones y sin dar la vuelta al modelo.

3. Comenzar por la parte superior, avanzando de línea a línea sin adjudicar nombre a lo que se está dibujando.

4. ${ }^{\circ} \quad$ No dibujar nunca de forma salteada. Pasar de una línea a la adyacente hasta completar el dibujo. 
5. ${ }^{\circ}$ A medida que vamos avanzando en el dibujo, comprobaremos cómo la modalidad de trabajo del hemisferio derecho nos mantiene completamente concentrados, y ya no pensamos con palabras sino con distancias y direcciones.
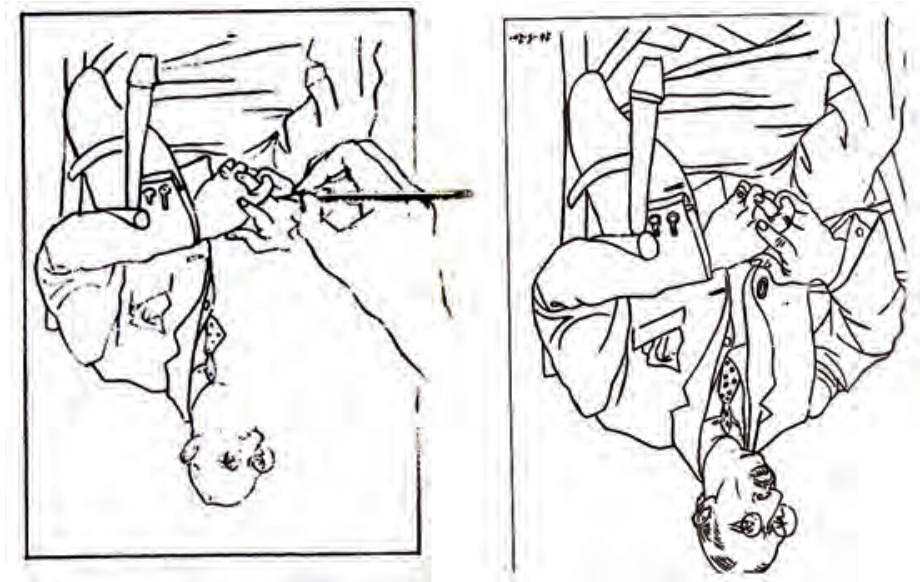

Dibujos extraídos del libro de EDWARDs, Betty, Aprender a dibujar con el lado derecho del cerebro. Ed. Urano

\section{Guía de autocorrección}

- Una vez finalizado el dibujo, colocamos la imagen y el dibujo en posición normal y nos sorprenderá comprobar que hemos sido capaces de reproducir una imagen con tanta precisión.

- Es importante recordar la tendencia de errores personales cometidos en la práctica anterior, para comprobar que hemos sido capaces de superarlos.

- Se recomienda realizar tres dibujos de figura invertida para afianzar el aprendizaje sobre proporción y análisis del modelo.

- Para encontrar esos errores de medición en el dibujo se superpone el dibujo al modelo y lo miramos a contraluz para encontrar rápidamente las desproporciones, omisión de detalles, etc. Es aconsejable reflexionar sobre las siguientes cuestiones:

- La capacidad de concentración. Sabremos si hemos conectado con el hemisferio derecho y hemos conseguido la suficiente concentración siempre que nuestro dibujo no muestre los errores que se relacionan a continuación:

- Nuestro dibujo tiene una apariencia esquemática porque no registra todas las líneas y detalles del modelo.

- El dibujo se sale del área de dibujo.

- El tiempo invertido en la realización del dibujo: el tiempo de referencia para trabajar el ejercicio es de 30 a 40 min aproximadamente. Tiene como objetivo comenzar a conocer nuestra agilidad gráfica y así podremos organizar mejor el trabajo en las próximas sesiones de dibujo. 
E. Ejemplos resueltos
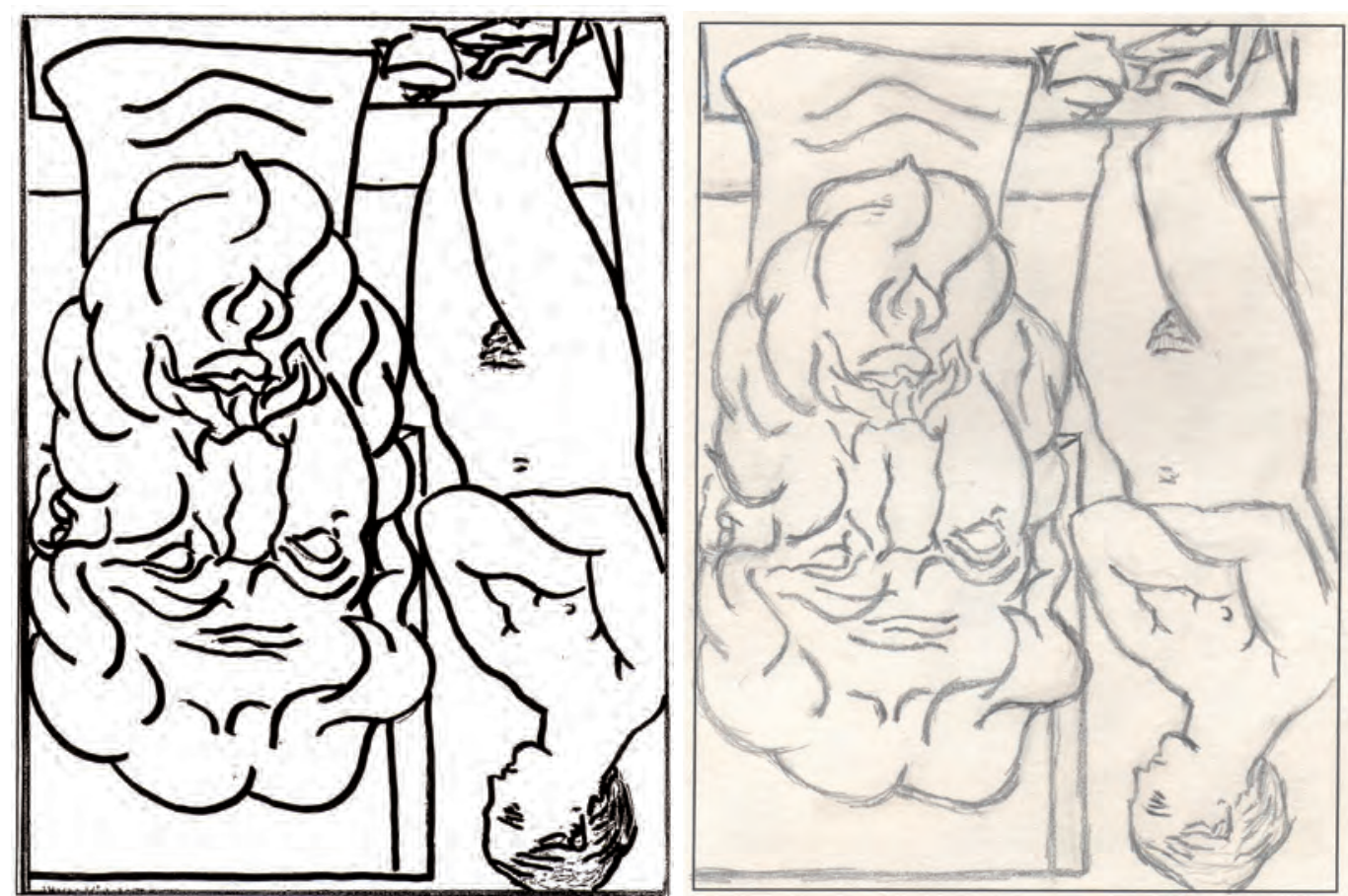

Realizado por Sara Gómez Tirado
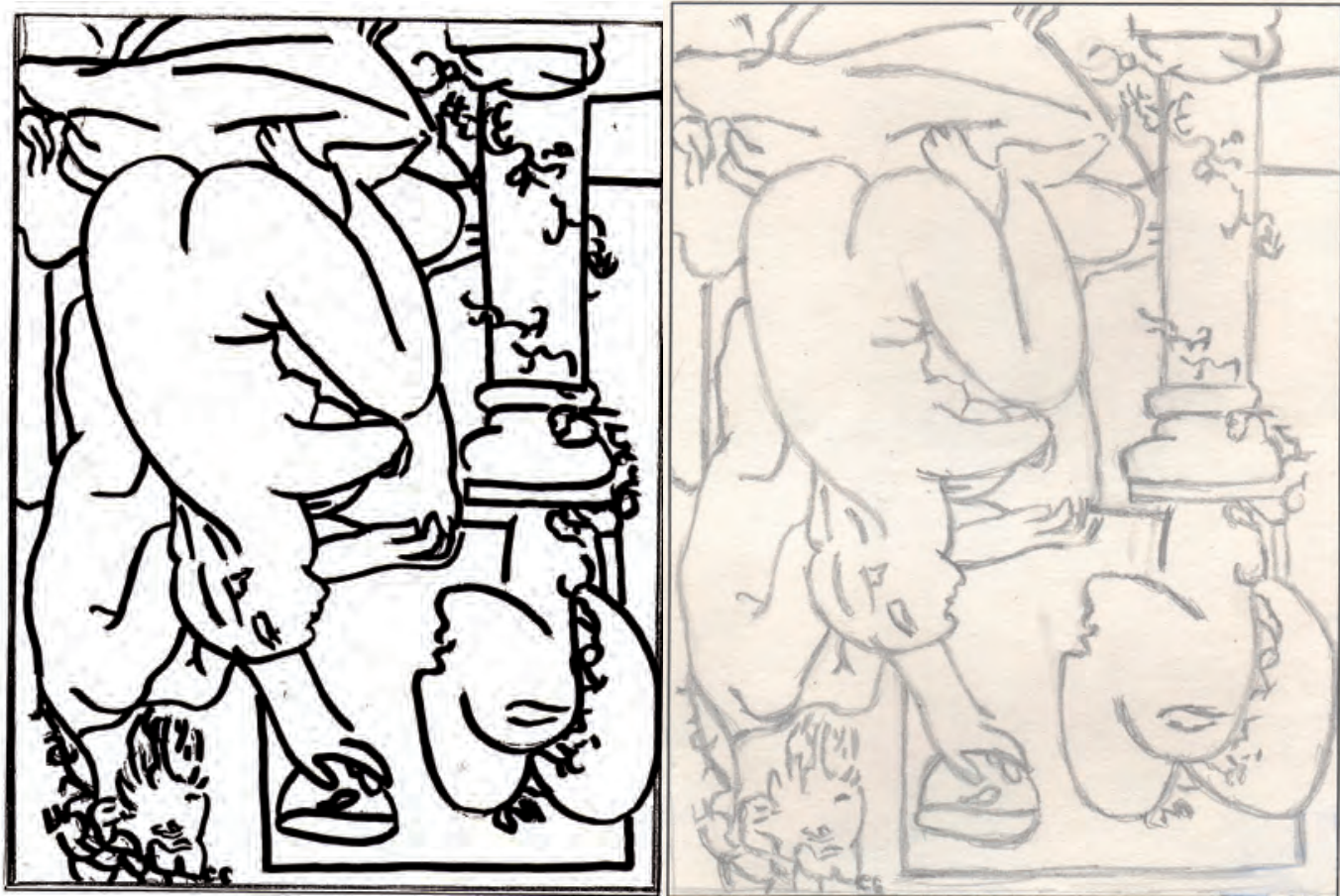

Realizado por Sara Gómez Tirado 


\section{Práctica 3 \\ Dibujo de contornos escuetos}

\section{A. Objetivos}

La principal finalidad de esta práctica consiste en agudizar nuestra visión para el estudio de las dimensiones y la proporción. Cada movimiento del ojo se traducirá en una línea en el papel. Por lo tanto, aprenderemos a sincronizar el movimiento de la visión con el de la mano.

- Desarrollar la capacidad de observación y análisis del modelo.

- Sincronizar la percepción con el movimiento de la mano cuando dibuja.

- Comenzar a dibujar midiendo distancias, direcciones y ángulos.

\section{B. Materiales}

- Papel formato DIN A4

- Lápiz de dureza HB

- Goma de lápiz

\section{Guía de ejecución}

\section{Planteamiento}

- Vamos a continuar dibujando con el lado derecho del cerebro, pero en esta ocasión la visión tendrá un protagonismo especial ya que se trata de dibujar sin mirar el papel.

- Elegiremos un modelo complicado a nivel formal para que, ante su complejidad, se desconecte el hemisferio izquierdo y podamos dibujar con la modalidad «D» del cerebro. Puede servir una flor, una rama, un llavero...

- Se trata de mirar el modelo sin nombrarlo, hay que observarlo como formas que tienen unos bordes que hay que saber analizar para traducirlos en el papel como líneas. 


\section{Proceso de ejecución del dibujo}

- Este ejercicio pretende efectuar todos los registros gráficos del proceso de percepción.

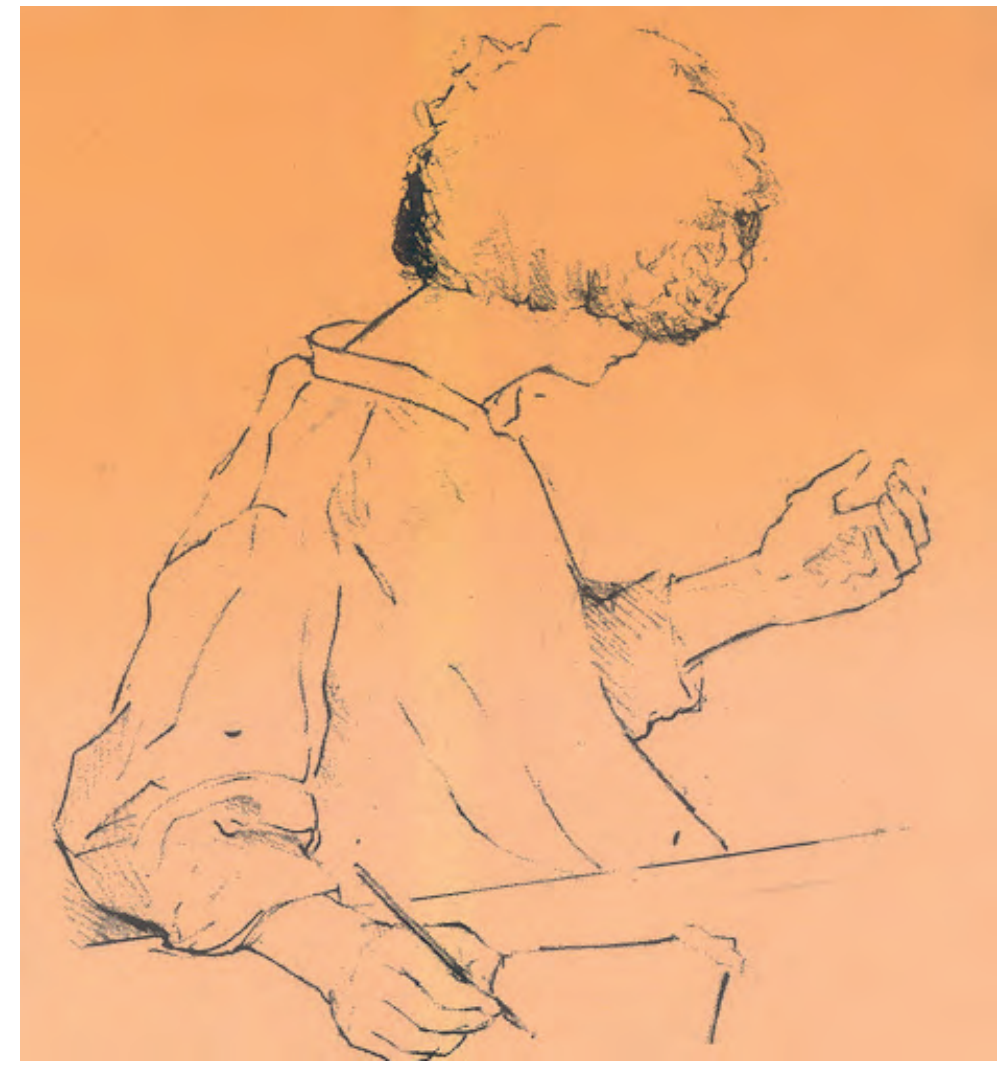

Dibujo extraído del libro de Edwards, Betty, Aprender a dibujar con el lado derecho del cerebro. Ed. Urano

- Dibujar sin interrupciones durante 20 min». Fijar la hoja de papel a la mesa con celo.

- Vamos a dibujar el modelo sin mirar el papel, para ello adoptamos la posición que indica la imagen.

- Dirigimos la mirada a alguna parte del modelo y buscamos un punto en el papel por donde comenzar a dibujar. Vamos trazando líneas para cada detalle que percibimos: contornos, detalles, etc., pero sin nombrar con palabras estos elementos. Imaginamos que tenemos delante un puzle de bordes que deben encajar a la perfección en el dibujo. Registramos todo lo que vemos en el preciso instante en que lo percibimos.

- A medida que vamos avanzando en el dibujo comprobamos cómo la modalidad de trabajo del hemisferio derecho nos mantiene completamente concentrados, nos olvidamos del tiempo que transcurre y solo nos preocupan las distancias, los ángulos, las direcciones, etc. 
- Dibujamos por zonas. Un borde nos lleva al contiguo, es decir, no dibujamos el borde exterior y luego rellenamos con los detalles interiores sino que vamos dibujando bordes de elementos adyacentes.

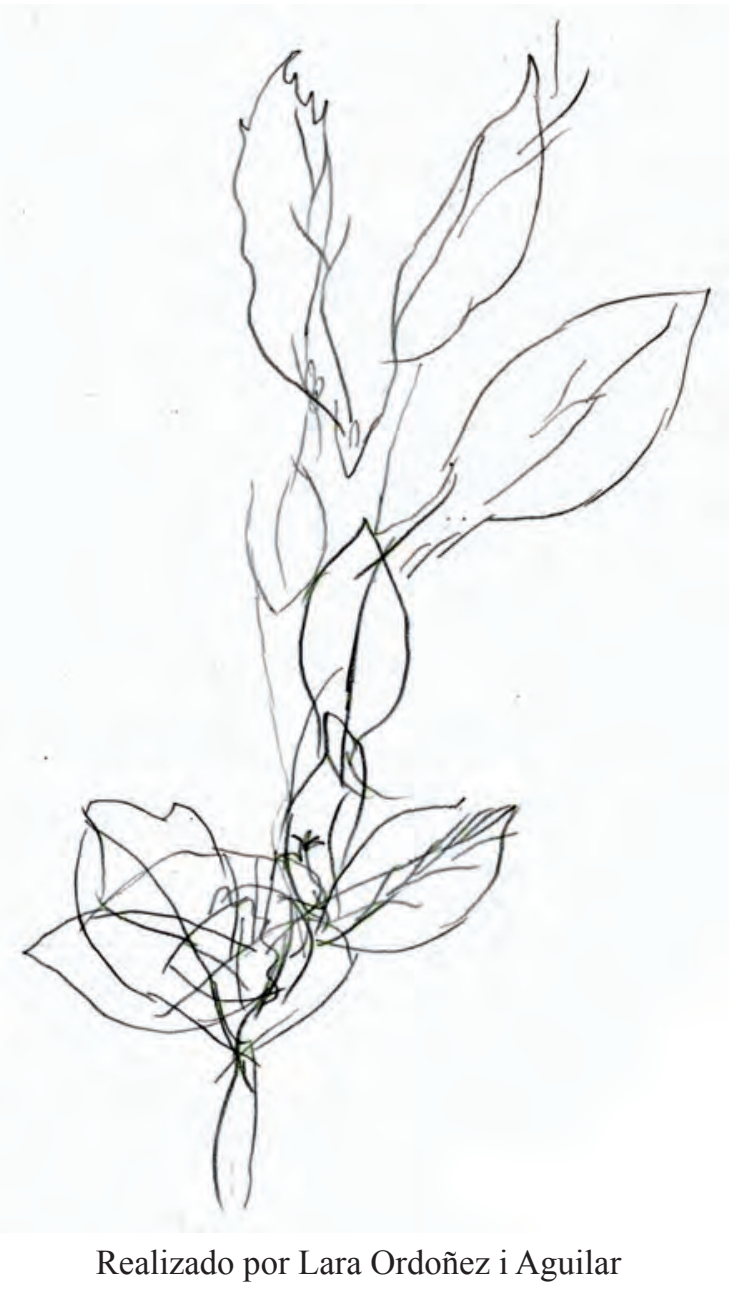

\section{Guía de autocorrección}

- Es importante haber resistido a la tentación de mirar el dibujo, pero una vez finalizado, como siempre, es importante reflexionar sobre el resultado.

- El dibujo obtenido será tremendamente extraño, pero en él podemos averiguar si nuestra percepción trabaja por el camino adecuado para lograr dibujar correctamente.

- Se recomienda utilizar este ejercicio como un breve calentamiento antes de comenzar cualquier sesión de dibujo, ya que de este modo nos forzamos a mirar con detenimiento el modelo para aprendérnoslo, y ser capaces posteriormente de reproducir su forma y sus proporciones. 
- Para analizar el dibujo obtenido, observaremos las siguientes cuestiones:

- Dibujo con pocas líneas. Si cada línea es un registro de la visión, un dibujo con pocas líneas manifiesta poca concentración y por lo tanto, no se ha conectado con el hemisferio derecho adecuadamente. En este caso, es aconsejable repetir el ejercicio hasta experimentar la correcta sincronización entre la visión y el movimiento de la mano. Tal y como observamos en las siguientes imágenes:
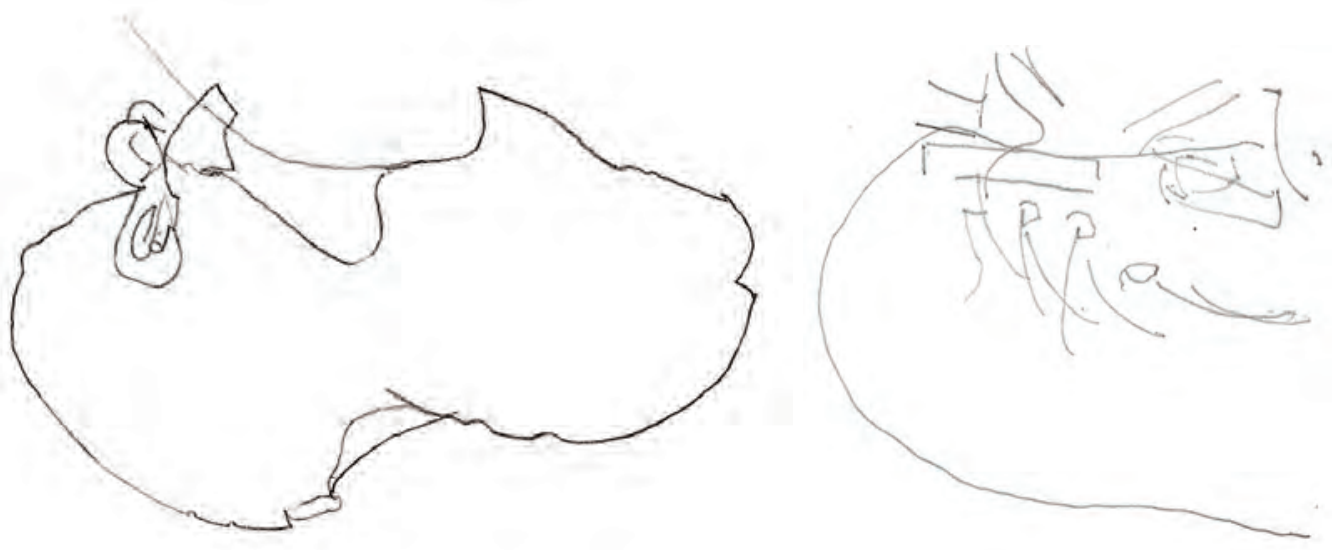

- Excesivo desplazamiento de los elementos representados. El dibujo resultante no puede ser realista porque no hemos mirado el papel, pero si vamos educando la visión espacial y sincronizamos correctamente el movimiento de la visión con el de nuestra mano, los dibujos deben mostrar un desplazamiento relativo de las formas.

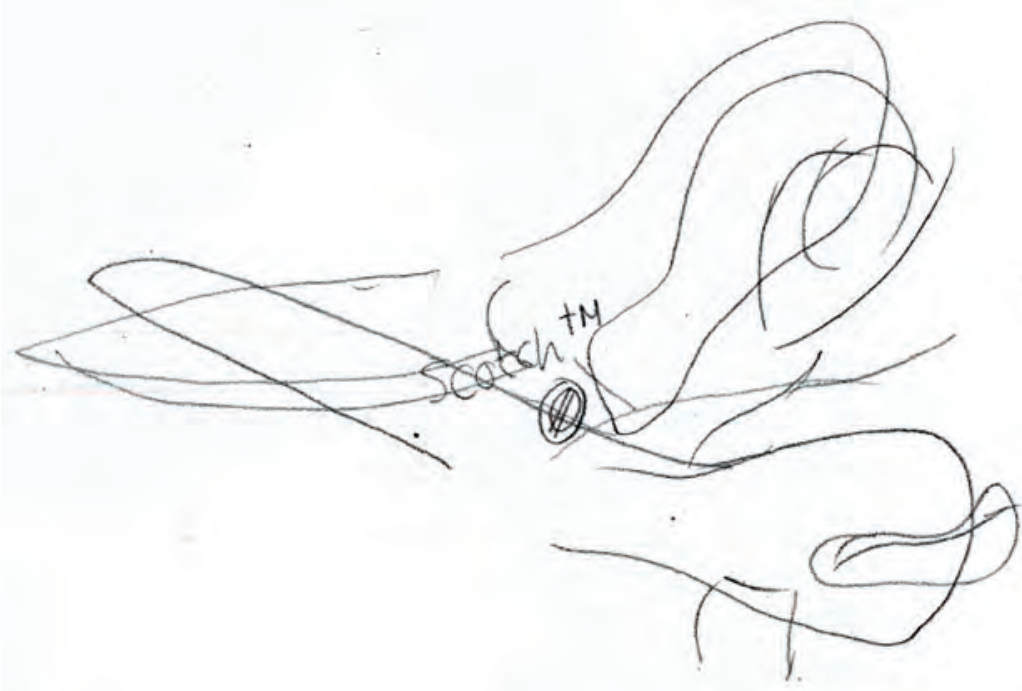




\section{E. Ejemplos resueltos}

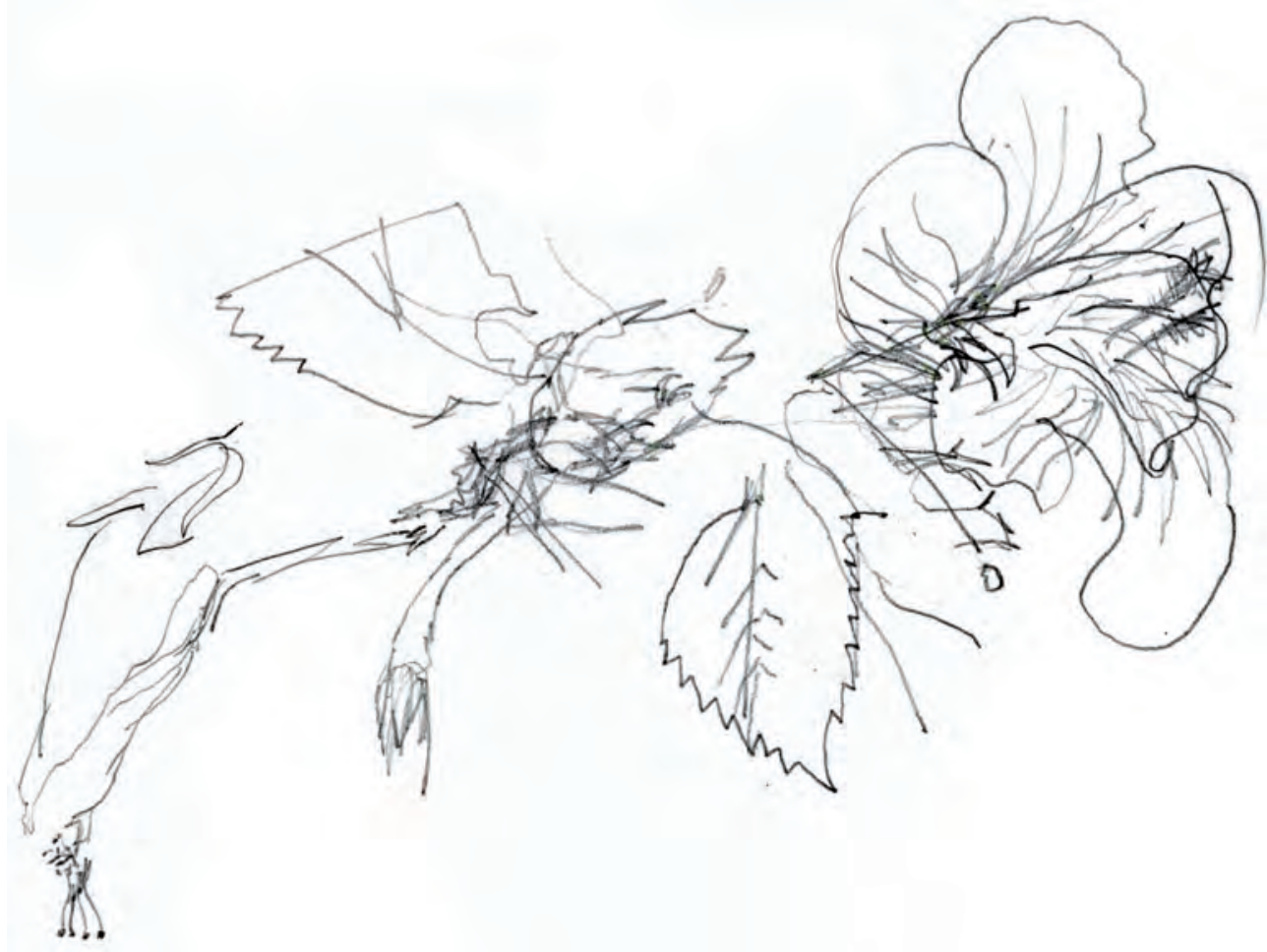

Realizado por Sandra Gual Gago

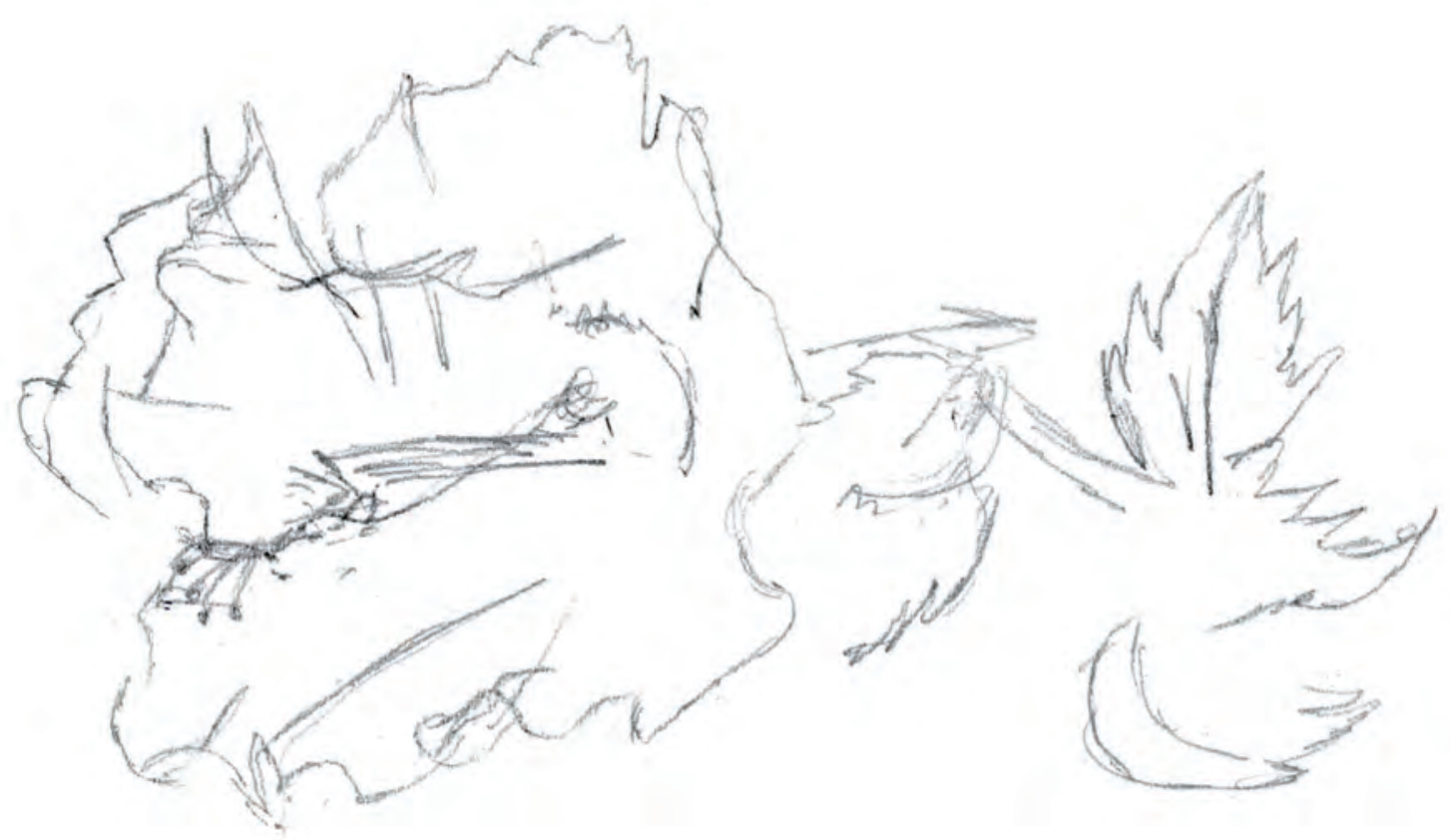

Realizado por Adrián García Delgado 


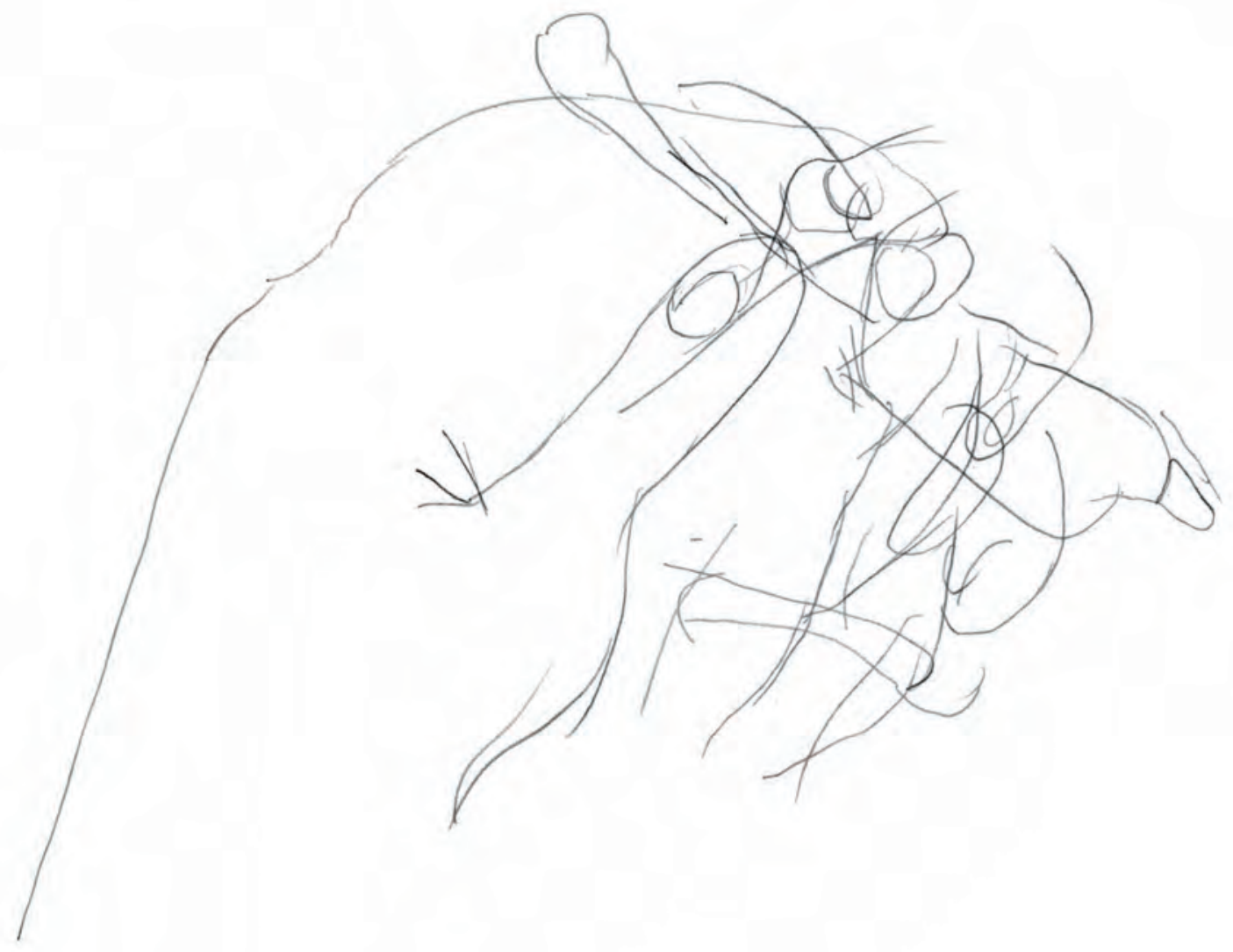

Realizado por Lara Ordóñez i Aguilar 


\section{Práctica 4 \\ Dibujo de un modelo al natural: dibujo de contornos modificados}

\section{A. Objetivos}

Esta práctica es la continuación de la anterior y sigue su planteamiento, pero ahora se nos permite mirar el dibujo, detectar errores y modificarlos. Sus objetivos se enumeran a continuación:

- Desarrollar la capacidad de observación y análisis del modelo.

- Sincronizar la percepción con el movimiento de la mano cuando dibuja.

- Comenzar a dibujar midiendo distancias, direcciones y ángulos.

- Detectar errores durante el proceso de dibujo y corregirlos.

B. Materiales

- Papel formato DIN A4

- Lápiz de dureza HB

- Goma de lápiz

\section{Guía de ejecución}

\section{Planteamiento}

- Elegiremos el modelo de la práctica anterior y, siguiendo el mismo proceso perceptivo, intentaremos captar la forma y el mayor número posible de detalles.

- Podemos mirar el dibujo y rectificarlo las veces que creamos conveniente.

\section{Proceso de ejecución del dibujo}

- Antes de iniciar este ejercicio, se debe realizar como calentamiento de la visión, un dibujo de contornos escuetos del mismo modelo. 
- Dibujar sin interrupciones durante al menos 30 min». Fijar la hoja de papel a la mesa con celo.

- Vamos a dibujar el modelo imaginando una línea vertical y otra horizontal junto a él. Luego miramos el papel e imaginamos que sus extremos son ambas coordenadas. Comenzamos a dibujar por una zona concreta del modelo mirando el papel únicamente para rectificar.

- Vamos describiendo con líneas cada detalle que percibimos. Registramos todo lo que vemos en el preciso instante que lo miramos.

- Dibujamos por zonas, un borde nos lleva al contiguo, es decir, no dibujamos el borde exterior y luego rellenamos con los detalles interiores sino que vamos dibujando bordes de elementos adyacentes.

\section{Guía de autocorrección}

- Esta vez hay que valorar el grado de parecido con el modelo, la corrección formal y la captación de los detalles que aportan identidad al modelo.

- Es probable que en este primer ejercicio detectemos errores de proporción, pero sin lugar a dudas se pueden ir corrigiendo a base de repetir la práctica con diferentes modelos y realizando las siguientes prácticas del cuaderno.

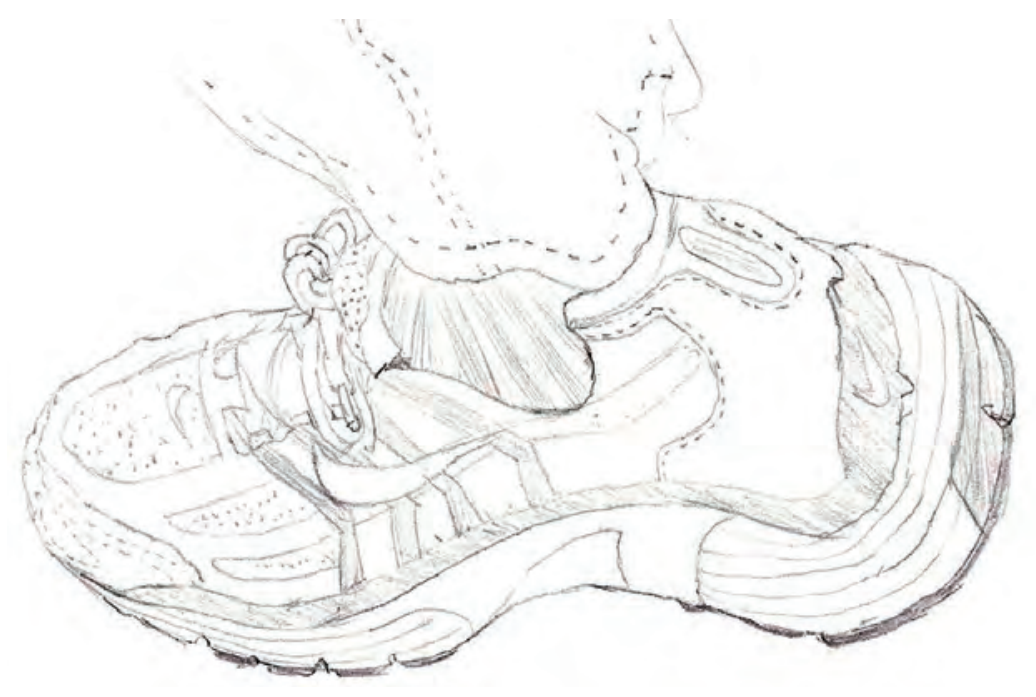

- Si observamos que algunas zonas del modelo, determinados acabados, o las texturas de los materiales están resueltos de forma esquemática, ello significa que no hemos alcanzado el grado de concentración necesaria para trabajar con el hemisferio derecho del cerebro. 


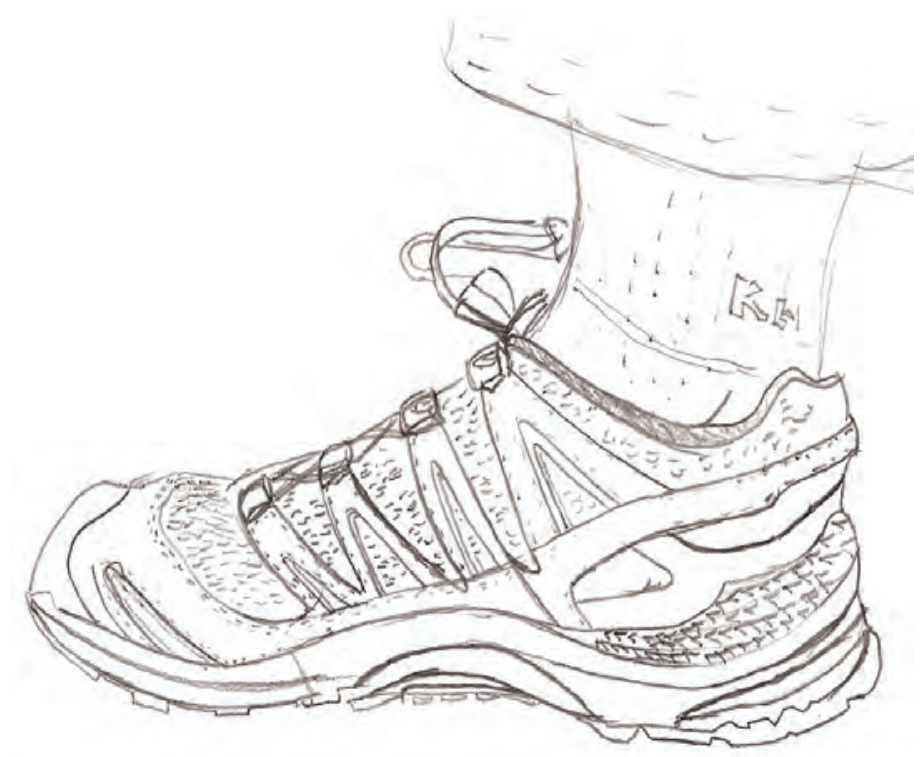

E. Ejemplos resueltos

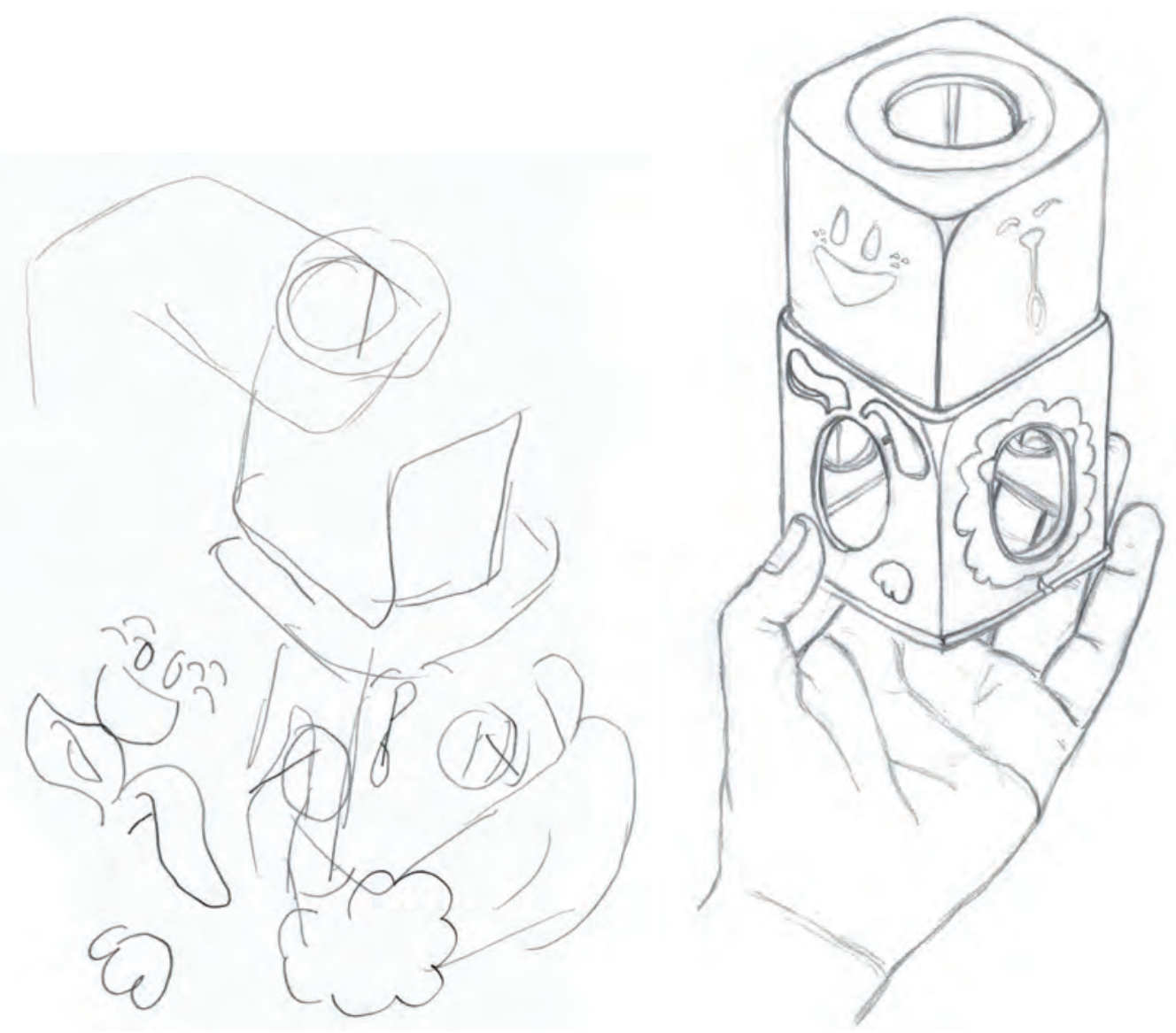

Realizado por Lara Ordóñez i Aguilar 


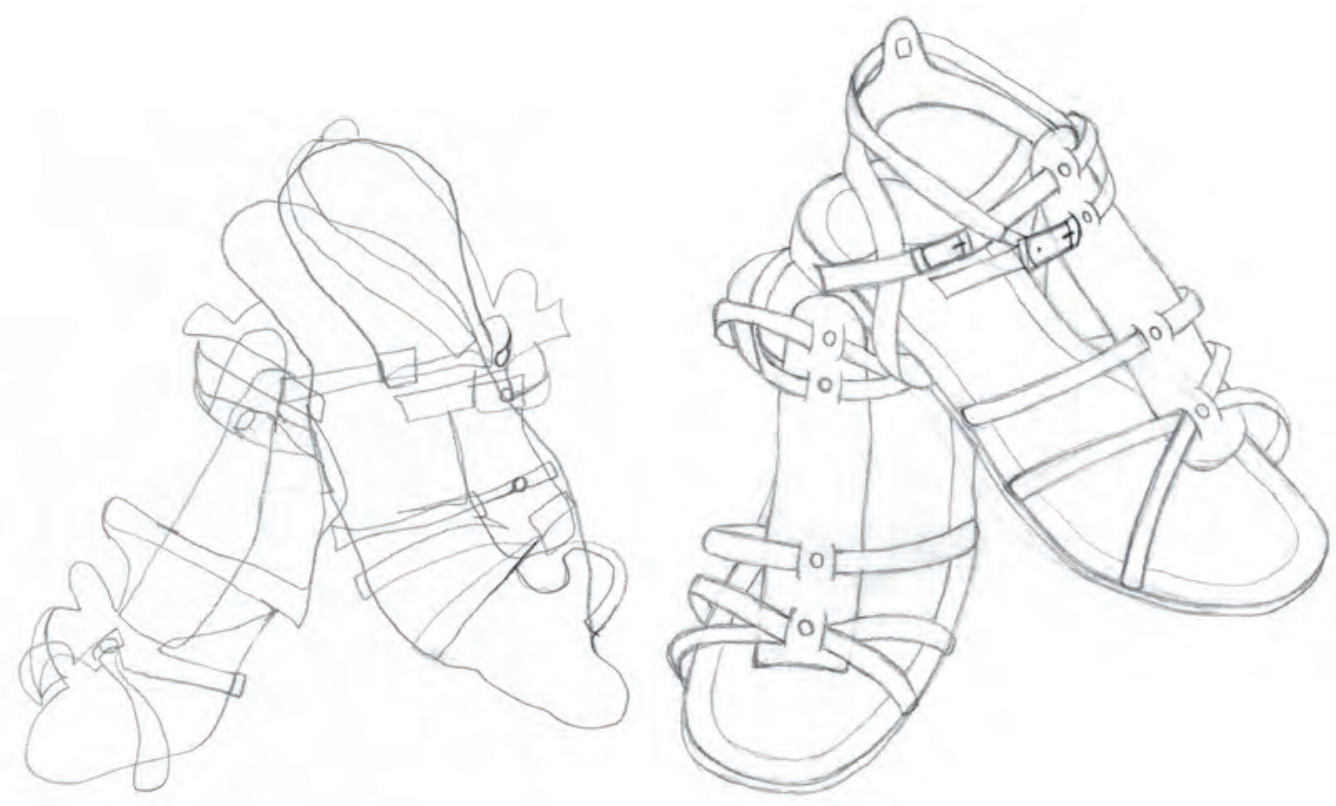

Realizado por Ana María Aznar

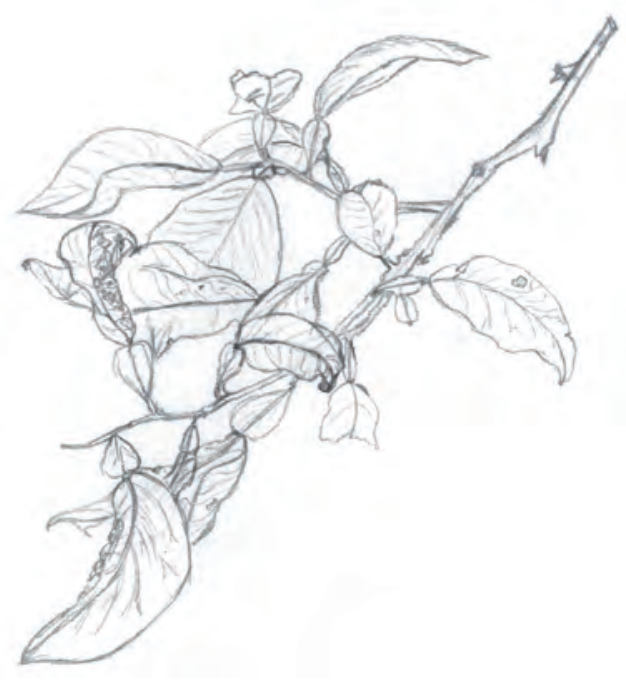

Realizado por Alexandra Nae

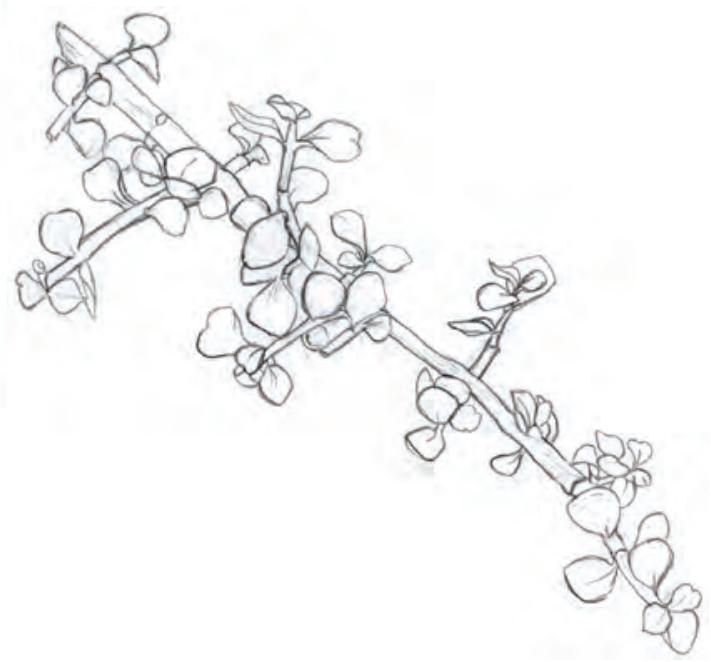

Realizado por Sara Gómez Tirado 

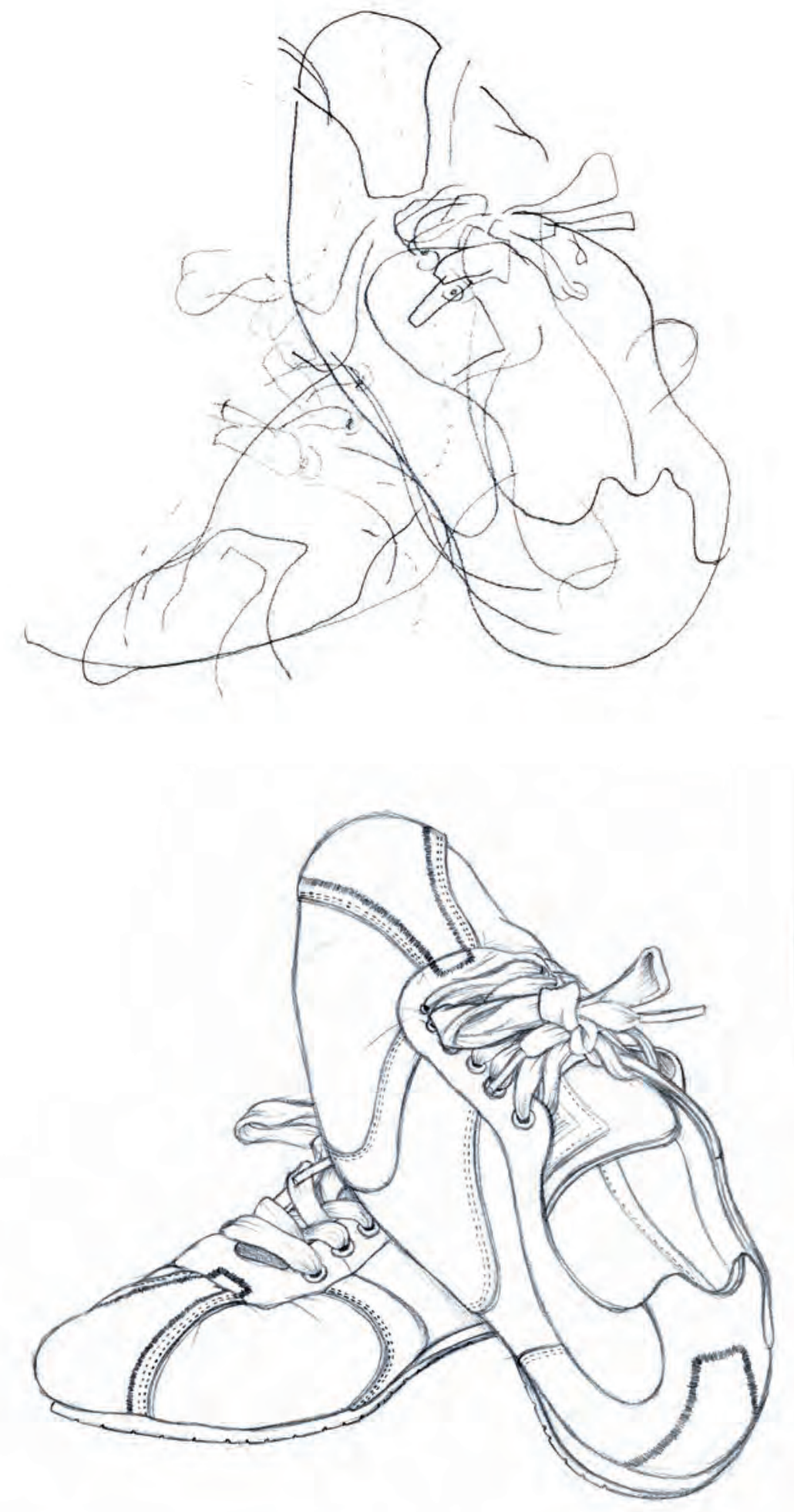

Realizado por Rubén Soler 

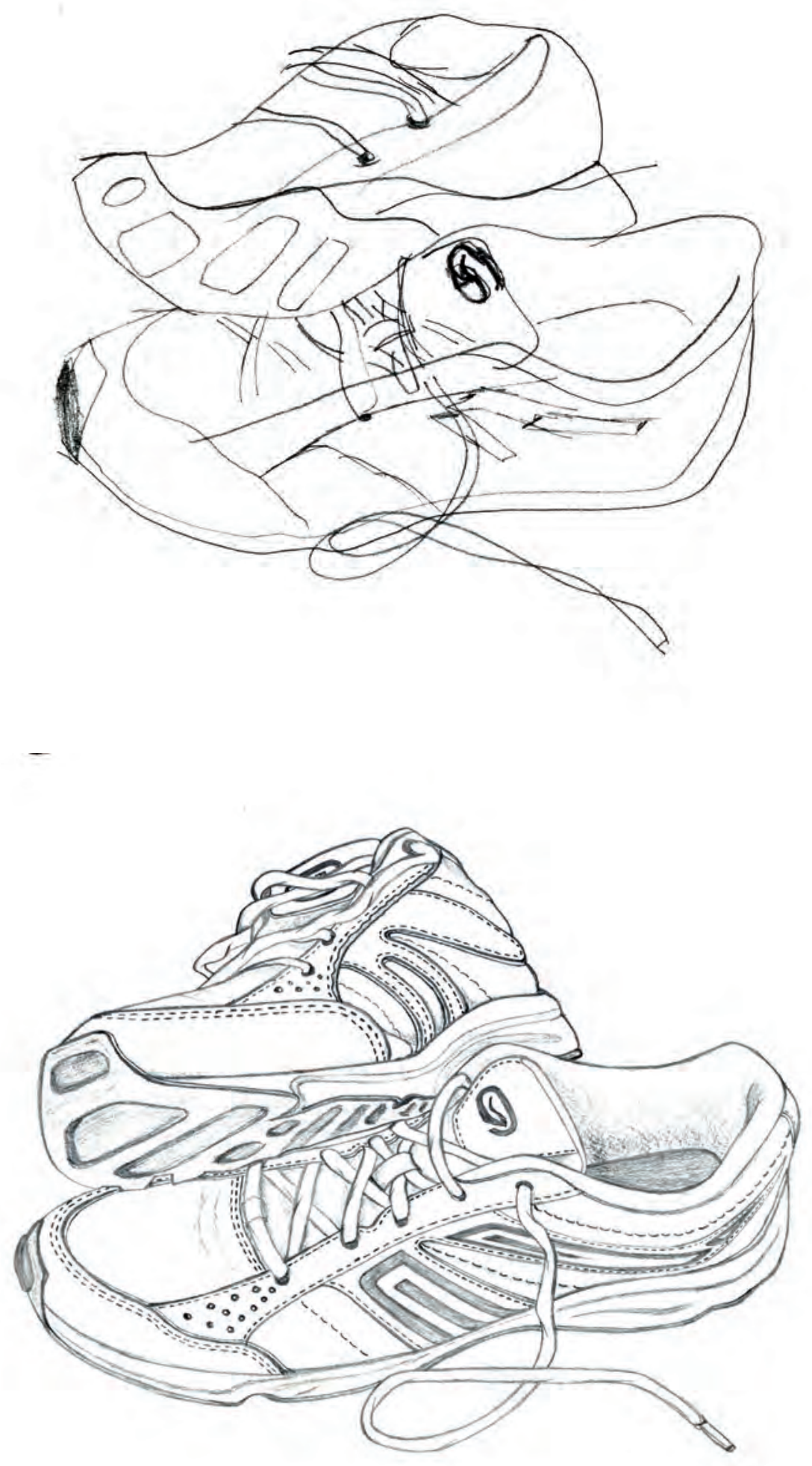

Realizado por Pedro Fiascunari 


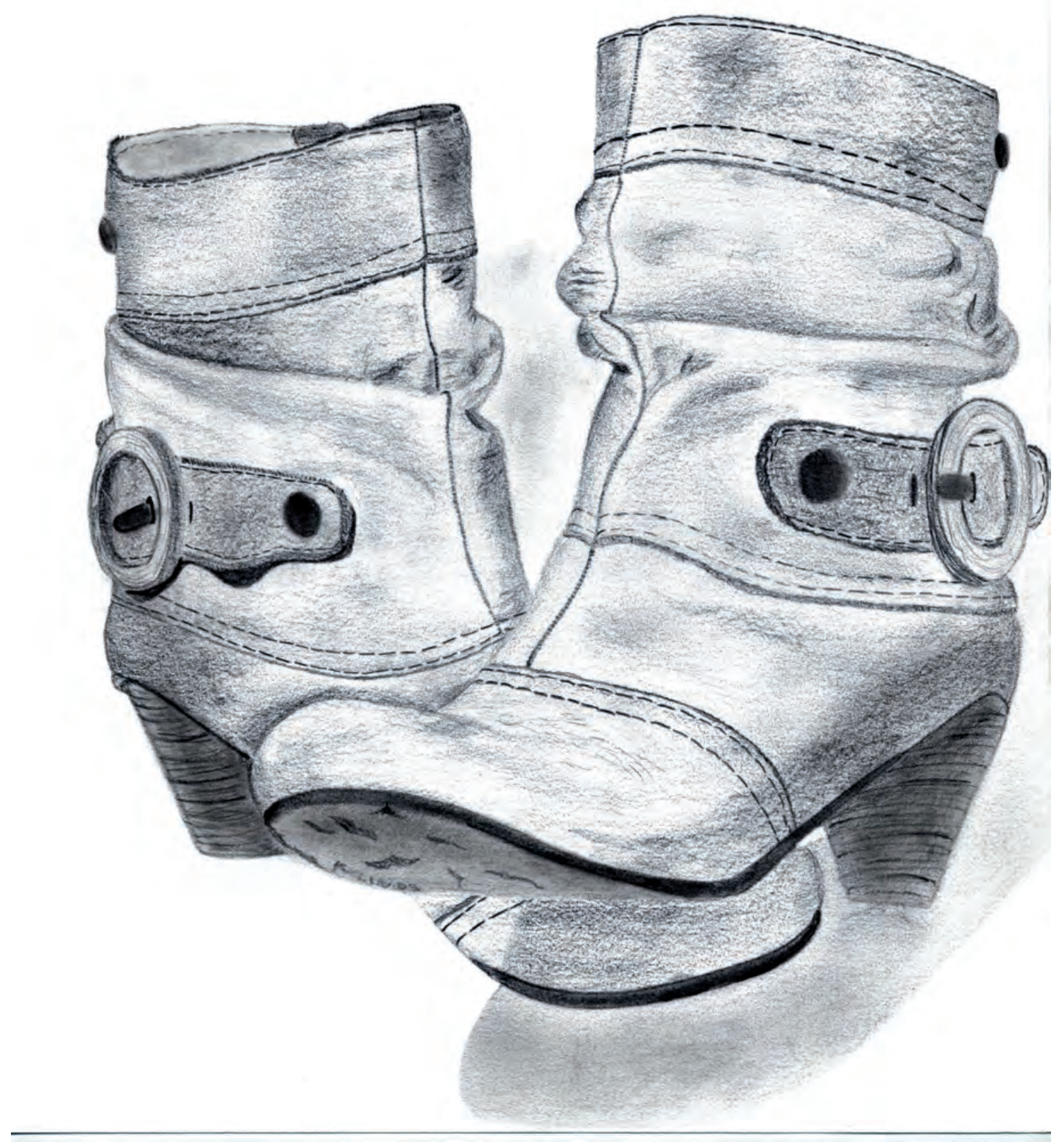

Realizado por Laura Martínez 
BLOQUE 2

Diversas prácticas
para la visualización
de la forma, encajado
de cuerpos geométricos,
método de las cajas,
eje de simetría y método
mixto 


\section{Introducción}

Si observamos detenidamente cualquier objeto, nos apercibiremos que la forma, las relaciones entre las distintas partes, sus dimensiones y las relaciones de tamaño, forma y distancias que se establecen entre sus distintas partes son las que determinan, definen y caracterizan a los objetos.

Si cambiamos alguna de esas relaciones, cambia el objeto. Ya no estamos definiendo ese objeto, sino otro con características muy diferentes.

Se llama encaje, o encajar, al procedimiento empleado para dibujar un objeto, lo más rápido, sencillo y fácilmente. El encajado consiste en trazar líneas auxiliares, sin apretar, que nos den una idea aproximada de la forma y la precisión de lo que dibujamos, y supone un paso previo a cualquier dibujo o pintura que sirve para calcular las dimensiones, proporciones y situación de los objetos o figuras que queremos representar.

Existen, entre otros, los siguientes métodos para encajar:

- Por medio de líneas que marcan las direcciones del movimiento.

- Por medio de manchas de luz y sombra.

- Inscribiendo los objetos en cajas de forma prismática o en cualquier volumen geométrico básico: cubo, cilindro, pirámide, cono y esfera.

- Por medio de los ejes de simetría.

La forma de cualquier objeto, sea plano o corpóreo, puede considerarse encerrada dentro de una figura geométrica regular o irregular de acorde con la forma del mismo, o bien en combinaciones de varias formas simples. Casi todas las formas pueden representarse deduciendo su estructura geométrica. Esta figura geométrica que envuelve el objeto podríamos decir que actúa como una caja de donde viene el nombre de «encajar». Las formas básicas que esquematizan la mayoría de los objetos son el cubo, la esfera, el cilindro y el cono.

Para encajar debemos hacer unas líneas auxiliares muy finas mediante las que reduciremos cada objeto del dibujo en formas sencillas geométricas (normalmente con forma de caja, de ahí el nombre) y que guarden relación de proporción entre ellas; estas líneas nos servirán de guía para realizar el contorno definitivo del objeto.

Antes de empezar a realizar el encajado, primero debemos tener en cuenta cuál será la orientación del papel más adecuada para nuestro dibujo. 


\section{Práctica 5}

\section{Encajado de cuerpos geométricos en diferentes posiciones y puntos de vista: cubos, prismas con diferentes bases poligonales, cilindros, conos y pirámides}

\section{A. Objetivos}

- Desarrollar el control sobre el trazo buscando direcciones de paralelismo.

- Captación del sentido del espacio y la perspectiva en los dibujos.

- Dominar la visualización de las estructuras geométricas fundamentales mediante el método de las cajas.

- Dominar la visualización de las estructuras geométricas de revolución mediante el método de los ejes de simetría.

- Representar las zonas no visibles del modelo.

- Representar el modelo captando todos sus detalles.

B. Materiales

- Papel formato DIN A4

- Lápiz de dureza HB

- Goma de lápiz

\section{Guía de ejecución}

\section{Planteamiento}

- Para ejercitarse en el trazado de volúmenes básicos es necesario realizar múltiples bocetos o ensayos hasta conseguir el correcto dibujo de cada uno de ellos. 
- Comenzaremos con el cubo. Cuando dominemos su representación, lo volveremos a intentar desde diferentes puntos de vista.

- A continuación, probaremos con prismas variando sus proporciones, posiciones y la forma de sus bases: triangular y hexagonal.

- Experimentaremos con la estructura formal del cilindro y encajaremos su forma por el sistema del eje de simetría.

- Realizaremos una figura cónica por el sistema de ejes.

- Por último, trazaremos una pirámide con la base que se prefiera.

\section{Encajado de un objeto de estructura prismática}

\section{Objetivos}

- Desarrollar el control sobre el trazo buscando direcciones de paralelismo.

- Captación del sentido del espacio y la perspectiva en los dibujos.

- Dominar la visualización de las estructuras geométricas fundamentales.

- Representar las zonas no visibles del modelo.

- Representar el modelo captando todos sus detalles.

\section{Proceso de ejecución del dibujo}

- Observar la figura a dibujar desde diferentes ángulos para comprender su forma.

- Dibujar la caja que inscribe al objeto eligiendo el punto de vista idóneo.

- Proporcionar correctamente las partes estructurales del modelo y representarlas en el interior de la caja.

- Trazar todas sus aristas, tanto las que se ven como las que no se ven.

- Conviene empezar por la base, de modo que los vértices anterior y posterior no coincidan.

- Luego, dibujar las demás aristas paralelas entre sí. 
- Cerrar la figura.

- A continuación, cuidar los espesores del material.

- Finalmente, añadir los detalles o piezas más pequeñas, estudiando su correcta ubicación y ensamblado dentro del conjunto.
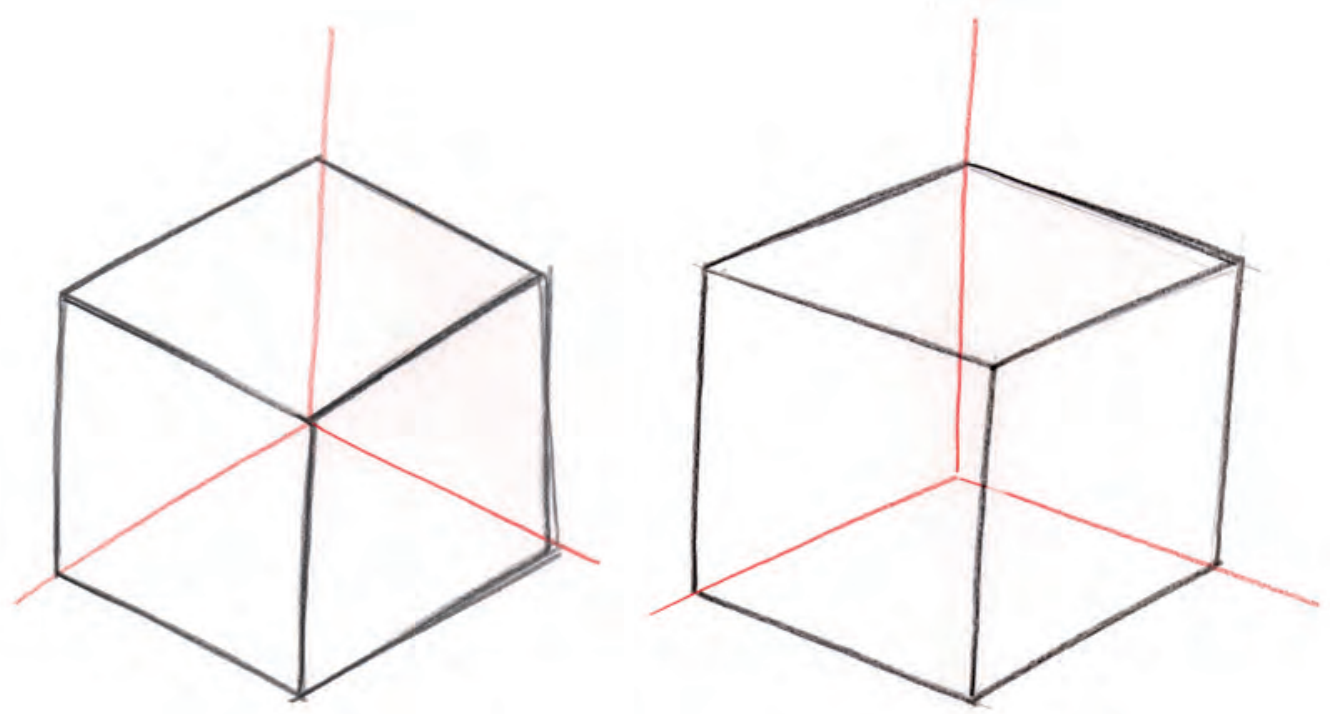

Forma cúbica en distintas perspectivas. Es preferible la segunda opción.

Realizado por Mario Fernández

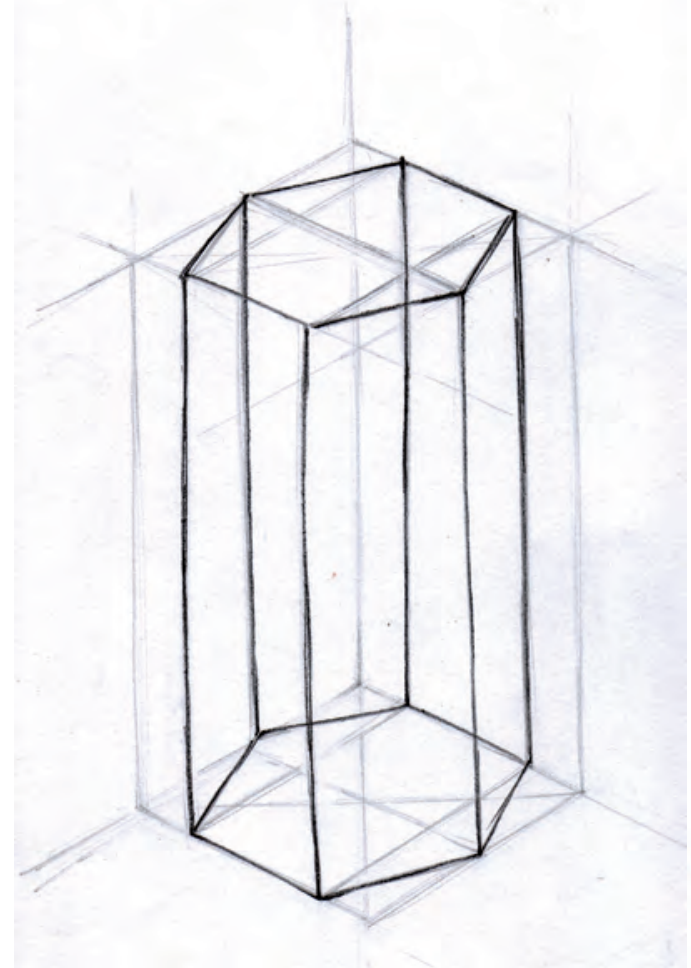

Realizado por Fabián Nebot Muñoz

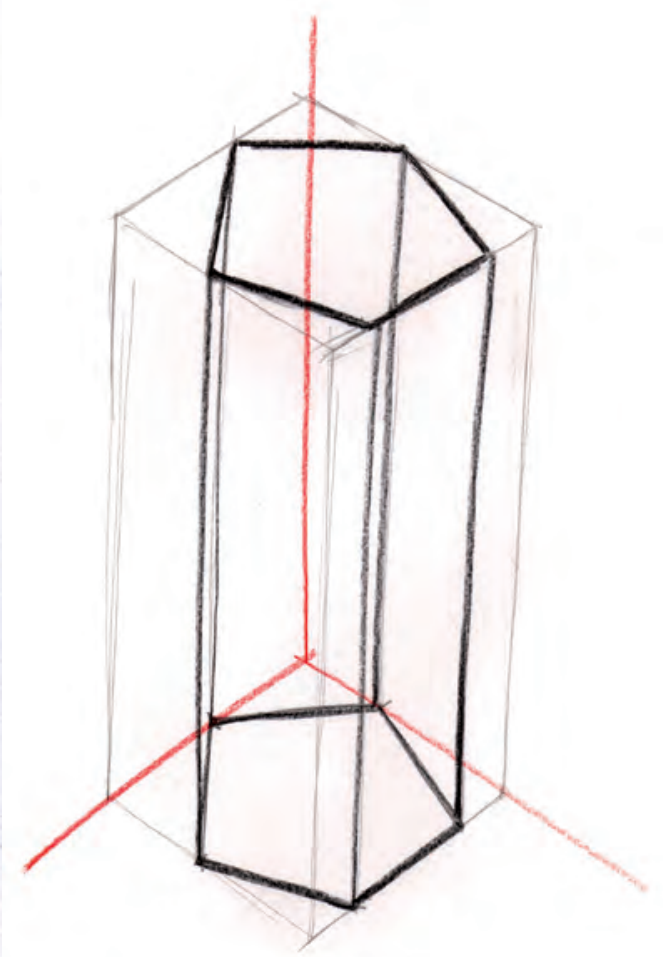

Realizado por Mario Fernández Estudio previo de varias figuras prismáticas en distintas posiciones.

Elección de una posición de ejes adecuada 


\section{E. Encajado de un objeto de estructura cilíndrica}

\section{Objetivos}

- Desarrollar el control sobre el trazo buscando direcciones de paralelismo.

- Captación del sentido del espacio y la perspectiva en los dibujos.

- Dominar la visualización de las estructuras geométricas fundamentales.

- Representar las zonas no visibles del modelo.

- Representar el modelo captando todos sus detalles.

\section{Proceso de ejecución del dibujo}

- Método de ejes: dibujar el eje de simetría. Ajustar el punto de vista controlando la redondez de las elipses.

- Método de cajas: se sitúa la forma dentro de una caja, se busca el centro de la base trazando las diagonales. Desde el punto en donde se cortan, se trazan dos rectas paralelas a las aristas de la base obteniendo cuatro cuadrantes. La circunferencia se traza a mano alzada por los puntos en los que las diagonales toquen a las caras.

- Una vez trazadas las elipses de las bases, estas se unen con dos verticales tangentes a sus partes más externas.

- Proporcionar correctamente las partes estructurales del modelo.

- A continuación, cuidar los espesores del material.

- Finalmente, añadir los detalles o piezas más pequeñas estudiando su correcta ubicación y ensamblado dentro del conjunto.

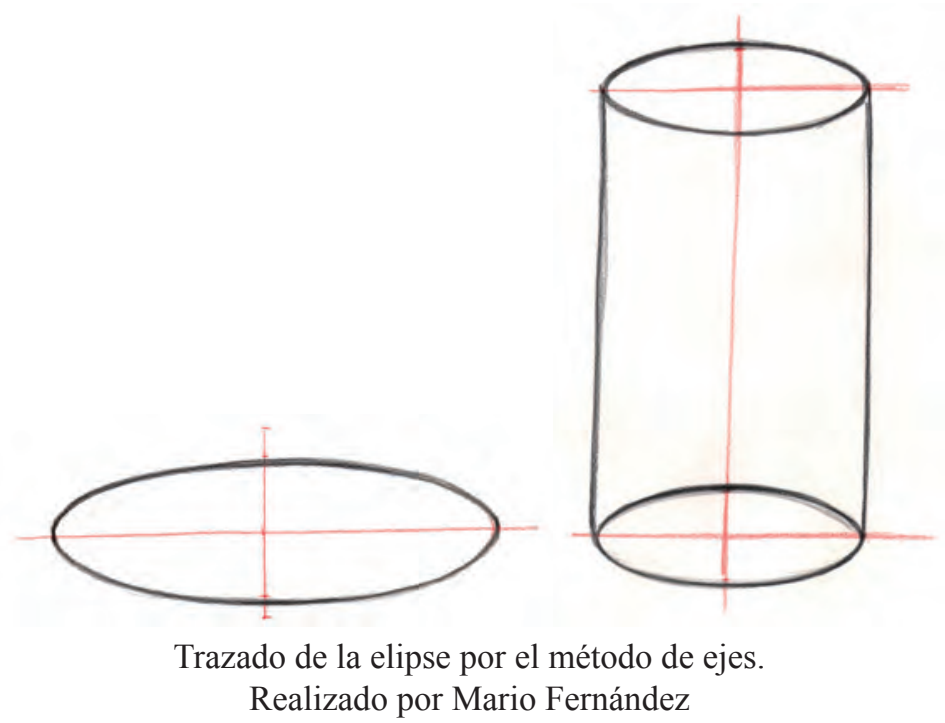



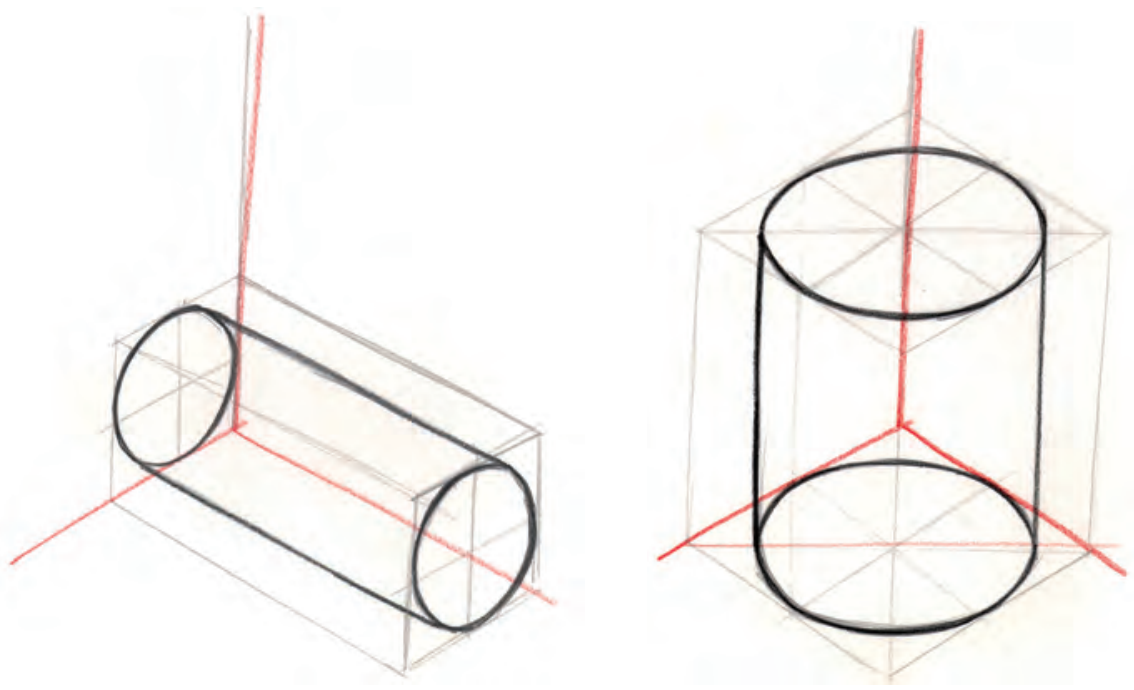

Cilindro en distintas posiciones realizado por el método de cajas. Realizado por Mario Fernández

\section{Guía de autocorrección}

- Comprobar que se ha elegido un punto de vista que represente las características más interesantes del cuerpo geométrico.

- Cerciorarse de que las aristas y las bases sean paralelas si así lo requieren.

- Verificar la simetría de la figura en general, y de las curvas de la elipse en particular.

\section{Ejemplos resueltos}
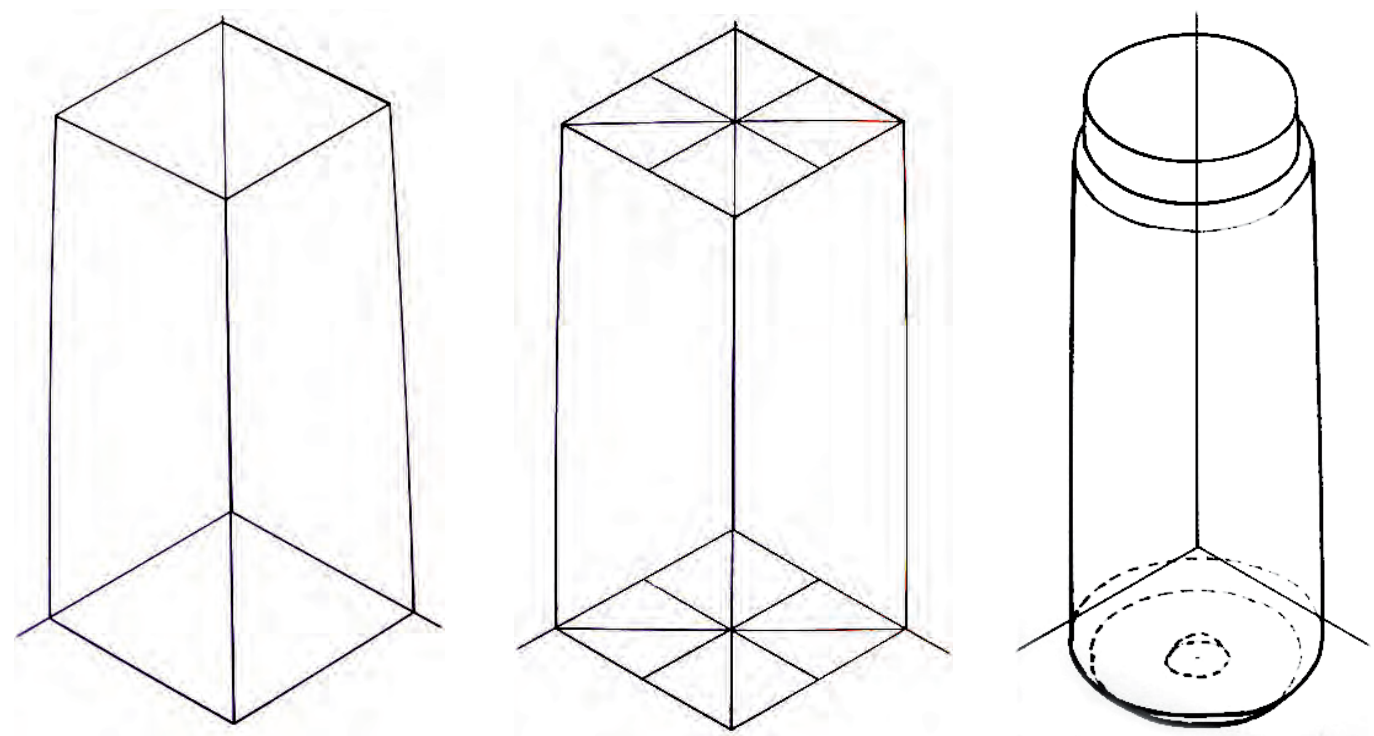

Realizado por Carmen Pesudo 

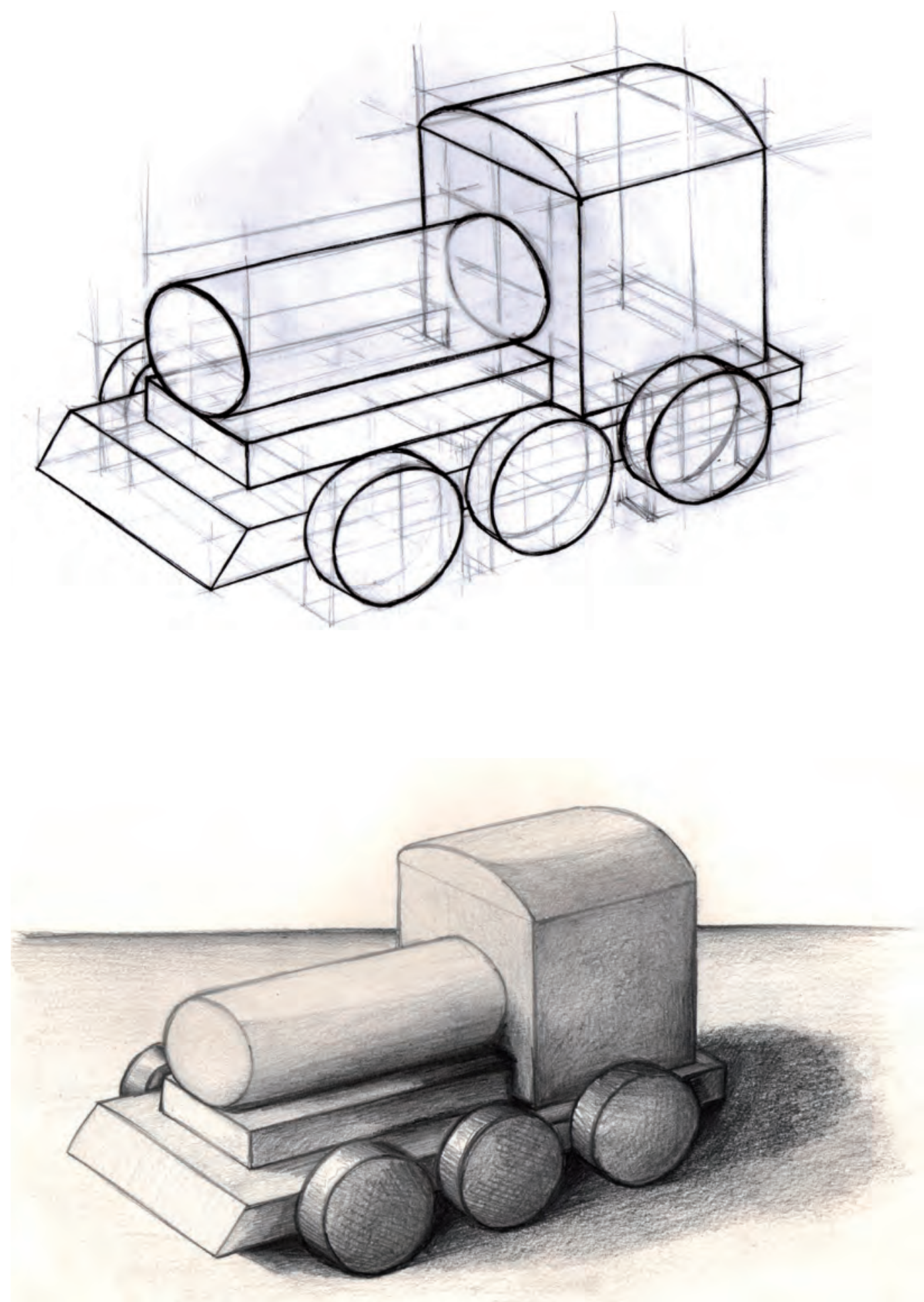

Realizado por Fabián Nebot Muñoz 

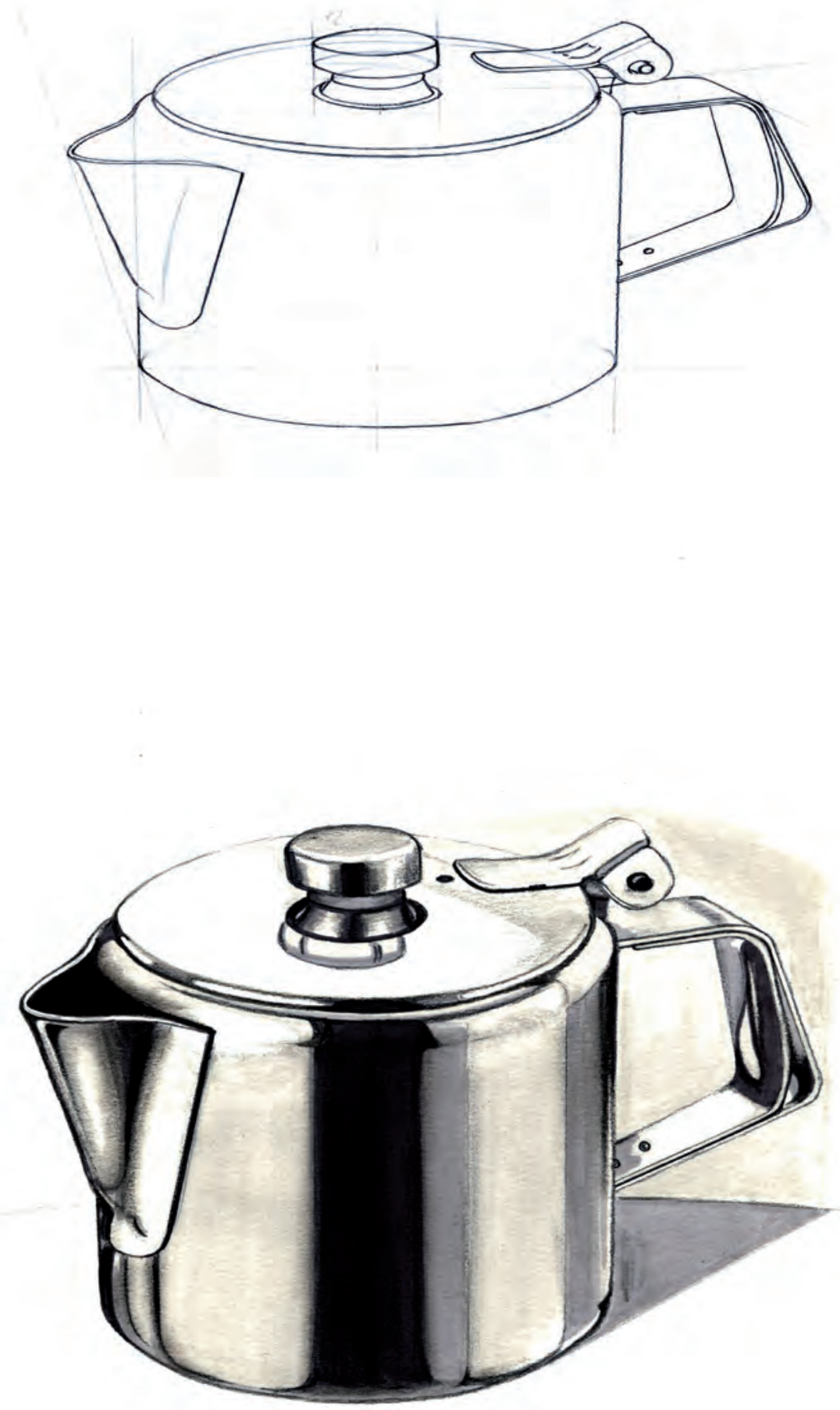

Realizado por Pedro Fiascunari 


\section{F. Proceso de ejecución del dibujo. Encajado de un objeto de forma cónica}

- Se encaja la figura en un prisma.

- La base se realiza siguiendo el mismo procedimiento explicado para la realización de la base del cilindro.

- El vértice del cono se obtiene a partir de la localización del centro de la cara superior, y posteriormente se une con las partes más sobresalientes de la circunferencia de la base.

- Si se prefiere utilizar el método de ejes, se traza una elipse como se ha explicado más arriba y se unen sus extremos más salientes con el punto que situemos sobre el mismo eje y a la altura que se nos requiera.

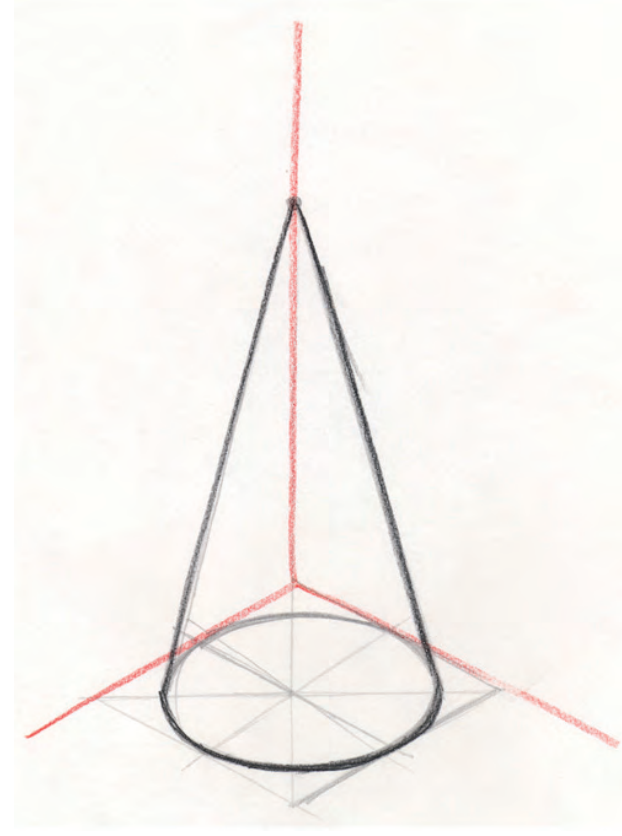

Base isométrica.

Realizado por Mario Fernández

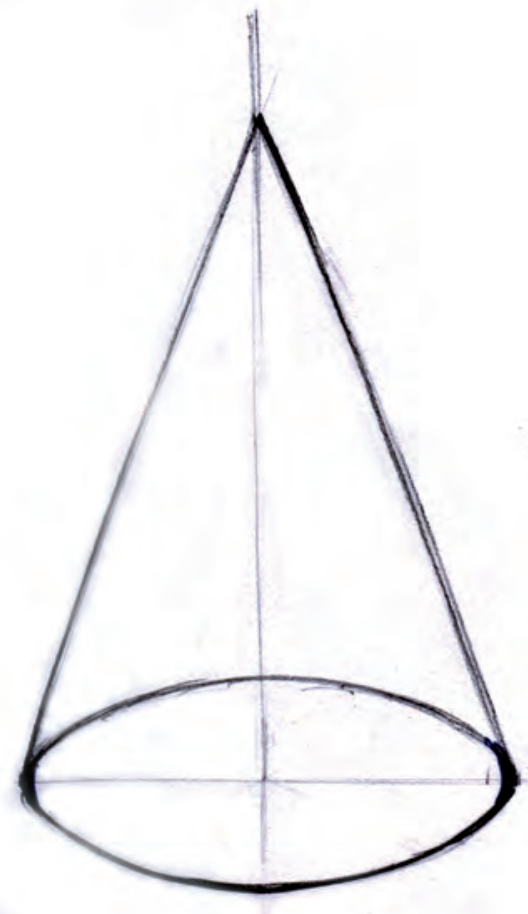

Método de la elipse. Realizado por Fabián Muñoz

\section{G. Proceso de ejecución del dibujo. Encajado de un objeto de forma piramidal}

- Encajar la figura con las dimensiones que se nos pidan.

- Obtener el centro de la cara superior del prisma.

- Unirlo con cada uno de los vértices de la cara inferior. 


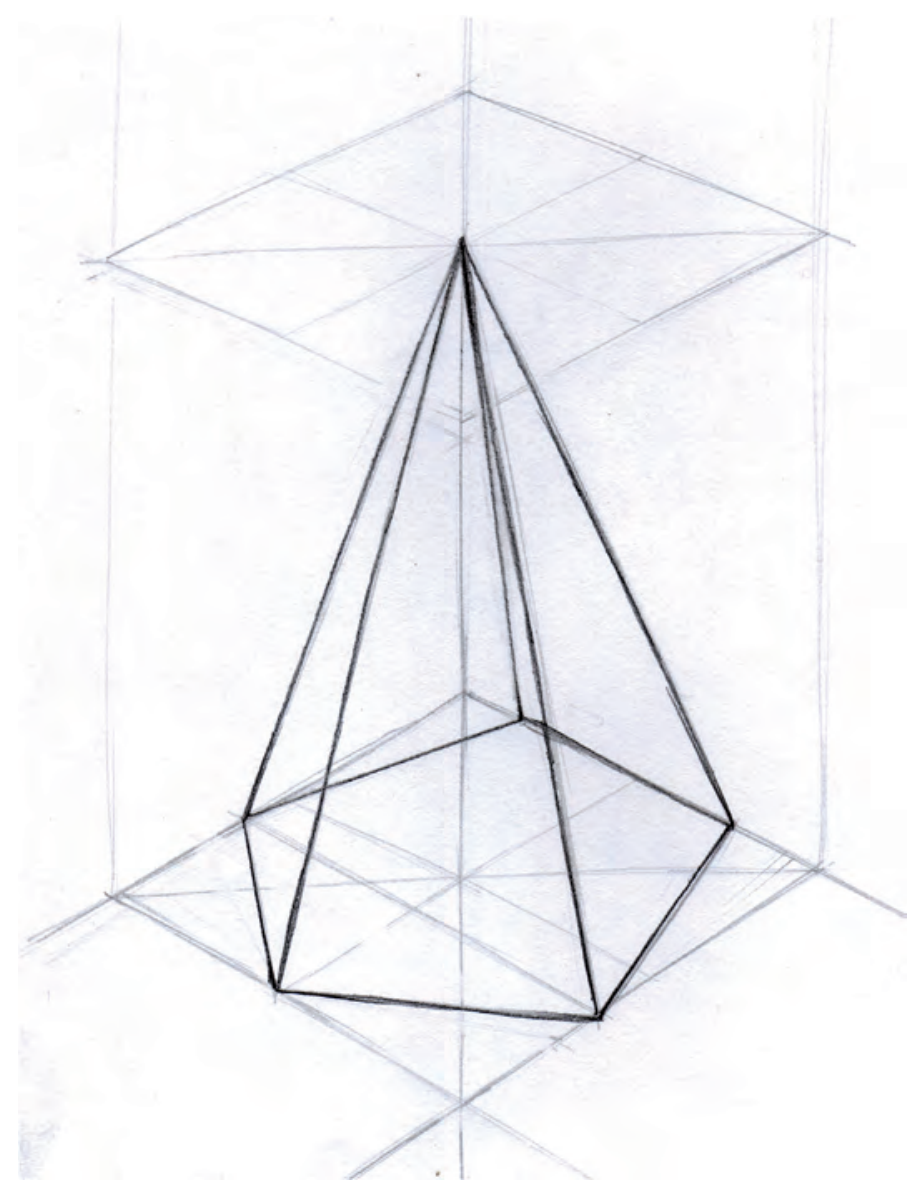

Realizado por Fabián Muñoz

\section{Guía de autocorrección}
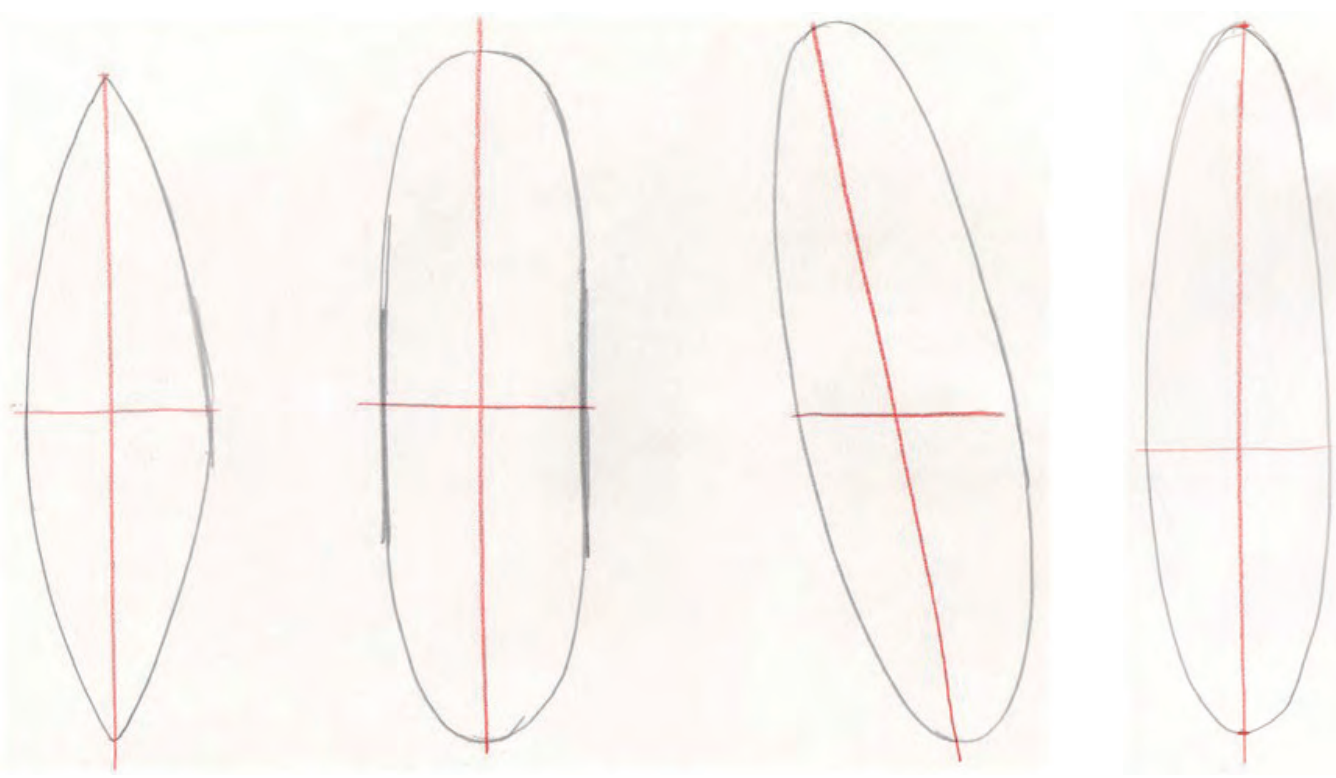

Extremos excesivamente puntiagudos o redondeados. Asimetría de la elipse 


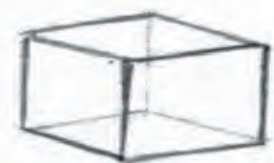
elemental

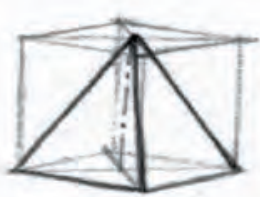

- Pirámide inscrita en un prisma

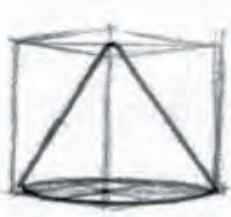

- Cono inscrito en un prisma

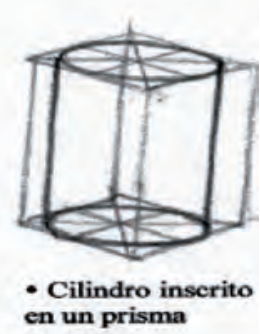

en un prisma

Errores habituales

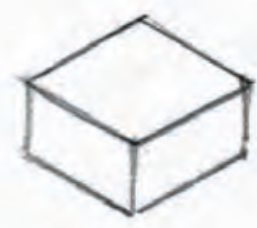

- Ángulo del punto de vista demasiado forzado

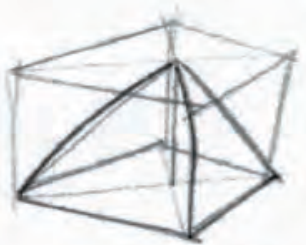

- Pérdida del paralelismo de los ejes

- Curvatura de las líneas rectas

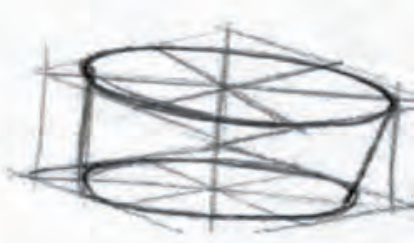

- Pérdida del paralelismo y tamaño de las bases la elipse

Realizado por Amelia Muñoz

\section{H. Composición con varios volúmenes geométricos}

\section{Objetivos}

- Situar volúmenes con lógica espacial en una composición.

- Desarrollar el control sobre el trazo buscando direcciones de paralelismo.

- Captación del sentido del espacio y la perspectiva en los dibujos.

- Dominar la visualización de las estructuras geométricas fundamentales.

- Representar las zonas no visibles del modelo.

- Representar el modelo captando todos sus detalles.

\section{Materiales}

- Papel formato DIN A4

- Lápiz de dureza HB

- Goma de lápiz 


\section{Guía de ejecución}

\section{Planteamiento}

- Para ejercitarse en el trazado de volúmenes básicos es necesario realizar múltiples bocetos o ensayos hasta conseguir el correcto dibujo de cada uno de ellos.

- Comenzaremos con el cubo. Cuando dominemos su representación, lo volveremos a intentar desde diferentes puntos de vista.

- A continuación, probaremos con prismas variando sus proporciones, posiciones y la forma de sus bases: triangular pentagonal y hexagonal.

- Finalmente, experimentaremos con la estructura formal del cilindro y encajaremos su forma, tanto a partir del método de las cajas como por el sistema del eje de simetría.

\section{Proceso de ejecución del dibujo}

- Elegir la orientación del papel según nuestra intención compositiva.

- Comenzaremos estudiando la ubicación de los elementos en una vista en planta.

- Seleccionaremos el grado de ángulo en picado deseada para el dibujo.

- Dibujaremos la planta de la composición en perspectiva.

- Encajar cada uno de los volúmenes.

- Definir los volúmenes tanto con sus aristas vistas como con sus partes ocultas. 


\section{Ejemplos resueltos}
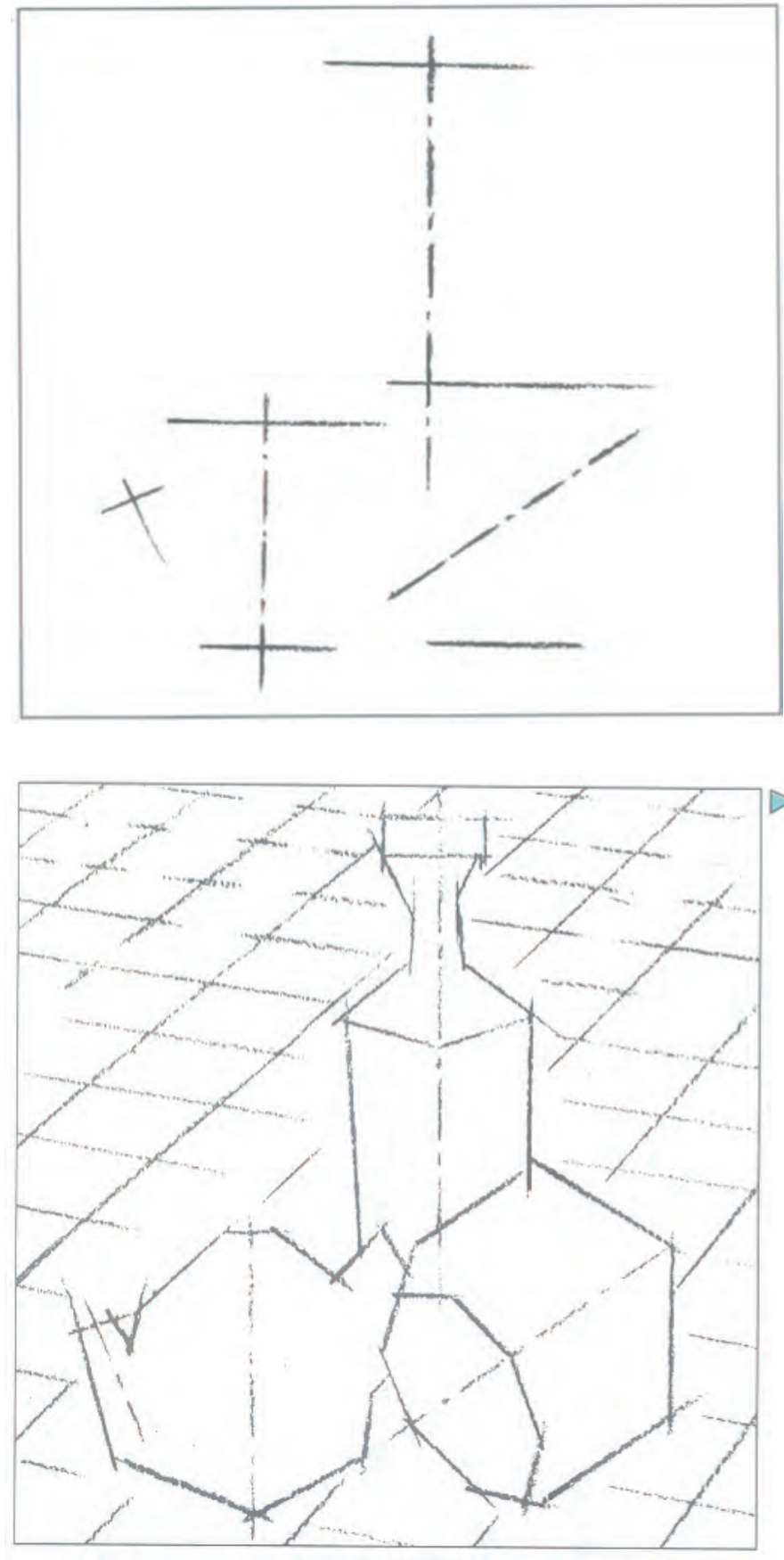

Giménez y otros (Santillana).

Encajado y estudio compositivo de un conjunto de objetos 


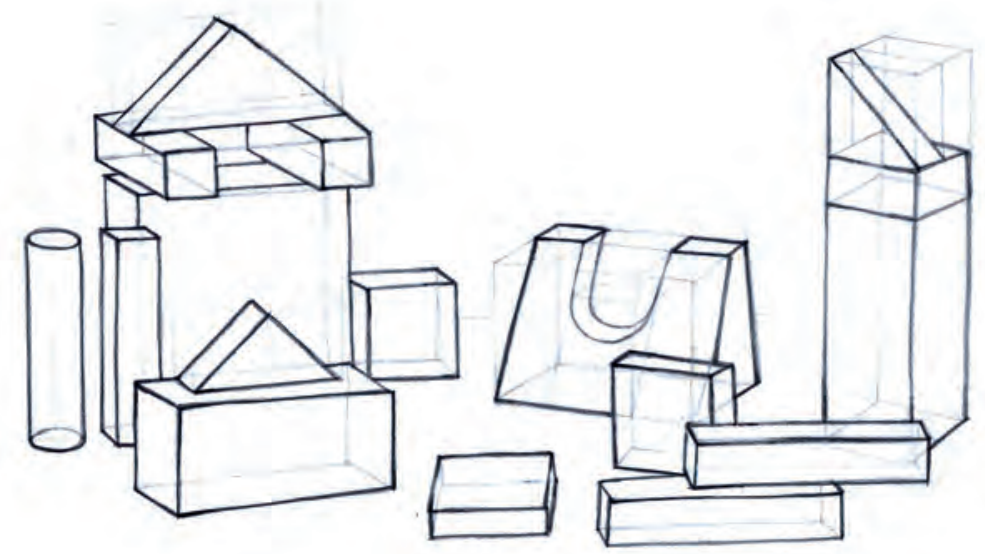

Realizado por Pedro Fiascunari

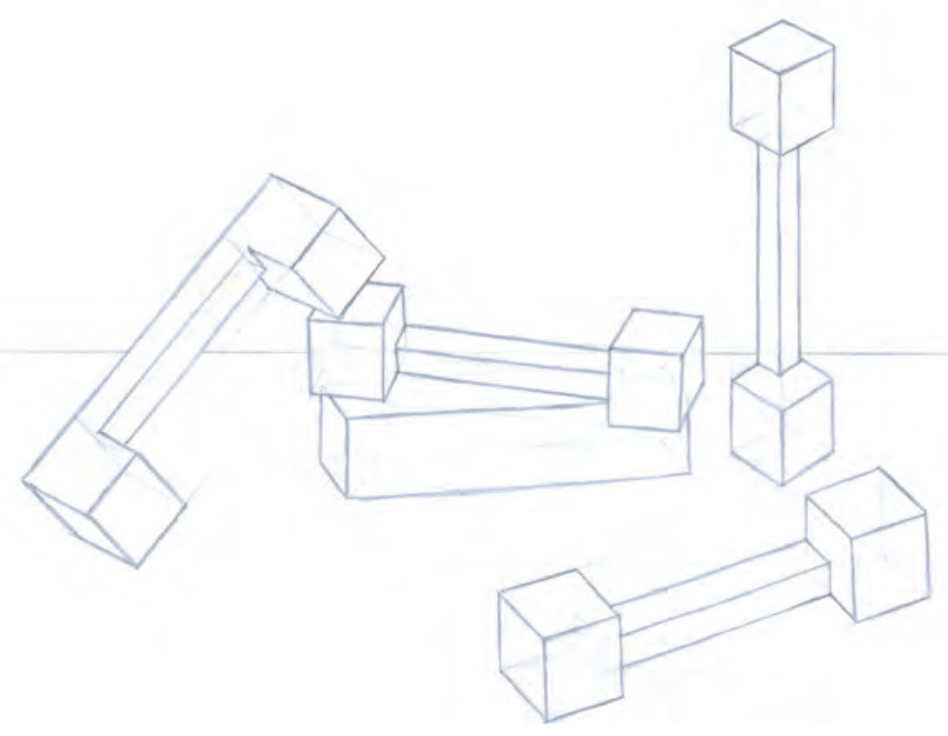

Realizado por Rubén Soler 


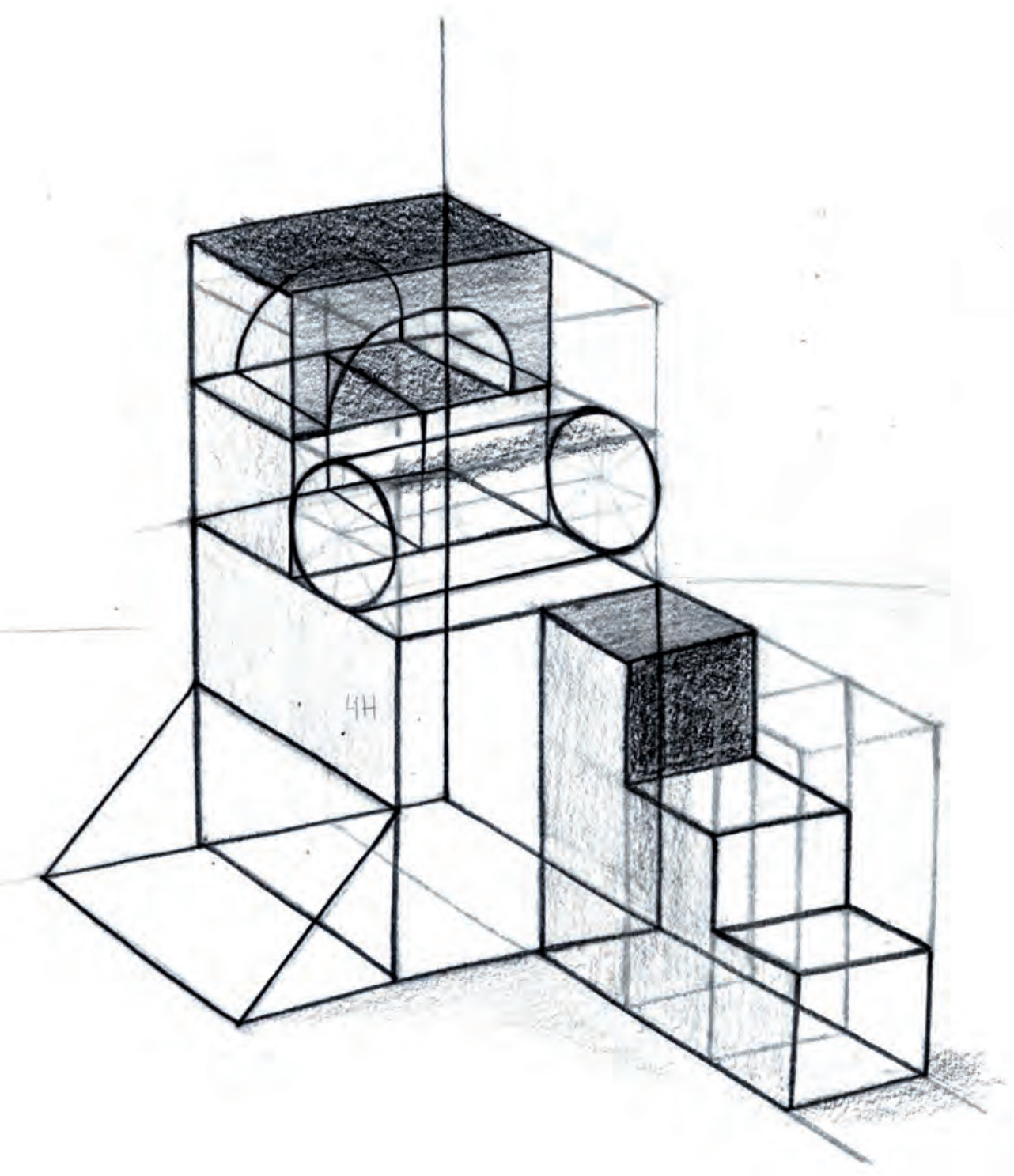

Realizado por Laura Martínez

\section{Guía de autocorrección}

- Evitar la descompensación de pesos visuales en la organización de los volúmenes.

- Organizar las figuras con riqueza de puntos de vista y con ángulos diferentes.

- Facilitar la comprensión de las figuras, eligiendo la composición más favorable que muestre las características propias de cada figura.

- Cerciorarse de que cada pieza en particular se ha construido correctamente. 


\section{Práctica 6 \\ Encajado de un objeto por el método de las cajas. Brick}

\section{A. Objetivos}

- Desarrollar el control sobre el trazo buscando direcciones de paralelismo.

- Captación del sentido del espacio y la perspectiva en los dibujos.

- Dominar la visualización de las estructuras geométricas fundamentales.

- Representar las zonas no visibles del modelo.

- Representar el modelo captando todos sus detalles.

\section{B. Materiales}

- Papel formato DIN A4

- Lápiz de dureza HB

- Goma de lápiz

\section{Guía de ejecución}

\section{Planteamiento}

- La práctica consiste en realizar el dibujo de un envase tipo brick.

- El sistema para abordar esta práctica consistirá en inscribir la figura dentro de un prisma con las proporciones que se ajusten al modelo.

- Es aconsejable poner a prueba nuestra capacidad de concentración para conseguir la máxima objetividad en este ejercicio gráfico.

\section{Proceso de ejecución del dibujo}

- Antes de empezar elegiremos el formato del papel, la disposición de la figura dentro de él, y analizaremos la forma desde distintos puntos de vista para comprender su conformación. 
- Dibujar la caja que inscribe al objeto eligiendo el punto de vista idóneo.

- Proporcionar correctamente las partes estructurales del modelo y representarlas en el interior de la caja.

- A continuación, cuidar los espesores del material y el sentido apropiado del tipo de líneas o detalles que se elijan para la representación del objeto.

- Finalmente, añadir los detalles o piezas más pequeñas, estudiando su correcta ubicación y ensamblado dentro del conjunto.
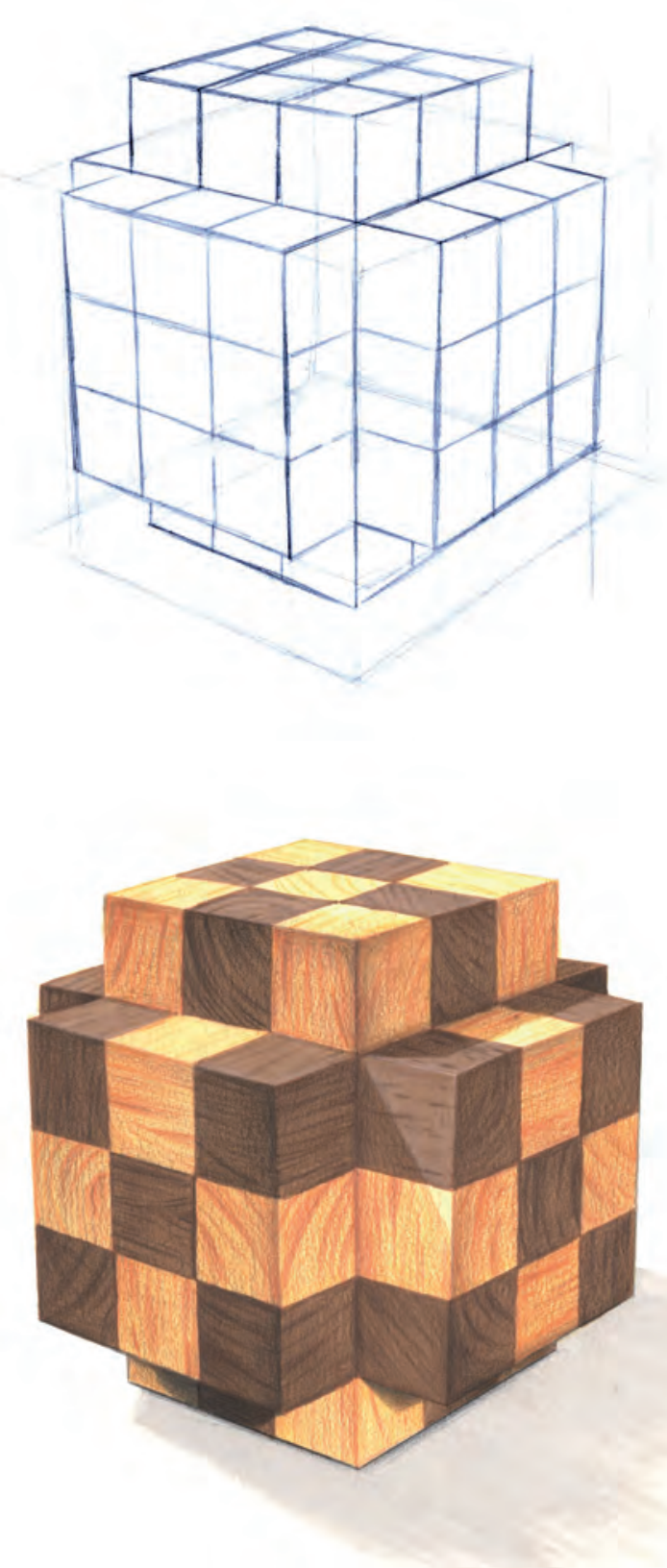

Realizado por Rubén Soler 


\section{Guía de autocorrección}

- Verificar que el formato y las proporciones del dibujo son coherentes.

- Comprobar que las bases y los lados son paralelos.

- Razonar si los tipos de líneas que se han utilizado (gruesas o finas, rígidas o sensibles, sutiles o contundentes...) son los adecuados a la configuración y sentido del objeto.

- Revisar si el grado de detalle y/o realismo del dibujo es el pretendido.

\section{Ejemplos resueltos}

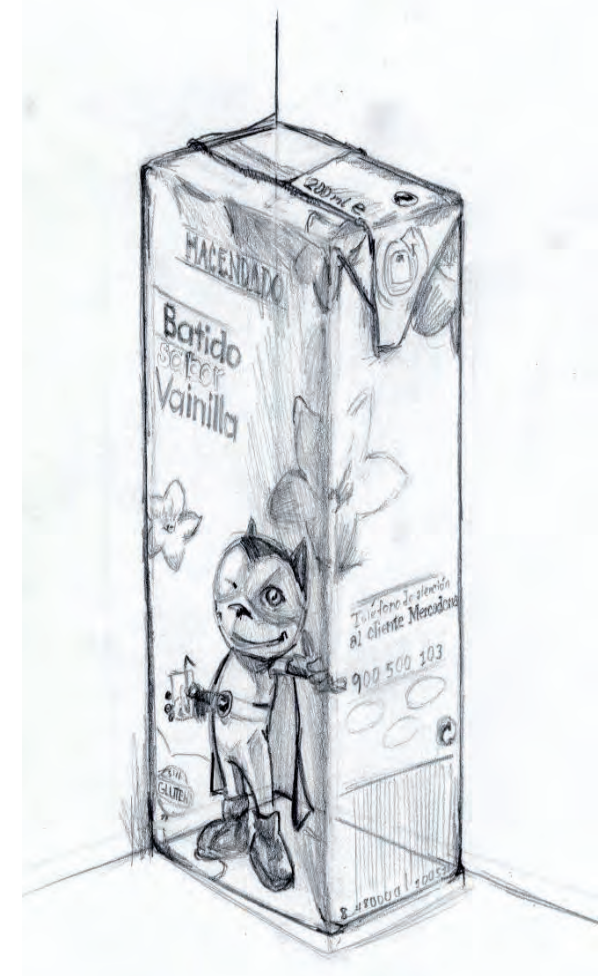

Realizado por Staci Warren

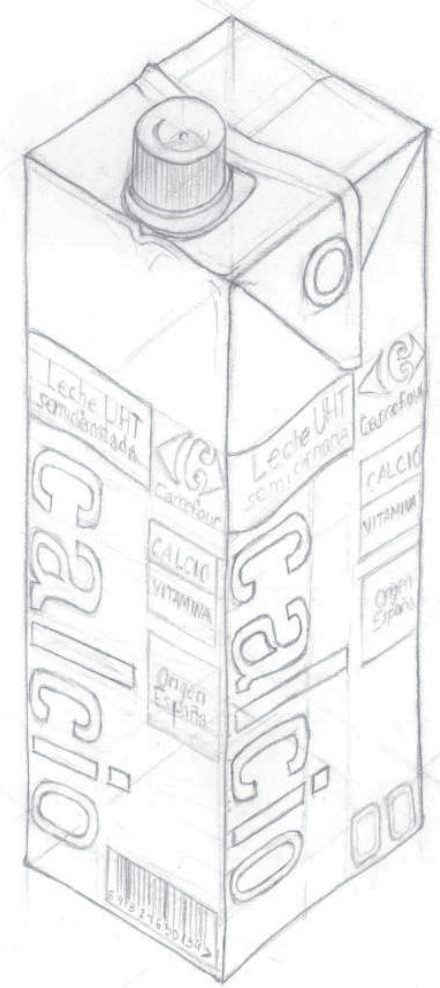

Realizado por Sara Gómez 


\section{Práctica 7 \\ Encajado de un objeto por el método del eje de simetría: lata de refresco}

\section{A. Objetivos}

- Desarrollar el control sobre el trazo buscando direcciones de paralelismo.

- Captación del sentido del espacio y la perspectiva en los dibujos.

- Dominar la visualización de las estructuras geométricas fundamentales.

- Representar las zonas no visibles del modelo.

- Representar el modelo captando todos sus detalles.

\section{B. Materiales}

- Papel formato DIN A4

- Lápiz de dureza HB

- Goma de lápiz

\section{Guía de ejecución}

\section{Planteamiento}

- Dibujar el eje de simetría. Ajustar el punto de vista controlando la redondez de las elipses.

- Proporcionar correctamente las partes estructurales del modelo.

- A continuación, cuidar los espesores del material.

- Finalmente, añadir los detalles o piezas más pequeñas estudiando su correcta ubicación y ensamblado dentro del conjunto 


\section{Proceso de ejecución del dibujo}

- Dibujar el eje de simetría prestando especial atención a su verticalidad respecto al extremo inferior del papel.

- Marcar el área de dibujo reservada para la figura.

- Trazar líneas horizontales por las zonas claves del objeto siempre que haya un cambio de diámetro, procurando que estas rectas queden perpendiculares al eje.

- Proporcionar las diferencias de anchura en cada una de estas secciones dibujadas y reproducir mediante una línea esquemática el contorno o silueta del objeto.

- Dibujar las elipses por cada una de las secciones marcadas para aportar el efecto tridimensional y volumétrico al dibujo.

- Finalmente, concretar la silueta del objeto cuidando el efecto simétrico del contorno y añadir los detalles procurando que se adapten a la curvatura de su superficie.

\section{Guía de autocorrección}

En cada una de las fases hay que meditar si se han cumplido los objetivos propuestos en la práctica:

- ¿Se ha seleccionado adecuadamente la posición del papel respecto a la forma del objeto?

- ¿Guarda el margen superior del papel un espacio de respeto mayor que el margen inferior para dotar al dibujo de una mayor estabilidad y peso visual?

- Respecto al eje de simetría de referencia, ¿está perpendicular el eje de simetría respecto a la base?

- En relación a la proporcionalidad entre las partes, ¿guardan las correctas relaciones de tamaño?

- Y en cuanto al trazado de las elipses, ¿se han trazado de manera adecuada y se han evitado los errores de pérdida de paralelismo entre ellas? 


\section{E. Ejemplos resueltos}

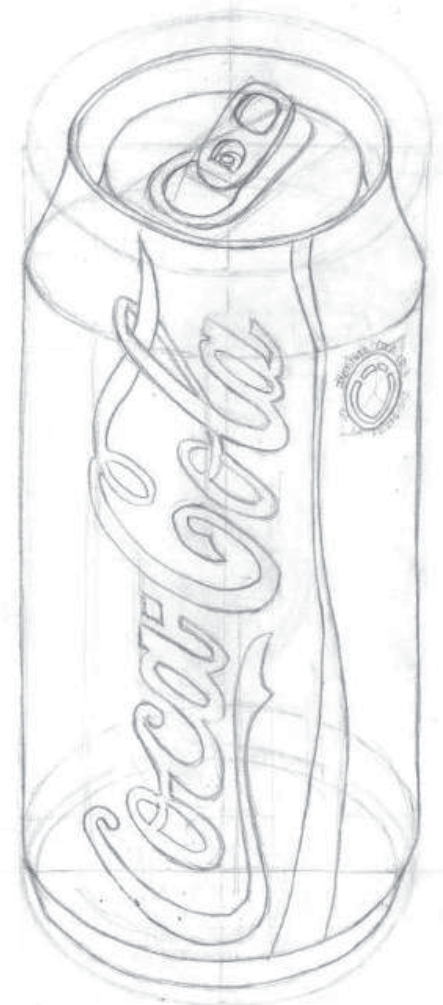

Realizado por Sara Gómez

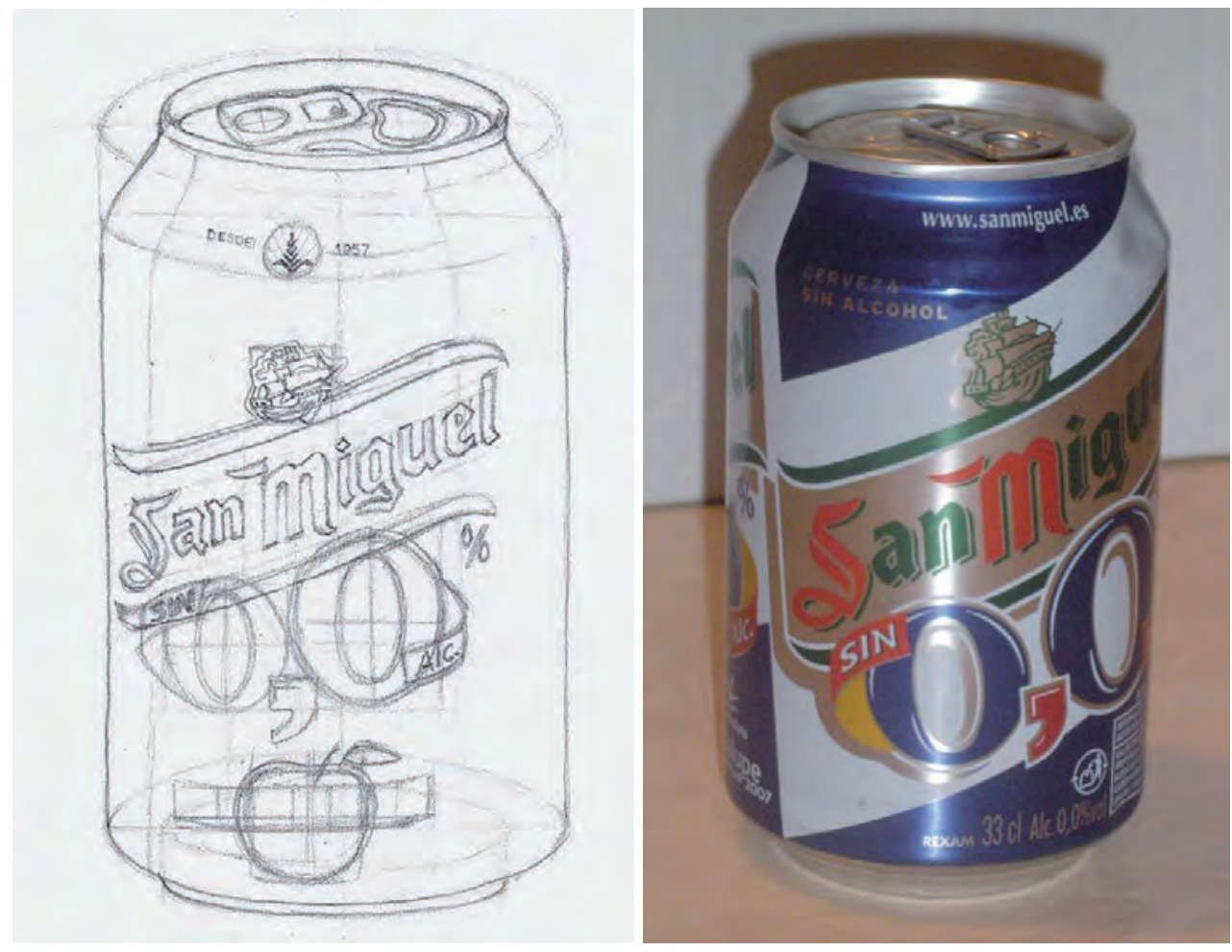

Realizado por Laura Cano Salinas 


\section{Práctica 8 \\ Encajado de un objeto por el método mixto. Cacerola}

\section{A. Objetivos}

- Observación y análisis de formas complejas.

- Captación del sentido del espacio y la perspectiva en los dibujos.

- Dominar la visualización de las estructuras geométricas fundamentales.

- Aplicación de las diferentes técnicas de trazado aprendidas en las prácticas anteriores: método de cajas y de ejes de simetría.

- Desarrollar el control sobre el trazo buscando direcciones de paralelismo.

- Representar el modelo captando todos sus detalles.

- Consolidar nociones y habilidades desarrolladas con anterioridad.

\section{B. Materiales}

- Papel formato DIN A4

- Lápiz de dureza HB

- Goma de lápiz

\section{Guía de ejecución}

\section{Planteamiento}

El desarrollo de la práctica se ha planteado como un ejercicio que potencie la capacidad de observación del alumno, a fin de que sea capaz de seleccionar el método de dibujo que mejor resuelva la estructura formal del objeto. El método empleado pretende facilitar el trazado correcto de las partes estructurales del modelo sobre un pequeño croquis de su alzado. Para ello se aconseja comenzar por el encaje del objeto.

Solo al final se añadirán los detalles o piezas más pequeñas estudiando su correcta ubicación y ensamblado dentro del conjunto. 


\section{Proceso de ejecución del dibujo}

Antes de empezar elegiremos el formato del papel, la disposición de la figura dentro de él y analizaremos la forma desde distintos puntos de vista para comprender su conformación.

- Se analizará la composición que mejor se adapte al formato, y se estudiará la estructura del objeto.

- Se tendrá en cuenta la relación entre la figura-fondo y el trazado de los ejes (atendiendo a su dirección, inclinación y tamaño).

- Se trazarán proporcionadas las líneas de encajado.

- Se concretarán las formas y se añadirán detalles.
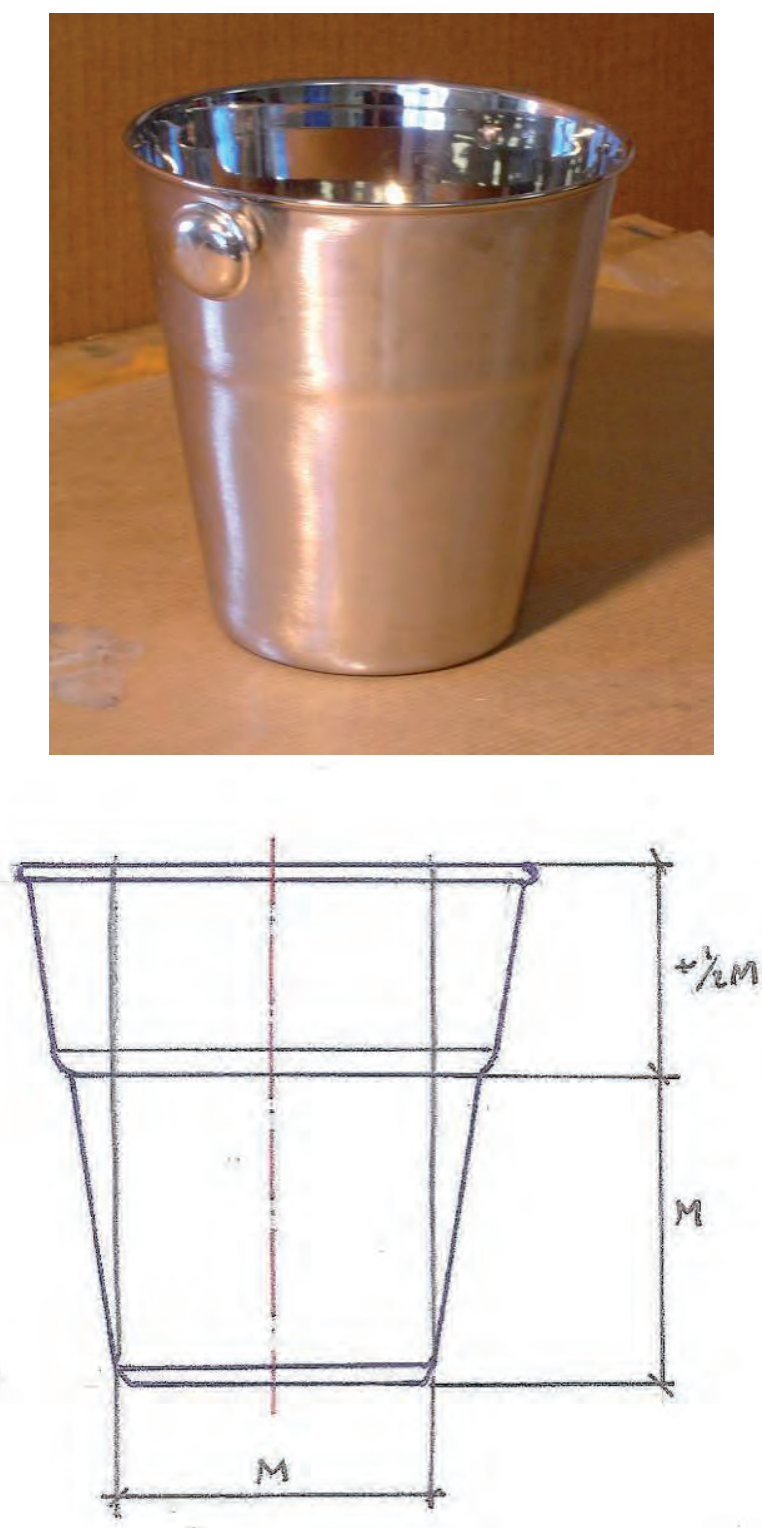

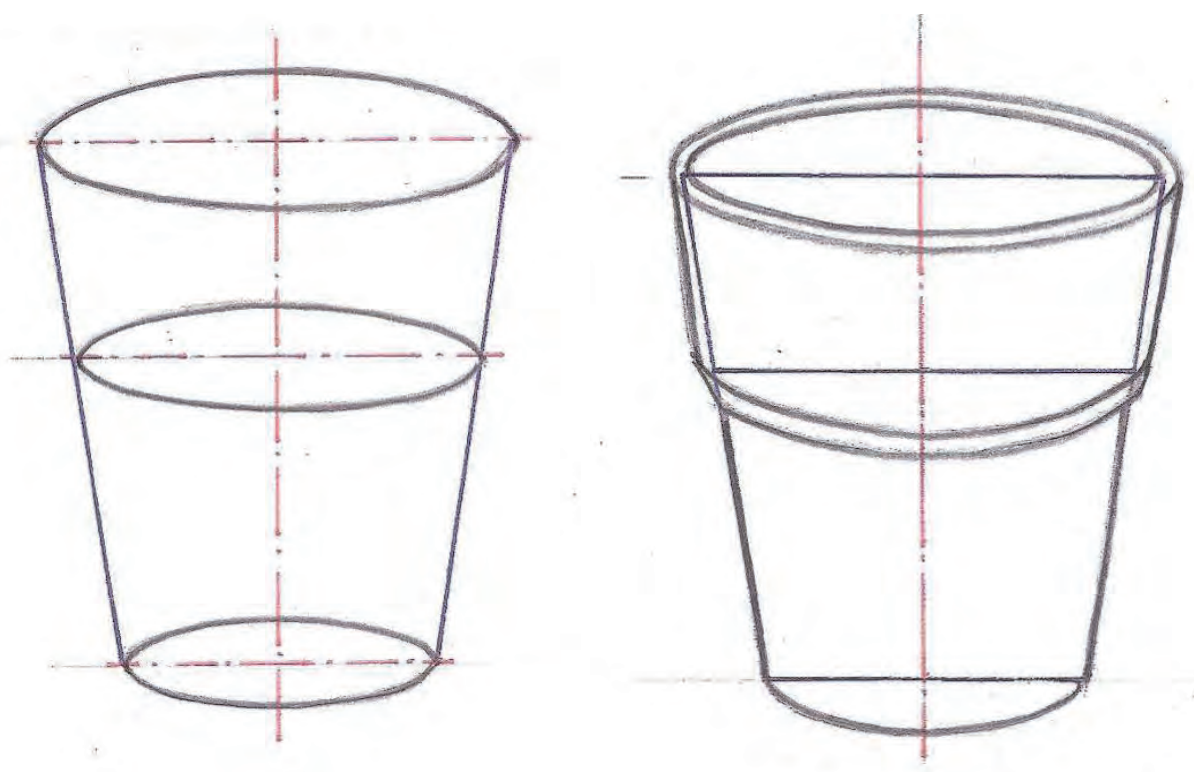

Realizado por Amelia Muñoz

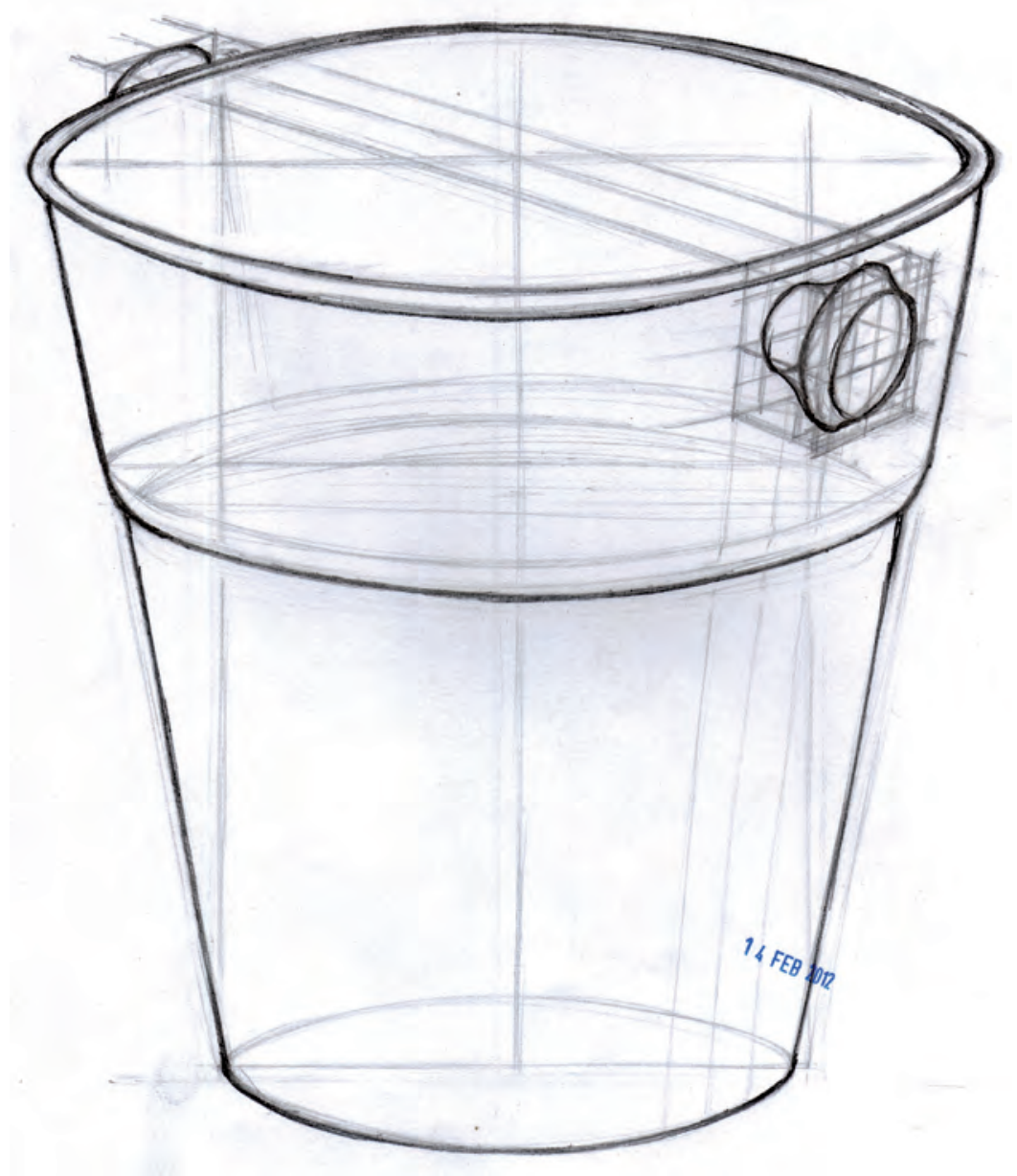

Realizado por Fabián Muñoz 


\section{Guía de autocorrección}

- Antes de empezar elegiremos el formato del papel, la disposición de la figura dentro de él y analizaremos la forma desde distintos puntos de vista para comprender su conformación. Es importante comprobar que la orientación del papel es la adecuada para las proporciones del objeto que vamos a dibujar.

- Verificaremos la simetría de la figura entre las bases y entre los lados.

- Comprobaremos las proporciones entre las distintas partes del objeto.

- Repasaremos que los detalles del objeto se ajusten a la realidad del objeto.

\section{E. Ejemplos resueltos}
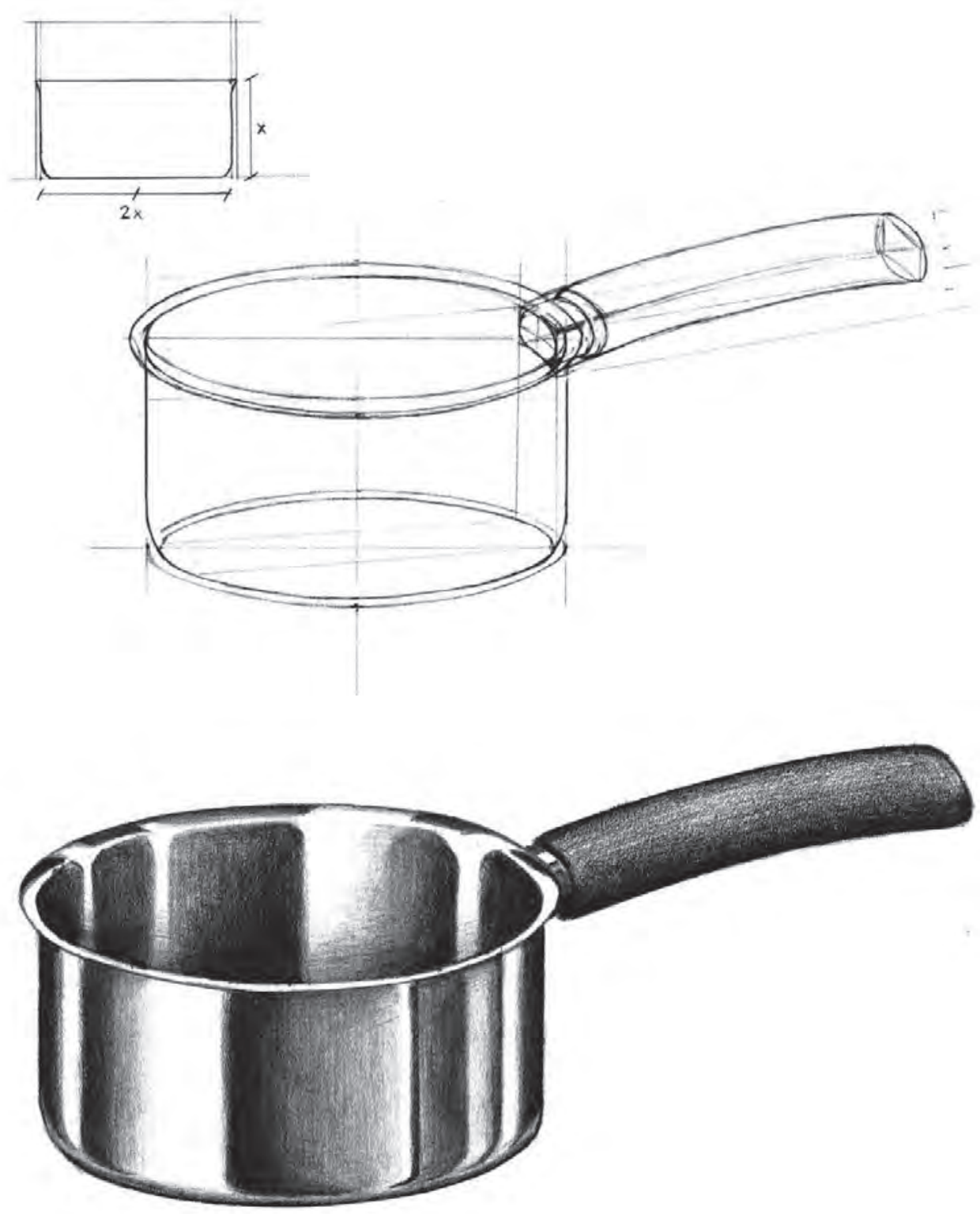

Realizado por Alejandro Garcés Silla 
BLOQUE 3

Prácticas para el claroscuro

y el color, escalas de valor,

claroscuro de una composición,

de un objeto sencillo,

círculo cromático, escalas

cromáticas 


\section{Introducción}

El claroscuro es el juego de luces y sombras presente en cualquier imagen. El claroscuro en un dibujo potencia la sensación de volumen.

La variación de sombreado de un objeto varía según la orientación del objeto respecto a la fuente de luz, de tal forma que las partes del objeto que reciben la luz son las partes claras, y las partes opuestas a la fuente luminosa son las partes oscuras del objeto.

- Tonos claros están en ángulo recto con la luz

- Tonos intermedios están oblicuamente a la luz

- Tonos de sombra son las zonas opuestas a la luz

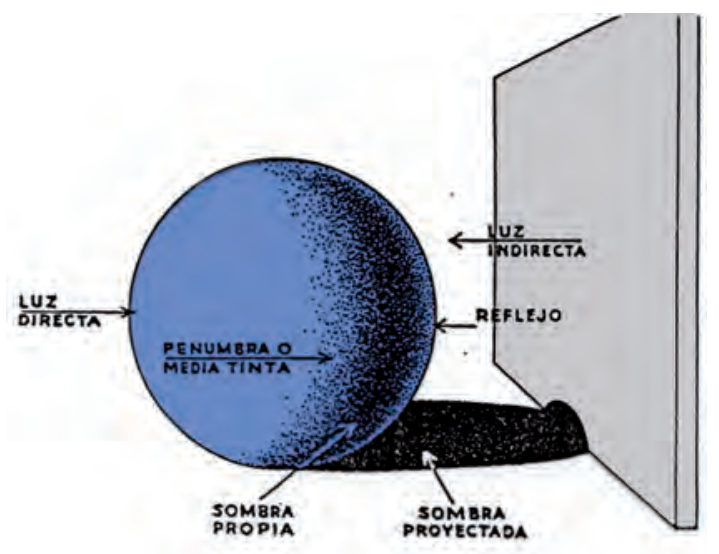

El objeto posee una sombra propia y otra sombra arrojada o proyectada, que es la que lanza el objeto sobre otra superficie

El valor de un tono es su grado de luminosidad. Una escala de valor gradúa de forma progresiva la luz de cada tono, desde el blanco del papel hasta la máxima oscuridad que permita la técnica plástica empleada.

La escala de valor monocromática trabaja el valor de un solo color mezclándolo con blanco y con negro. Mediante la elaboración de las escalas de valor, podemos comprobar cómo se modifica el valor de un tono añadiendole blanco para ganar claridad o negro para obtener mayor oscuridad.

En una escala cromática de valores, los colores próximos al blanco reciben el nombre de valores altos. Los que se encuentran cercanos al negro se conocen como valores bajos. 
Escala acromática y escala cromática.

Realizado por Mario Fernández

En el dibujo se trabaja con gran variedad de grises con los cuales se va interpretando el grado de luz de cada color.

Todos los colores poseen una escala de luminosidad que va desde la luz hasta la sombra:

- Amarillos

- Naranjas

- Rojo-marrones

- Verdes

- Azules

- Violetas

De este modo los colores se pueden hacer más cálidos o más luminosos y más fríos o más oscuros. La luz y el color del objeto también dependen de la textura del material con el que está construido. Hay materiales muy reflectantes y otros absorben mucho la luz.

Somos capaces de percibir los colores gracias a la confluencia de tres factores:

- El sentido de la vista

- La luz

- Y la cualidad pigmentaria de las cosas

Se pueden dividir los colores en dos clases según sea su origen:

- El color luz se origina por la capacidad de la luz blanca para descomponerse en los colores del espectro solar.

- El color pigmento son todas aquellas sustancias o materias que sirven para pintar. Están compuestas por dos elementos: pigmentos y aglutinantes.

El círculo cromático es una ordenación de los colores que nos permite estudiar las combinaciones que se pueden efectuar con los tonos, así como visualizar las 
relaciones entre ellos. Podemos construir círculos cromáticos de tres, seis, doce o más colores.

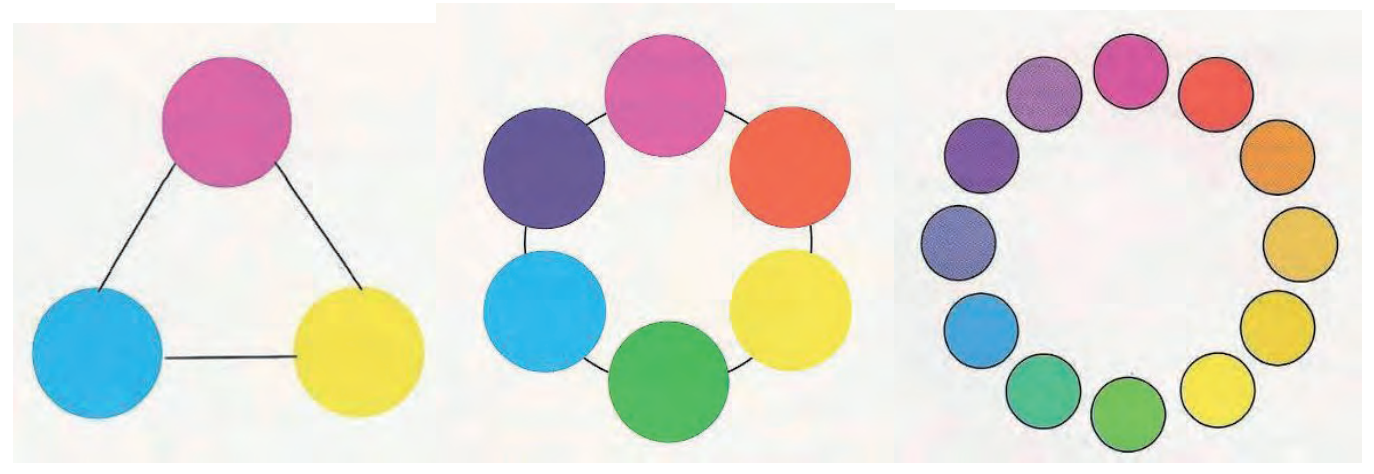

Diversos sistemas de ordenación cromática
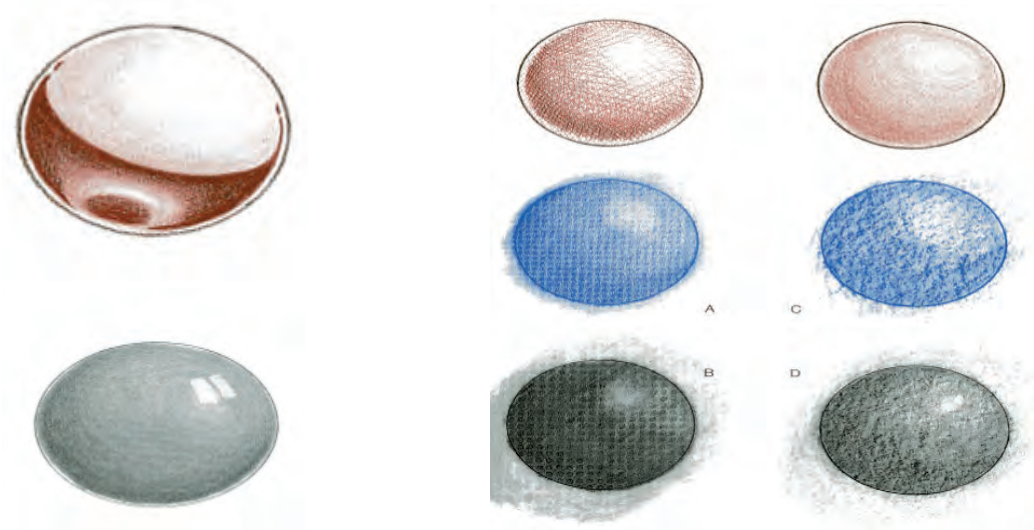

Los gradientes o escalas de valor de un tono producen efectos de volumen y espacio 


\section{Práctica 9 \\ Escalas de valor}

\section{A. Objetivos}

- Experimentar con diferentes durezas de lápices y modos de saturación del soporte.

- Obtención de diferentes valores trabajados sobre tintas planas y sobre gradientes.

- Aplicar a una esfera y a un cubo los valores antes reseñados.

\section{B. Materiales}

- Papel formato DIN A4

- Rayados y difuminados sobre tiras de papel tipo Basik

- Lápiz de diferentes durezas y difuminos

\section{Guía de ejecución}

\section{Planteamiento}

- La práctica consiste en elaborar dos escalas de valor que abarquen diferentes tonalidades y en su aplicación a dos figuras geométricas básicas.

- Formato de las escalas: 18 x $4 \mathrm{~cm}$ (la escala de tintas planas se subdividirá en nueve partes iguales).

- Tratamiento de las diferentes escalas:

- Escala de tintas planas ejecutada con lápices de durezas 4H hasta 4B.

- Escala de gradientes que se ejecutará con los mismos lápices del ejercicio anterior y con un rayado en una sola dirección. 


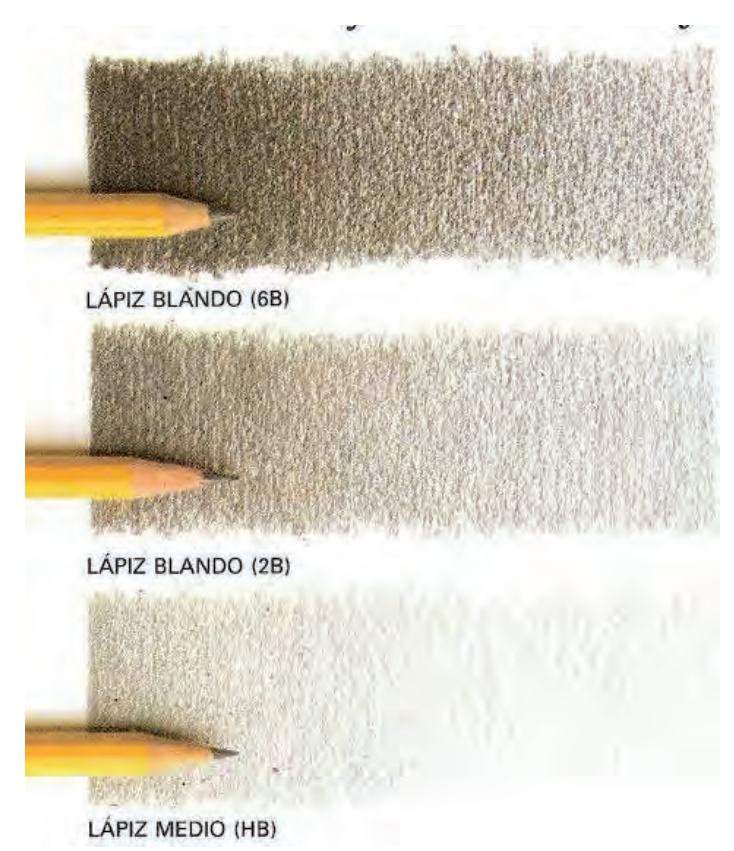

\section{Proceso de ejecución del dibujo}

- Dividir el primer rectángulo en partes iguales con ayuda de las plantillas y la regla.

- Probar los distintos grados de dureza de varios lápices sobre un papel aparte.

- Controlar previamente cómo se van a disponer los tonos dependiendo del tono obtenido.

- Trasladar los valores a la escala de gradientes en papel Basik.

- Iniciar el trazado del rectángulo para curvas. Puedes basarte en los tonos obtenidos en la escala de gradientes anterior, para que los grados de luminosidad obtenidos te sirvan de pauta.
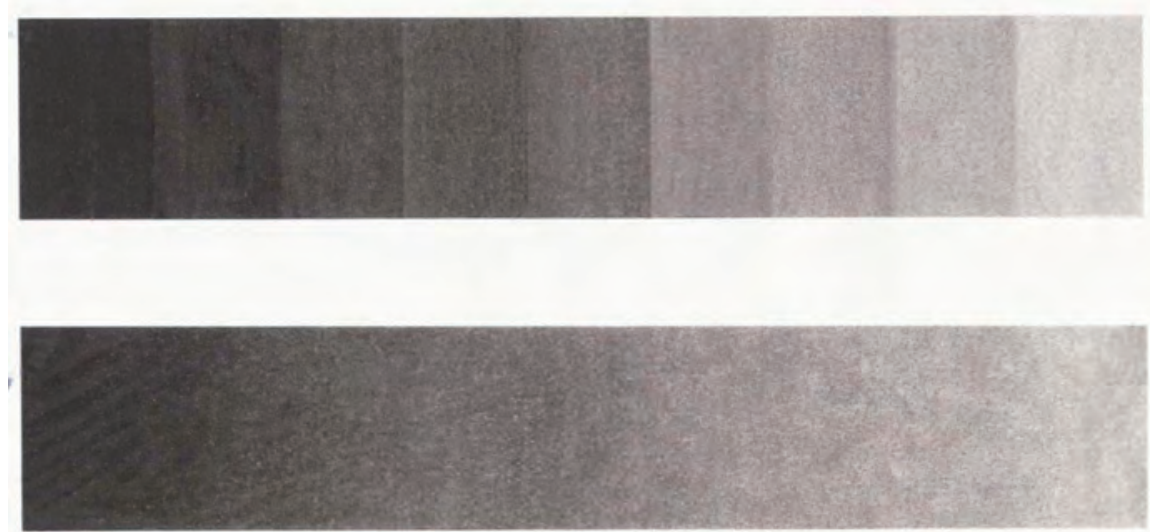

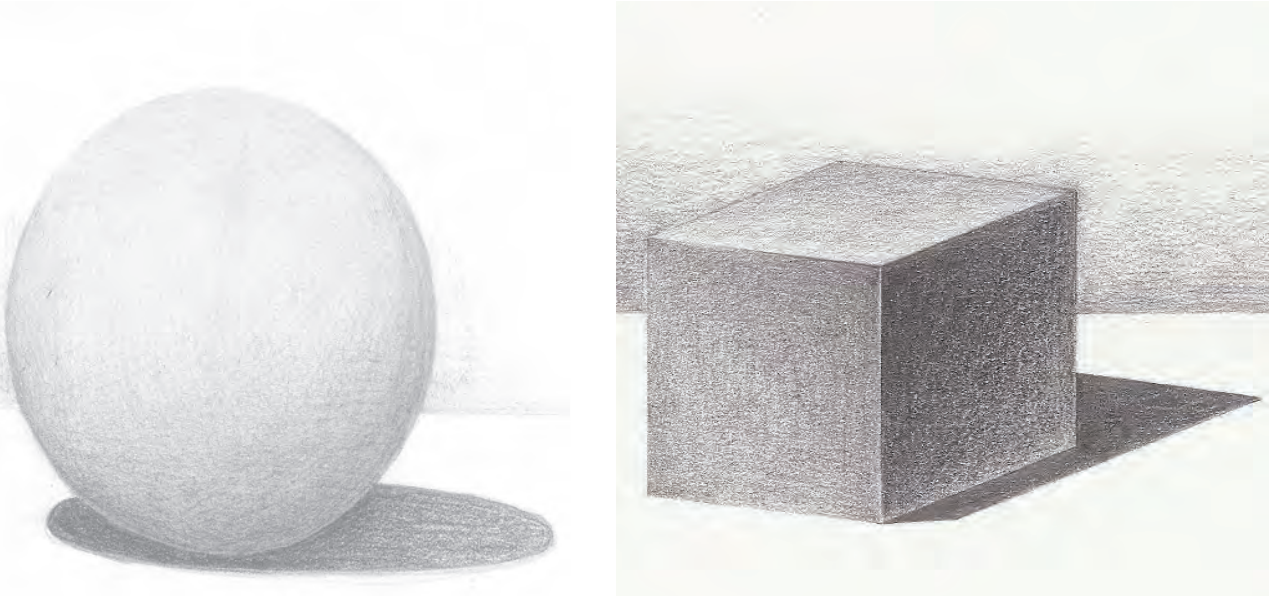

\section{Guía de autocorrección}

- Verificar la coherencia en la aplicación de una escala de valor para caras planas y de un gradiente para planos curvos.

- Controlar la escala gradual de los tonos para las caras planas y la paulatina para los curvos.

- Identificar en la realización de varias figuras la aplicación del estudio de los valores resueltos anteriormente.

La entonación de un dibujo se realiza de forma diferente según esté configurado por superficies planas o curvas.
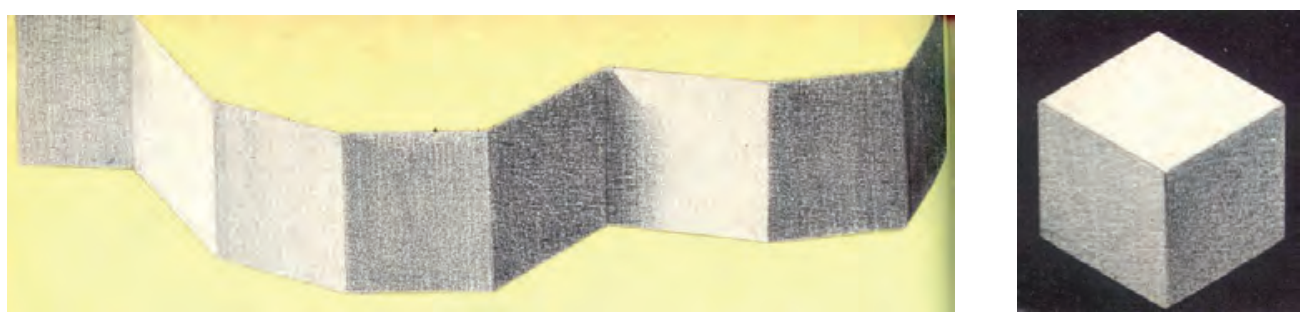

Aplicación de las escalas a caras planas

La entonación de las caras planas se realiza con superficies tonales homogéneas, cuyo valor lumínico depende de la proximidad al foco de luz.

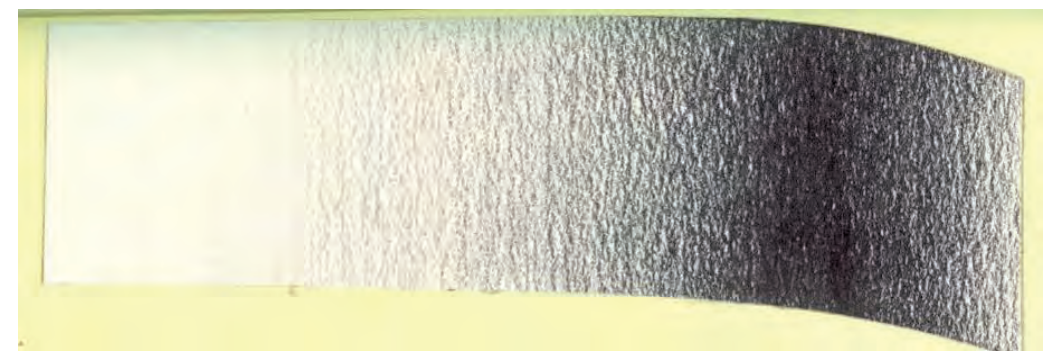


La entonación de las caras curvas se realiza con degradados tonales.

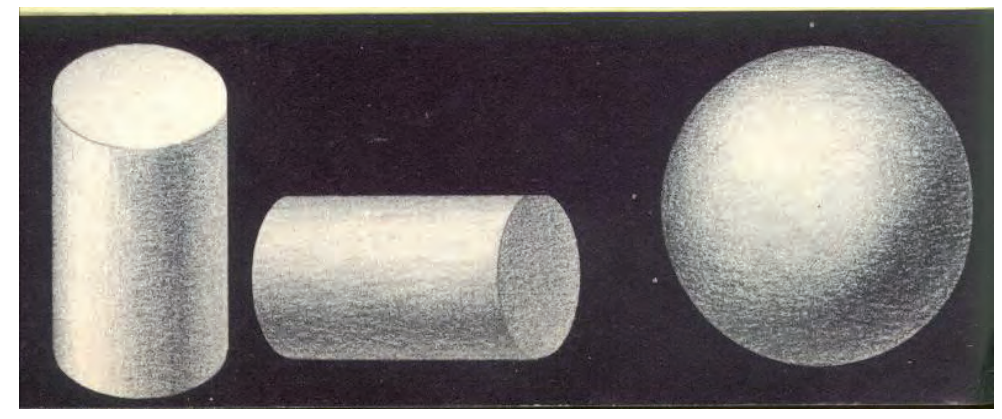

Aplicación de las escalas a planos curvos

\section{E. Ejemplos resueltos}

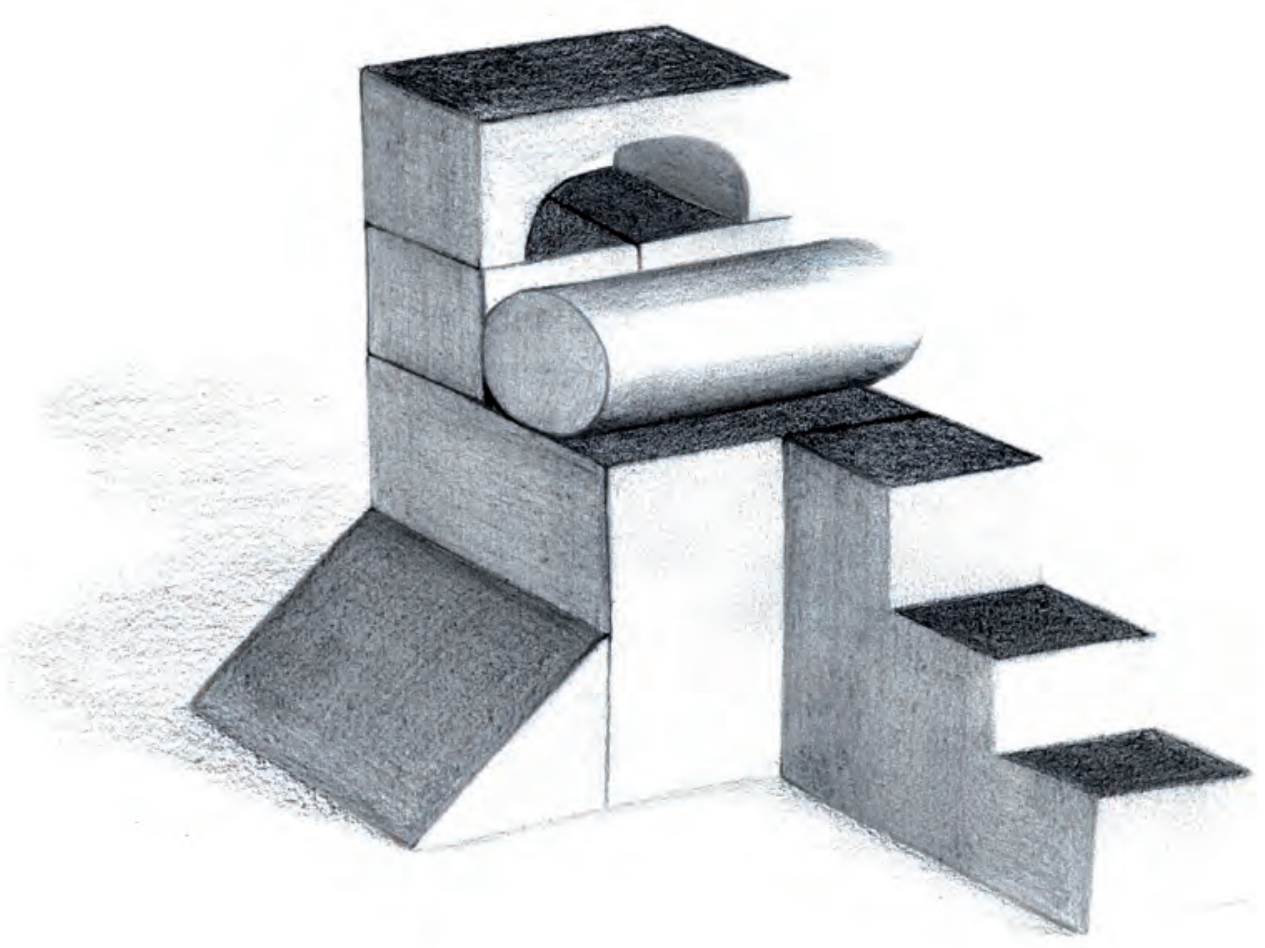

Aplicación de valores en caras planas y en curvas.

Realizado por Laura Martínez 


\section{Práctica 10 \\ Claroscuro de una composición de volúmenes geométricos}

\section{A. Objetivos}

- Experimentar con diferentes durezas de lápices y modos de saturación del soporte.

- Obtención de diferentes valores trabajados sobre tintas planas y sobre gradientes.

- Dominar la visualización de las estructuras geométricas fundamentales.

- Control conceptual de la distribución del claroscuro en una composición.

\section{B. Materiales}

- Hoja papel DIN A4 Basik

- Lápices de diferentes durezas

- Gomas de borrar

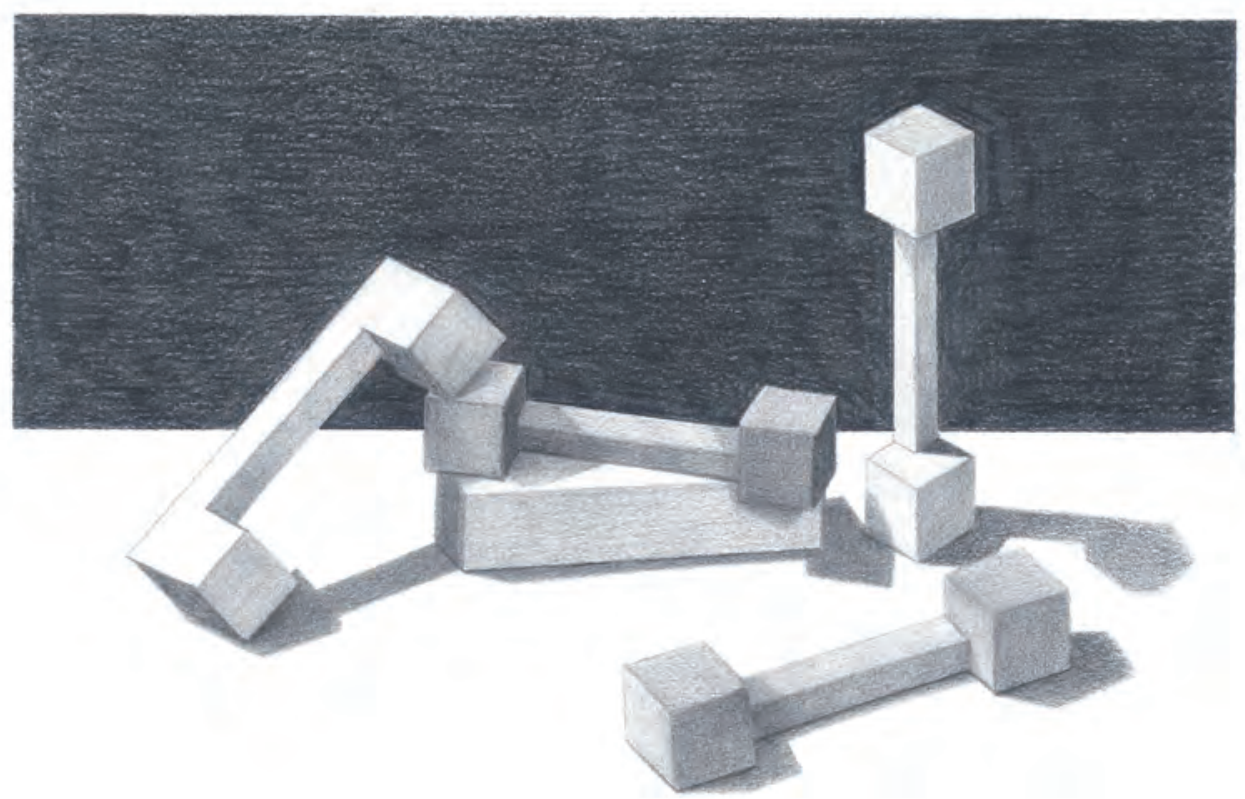

Realizado por Rubén Soler 


\section{Guía de ejecución}

\section{Planteamiento}

Aplicar los gradientes lumínicos al ejercicio compositivo desarrollado en las prácticas anteriores, aplicando los conocimientos de la reflexión de la luz a distintas problemáticas volumétricas.

\section{Proceso de ejecución del dibujo}

- Elegir la orientación del papel según nuestras intenciones compositivas.

- Comenzaremos estudiando la ubicación de los elementos en una vista en planta.

- Seleccionaremos el grado del ángulo en picado deseado para el dibujo.

- Se transfiere el dibujo de la práctica realizada en la práctica: composición de varios volúmenes geométricos a papel Basik.

- Se elige una posición para el foco de luz que potencie la corporeidad del cubo.

- A continuación, se dibuja la silueta de la sombra proyectada de cada uno de los volúmenes.

- Finalmente, se sombrearán los volúmenes teniendo en cuenta la posición del foco luminoso.

- Se aplicarán las escalas de valor realizadas en la práctica anterior ajustándola a las formas analizadas.
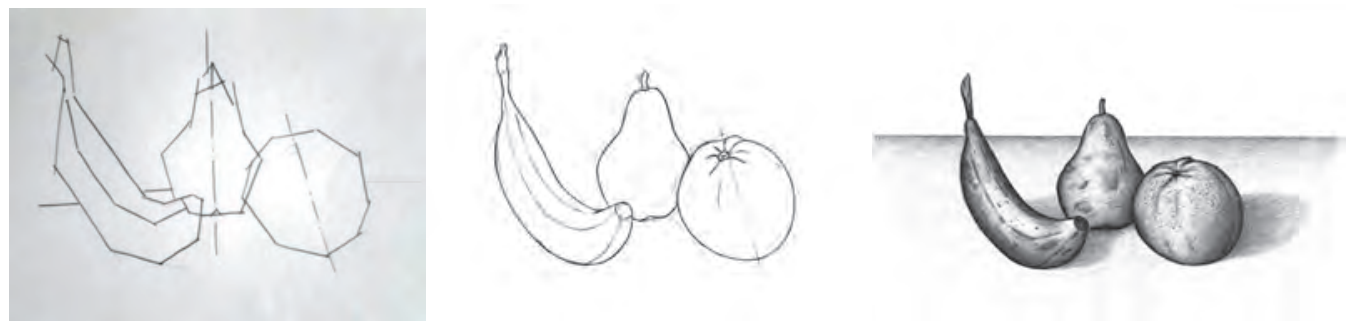

Fases de entonación de un dibujo.

Realizado por Alejandro Garcés 


\section{Ejemplos resueltos}

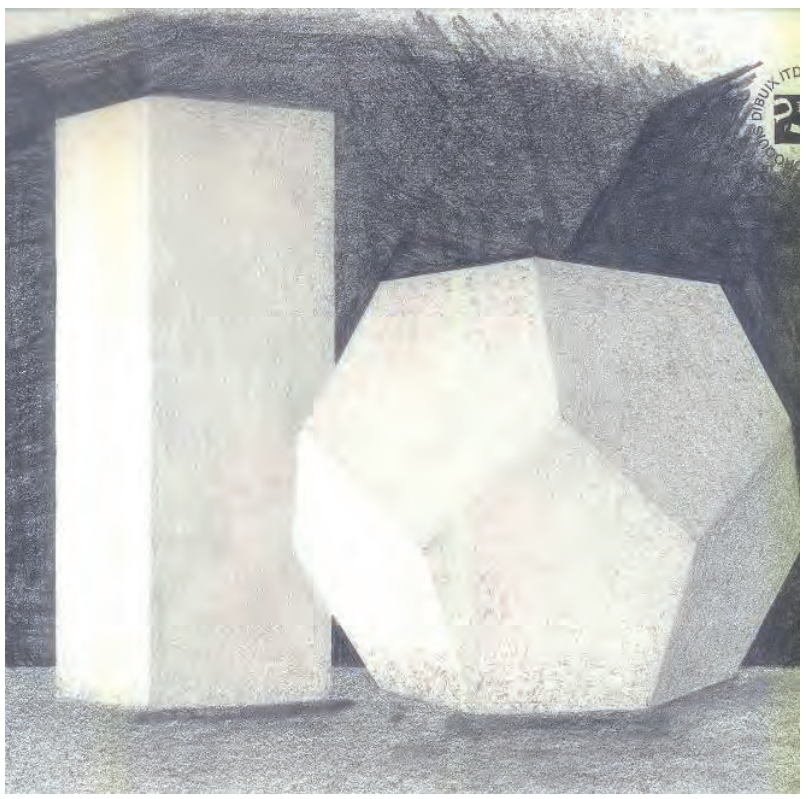

Realizado por Alba Llop
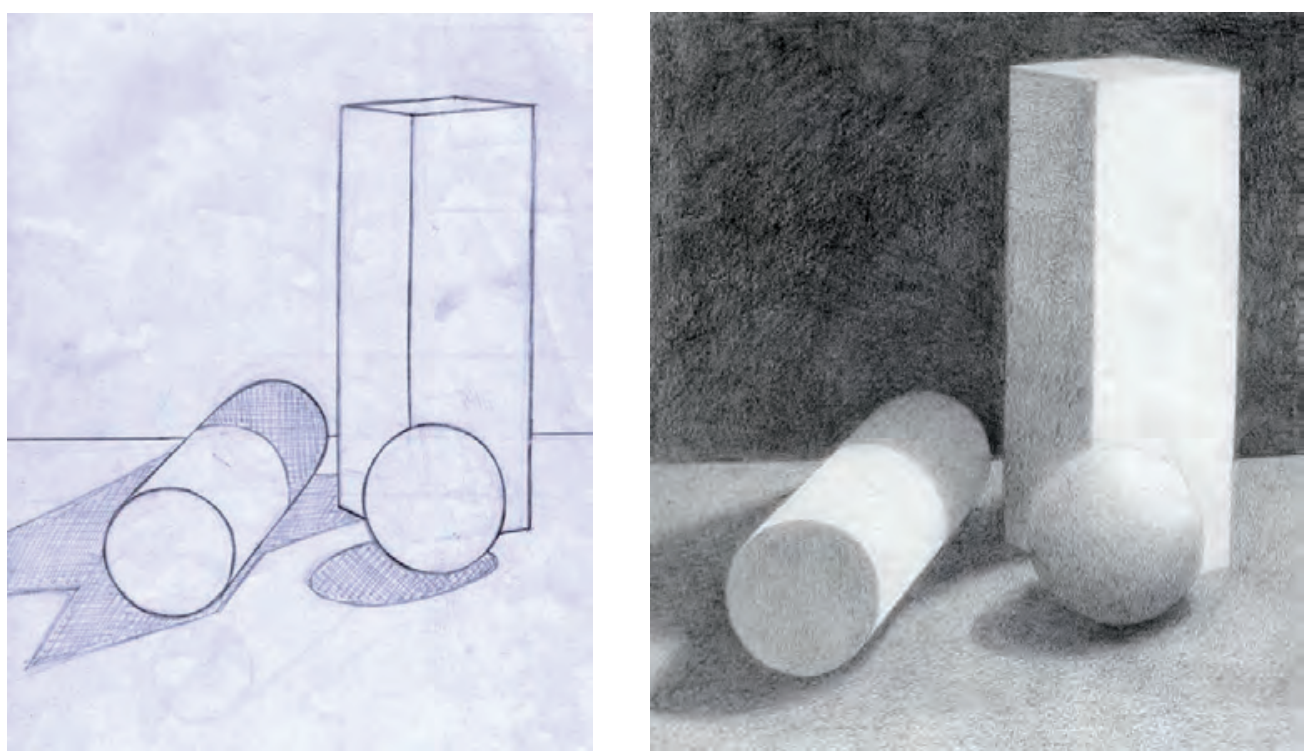

Realizado por Alba Gimeno Gómez 


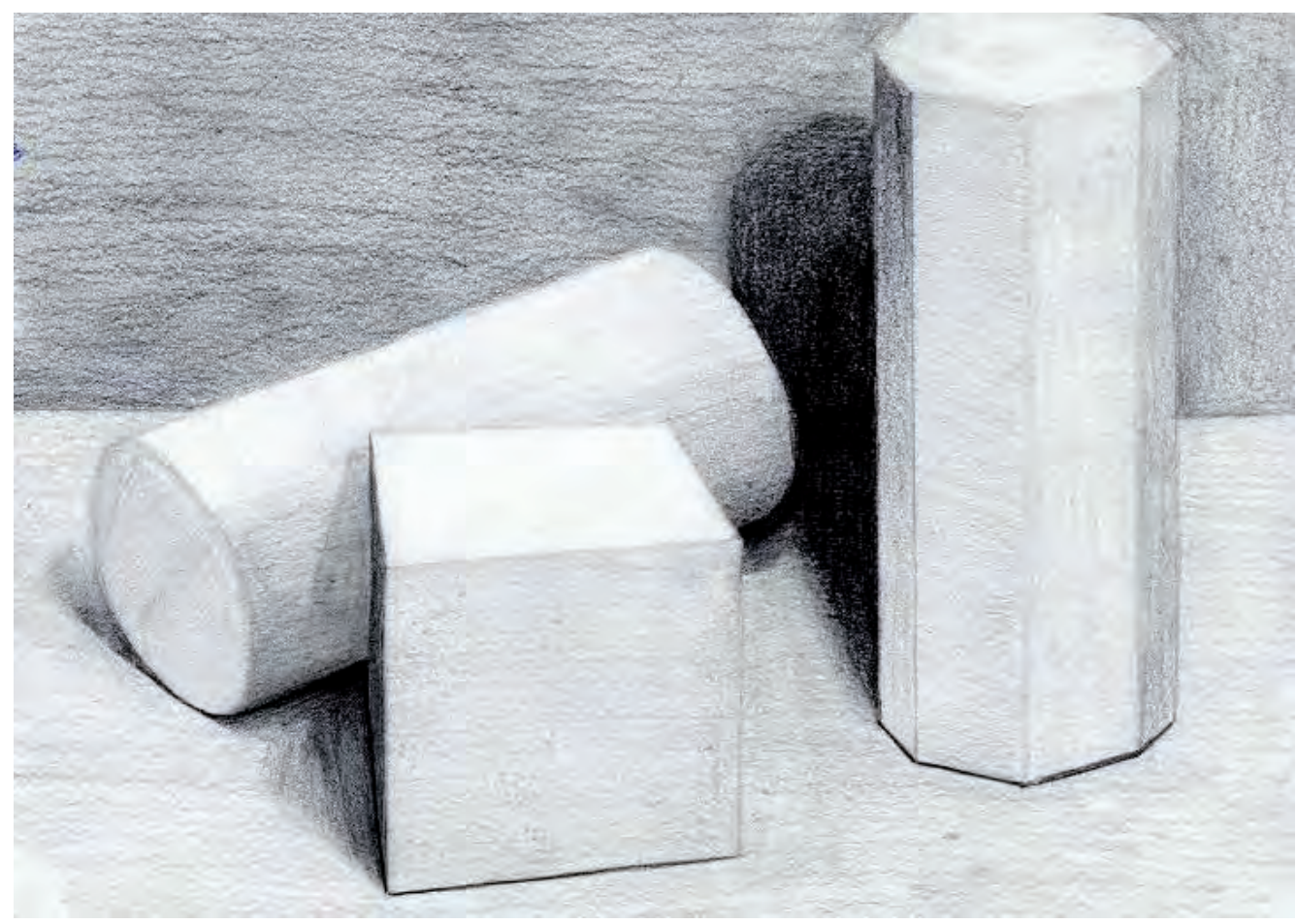

Realizado por Vicente Varella Forcada

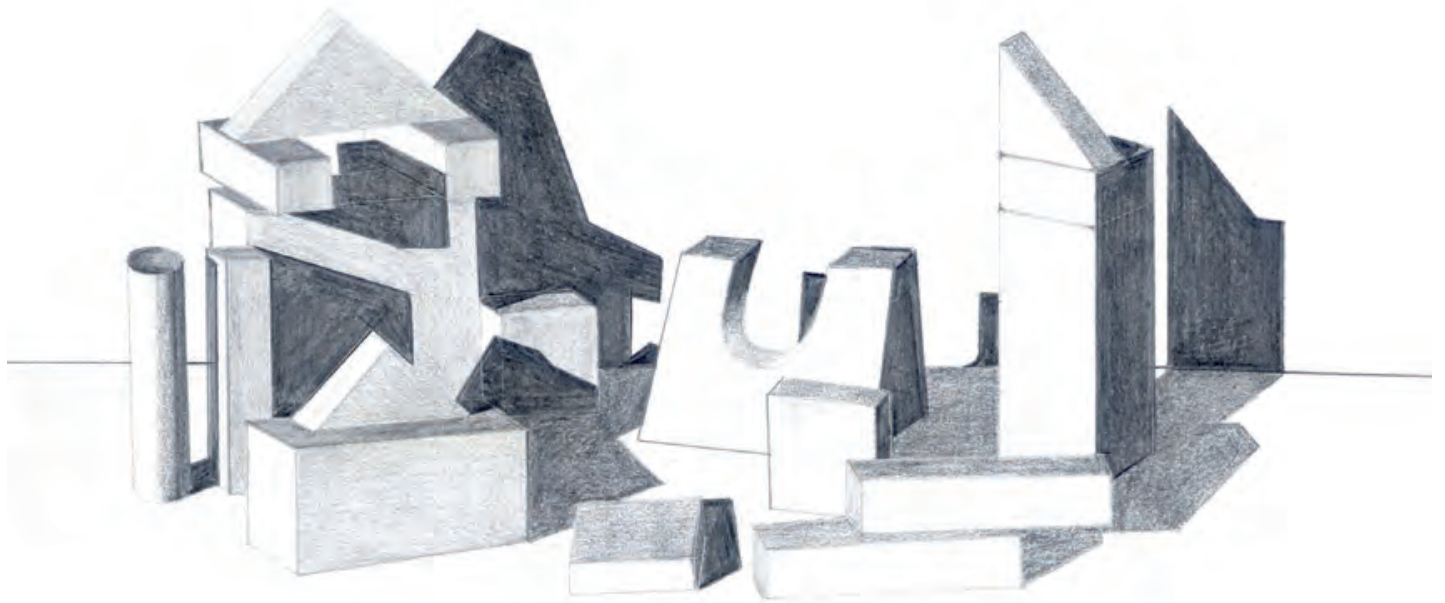

Realizado por Pedro Fiascunari 

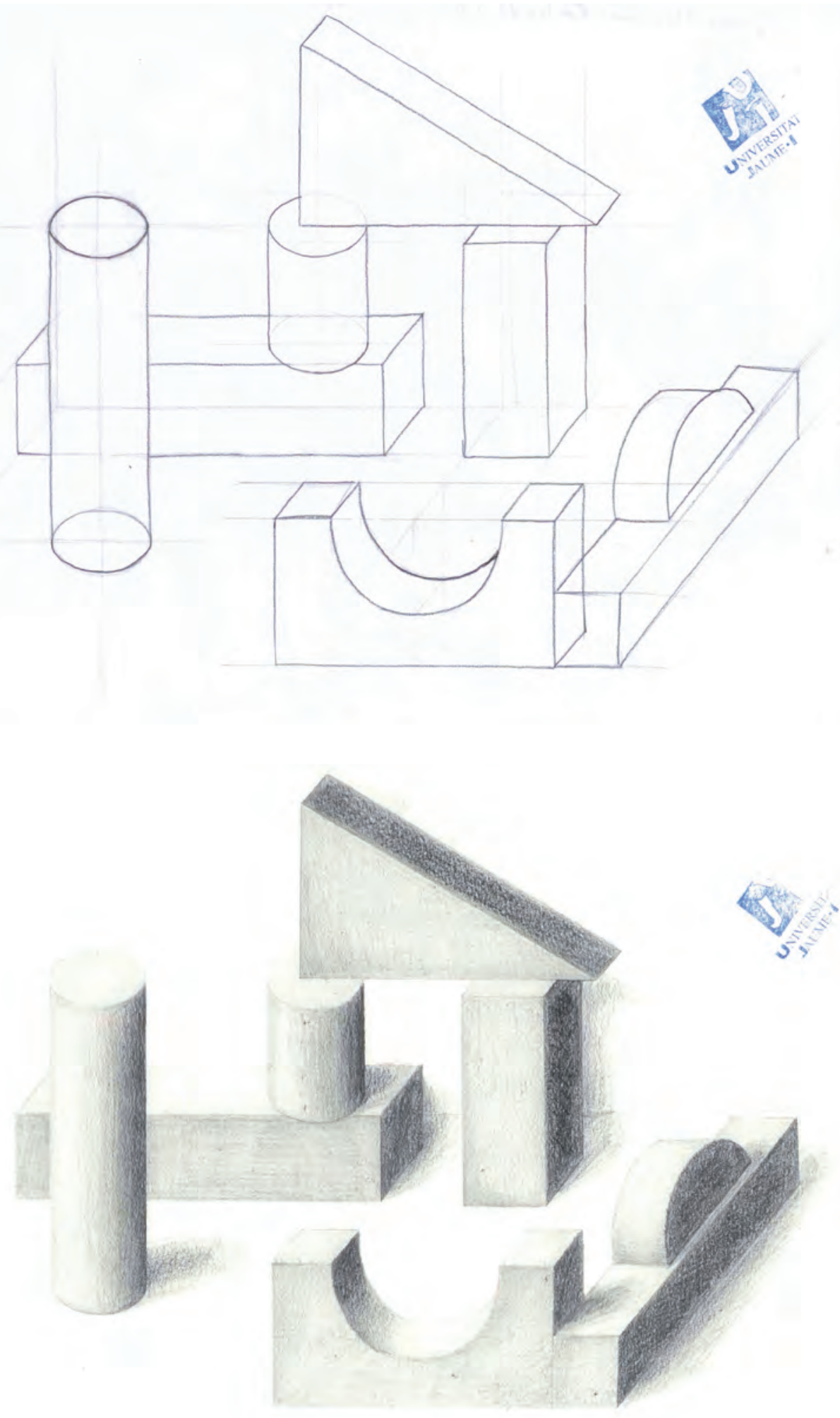

Realizado por Josep Serrano Cabedo 

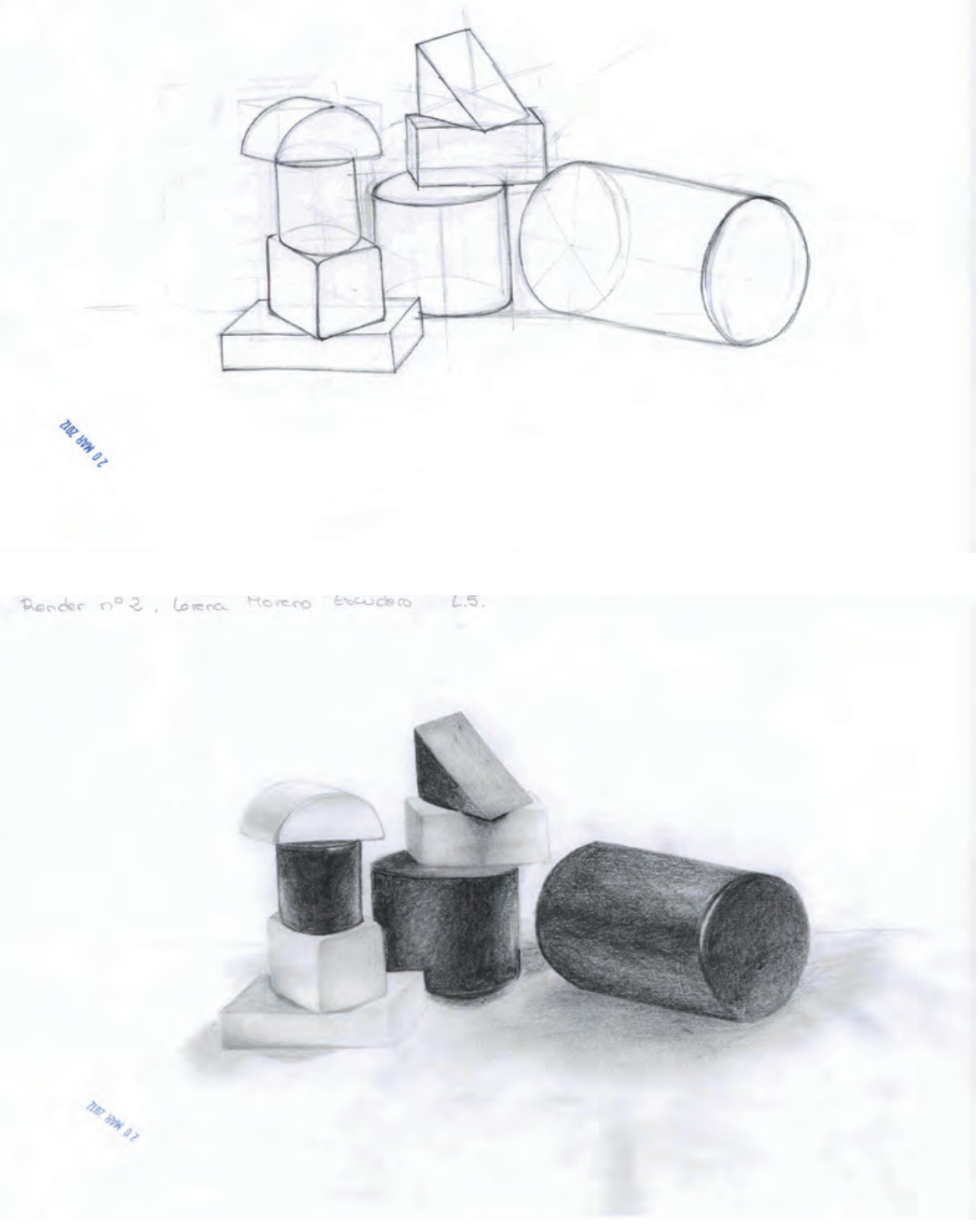

Realizado por Lorena Moreno Escudero 

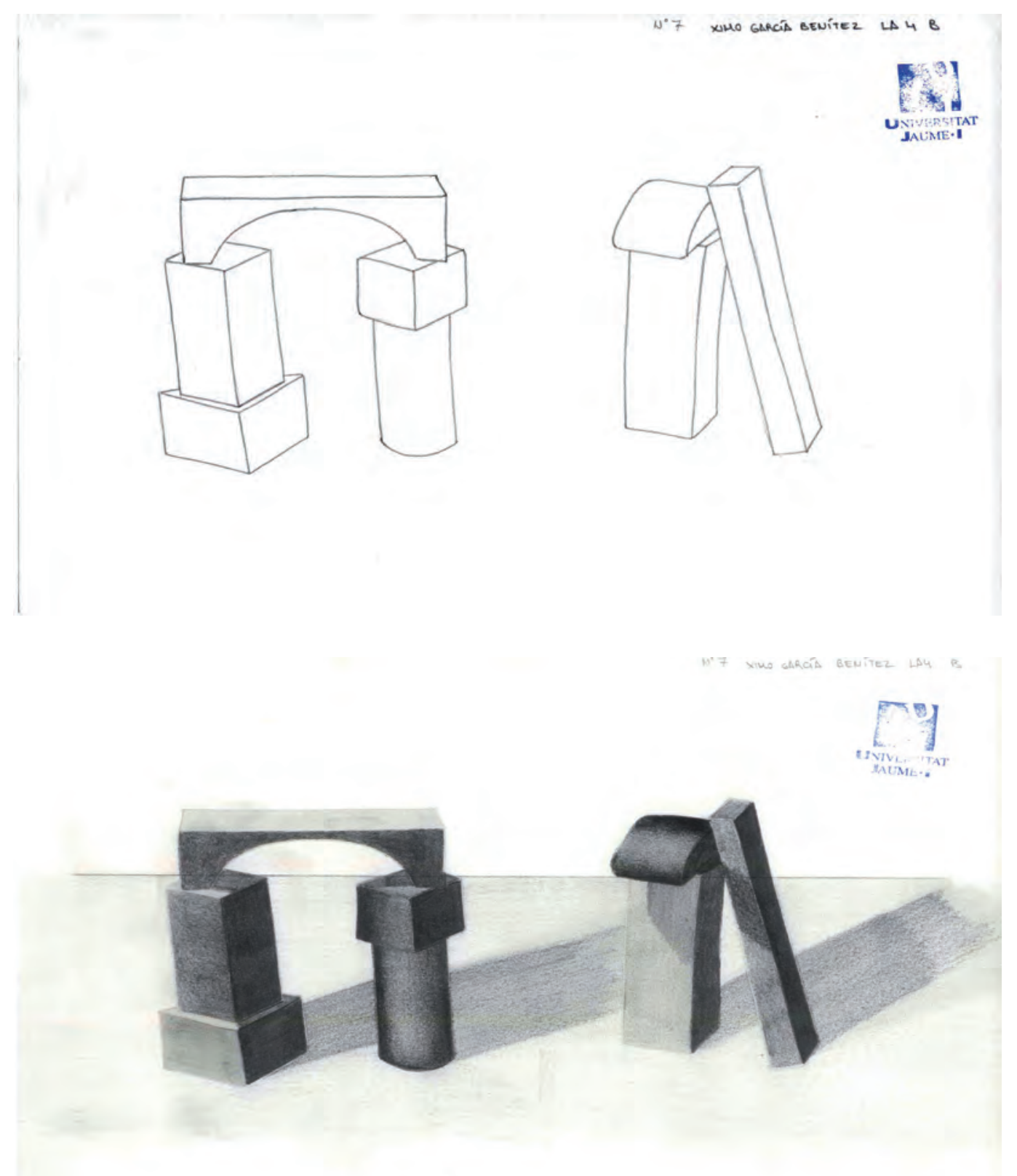

Realizado por Ximo García Benítez 

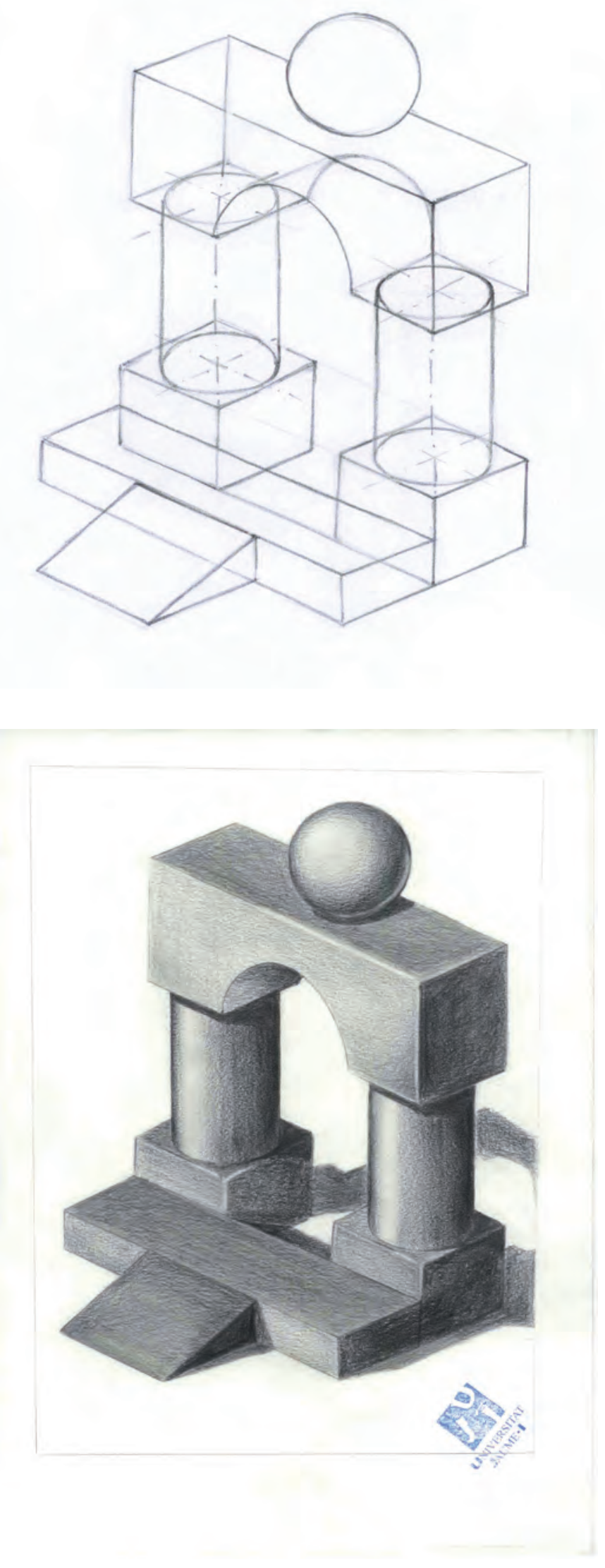

Realizado por Rafael Font Fornés 


\section{Práctica 11 \\ Claroscuro de un objeto sencillo}

\section{A. Objetivos}

- Planificar de manera lógica las fases de la representación de un objeto industrial sencillo.

- Abordar satisfactoriamente las diversas maneras empleadas anteriormente en la resolución gráfica de la forma.

- Control conceptual de la distribución del claroscuro en un objeto.

- Aplicar el claroscuro a un objeto sencillo con la técnica y los materiales específicos, usando diferentes durezas de lápices y grados de saturación en el soporte.

\section{B. Materiales}

- Lápices de grafito de diferentes durezas

- Papel de croquis para boceto y papel Basik para el arte final tamaño DIN A4

- Goma de borrar

\section{Guía de ejecución}

\section{Planteamiento}

- La práctica consiste en abordar de manera autónoma el análisis y la resolución gráfica de un objeto industrial sencillo.

- La técnica utilizada es el estudio y valoración empleando lápices de grafito de diferente dureza.

- Se valorará la riqueza tonal en la ejecución de la práctica.

\section{Proceso de ejecución del dibujo}

- El estudio del objeto se dibujará en un papel diferente.

- El alumno/a seleccionará el método de encaje adecuado a la estructura constituyente del objeto. 
- Se realizarán las mediciones pertinentes para poder proporcionar y se plasmarán con líneas de encaje en el papel.

- Se dibujará el contorno y las partes fundamentales de la forma.

- Se calca el estudio al papel definitivo.

- Se procederá con la fase de acabado del dibujo de contorno, donde se mejoraran los trazos, la forma y se añadirán todos los detalles.

- Se procede con el estudio de manchas tonales tiznando las zonas no iluminadas $\mathrm{y}$, posteriormente a la valoración detallada del objeto, acentuamos los brillos borrando con goma en zonas puntuales y oscurecemos remarcando con lápiz blando (B) los detalles más oscuros del dibujo.
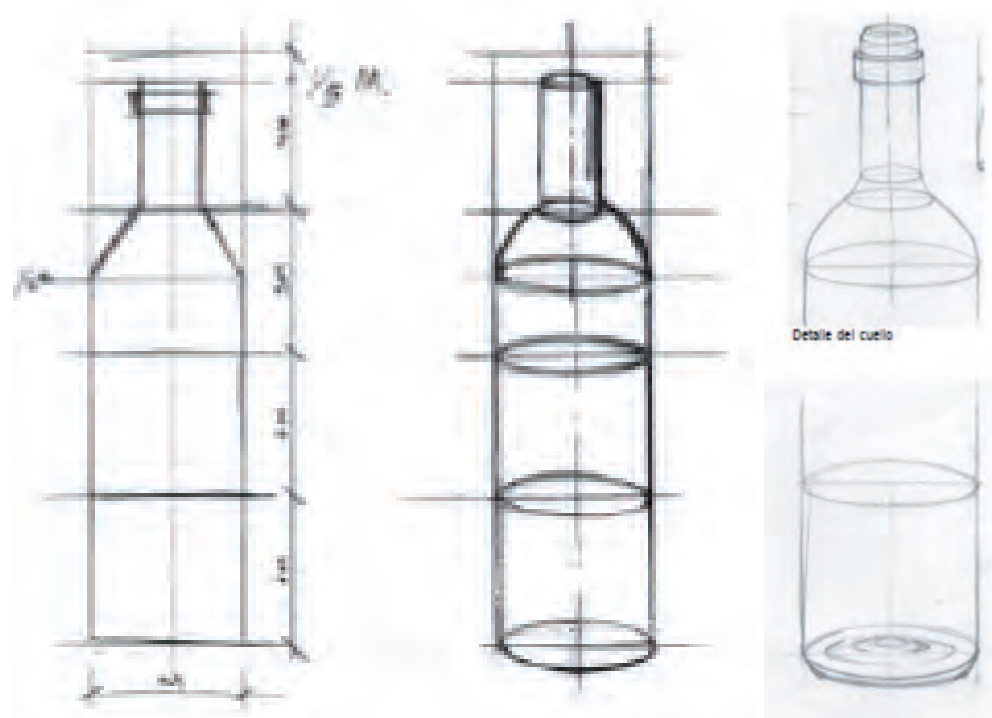

Estudio de un envase contenedor: proporciones, simetría y dibujo de detalles. Amelia Muñoz

\section{Guía de autocorrección}

- Comprobar si la elección del formato del papel, las proporciones del objeto y su ubicación en el espacio compositivo es la más adecuada.

- Repasar las simetrías y el trazado de elipses.

- Verificar que el foco de luz es el más adecuado para potenciar las características del objeto. La posición del foco luminoso será determinante en el resultado plástico del dibujo.

- Cotejar si la escala de luminosidad empleada se adecua al objeto y a sus volúmenes. 


\section{E. Ejemplos resueltos}

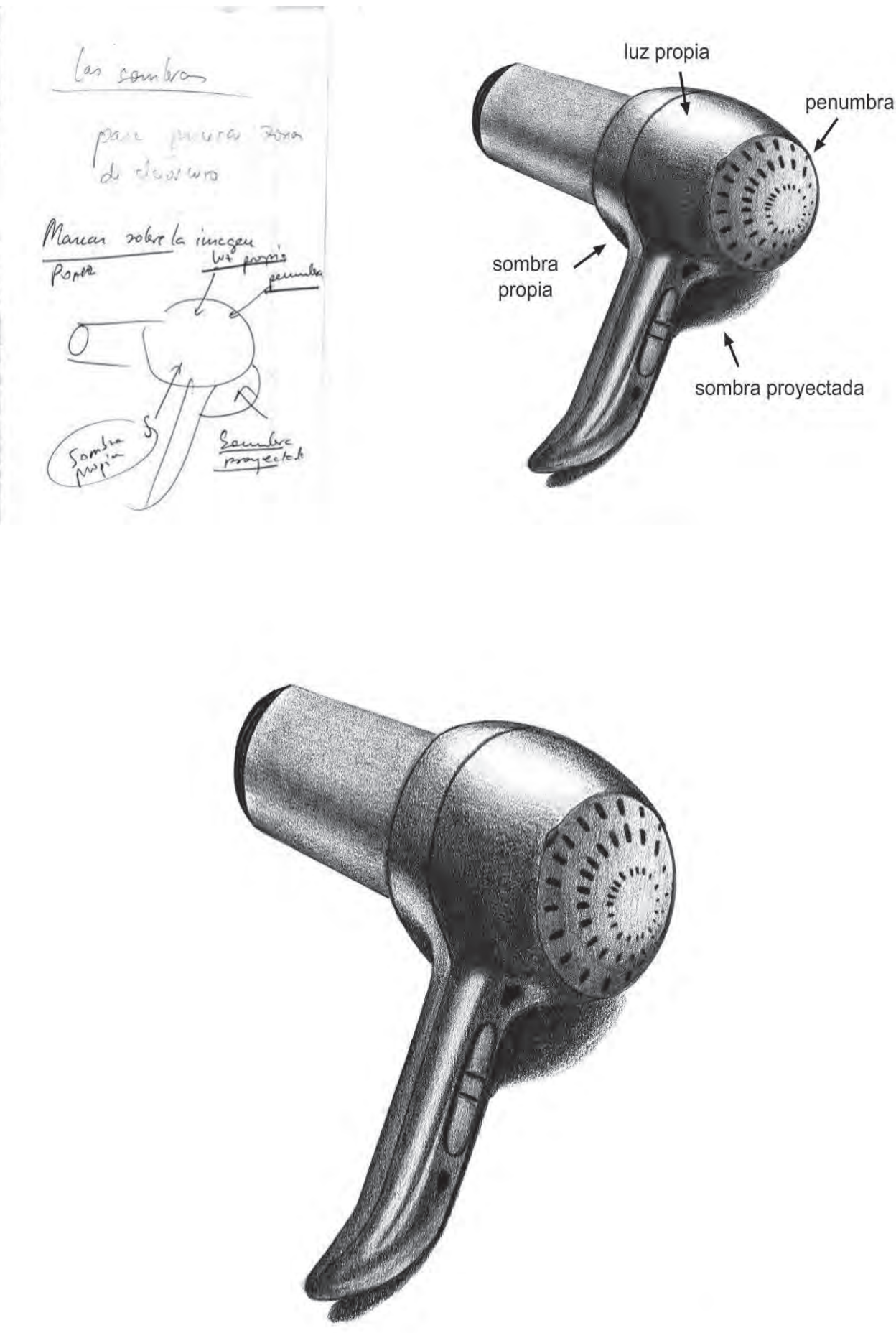

Realizado por Álvaro Campos 

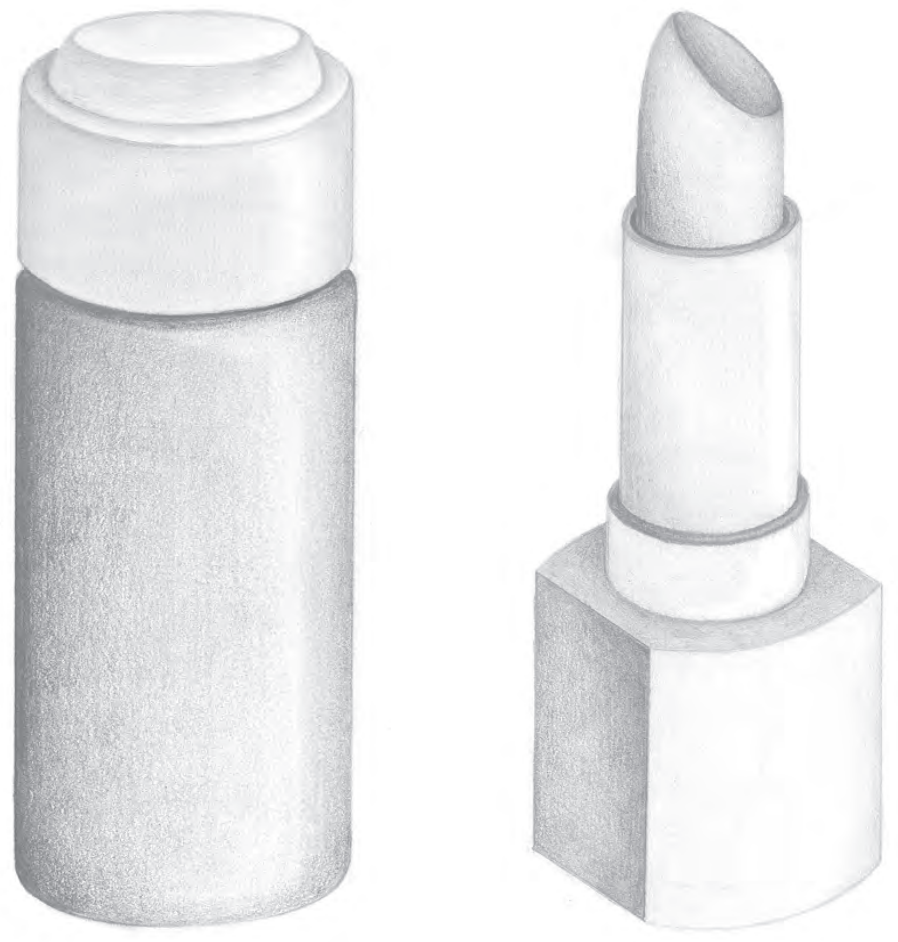

Realizado por Alba Llop 


\section{Práctica 12 \\ Círculo cromático}

\section{A. Objetivos}

- Entender los fundamentos teóricos del círculo cromático.

- Analizar los colores primarios y secundarios, y sus relaciones.

- Controlar la técnica del rotulador.

- Controlar la técnica mixta (lápices de colores y rotulador).

\section{B. Materiales}

- Lápiz de dureza HB

- Goma de lápiz

- Material dibujo técnico: compás, escuadra, cartabón y regla milimetrada

- Papel para rotuladores: Letraset, Universal, Caballo y formato DIN A4

- Rotuladores: Tria, Copic...

- Lápices de colores Lyra, Faber Castell...

\section{Guía de ejecución}

La elaboración de un círculo cromático requiere de la aplicación de los tres colores primarios (los tres colores fundamentales que no se pueden obtener por la mezcla de ningún color), la aplicación de los tres colores secundarios (se obtienen al mezclar a partes iguales dos colores primarios) y de los colores complementarios (aquellos que se encuentran en posiciones opuestas dentro del círculo cromático; si se mezclan a partes iguales dos colores complementarios se obtiene un color sucio próximo al negro).

\section{COLORES PRIMARIOS}

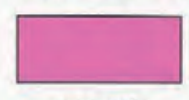

magenta

COLORES SECUNDARIOS

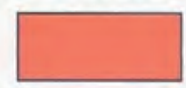

rojo

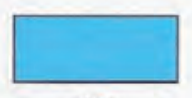

cian

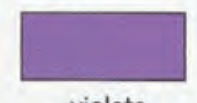

violeta

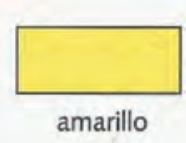

amarillo

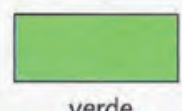

verde
COLORES COMPLEMENTARIOS
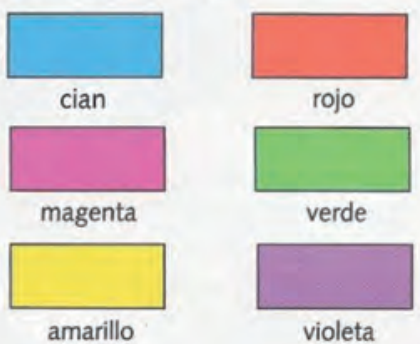
Conviene recordar que los colores análogos poseen un color en común y se hallan próximos en el círculo cromático, que los colores cálidos son todos los colores próximos al rojo y que tienen la cualidad de acercarse visualmente al espectador y son luminosos, y por último, que los colores fríos son todos los colores próximos al azul, y son huidizos y oscuros.

\section{Planteamiento}

- Dibujar la estructura de un círculo cromático de seis colores. En él deben trabajarse los tres colores primarios y los tres secundarios.

- En el círculo cromático se trabajarán, de cada uno de los seis colores, dos tonos progresivos más oscuros.

- El trazado geométrico previo se realizará con un lápiz de dureza HB.

- En primer lugar, se delinearán los bordes de cada sección cromática con los instrumentos de precisión.

- A continuación, manchar cada sección de los colores primarios con el rotulador del color correspondiente.

- En las secciones que sea necesario dar varias capas de rotulador para aumentar el tono del color. Siempre esperar a que seque la capa anterior.

- Repasar con lápiz de colores las secciones que lo requieran para demarcar los bordes y el tono.

\section{Proceso de ejecución del dibujo}

- Trazar el círculo cromático con ayuda de instrumentos de precisión (compás, escuadras...).

- Subdividir en tantas partes como sea necesario para la posterior aplicación de color.

- Realizar pruebas de color con anterioridad en previsión de valores erróneos.

- Aplicar el color utilizando el material y la técnica propuesta.

- Realizar los ajustes necesarios para que la lectura cromática se adapte a la gradación ordenada de los colores. 


\section{Guía de autocorrección}

- Verificar que los gradientes sean paulatinos y que las relaciones entre los colores vecinos guarden la proporción justa y armoniosa de diferencias, asícomo la semejanza entre ellas.

- Rectificar los tonos cuanto sea necesario con ayuda de los lápices de colores.

\section{E. Ejemplos resueltos}

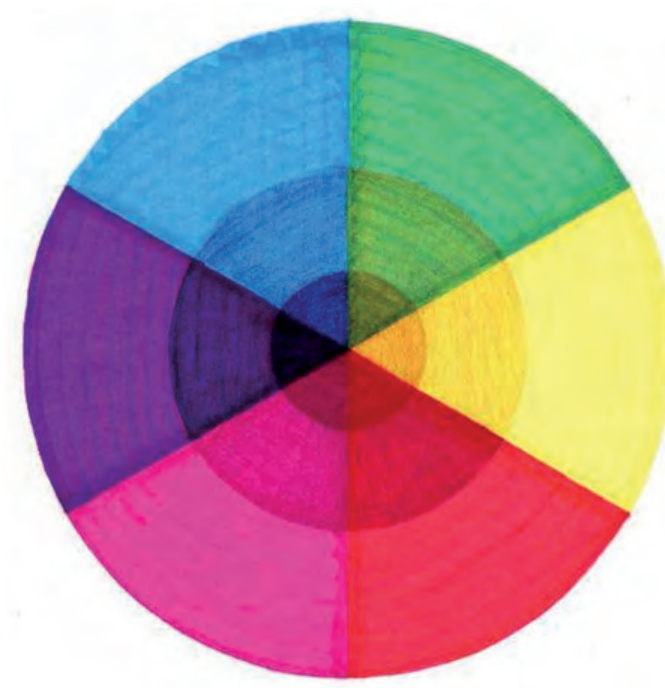

Realizado por Vicente Varella Forcada

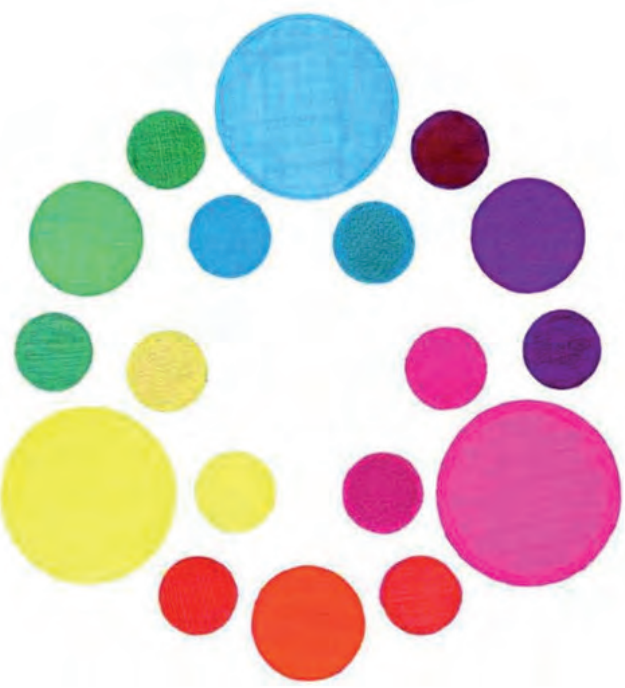

Realizado por María Ángeles Gómez Caser

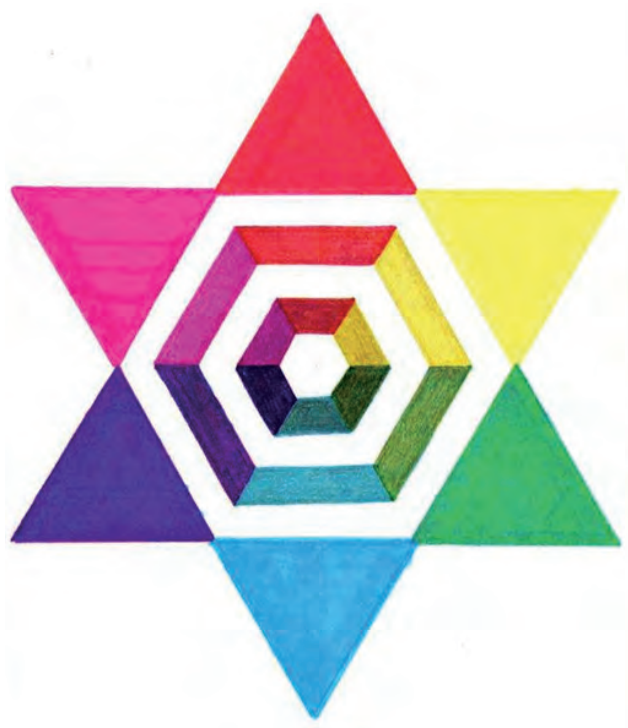

Realizado por Raquel Adell Sabater

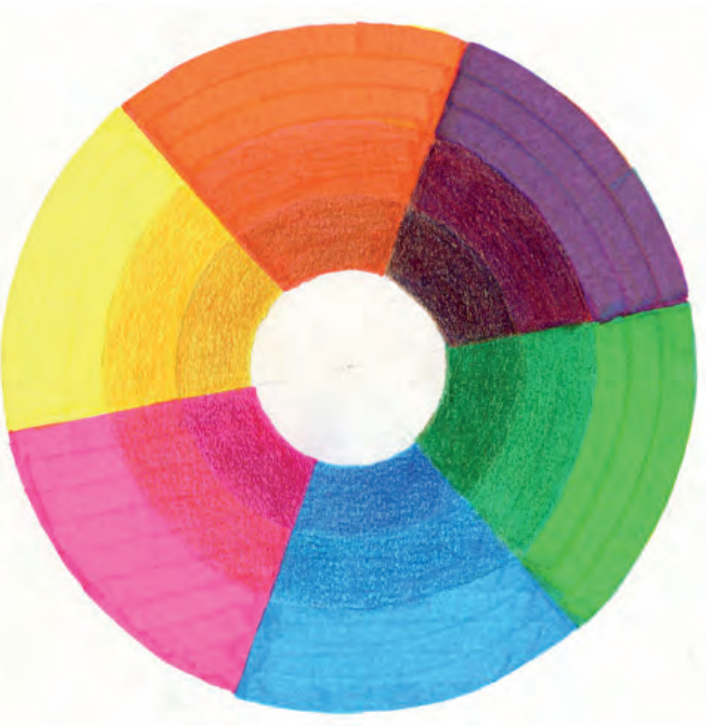

Realizado por Clara Gómez Mocholí 


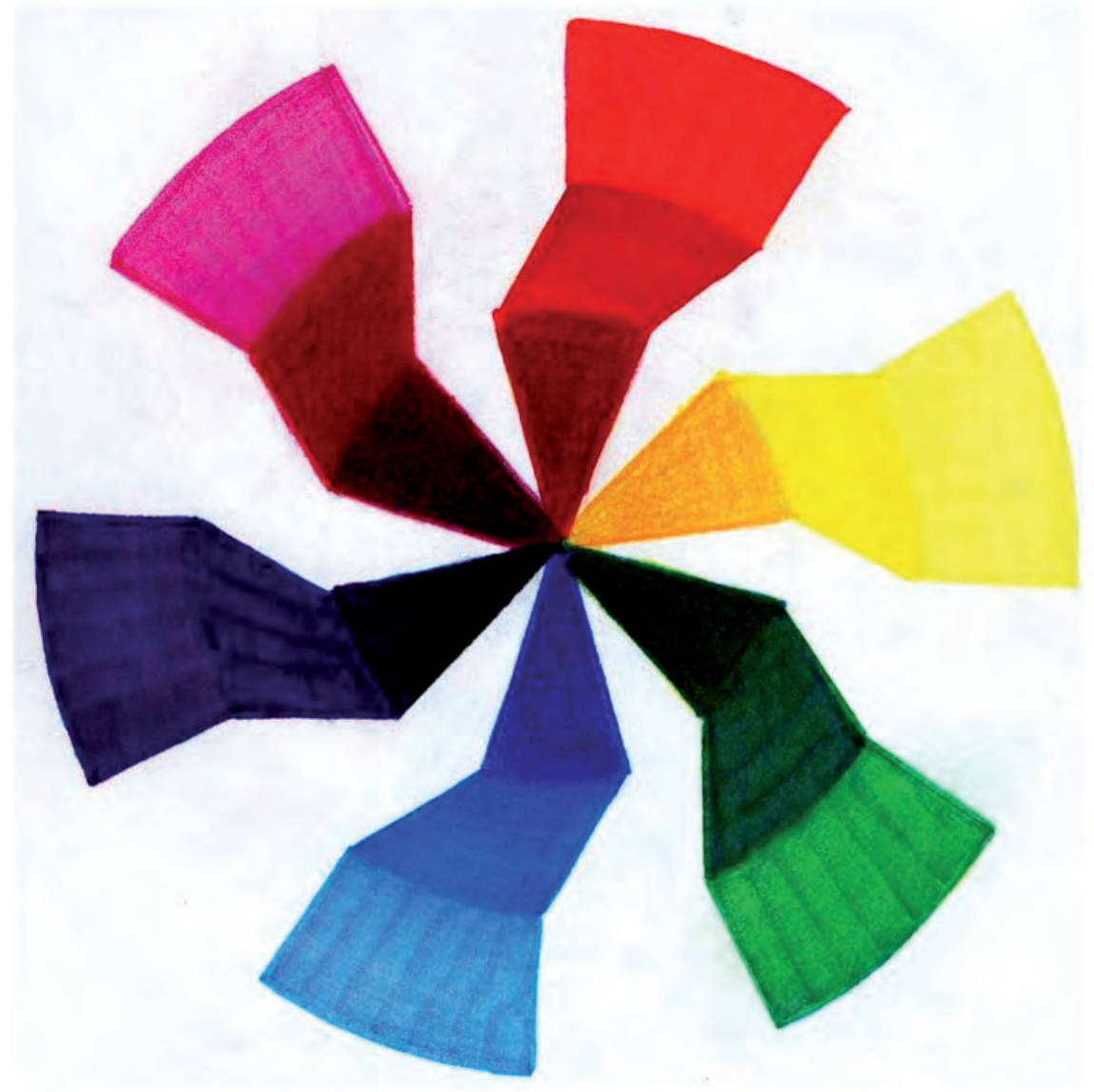

Realizado por Daniel López Gramaje 


\section{Práctica 13 \\ Escalas cromáticas. Gama cálida y gama fría}

\section{A. Objetivos}

- Conocer el concepto de la distribución del claroscuro en un objeto.

- Experimentar con diferentes durezas de lápices y modos de saturación del soporte.

- Practicar las transiciones entre dos colores.

- Control del gradiente y tintas planas.

- Analizar los tonos fríos y cálidos.

- Analizar las gamas de colores cálidos y fríos.

- Manejar controladamente el valor y la saturación de cada tipo cromático.

- Controlar la técnica del rotulador.

- Dominar la técnica mixta (lápices de colores y roturador).

B. Materiales

- Papel formato DIN A4

- Lápiz de dureza HB

- Goma de lápiz

- Rotuladores de colores

- Lápices de colores

\section{Guía de ejecución}

\section{Planteamiento}

- Se aplicarán los conocimientos adquiridos en cuanto al comportamiento del color y su uso en la configuración formal de los objetos. 
- La práctica consistirá en realizar para cada gama cromática (cálida y fría) dos escalas de valor - una de tintas planas para dar claroscuro a objetos de caras planas y la otra un gradiente para objetos de caras curvas-, y además se realizará una escala de valor gradual de transición entre dos colores primarios.

\section{Proceso de ejecución del dibujo}

- Dibujar cinco rectángulos de 16 x $3 \mathrm{~cm}$. Utilizar el lápiz de dureza HB.

- Rellenar con el rotulador de un tono primario desde uno de los extremos hacia el centro. Parar por la mitad del rectángulo y comenzar desde el extremo contrario con otro color primario.

- Superponer un color sobre otro desde la zona central hacia los extremos hasta que se fundan por transparencia ambos colores.

- Dar varias capas de color para ir subiendo el tono.

- Remarcar el gradiente con los lápices de colores.
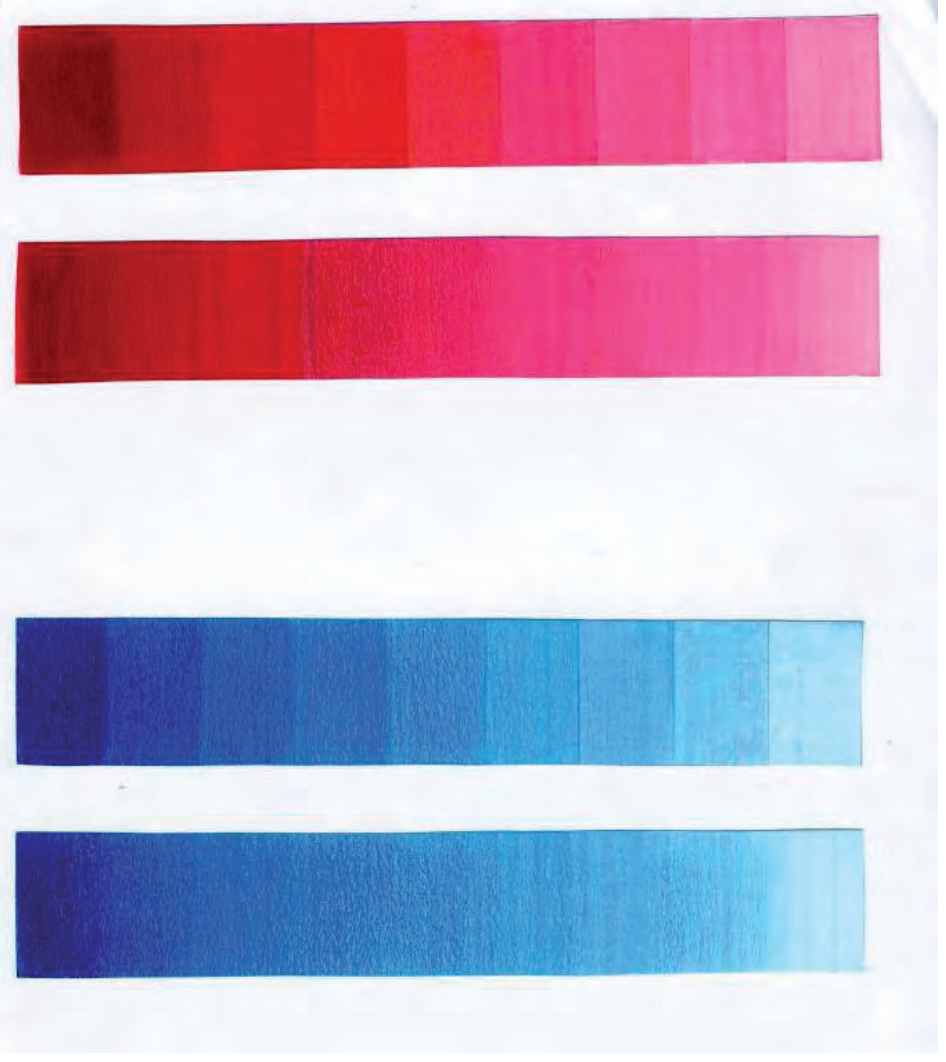

Escalas lumínicas monocromáticas. Realizado por María Ángeles Gómez Cases 

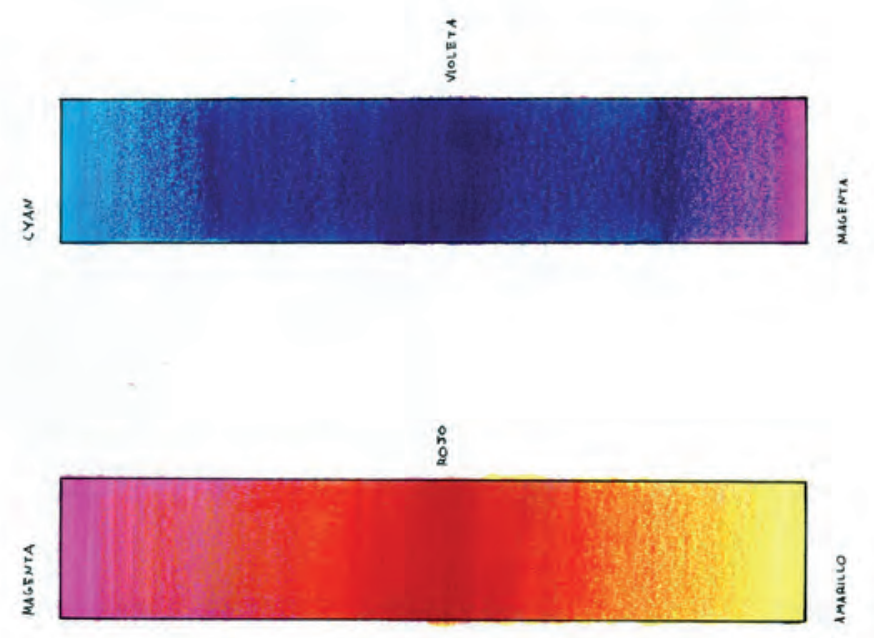

Escalas de transición entre colores primarios.

Realizado por José Miguel Sánchez

\section{Guía de autocorrección}

- Verificar que la transición entre dos colores diferentes sea paulatina y sin saltos bruscos.

- Comprobar que la técnica mixta rotulador-lápiz se ha realizado de manera cohesionada y ambos materiales de funden en un misma mancha cromática.

\section{E. Ejemplos resueltos}
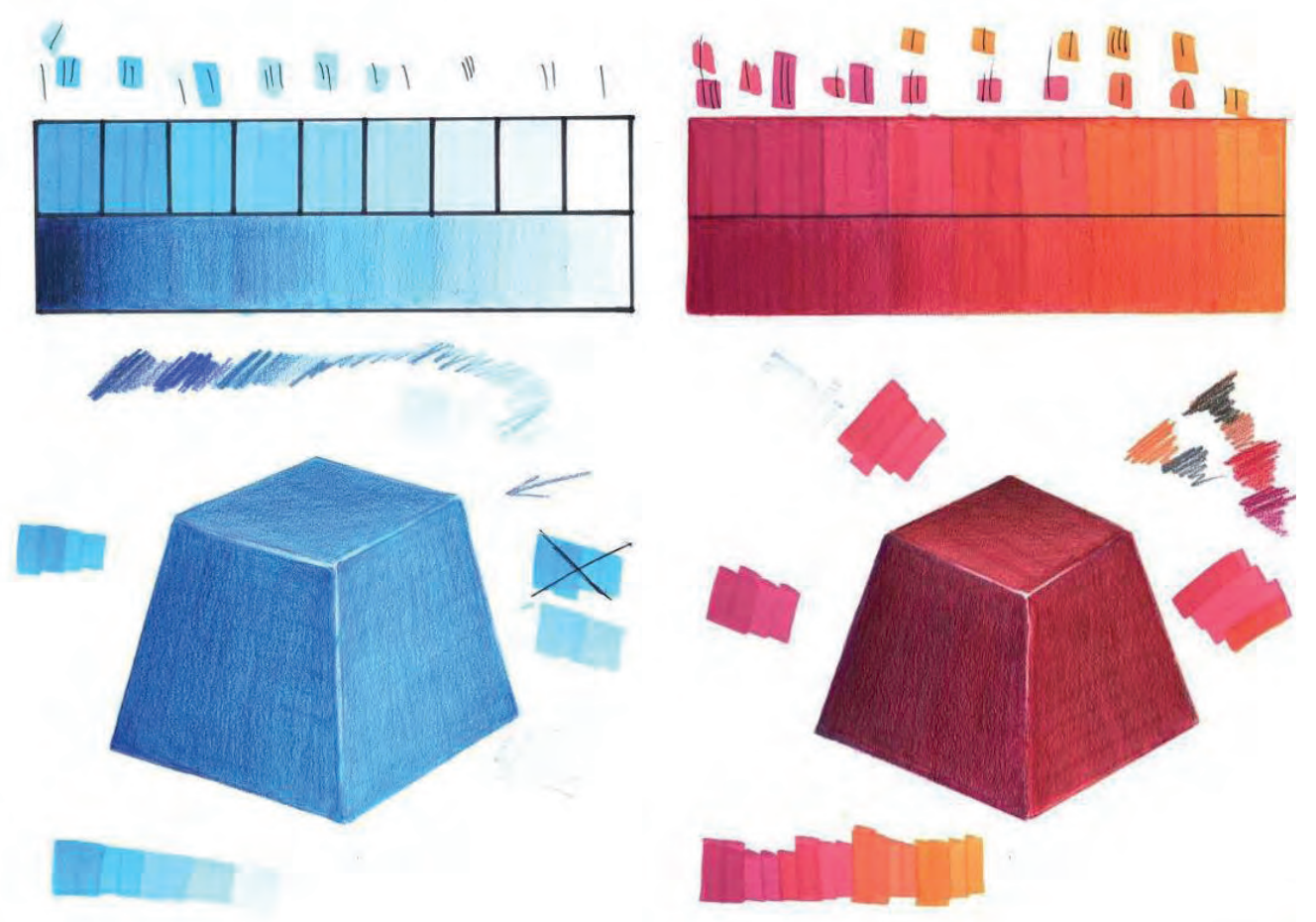

Aplicación de gamas frías y cálidas a caras planas de un volumen.

Realizado por Daniel Valero Cano 

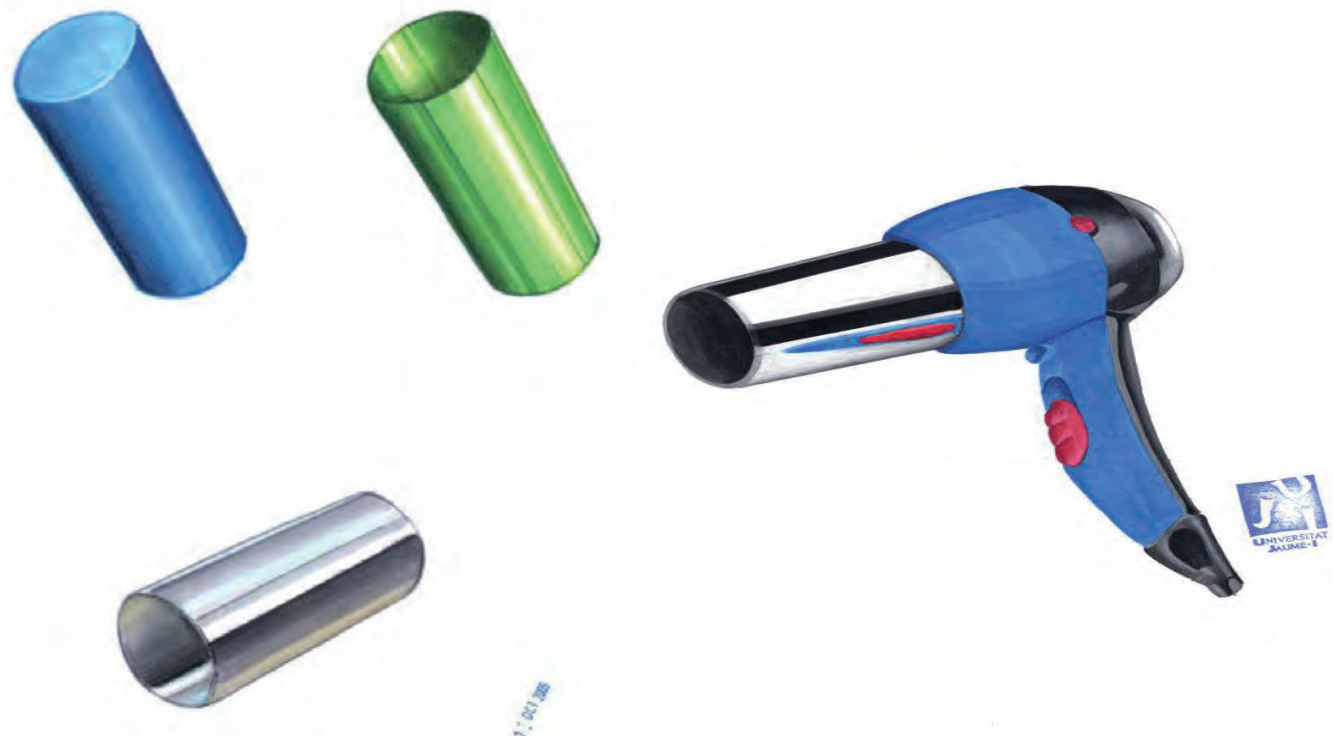

Realizado por José David Martín

Realizado por Laia Maroto

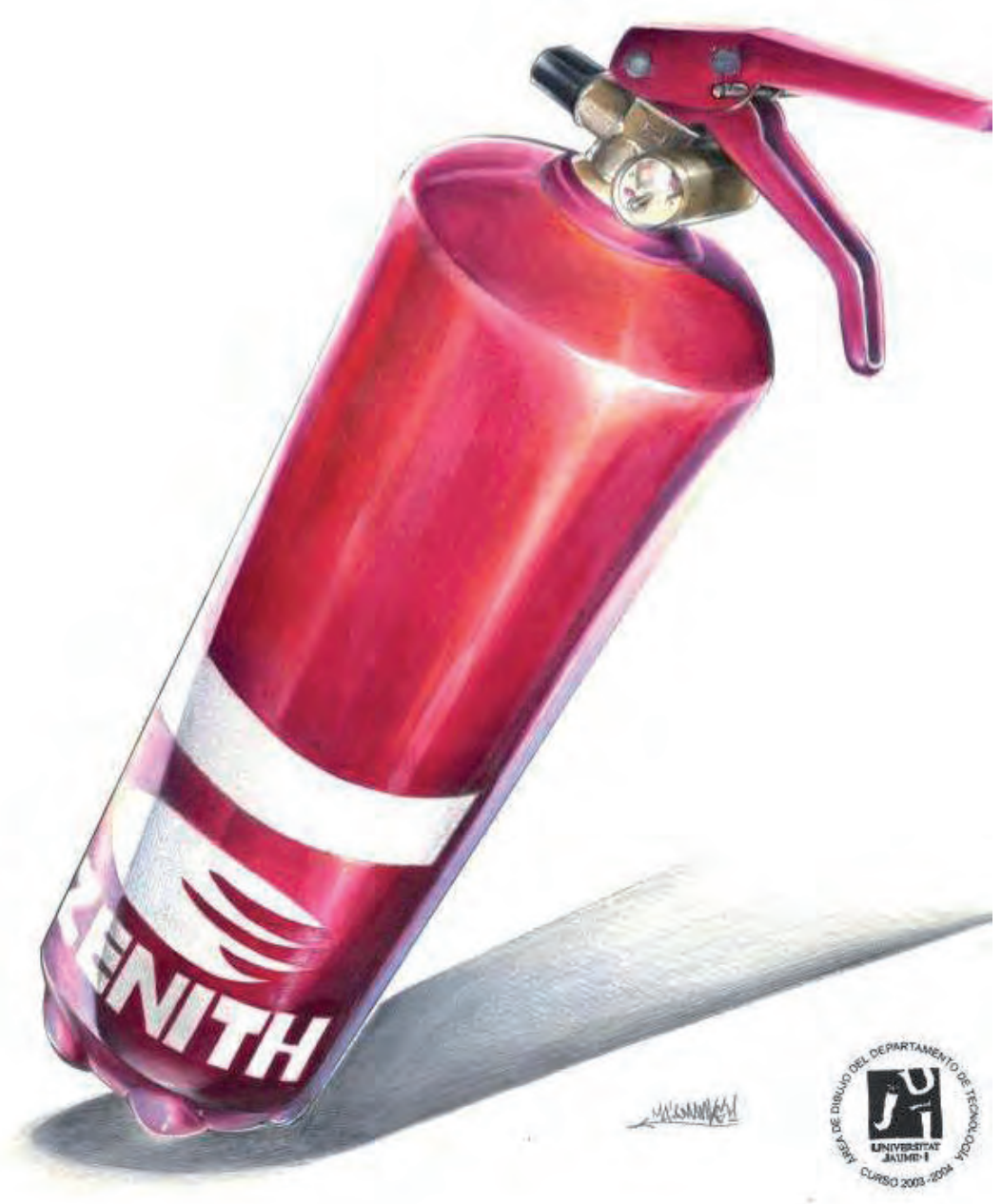

Resolución de un objeto industrial aplicando una escala cromática de gama cálida. Realizado por Mario Fernández López 

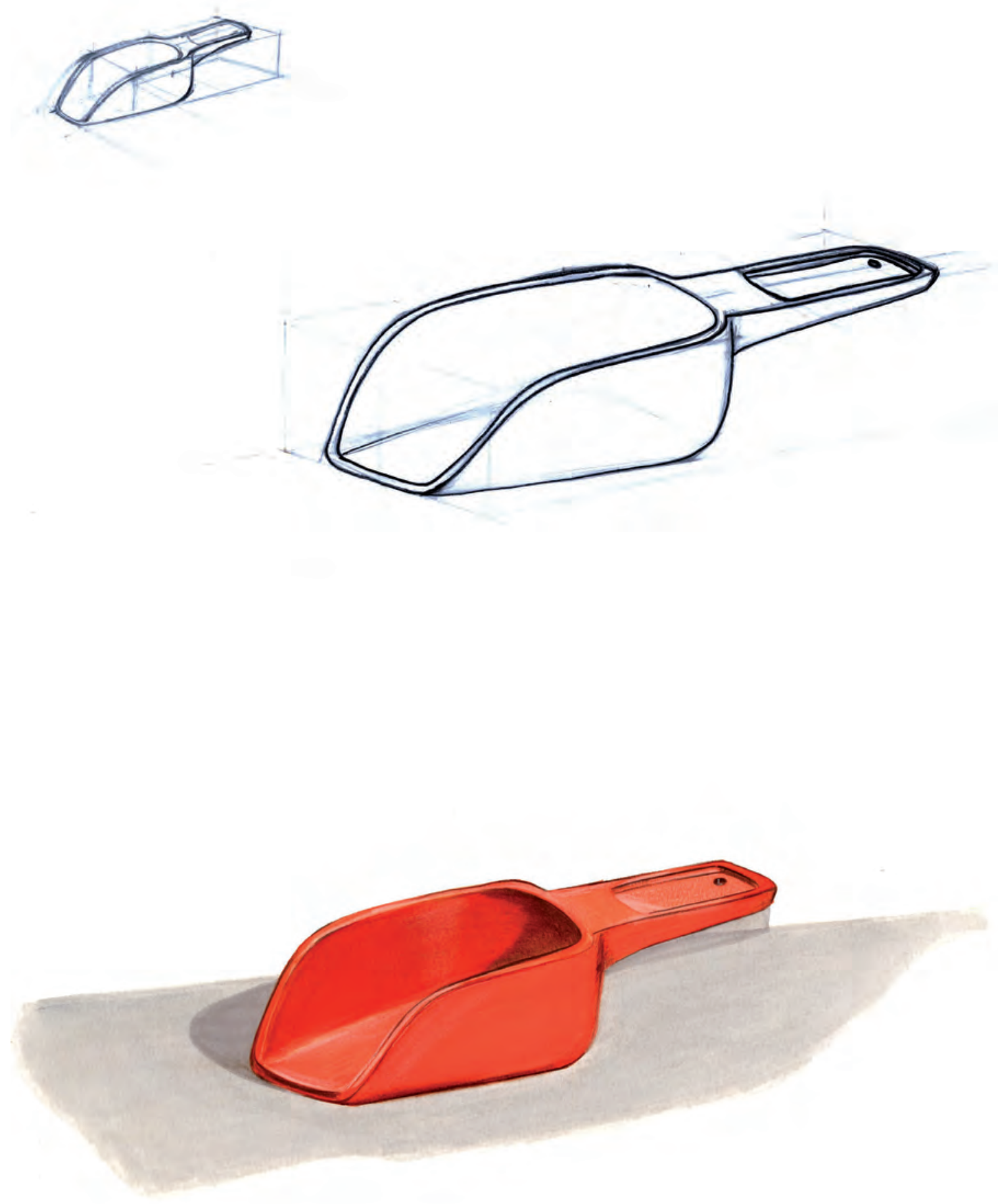

Resolución de un objeto industrial aplicando una escala cromática de gama cálida. Realizado por Laura Martínez 


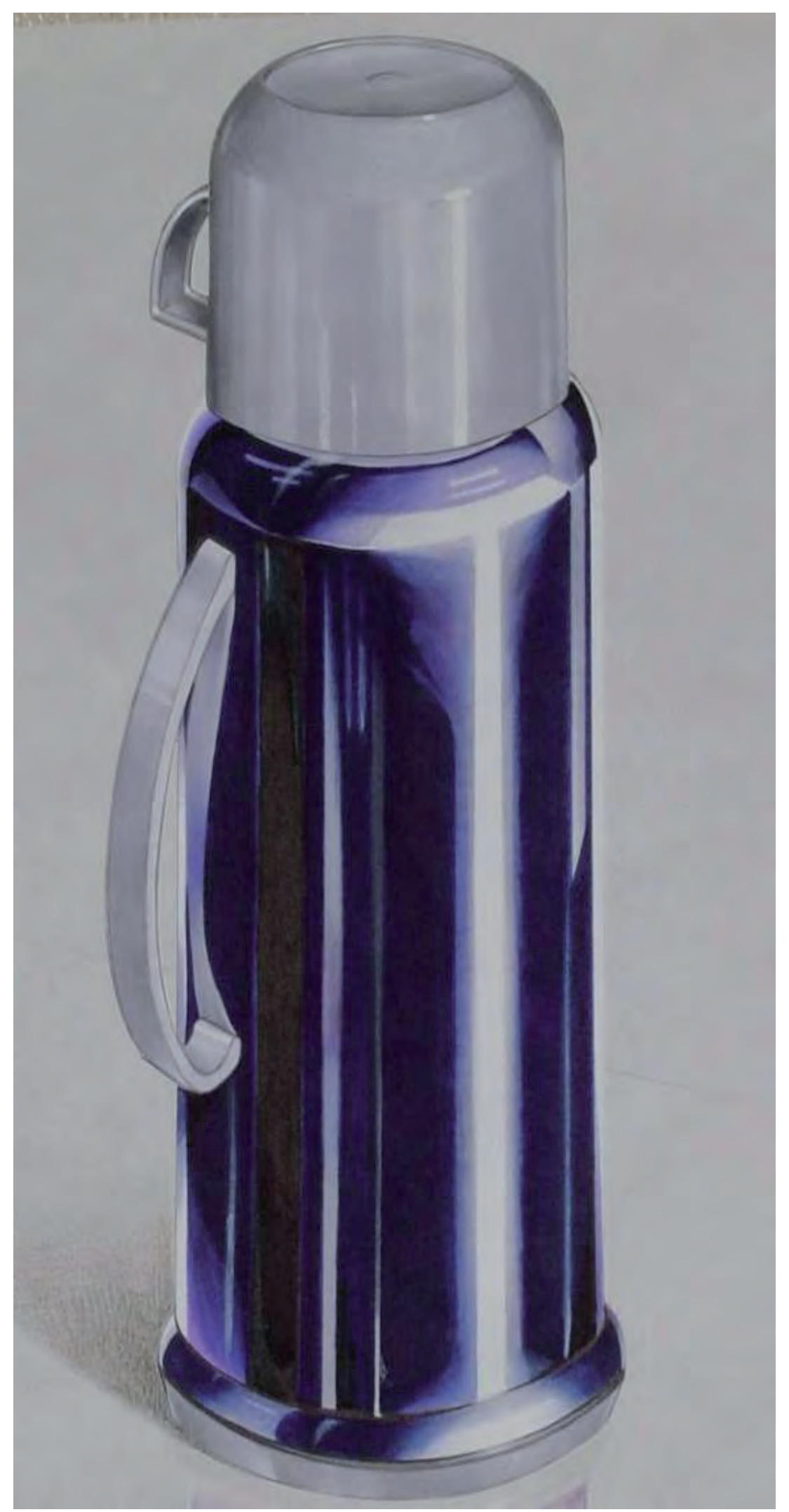

Resolución de un objeto industrial aplicando una escala cromática de gama fría. Realizado por Mario Fernández 
BLOQUE 4

Prácticas para la simulación de materiales, escalas

de valor y renderizados

para diversos materiales 


\section{Introducción}

Los objetos están compuestos por familias de materiales con determinados tipos de acabados, características táctiles y comportamiento respecto a la iluminación.

Entendemos por «piel del objeto» aquella terminación superficial que les confiere determinadas características táctiles como suavidad, rugosidad, aspereza, dureza, etc. El efecto lumínico puede variar considerablemente dependiendo de la forma y del material con el que el objeto esté construido, pudiendo encontrar, por ejemplo, materiales con acabado rugoso que producen suavidad de transiciones entre luz y sombra o por el contrario, materiales altamente pulidos donde los brillos y reflejos son muy comunes.

El objetivo principal del conjunto de prácticas propuestas en este bloque es doble, por un lado ser capaz de representar correctamente la estructura formal del objeto industrial y por otro lado, simular el acabado de las principales familias de materiales empleadas en la fabricación de los objetos: plástico mate, plástico brillante, metal, madera y material transparente. 


\section{Práctica 14 \\ Escala de valor para plástico mate}

\section{A. Objetivos}

- Simular el claroscuro cromático propio de los materiales mates.

- Manejar la técnica de rotulador combinada con los lápices de colores para conseguir efectos de claroscuro con una gradación tonal suave.

B. Materiales

- Lápiz HB.

- Papel para rotulador formato DIN A4.

- Rotuladores.

- Lápices de colores.

\section{Guía de ejecución}

\section{Planteamiento}

- La práctica consiste en elaborar cuatro escalas de valor para simular materiales mates.

- Se realizarán con la técnica de rotulador combinado con lápices de colores.

- Formato de la escalas: 18 x $3 \mathrm{~cm}$ (las escalas de tintas planas se subdividirán en nueve partes iguales).

- Tratamiento de las diferentes escalas:

- Escala de tintas planas ejecutada con tonos cálidos (saltos entre tonos).

- Gradiente para superficies curvas ejecutada con tonos cálidos (cambio tonal progresivo).

- Escala de tintas planas ejecutada con tonos fríos (saltos entre tonos).

- Gradiente para superficies curvas ejecutada con tonos fríos (cambio tonal progresivo). 


\section{Proceso de ejecución del dibujo}

- Con un lápiz duro hay que dibujar los cuatro rectángulos donde crearemos las escalas de color. Dos de ellos, el primero y el tercero, han de subdividirse en nueve partes iguales.

- Seleccionar dos grupos de rotuladores, uno con tono cálido y otro con tono frío.

- Para elaborar las escalas de tintas planas hay que tener presente que cada paso cromático debe tener marcados sus límites, mientras que en las escalas de gradientes, estos pasos deben graduarse y llegar a ser imperceptibles.

- Hay que tener en cuenta que los blancos son el propio papel, por lo que hay que respetar determinados espacios sin aplicar ninguna tonalidad sobre el mismo.

- Puesto que el claroscuro que produce un material mate no tiene sombras ni luces muy contrastadas, en estas escalas graduaremos los tonos claros hacia los más oscuros, con una primera capa del rotulador de color base, e iremos aumentando su saturación superponiendo capas. A continuación se puede añadir otro color más oscuro del mismo tono o grises hasta alcanzar los máximos grados de oscuridad.

- Conviene experimentar estas técnicas varias veces sobre una superficie de prueba para comprobar y controlar las peculiaridades del rotulador.

- Una vez aplicado el rotulador utilizaremos los lápices de colores para delimitar el salto entre tonos, en el caso de la escala de tintas planas, o suavizarlos en el caso de la escala de cambio gradual.

- Realizar el mismo proceso para las escalas de tonos fríos y cálidos.

\section{Guía de autocorrección}

Para la correcta ejecución de este ejercicio se han de tener en cuenta los siguientes aspectos:

- Verificar que los brillos del objeto se han conseguido reservando los blancos del papel.

- El tono más oscuro se acerca al valor máximo de la escala. En ocasiones será el negro.

- Entre el valor más claro y el más oscuro de la escala existe una progresión gradual de color para representar las superficies curvas.

- Entre el valor más claro y el más oscuro de la escala existe un cambio delimitado por contornos recortados en los neuve saltos tonales. 


\section{E. Ejemplos resueltos}
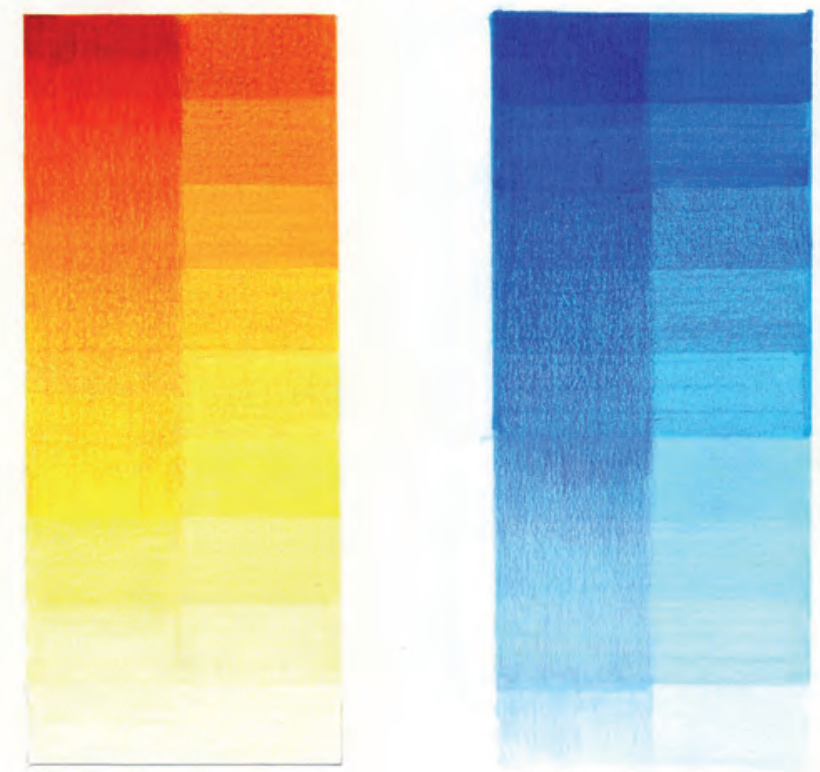

Realizado por Raquel Adell Sabater
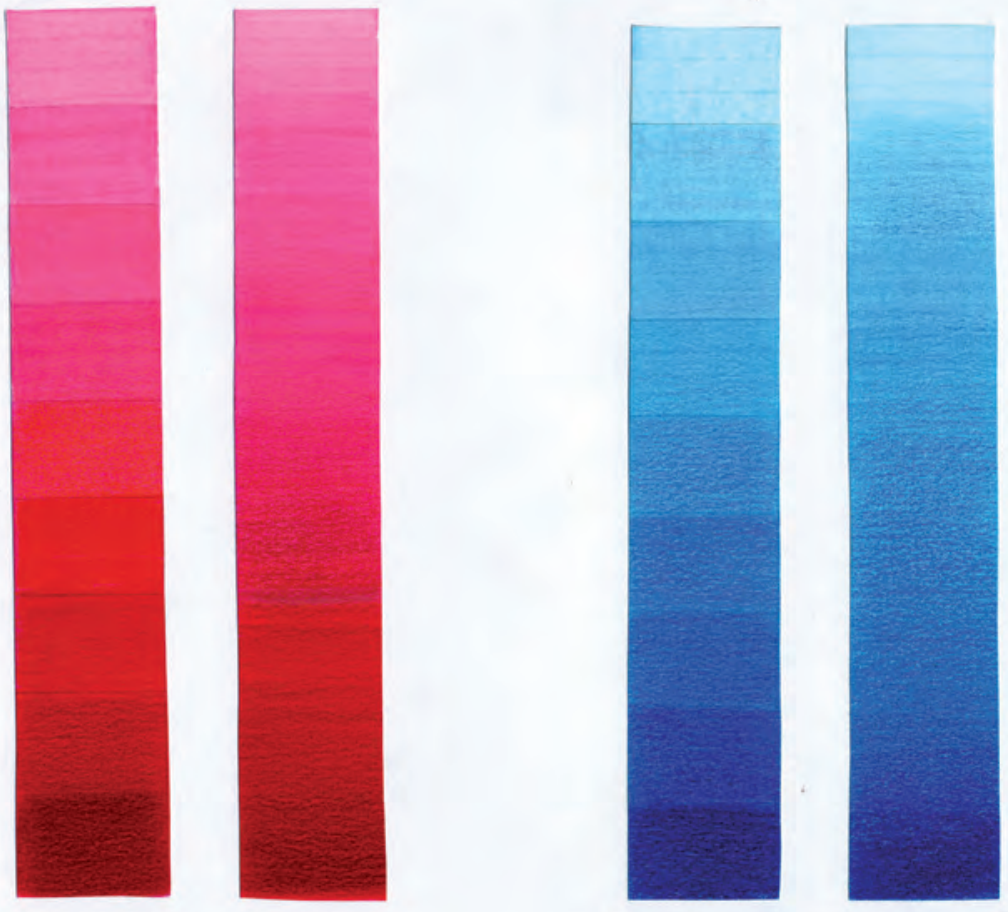

Realizado por María Ángeles Gómez 


\section{Práctica 15 \\ Encajado de un objeto compuesto para plástico mate}

\section{A. Objetivos}

- Dominar la visualización y encaje de objetos de estructura simple.

- Equilibrar el tamaño del dibujo en relación al tamaño del papel.

- Orientar adecuadamente el papel según las proporciones del objeto.

- Realizar una correcta representación formal del objeto.

\section{B. Materiales}

- Papel formato DIN A4

- Lápices de grafito con distinta dureza

- Goma de borrar

\section{Guía de ejecución}

\section{Planteamiento}

La práctica consiste en dibujar correctamente el encaje de un objeto dado. Posteriormente le aplicaremos un claroscuro cromático que potencie su volumetría, representando las características del plástico mate. Hay que prestar especial atención a las proporciones del objeto y a la correcta orientación del papel. Es aconsejable utilizar los diversos métodos de encaje ya estudiados en prácticas anteriores.

\section{Proceso de ejecución del dibujo}

- Observaremos la estructura del objeto y calcularemos el tamaño del dibujo con relación al formato del papel.

- Analizaremos los efectos de claroscuro que produce la incidencia de la luz en el objeto y su sombra proyectada sobre la superficie en la cual se apoya.

- A continuación, realizaremos un encaje teniendo en cuenta las proporciones del objeto.

- Estudiaremos los detalles y delimitaremos la síntesis final del dibujo. 


\section{Guía de autocorrección}

- Verificar el correcto equilibrio entre el tamaño del dibujo y la superficie del papel.

- Comprobar que las proporciones y los detalles del modelo están perfectamente plasmados.

- Verificar que el dibujo tiene un acabado limpio y que comunica con claridad la estructura formal del objeto.

\section{E. Ejemplos resueltos}

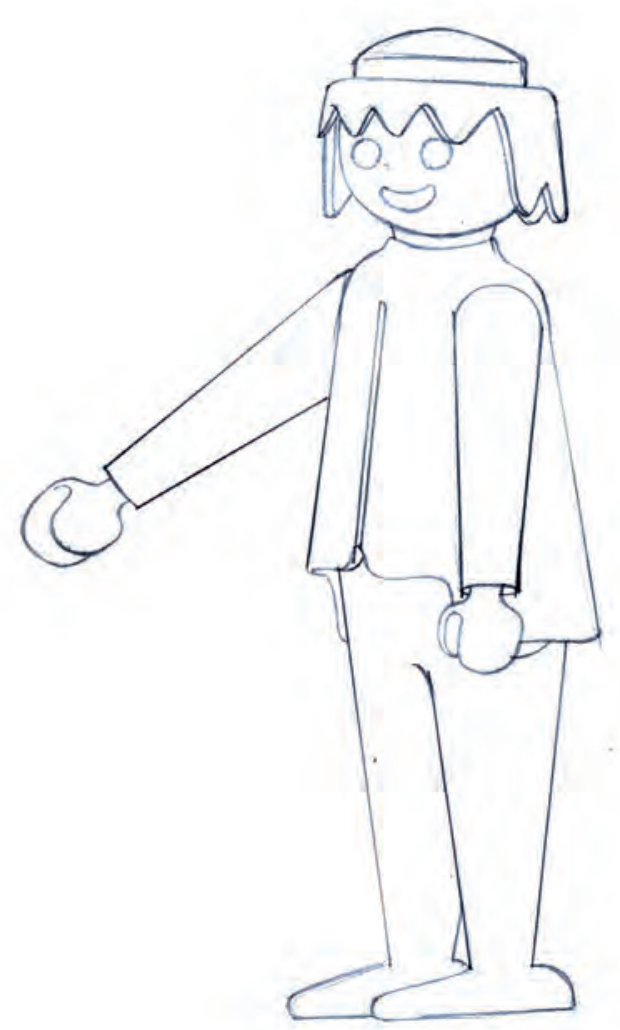

Realizado por Carlos Cotanda Gisbert 


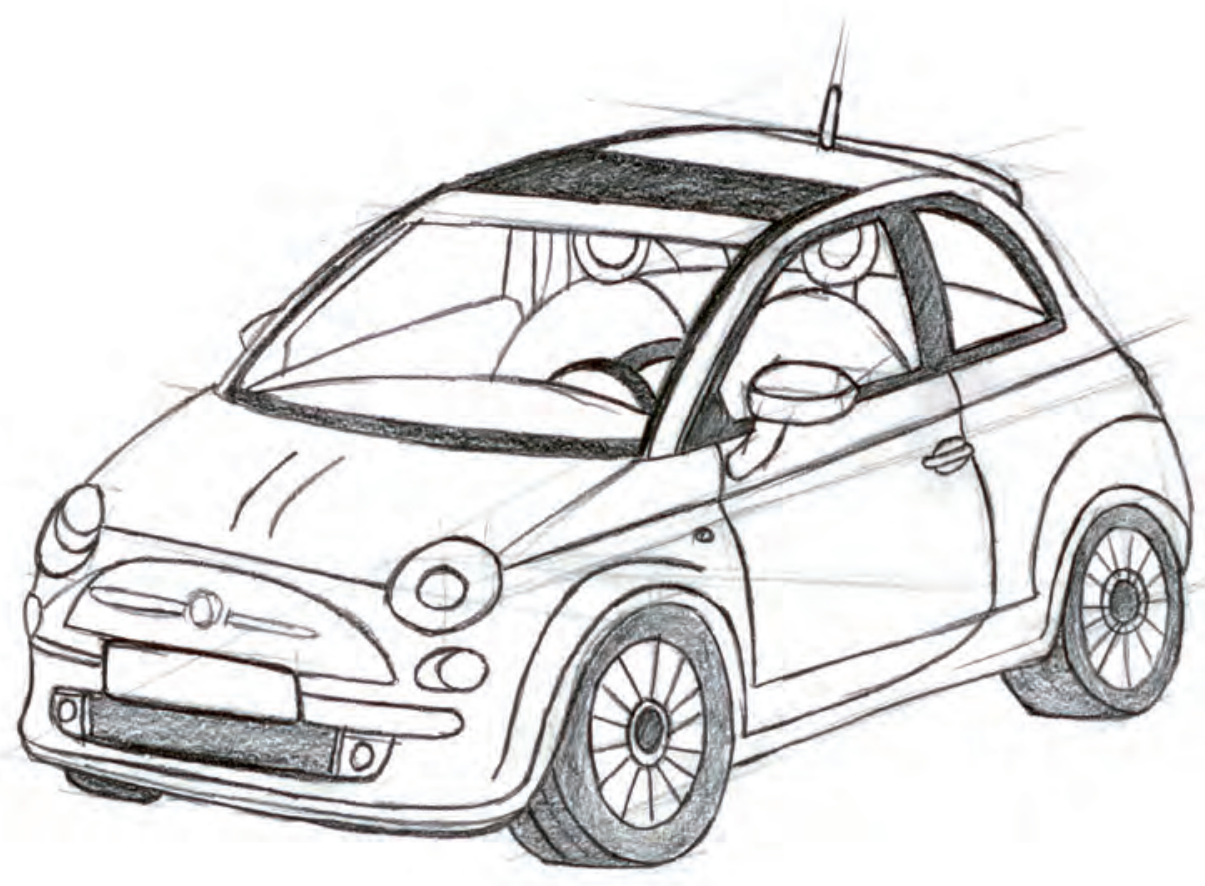

Realizado por Carlos García García 


\section{Práctica 16 \\ Renderizado a color con simulación de plástico mate}

\section{A. Objetivos}

- Dominar la técnica mixta de rotulador y lápices de colores.

- Manejar controladamente el claroscuro que produce la luz sobre un objeto mate.

- Ser capaz de simular las características propias del claroscuro sobre un material mate.

\section{B. Materiales}

- Folios y lápiz HB

- Papel para rotulador formato DIN A4

- Rotuladores

- Lápices de colores

- Bolígrafo negro tipo BIC

- Rotulador blanco

\section{Guía de ejecución}

\section{Planteamiento}

A partir del encaje de la práctica anterior, realizaremos un renderizado a color del objeto dado, utilizando la técnica mixta de rotulador más lápices de colores, teniendo como objetivo la simulación del plástico mate.

\section{Proceso de ejecución del dibujo}

- Calca el dibujo de la práctica anterior a un nuevo papel de rotulador.

- Posteriormente elegimos una posición para el foco de luz que potencie el volumen del objeto. Esta iluminación ha de mostrar una cara del objeto con mayor incidencia de luz, la segunda con una sombra media y la tercera con la oscuridad máxima. 
- Aplicamos una primera capa de color utilizando el rotulador más claro sobre todo el objeto.

- Tras esperar a que seque, se aplica una segunda capa de color con el mismo rotulador sobre las caras de tono medio y sombra. A continuación se añade una tercera capa de color sobre la cara más oscura. Con este método podemos ir oscureciendo y diferenciando las distintas caras del modelo. También podemos enfatizar el claroscuro utilizando rotuladores que, siendo de la misma gama, tengan un mayor grado de oscuridad.

- Para simular el efecto mate, evitaremos las estridencias en el contraste del claroscuro. Tanto para las aristas como para la cara más clara del modelo no dejaremos blancos absolutos del papel, sino que utilizaremos colores muy claros.

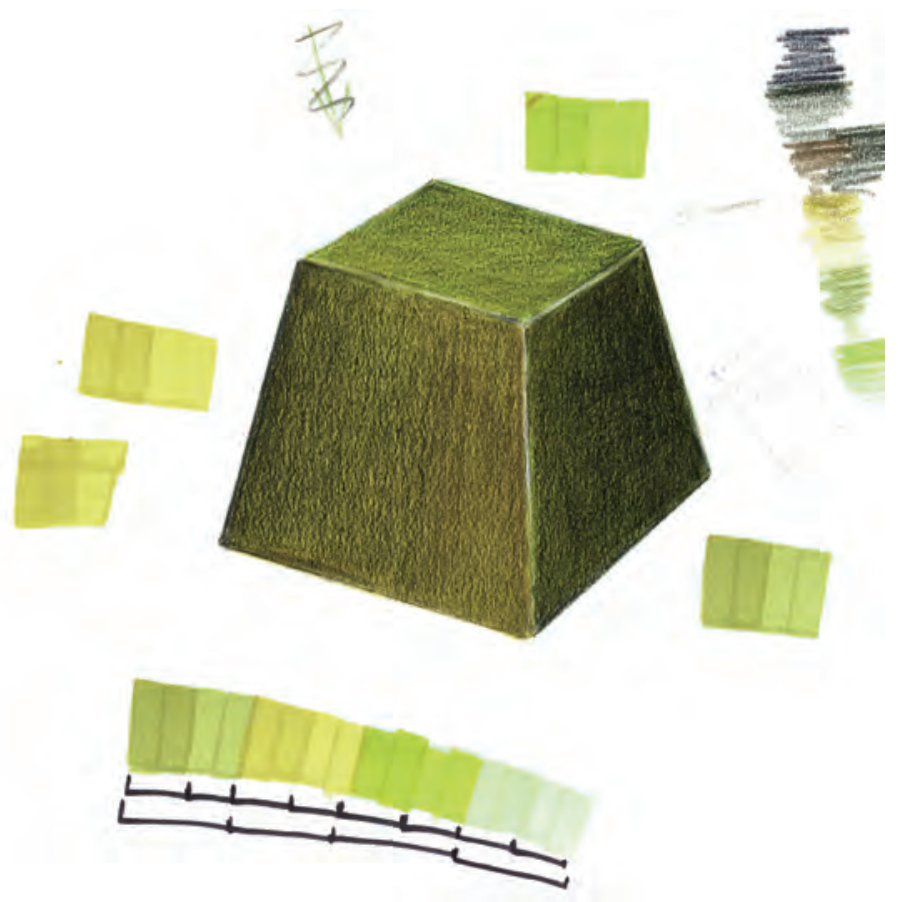

\section{Guía de autocorrección}

- Comprobar que está bien resuelta la volumetría del objeto y si hay un correcto contraste entre las caras iluminadas y las que están en sombra.

- Verificar que las aristas están bien definidas y perfiladas.

- Observar si la iluminación que se ha representado en el objeto refleja la ubicación del foco de luz y por tanto, si son coherentes las sombras que hemos plasmado. 
E. Ejemplos resueltos
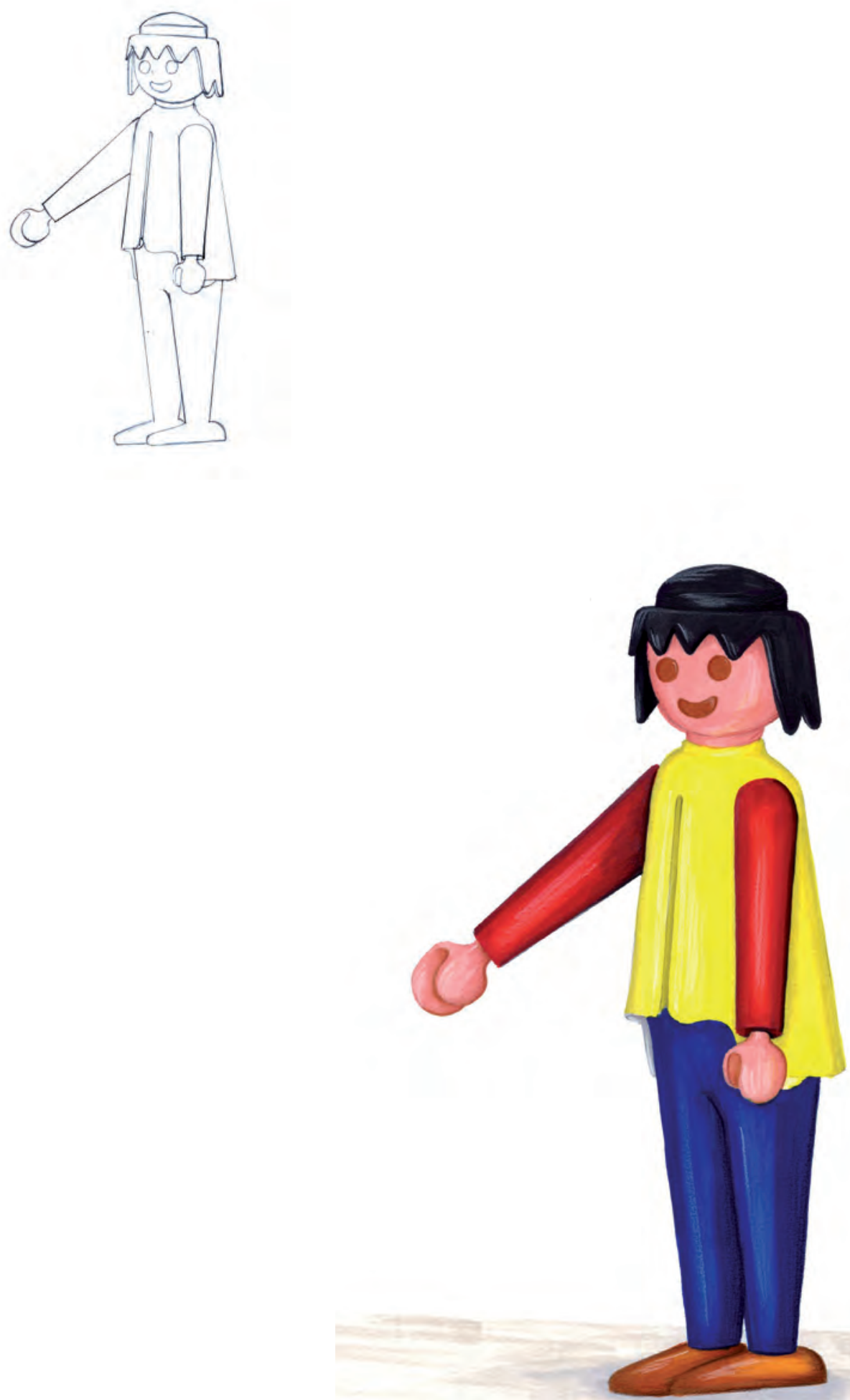

Realizado por Carlos Cotanda Gisbert 

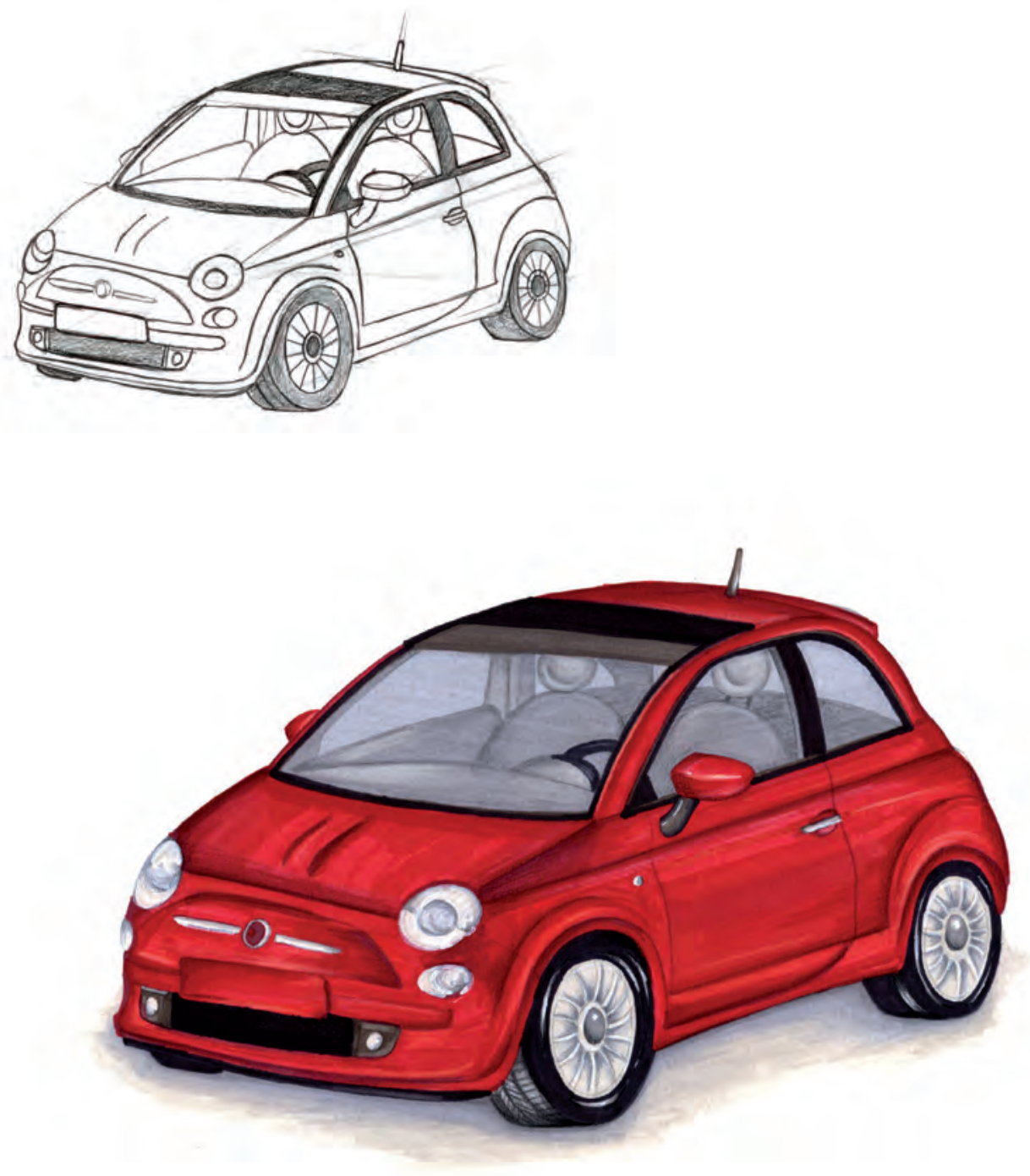

Renderizado de un juguete.

Realizado por Carlos Cotanda Gisbert 


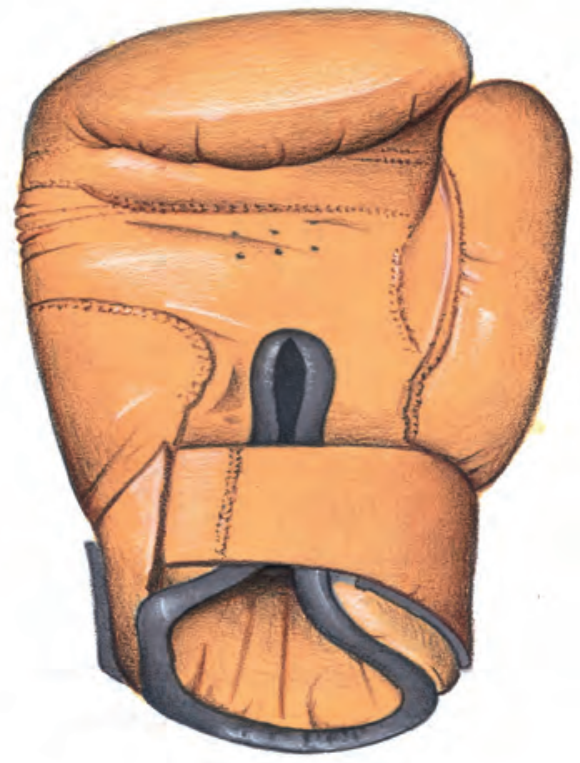

Realizado por Francisco Javier Torres Delcura

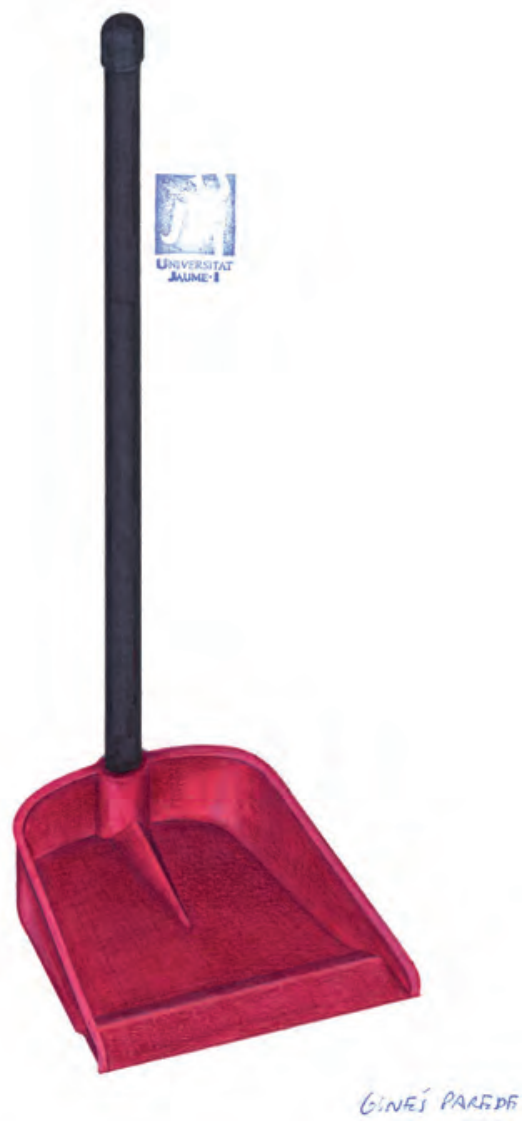

Realizado por Ginés Paredes García 


\section{Práctica 17 \\ Escala de valor para plástico brillante}

\section{A. Objetivos}

- Manejar la técnica de rotulador combinada con los lápices de color para conseguir efectos de claroscuro.

- Simular el claroscuro propio de los materiales brillantes.

\section{B. Materiales}

- Folios y lápiz HB

- Papel para rotulador formato DIN A4

- Rotuladores

- Lápices de colores

\section{Guía de ejecución}

\section{Planteamiento}

- La práctica consiste en elaborar una escala de valor para simular materiales brillantes.

- El formato de la escala será de $18 \times 3 \mathrm{~cm}$.

- Escoge un objeto simple y dibújalo tres o cuatro veces para practicar el efecto del claroscuro propio del material brillante sobre un volumen concreto.

\section{Proceso de ejecución del dibujo}

- En la parte superior del papel dibujaremos cuatro copias del objeto seleccionado obviando los detalles y esquematizando su forma. Es aconsejable que el objeto tenga caras curvas para que se produzcan brillos y reflejos en su superficie.

- En la parte inferior del papel dibujaremos con un lápiz HB el rectángulo donde crearemos la escala de color para plástico brillante.

- Se elige la posición del foco luminoso. Reservaremos con el blanco del papel una o dos bandas verticales, de diferente anchura, que corresponderán a los brillos máximos que produce el material brillante. 
- Aplicaremos la primera capa del color base. A continuación iremos superponiendo diferentes capas de rotulador para crear zonas con varios grados de saturación, que simularán la alternancia de reflejos y sombras propias que se producen en las superficies brillantes.

- Finalmente potenciaremos las sombras con un rotulador más oscuro del mismo tono, o con rotuladores grises. No olvides dejar secar el papel entre pasada y pasada.

- Los retoques finales de renderizado se pueden realizar con los lápices de colores. Con ellos mejoraremos el perfilado de las formas y enfatizaremos los contrastes.

- Cuando se haya resuelto satisfactoriamente la escala de color será el momento de aplicarla al objeto propuesto. Reproduce el mismo efecto de claroscuro pero adaptándolo a la superficie del volumen.

\section{Guía de autocorrección}

Para la correcta ejecución de este ejercicio se han de tener en cuenta los siguientes aspectos:

- Verificar que los brillos del objeto se han conseguido reservando los blancos del papel.

- Comprobar que en la escala se han alternado de forma aleatoria reflejos y sombras propios del material brillante.

- Comprobar que la dirección de los gradientes del claroscuro se adapta a la estructura volumétrica del objeto. 


\section{E. Ejemplos resueltos}

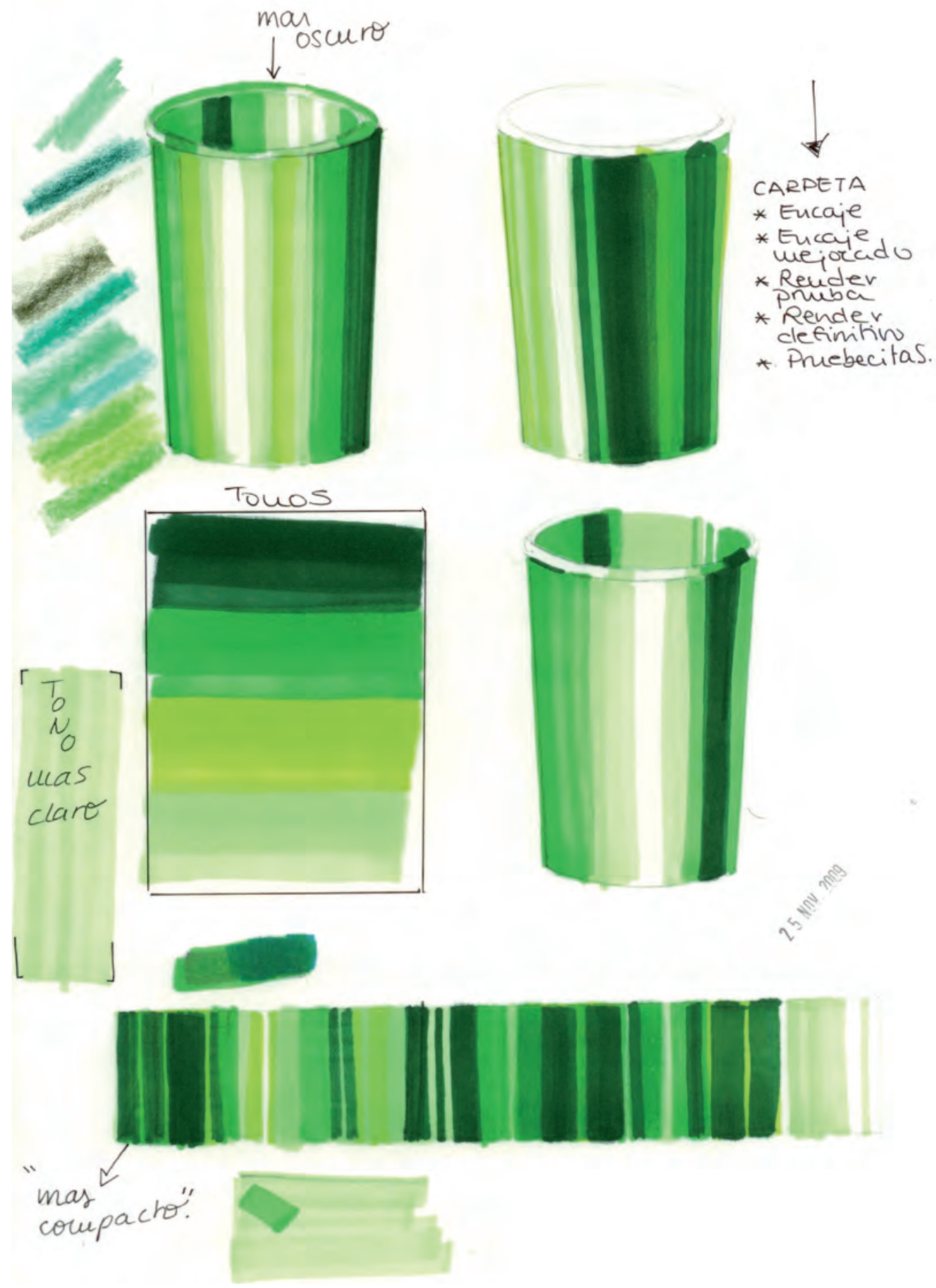



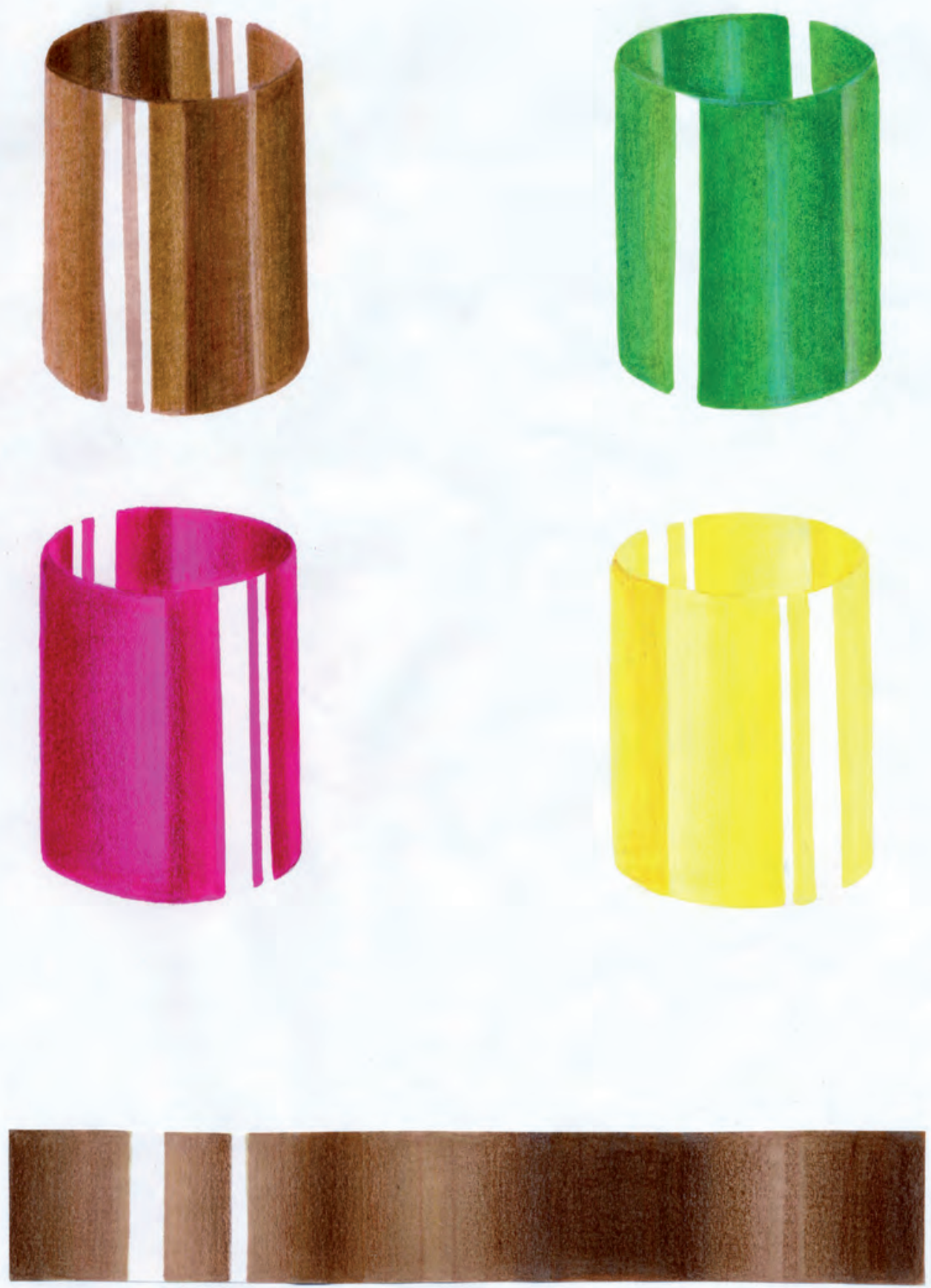

Realizado por Gimeno Gómez 


\section{Práctica 18 \\ Encajado de un objeto para plástico brillante}

\section{A. Objetivos}

- Dominar la visualización y encaje de objetos de estructura simple.

- Equilibrar el tamaño del dibujo en relación al tamaño del papel.

- Orientar adecuadamente el papel según las proporciones del objeto.

- Realizar una correcta representación formal del objeto.

\section{B. Materiales}

- Papel formato DIN A4

- Lápices de diferentes durezas

- Gomas de borrar

\section{Guía de ejecución}

\section{Planteamiento}

- Seleccionaremos el método de encaje adecuado para la estructura constituyente del objeto.

- Realizaremos las mediciones pertinentes para poder proporcionar el objeto que se plasmará con líneas de encaje en el papel.

- Dibujaremos el contorno y las partes fundamentales de la forma.

- Procederemos con la fase de acabado del dibujo, en el cual mejoraremos los trazos, la forma y añadiremos todos los detalles. 


\section{Proceso de ejecución del dibujo}

- En primer lugar, se analizará la forma general del objeto hasta encontrar la figura geométrica que puede contenerlo.

- Seguidamente se calculará el tamaño de dicha figura en relación al formato del papel para que quede bien encajado.

- Analizaremos la posición y dirección del foco de luz, con el fin de definir cómo debe ser la sombra proyectada sobre el plano del soporte y potenciaremos las formas volumétricas.

- Realizaremos un dibujo de encaje con lápiz HB, prestando especial atención a las proporciones del objeto, utilizando para ello trazos finos con el fin de no marcar en exceso el papel.

- Limpiaremos las líneas sobrantes y delimitaremos el objeto definiendo detalles y aristas.

\section{Guía de autocorrección}

- Verificar el correcto equilibrio entre el tamaño del dibujo y la superficie del papel.

- Comprobar que las proporciones y los detalles del modelo están perfectamente plasmados.

- Verificar que el dibujo tiene un acabado limpio y que comunica con claridad la estructura formal del objeto. 
E. Ejemplos resueltos
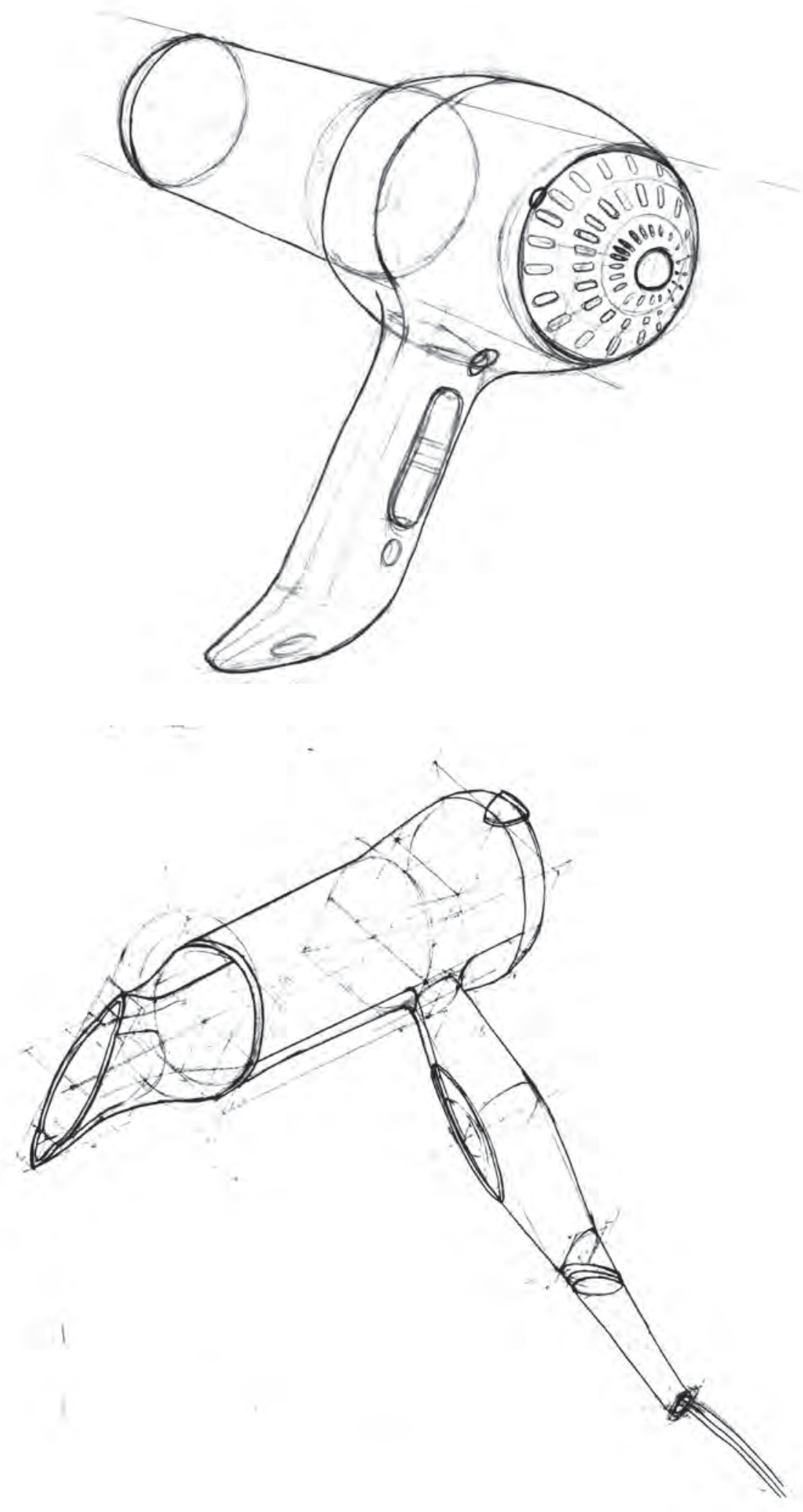

Realizado por Álvaro Campos 


\section{Práctica 19 \\ Renderizado a color con simulación de plástico brillante}

\section{A. Objetivos}

- Dominar la técnica mixta de rotulador y lápices de colores.

- Manejar controladamente el claroscuro que produce la luz sobre un objeto brillante.

- Ser capaz de simular las características propias del claroscuro sobre un material brillante.

\section{B. Materiales}

- Folios y lápiz HB

- Papel para rotulador formato DIN A4

- Rotuladores

- Lápices de colores

- Bolígrafo negro tipo BIC

- Bolígrafo blanco tipo Uni-ball Signo Broad uM-153 Gel Ink Pen White Ink.

- Cera tipo Caran d'Ache Neocolor I White Oil Pastel 7400.001

\section{Guía de ejecución}

\section{Planteamiento}

A partir del encaje de la práctica anterior, realizaremos un renderizado a color del objeto dado, utilizando la técnica mixta de rotulador más lápices de colores, teniendo como objetivo la simulación del plástico brillante.

\section{Proceso de ejecución del dibujo}

- Calca el dibujo de la práctica anterior a un nuevo papel de rotulador.

- Elige una posición para el foco de luz que potencie el volumen del objeto. Esta iluminación ha de mostrar una primera cara del objeto con mayor incidencia de luz; la segunda, con una sombra media, y la tercera, con la oscuridad máxima. 
- Aplica una primera capa de color utilizando el rotulador más claro sobre todo el objeto, reservando el blanco del papel en las zonas de máximo brillo.

- Tras esperar a que seque, aplica una segunda capa de color con el mismo rotulador sobre las zonas de tono medio y sombra, creando zonas con diferentes grados de saturación que simularán la alternancia de reflejos y sombras propias del material brillante.

- A continuación, aplicaremos una tercera capa de color sobre las zonas más oscuras. Con este método podemos ir oscureciendo y diferenciando las distintas caras del modelo, manteniendo el efecto de brillo superficial. También podemos enfatizar el claroscuro utilizando rotuladores que, siendo de la misma gama, tengan un mayor grado de oscuridad.

- Los retoques finales de renderizado se pueden realizar con los lápices de colores. Con ellos mejoraremos el perfilado de las formas y enfatizaremos los contrastes.

- Resaltaremos la luz añadiendo pequeños brillos con el bolígrafo blanco.

\section{Guía de autocorrección}

- Comprobar si está correctamente dibujado el objeto, atendiendo a sus proporciones y detalles formales.

- Verificar que los gradientes y zonas tonales están correctamente adaptadas a la morfología del objeto.

- Valorar cómo se ha preservado el blanco del papel en las zonas de máximo bri1lo, y cómo se han distribuido dichas zonas en el objeto atendiendo a la iluminación de la escena.

- Analizar si se ha conseguido simular el efecto de claroscuro propio del material brillante. 


\section{E. Ejemplos resueltos}

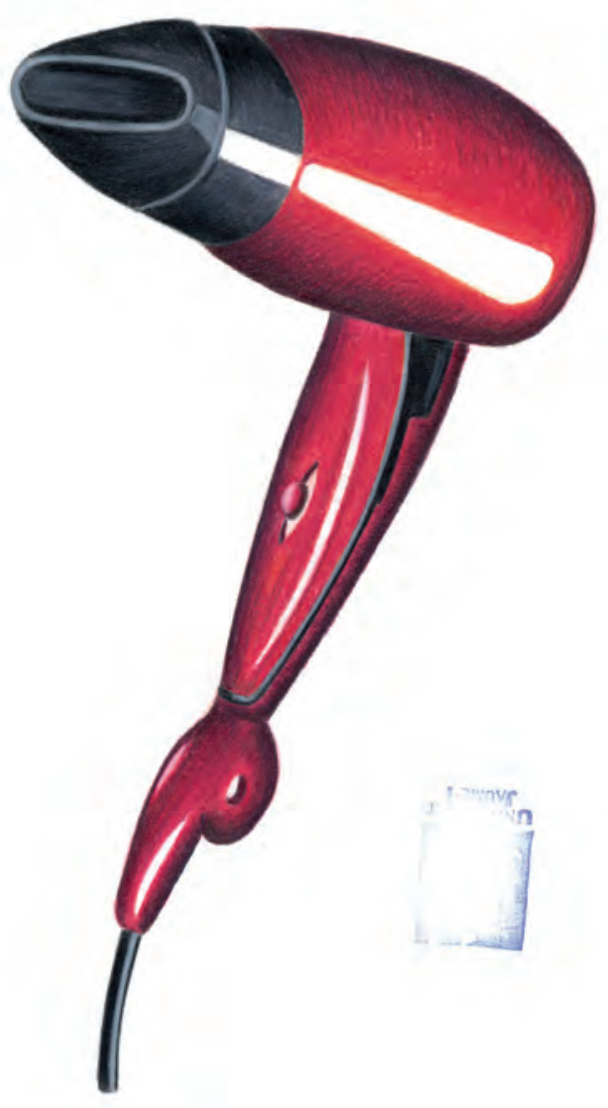

Realizado por Mireia Ibáñez Moliner

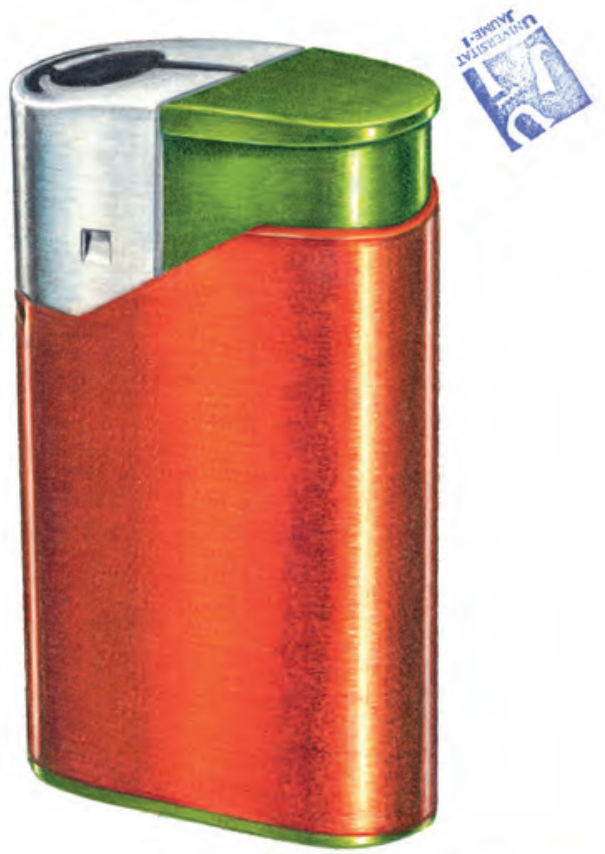

Realizado por Daniel Antón Morales 


\section{Práctica 20 \\ Escala de valor para metal}

\section{A. Objetivos}

- Manejar la técnica de rotulador combinada con los lápices de madera para conseguir efectos de claroscuro.

- Simulación del claroscuro propio de los metales.

\section{B. Materiales}

- Folios y lápiz HB

- Papel para rotulador formato DIN A4

- Rotuladores

- Lápices de colores

- Bolígrafo negro tipo BIC

- Bolígrafo blanco tipo Uni-ball Signo Broad um-153 Gel Ink Pen White Ink.

- Cera tipo Caran d'Ache Neocolor I White Oil Pastel 7400.001

\section{Guía de ejecución}

\section{Planteamiento}

- La práctica consiste en elaborar una escala de valor para simular el metal (formato de la escala $18 \times 3 \mathrm{~cm}$ ).

- Posteriormente aplicaremos esta escala sobre cuatro formas básicas.

\section{Proceso de ejecución del dibujo}

- En la parte superior del papel dibujaremos cuatro veces el objeto propuesto para las pruebas de color. Estos objetos han de tener la cara curva, ya que de esta manera es más conveniente para representar los brillos del metal producidos en el objeto.

- En la parte inferior del papel dibujaremos con un lápiz duro el rectángulo donde crearemos la escala de color.

- Utilizaremos el rotulador más claro de la escala de grises para ir marcando los diferentes tonos. Hay que tener en cuenta que el blanco máximo ha de 
ser el papel, por lo que hay que reservarlo sin aplicar ningún color sobre el mismo.

- Aumentamos progresivamente la saturación del tono aplicando varias capas de rotulador, y si es necesario utilizaremos tonalidades más oscuras.

- Superponemos una nueva capa de rotulador antes de que la anterior se seque completamente, con ello se suaviza el cambio de tono, generándose un gradiente progresivo. Sin embargo, en ocasiones es conveniente esperar a que se seque para perfilar los bordes o límites de la escala.

- Es aconsejable experimentar estas técnicas varias veces sobre una superficie de prueba para controlar las peculiaridades del rotulador y utilizar los diferentes efectos de la manera más conveniente.

- En la aplicación de las capas de rotulador hay que tener presente el efecto espejo del metal. Las luces y las sombras se distribuyen aleatoriamente, generando zonas muy oscuras con bordes muy marcados al lado de superficies blancas con brillos potentes.

- Debido al efecto espejo de las superficies metálicas, los colores del entorno interactúan sobre el objeto. Este efecto peculiar lo podemos representar añadiendo alguna pasada de otros colores claros y transparentes.

- Cuando se haya resuelto satisfactoriamente la escala de color es el momento de aplicarla a los objetos propuestos, intentando reproducirla de manera similar a como se ha realizado en la escala y adaptarla a las características formales del modelo.

\section{Guía de autocorrección}

Para la correcta ejecución de este ejercicio se han de tener en cuenta los siguientes aspectos:

- Verificar que los brillos del objeto se han conseguido reservando los blancos del papel.

- El tono más oscuro de las escalas se acerca al negro.

- Comprobar que en la escala se han alternado de forma aleatoria reflejos y sombras propios del metal.

- Comprobar que la dirección de los gradientes del claroscuro se adapta a la estructura volumétrica del objeto. 


\section{E. Ejemplos resueltos}
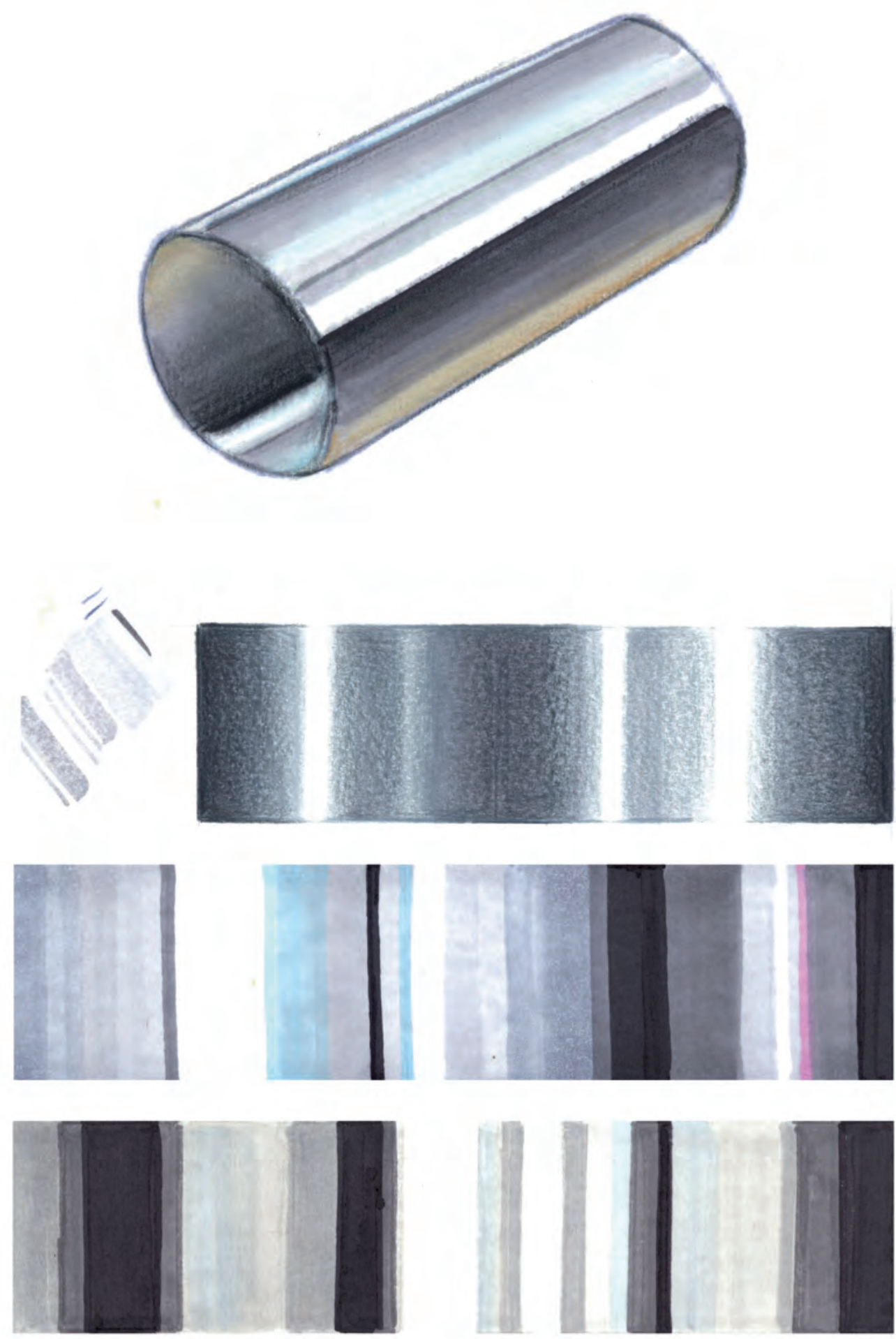


\section{Práctica 21 \\ Encajado de un objeto para metal}

\section{A. Objetivos}

- Dominar la visualización y encajado de objetos de estructura simple.

- Equilibrar el tamaño del dibujo en relación al tamaño del papel.

- Orientar adecuadamente el papel según las proporciones del objeto.

- Realizar una correcta representación formal del objeto.

\section{B. Materiales}

- Papel formato DIN A4

- Lápices de diferentes durezas

- Gomas de borrar

\section{Guía de ejecución}

\section{Planteamiento}

- Seleccionaremos el método de encaje adecuado a la estructura constituyente del objeto.

- Realizaremos las mediciones pertinentes para poder proporcionar el objeto que se plasmarán con líneas de encaje en el papel.

- Dibujaremos el contorno y las partes fundamentales de la forma.

- Procederemos con la fase de acabado del dibujo, en la que mejoraremos los trazos, la forma y añadiremos todos los detalles.

\section{Proceso de ejecución del dibujo}

- Tras observar la estructura del objeto calcularemos el tamaño del dibujo con relación al formato del papel.

- Analizaremos los efectos de claroscuro que produce la incidencia de la luz en el objeto, y su sombra proyectada sobre la superficie sobre la cual se apoya. 
- A continuación, realizaremos un encaje teniendo en cuenta las proporciones del objeto.

- Estudiaremos los detalles y delimitaremos la síntesis final del dibujo.

\section{Guía de autocorrección}

- Verificar el correcto equilibrio entre el tamaño del dibujo y la superficie del papel.

- Comprobar que las proporciones y los detalles del modelo están perfectamente visualizados.

- Verificar que el dibujo tiene un acabado limpio y que comunica con claridad la estructura formal del objeto.

\section{E. Ejemplos resueltos}

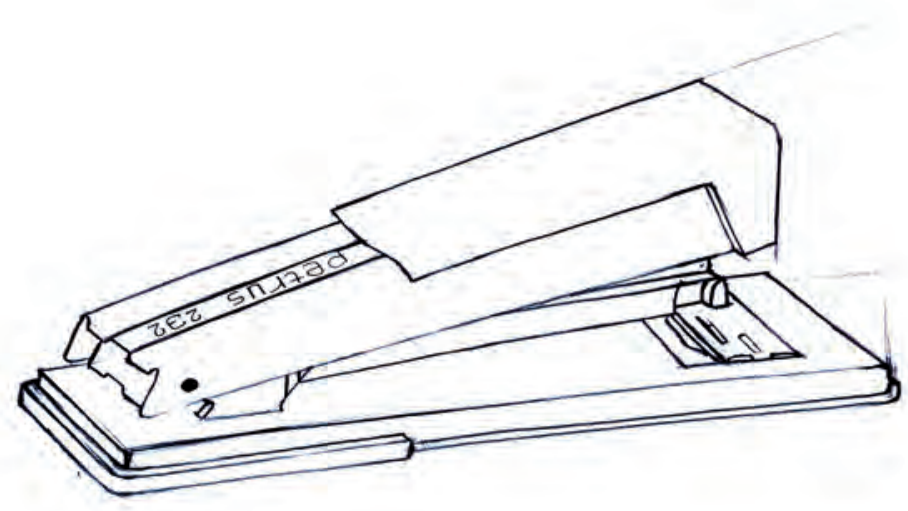

Realizado por Miguel Herrasti Amer 


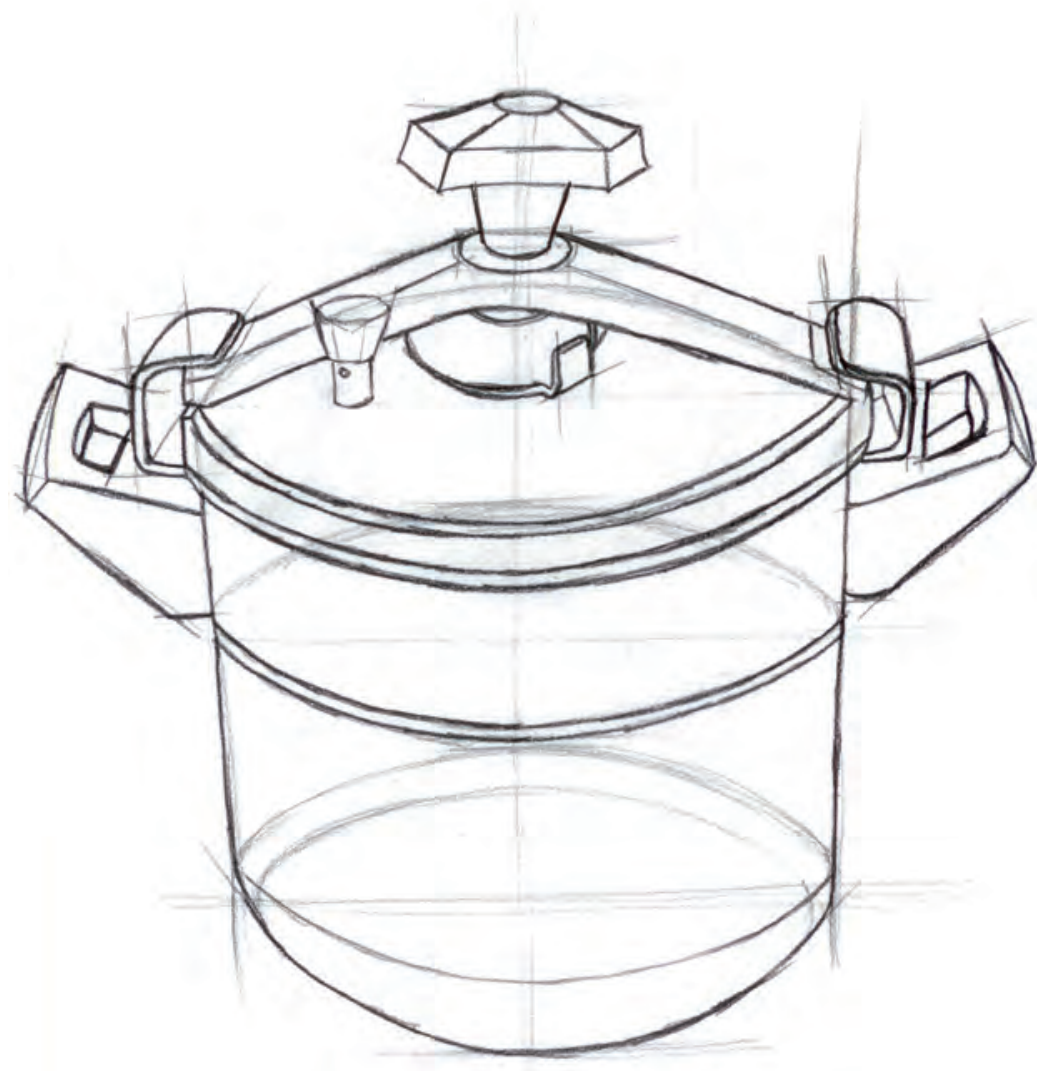

Realizado por Carlos García García

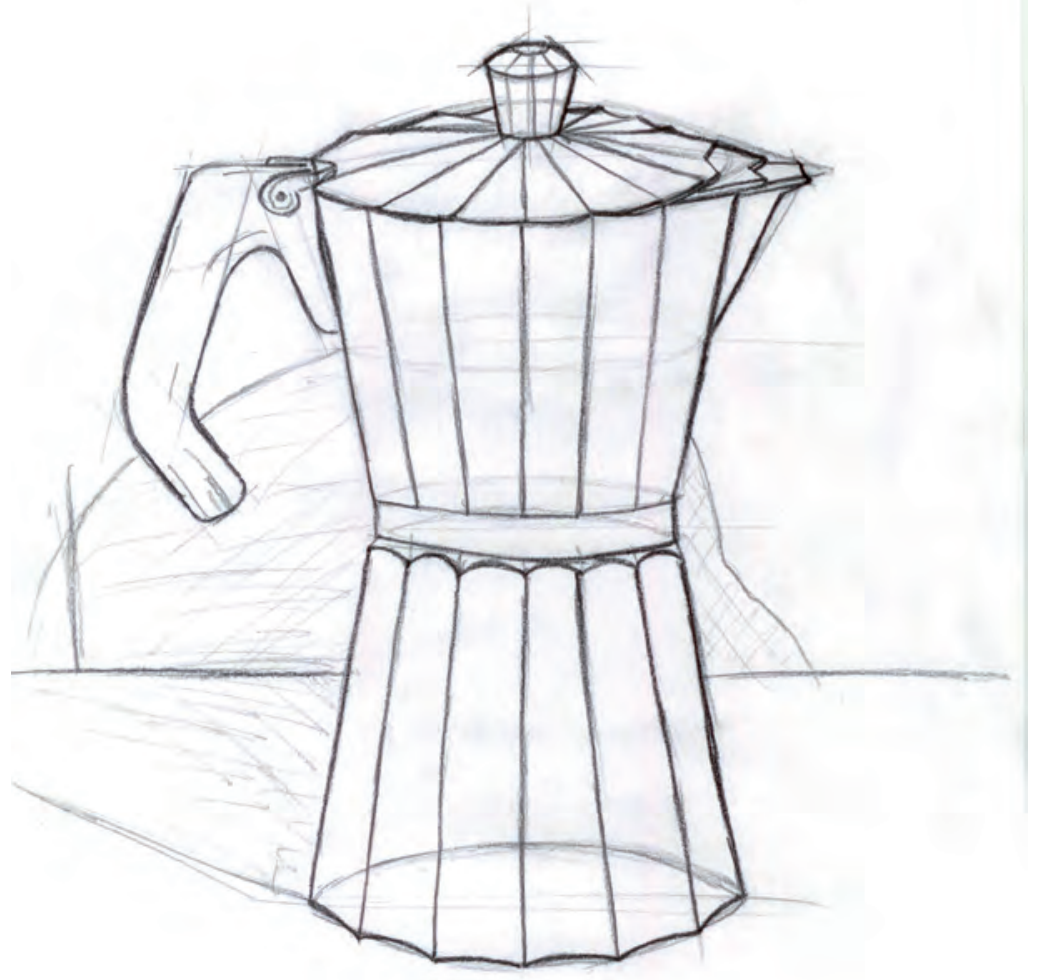

Realizado por Carlos García García 


\section{Práctica 22 Renderizado a color con simulación de metal}

\section{A. Objetivos}

- Dominar la técnica mixta de rotulador y lápices de colores.

- Manejar controladamente el claroscuro que produce la luz sobre un objeto metálico.

- Ser capaz de simular las características propias del claroscuro sobre un metal.

\section{B. Materiales}

- Folios y lápiz HB

- Papel para rotulador formato DIN A4

- Rotuladores

- Lápices de colores

- Bolígrafo negro tipo BIC

- Bolígrafo blanco tipo Uni-ball Signo Broad UM-153 Gel Ink Pen White Ink.

- Cera tipo Caran d'Ache Neocolor I White Oil Pastel 7400.001

\section{Guía de ejecución}

\section{Planteamiento}

A partir del encaje de la práctica anterior realizaremos un renderizado a color del objeto dado, utilizando la técnica mixta de rotulador más lápices de colores, y teniendo como objetivo la simulación del metal.

\section{Proceso de ejecución del dibujo}

- Calcar el dibujo de la práctica anterior a un nuevo papel de rotulador.

- Elegiremos una posición para el foco de luz que potencie el volumen del objeto. Esta iluminación ha de mostrar una primera cara del objeto con mayor incidencia de luz; la segunda, con una sombra media, y la tercera, con la oscuridad máxima. 
- Aplicaremos una primera capa de color utilizando el rotulador más claro sobre todo el objeto.

- Dependiendo de los acabados superficiales del metal, aplicaremos las siguientes capas sobre el papel húmedo o esperaremos a que se seque. Con las sucesivas capas de color podemos ir oscureciendo y diferenciando los distintos planos del modelo. También podemos enfatizar el claroscuro utilizando rotuladores, que siendo de la misma gama, tengan un mayor grado de oscuridad.

- Para simular el efecto del metal se aplicará el mismo procedimiento realizado en el ejercicio anterior, pero adaptándolo a las características estructurales propias del objeto.

\section{Guía de autocorrección}

- Comprobar si está correctamente dibujado el objeto, atendiendo a sus proporciones y detalles formales.

- Verificar que los gradientes y zonas tonales están correctamente adaptados a la morfología del objeto.

- Valorar cómo se ha preservado el blanco del papel en las zonas de máximo bri1lo, y cómo se han distribuido dichas zonas en el objeto atendiendo a la iluminación de la escena.

- Analizar si se ha conseguido simular el efecto de claroscuro propio del metal. 


\section{E. Ejemplos resueltos}
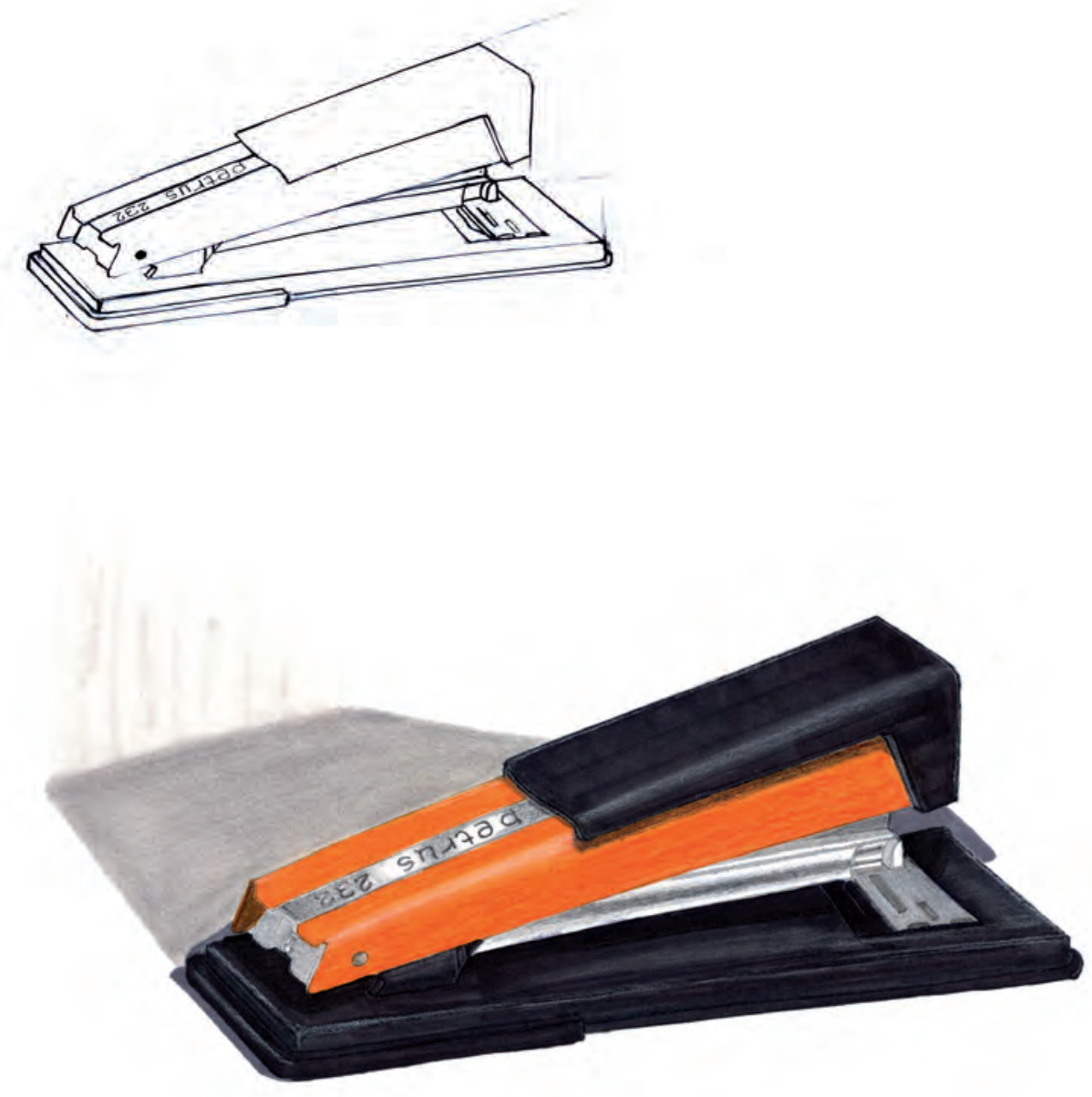

Realizado por Miguel Herrasti Amer 

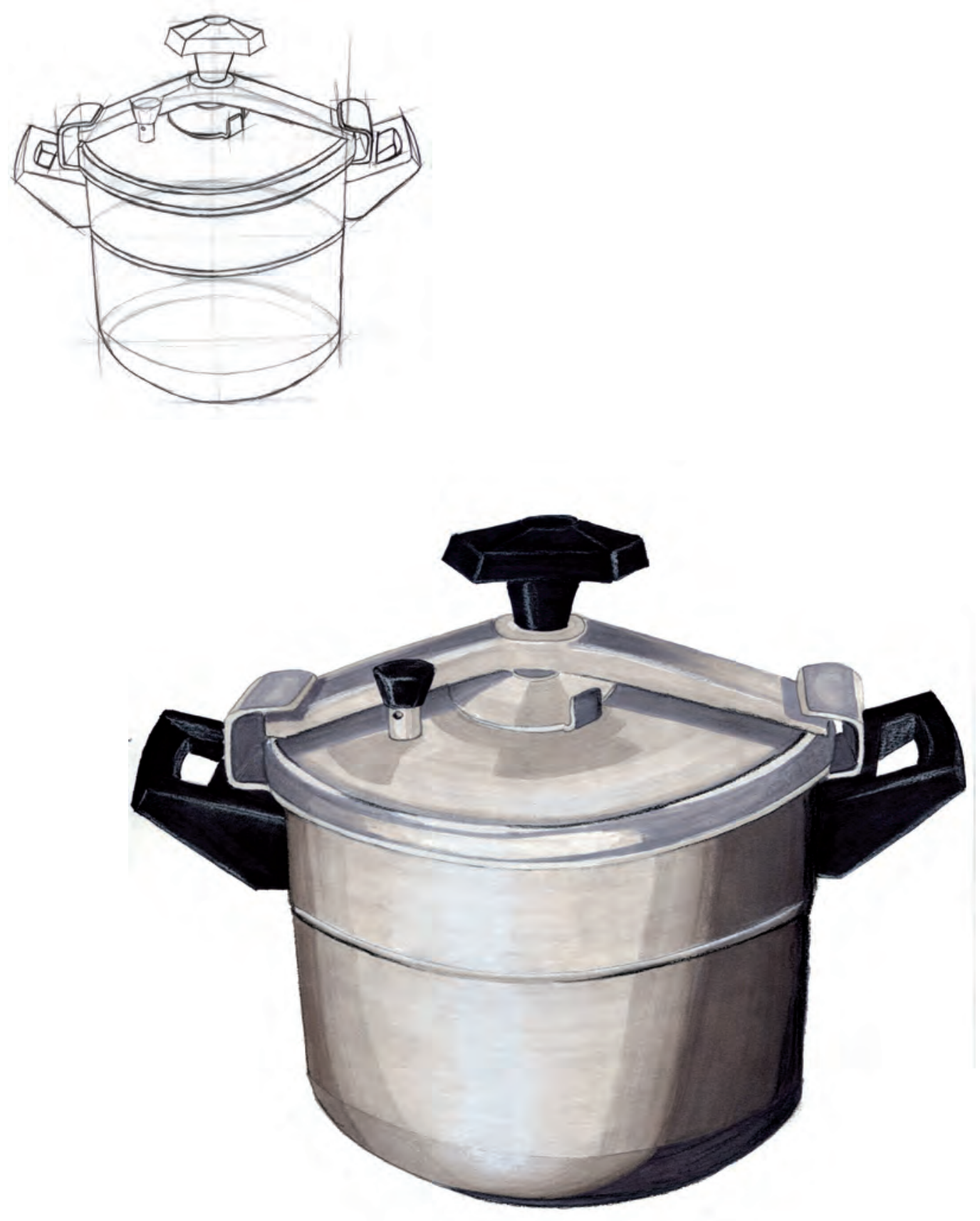

Realizado por Miguel Herrasti Amer 

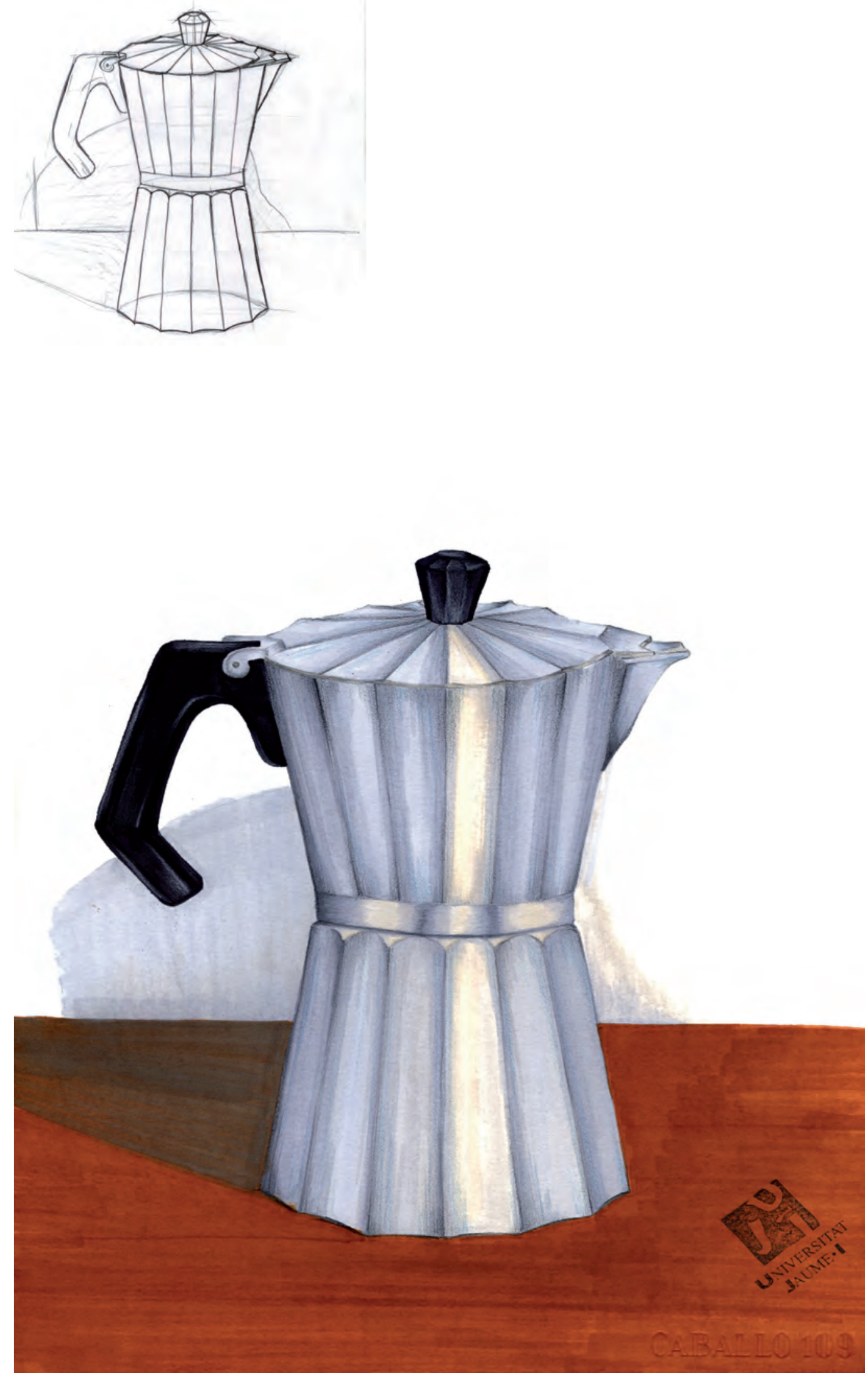

Realizado por Carlos Cotanda Gisbert 


\section{Práctica 23 \\ Escala de valor para madera}

\section{A. Objetivos}

- Manejar la técnica de rotulador combinada con los lápices de color para conseguir efectos de claroscuro.

- Simulación del claroscuro propio de la madera y su estructura veteada.

\section{B. Materiales}

- Folios y lápiz HB

- Papel para rotulador formato DIN A4

- Rotuladores

- Lápices de colores

- Bolígrafo negro tipo BIC

- Bolígrafo blanco tipo Uni-ball Signo Broad uM-153 Gel Ink Pen White Ink.

- Cera tipo Caran d'Ache Neocolor I White Oil Pastel 7400.001

\section{Guía de ejecución}

\section{Planteamiento}

- La práctica consiste en realizar una escala de valor para madera y aplicarla a un volumen cilíndrico.

- El formato de la escala será de $18 \times 3 \mathrm{~cm}$.

\section{Proceso de ejecución del dibujo}

- Dibujaremos un rectángulo de 18 x $3 \mathrm{~cm}$ y un cilindro del tamaño deseado.

- En el rectángulo realizaremos la escala de valor para madera. Iniciaremos el dibujo de dicha escala marcando los distintos tonos de la misma con un rotulador de color suave que simule la madera (ocre/marrón). Aumentaremos la saturación con varias pasadas de rotulador y/o con rotuladores más oscuros.

- Posteriormente simularemos el veteado y el grano de la madera con lápices de color marrón oscuro o con un rotulador marrón.

- Aplicaremos dicha escala de color al cilindro, representando el claroscuro volumétrico según el punto de luz seleccionado. 


\section{Guía de autocorrección}

Para la correcta ejecución de este ejercicio se han de tener en cuenta los siguientes aspectos:

- Comprobar que los distintos tonos de la madera representados se acercan a la naturaleza de la madera (caoba, arce, nogal, etc.).

- Revisar que en la escala se han plasmado los detalles propios de la textura de una madera.

- Comprobar que la dirección de los gradientes del claroscuro se adapta a la estructura volumétrica del objeto.

\section{E. Ejemplos resueltos}

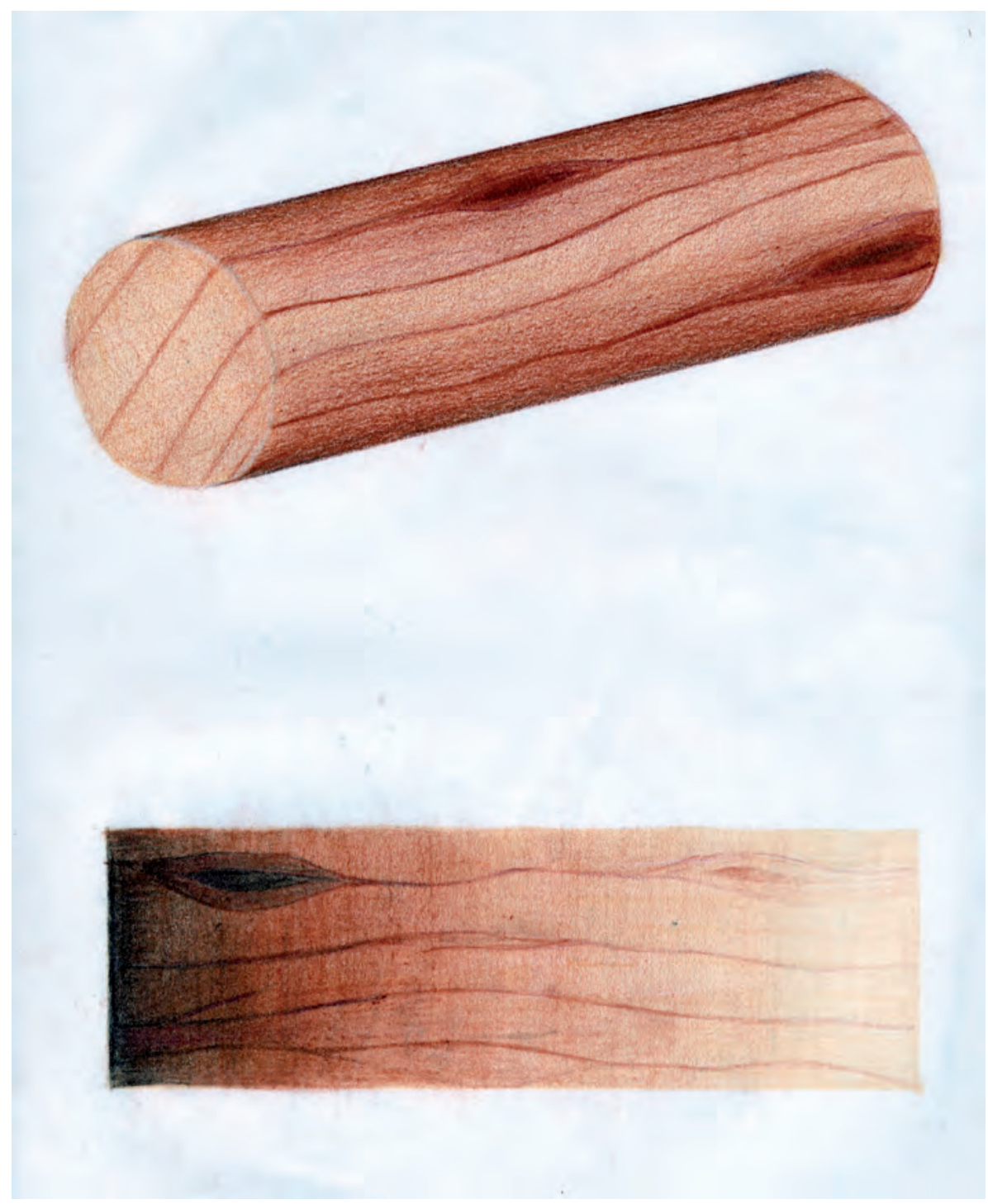

Realizado por Daniel López Gramaje 

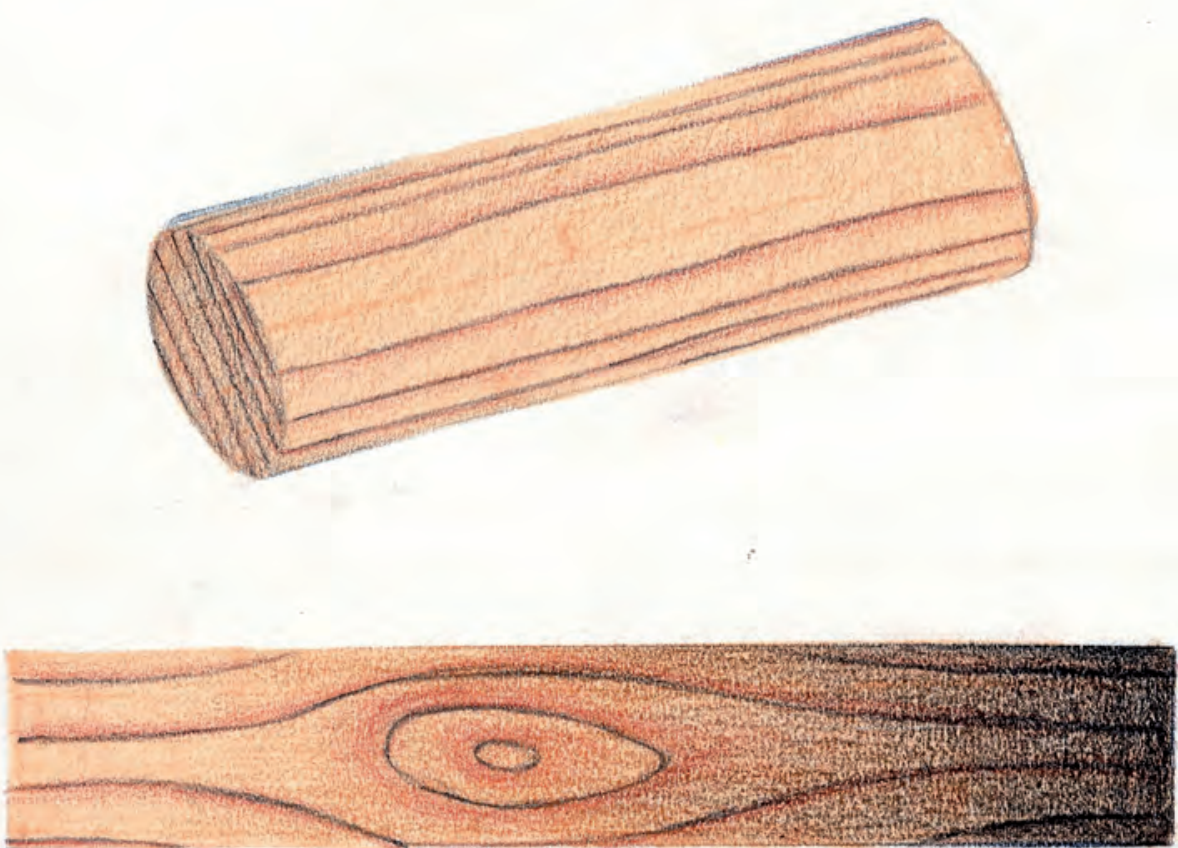

Realizado por Víctor Esteve Rubio 


\section{Práctica 24 \\ Renderizado a color con simulación de madera}

\section{A. Objetivos}

- Dominar la técnica mixta de rotulador y lápices de colores.

- Manejar controladamente el claroscuro que produce la luz sobre un objeto de madera.

- Ser capaz de simular las características propias del claroscuro sobre madera.

- Ser capaz de representar las peculiaridades de la textura veteada y/o granulada de diferentes tipos de madera.

\section{B. Materiales}

- Folios y lápiz HB

- Papel para rotulador formato DIN A4

- Rotuladores

- Lápices de colores

- Bolígrafo negro tipo BIC

- Bolígrafo blanco tipo Uni-ball Signo Broad uM-153 Gel Ink Pen White Ink.

- Cera tipo Caran d'Ache Neocolor I White Oil Pastel 7400.001

\section{Guía de ejecución}

\section{Planteamiento}

- En primer lugar, deberemos realizar un encaje de un objeto industrial de madera.

- A continuación, realizaremos un renderizado a color del objeto, utilizando la técnica mixta de rotulador más lápices de colores, teniendo como objetivo la simulación de la textura propia que ofrece la madera. 


\section{Proceso de ejecución del dibujo}

- En primer lugar, se analizará la forma general del objeto hasta encontrar la figura geométrica que puede contenerlo.

- Seguidamente se calculará el tamaño de dicha figura en relación al formato del papel para que quede bien encajado.

- Realizaremos un dibujo de encaje con lápiz HB, prestando especial atención a las proporciones del objeto, utilizando para ello trazos finos con el fin de no marcar en exceso el papel.

- Limpiaremos las líneas sobrantes y delimitaremos el objeto definiendo detalles y aristas.

- Calca el dibujo a un nuevo papel de rotulador.

- Elige una posición para el foco de luz que potencie el volumen del objeto. Esta iluminación ha de mostrar una primera cara del objeto con mayor incidencia de luz; la segunda, con una sombra media, y la tercera, con la oscuridad máxima.

- Aplica una primera capa de color utilizando el rotulador más claro sobre todo el objeto.

- Aumentaremos la saturación con varias pasadas de rotulador y/o con rotuladores más oscuros.

- Simularemos el veteado y el grano de la madera con lápices de color marrón oscuro o con rotulador marrón.

- Finalmente, daremos algunos retoques al renderizado con los lápices de colores, mejorando el perfilado de las formas y enfatizando los contrastes.

\section{Guía de autocorrección}

Para la correcta ejecución de este ejercicio se han de tener en cuenta los siguientes aspectos:

- Comprobar que los distintos tonos de la madera representados se acercan a la naturaleza de la madera (caoba, arce, nogal, etc.).

- Revisar que se han plasmado los detalles propios de la textura de una madera.

- Comprobar que la dirección de los gradientes del claroscuro se adapta a la estructura volumétrica del objeto. 


\section{E. Ejemplos resueltos}

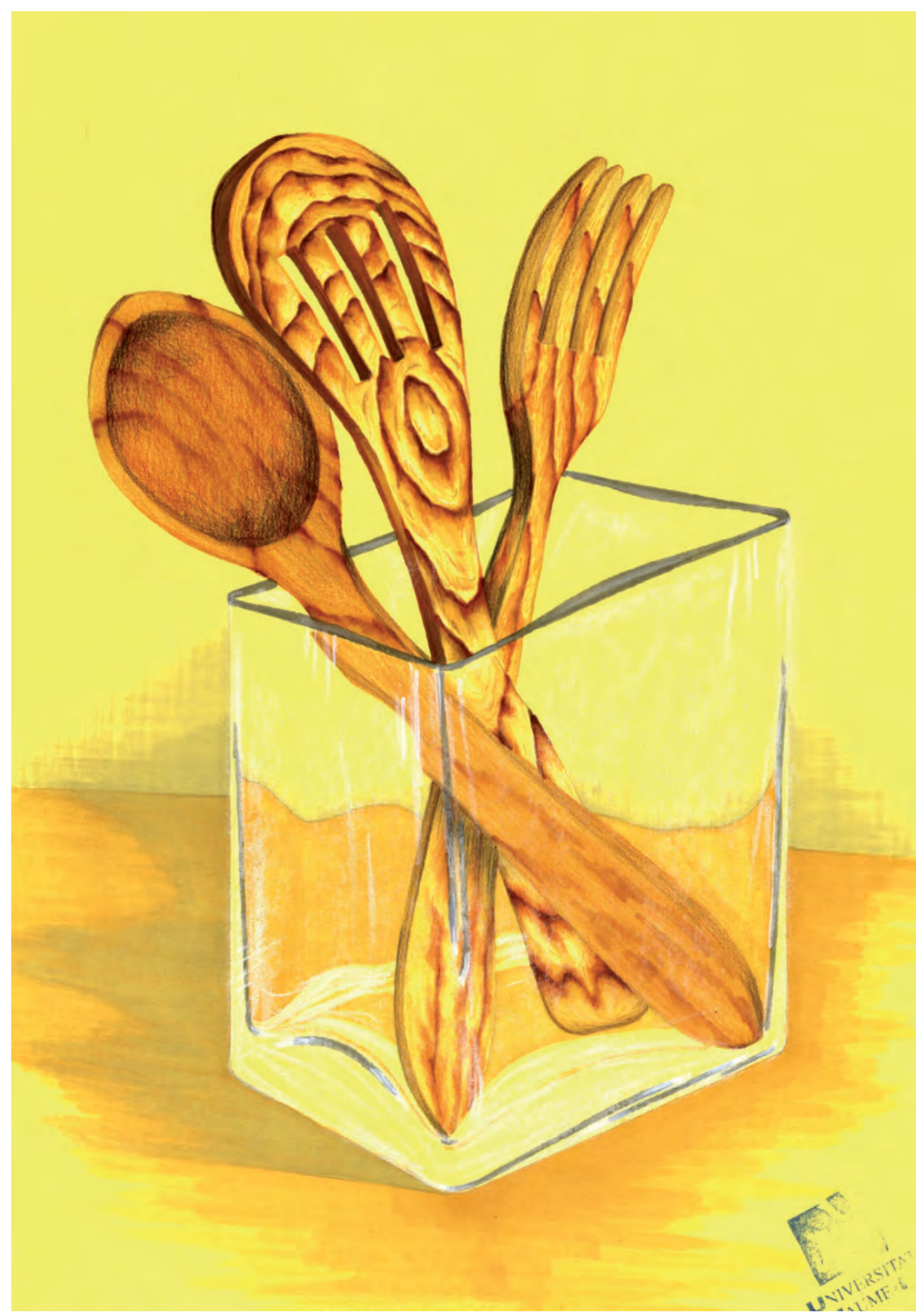

Realizado por Carlos Cotanda Gisbert 


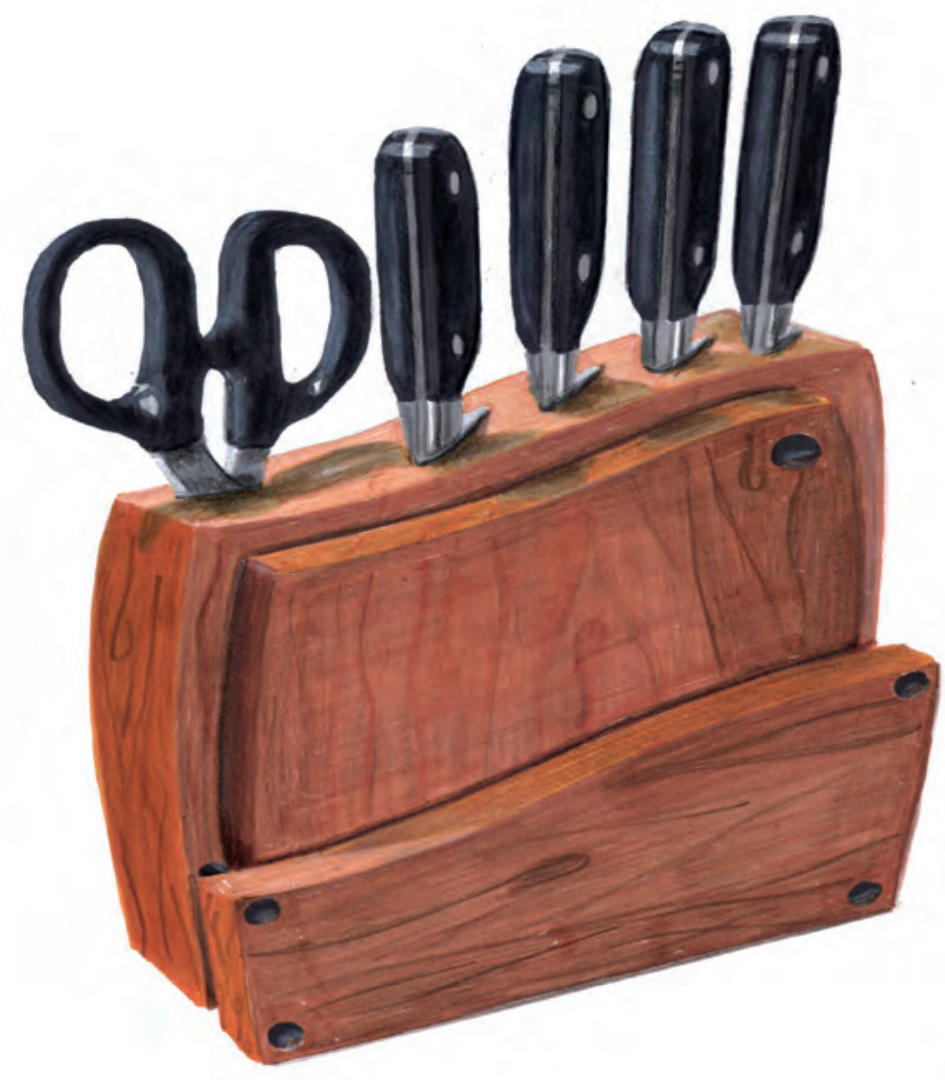

Realizado por Carmina Danna Amodeo 


\section{$\rightleftharpoons$}
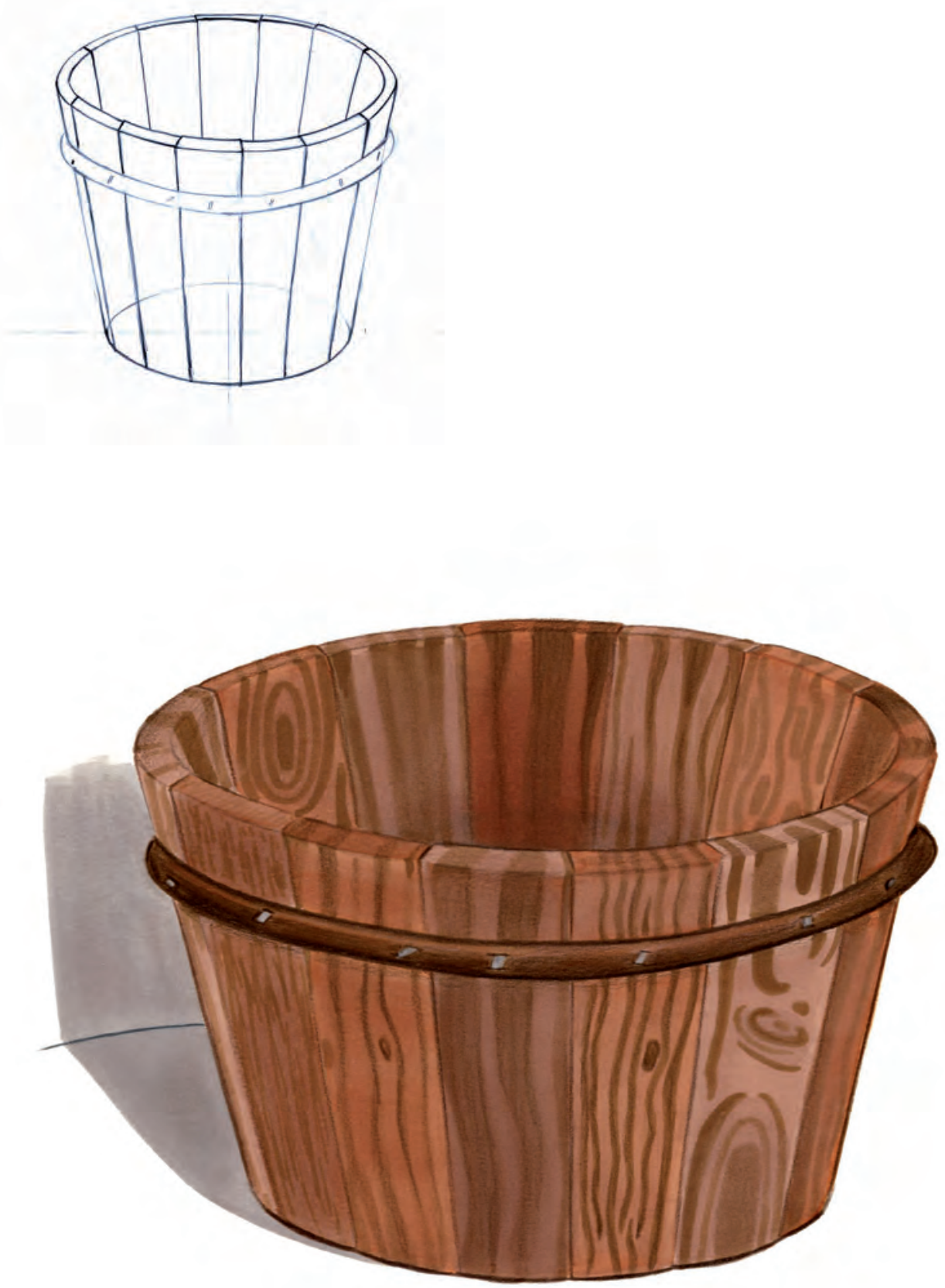

Realizado por Laura Martínez 


\section{Práctica 25}

\section{Escala de valor para material transparente}

\section{A. Objetivos}

- Manejar la técnica de rotulador combinada con los lápices de color para conseguir efectos de claroscuro.

- Simulación del claroscuro propio del material transparente.

\section{B. Materiales}

- Folios y lápiz HB

- Papel para rotulador formato DIN A4

- Rotuladores

- Lápices de colores

- Bolígrafo negro tipo BIC

- Bolígrafo blanco tipo Uni-ball Signo Broad UM-153 Gel Ink Pen White Ink

- Cera tipo Caran d'Ache Neocolor I White Oil Pastel 7400.001

\section{Guía de ejecución}

\section{Planteamiento}

- La práctica consiste en realizar una escala de valor para simular un material transparente.

- Aplicaremos la escala sobre seis formas básicas estudiando las diferentes posibilidades que tenemos para simular el efecto de transparencia.

\section{Proceso de ejecución del dibujo}

- Dibujar seis veces un objeto cilíndrico. En cada uno de ellos trabajaremos una variación del efecto superficial en lo que concierne a brillos, reflejos y transparencia.

- El plano posterior debe aparecer desdibujado o distorsionado por el efecto del material.

- Aplicaremos los tonos más claros del material a modo de veladuras, reservando los brillos más fuertes de la superficie del objeto.

- Mediante la superposición de trazos y la utilización de diferentes tonos de un mismo color conseguiremos variaciones aleatorias de color. 
- Para simular el material translúcido es importante que se visualicen las zonas posteriores del objeto. Para ello, con la punta fina del rotulador definiremos algunos límites del objeto y algunos detalles.

- Oscureceremos progresivamente el tono, utilizando rotuladores más oscuros, respetando siempre las zonas de máximo brillo.

- Posteriormente con un lápiz de color gris oscuro se perfilan aristas y detalles, potenciando algunas zonas de contraste.

- Por último, con un bolígrafo de punta fina blanco se definen algunos brillos superficiales de la parte frontal.

\section{Guía de autocorrección}

- Verificar el correcto contraste entre las caras iluminadas y las que están en sombra.

- Comprobar que se ha conseguido un efecto de transparencia coherente.

- Revisar que las aristas están bien definidas y perfiladas.

\section{E. Ejemplos resueltos}
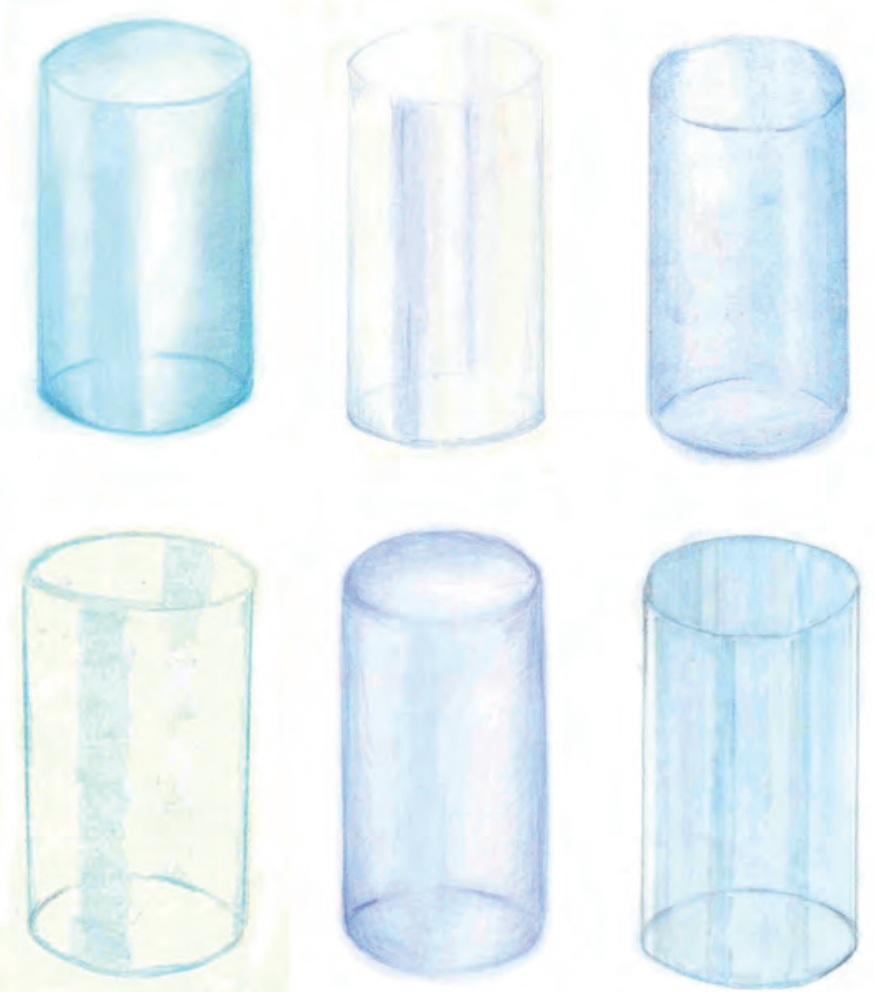

Ejemplo de simulación de material transparente 


\section{Práctica 26 \\ Renderizado a color con simulación de material transparente}

\section{A. Objetivos}

- Dominar la técnica mixta de rotulador y lápices de colores.

- Manejar controladamente el claroscuro que produce la luz sobre un objeto transparente.

- Ser capaz de simular las características propias del claroscuro sobre material transparente.

\section{B. Materiales}

- Folios y lápiz HB

- Papel para rotulador formato DIN A4

- Rotuladores

- Lápices de colores

- Bolígrafo negro tipo BIC

- Bolígrafo blanco tipo Uni-ball Signo Broad um-153 Gel Ink Pen White Ink

- Cera tipo Caran d'Ache Neocolor I White Oil Pastel 7400.001

\section{Guía de ejecución}

\section{Planteamiento}

- La práctica consiste en realizar un renderizado de un material transparente.

- Para ello se realizará un encaje del modelo que se transferirá al papel para rotulador, con el fin de realizar el correspondiente tratamiento del claroscuro cromático y la representación de las texturas.

- Se escogerá una posición adecuada del foco lumínico, para potenciar la corporeidad del objeto, facilitando así su visualización.

- Cabe prestar especial atención al tratamiento realizado sobre las zonas posteriores al objeto, que se verán a través del mismo con mayor o menor definición en función de la transparencia del material escogido. Para simular 
el efecto de transparencia es conveniente matizar las formas posteriores, así como deformar o desdibujar los detalles.

\section{Proceso de ejecución del dibujo}

- Transferiremos el dibujo al nuevo papel de rotulador. Deberán aparecer los planos posteriores de los elementos translúcidos, deformados y ligeramente descolocados de su posición real (como vistos a través de una lente).

- Empezaremos trabajando el fondo para que se note la distorsión que produce el material translúcido. Con el fin de obtener una riqueza cromática en el fondo utilizaremos diferentes tonalidades. Para este trabajo se recomienda trabajar con una escala de valores grises.

- Aplicaremos los tonos más claros del material a modo de veladuras, reservando los brillos más fuertes de la superficie del objeto.

- Mediante la superposición de trazos y la utilización de diferentes tonos de gris conseguiremos variaciones aleatorias de color.

- Para simular el material translúcido es importante que se visualicen las zonas posteriores del objeto. Para ello, con la punta fina del rotulador definiremos algunos límites del objeto y algunos detalles.

- Además, habrá que tener en cuenta que la coloración del fondo, si la hubiera, deberá influir en la variación cromática de la superficie frontal del objeto.

- Oscureceremos progresivamente el tono utilizando rotuladores más oscuros, respetando siempre las zonas de máximo brillo.

- Posteriormente, con un lápiz de color gris oscuro se perfilan aristas y detalles, potenciando algunas zonas de contraste.

- Por último, con un bolígrafo de punta fina blanco se definen algunos brillos superficiales de la parte frontal.

\section{Guía de autocorrección}

- Comprobar el correcto encajado del objeto, atendiendo a sus proporciones.

- Comprobar que está bien resuelta la estructura formal del objeto.

- Verificar el correcto contraste entre las caras iluminadas y las que están en sombra. 
- Revisar que las aristas están bien definidas y perfiladas.

- Asegurarnos que la iluminación que se ha representado en el objeto refleja la ubicación del foco de luz y por tanto, si son coherentes las sombras que se han plasmado.

\section{E. Ejemplos resueltos}

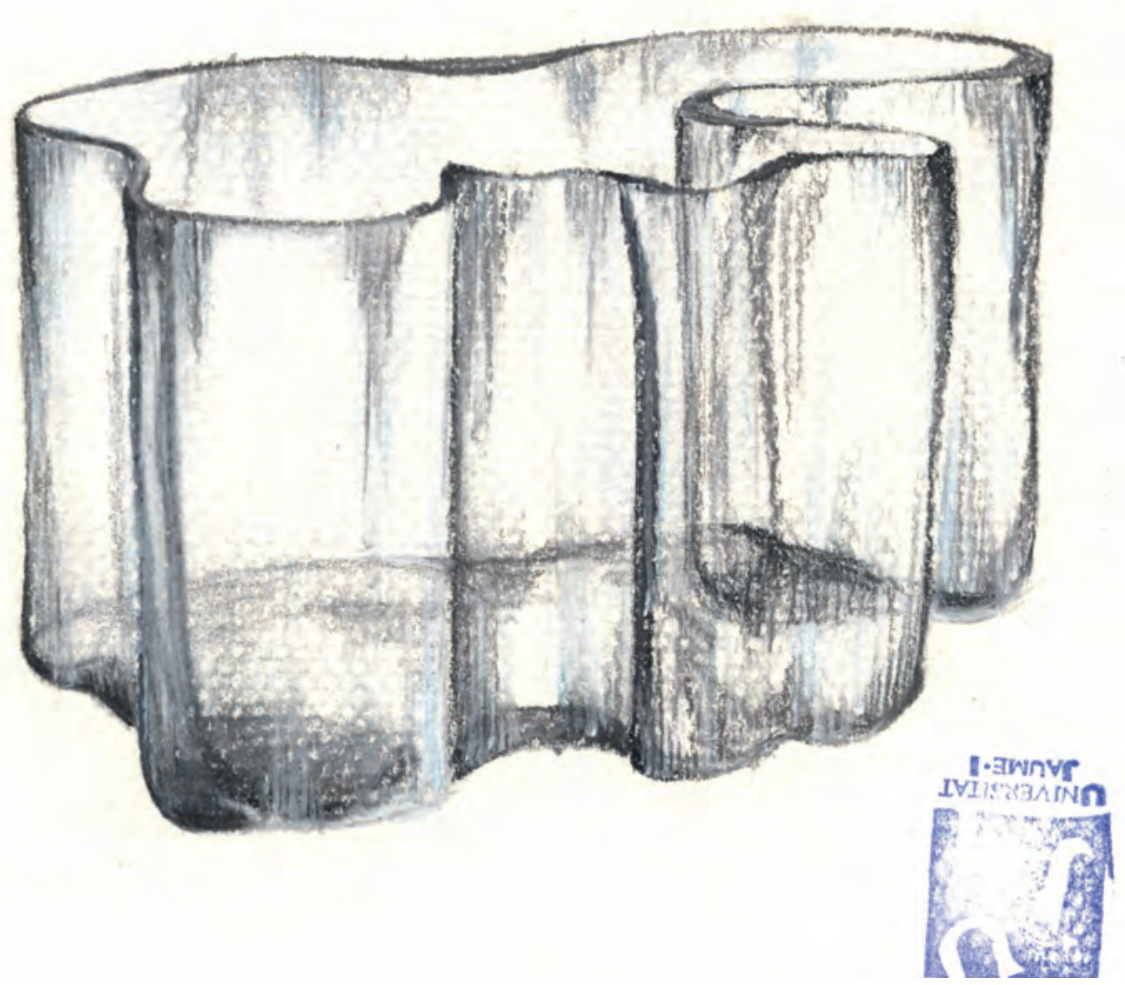

Realizado por Laia Maroto Ramos 


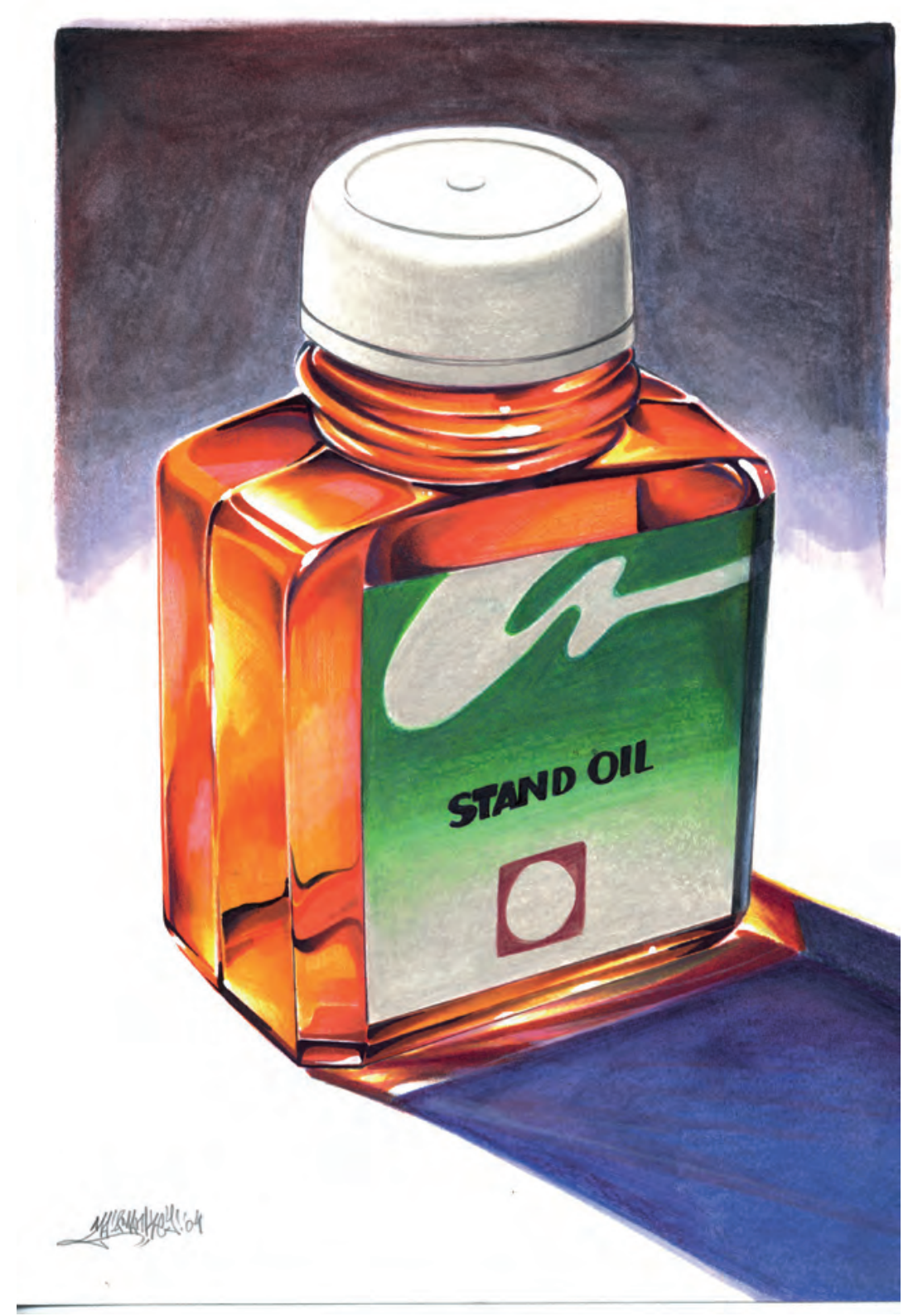

Realizado por Mario Fernández López 


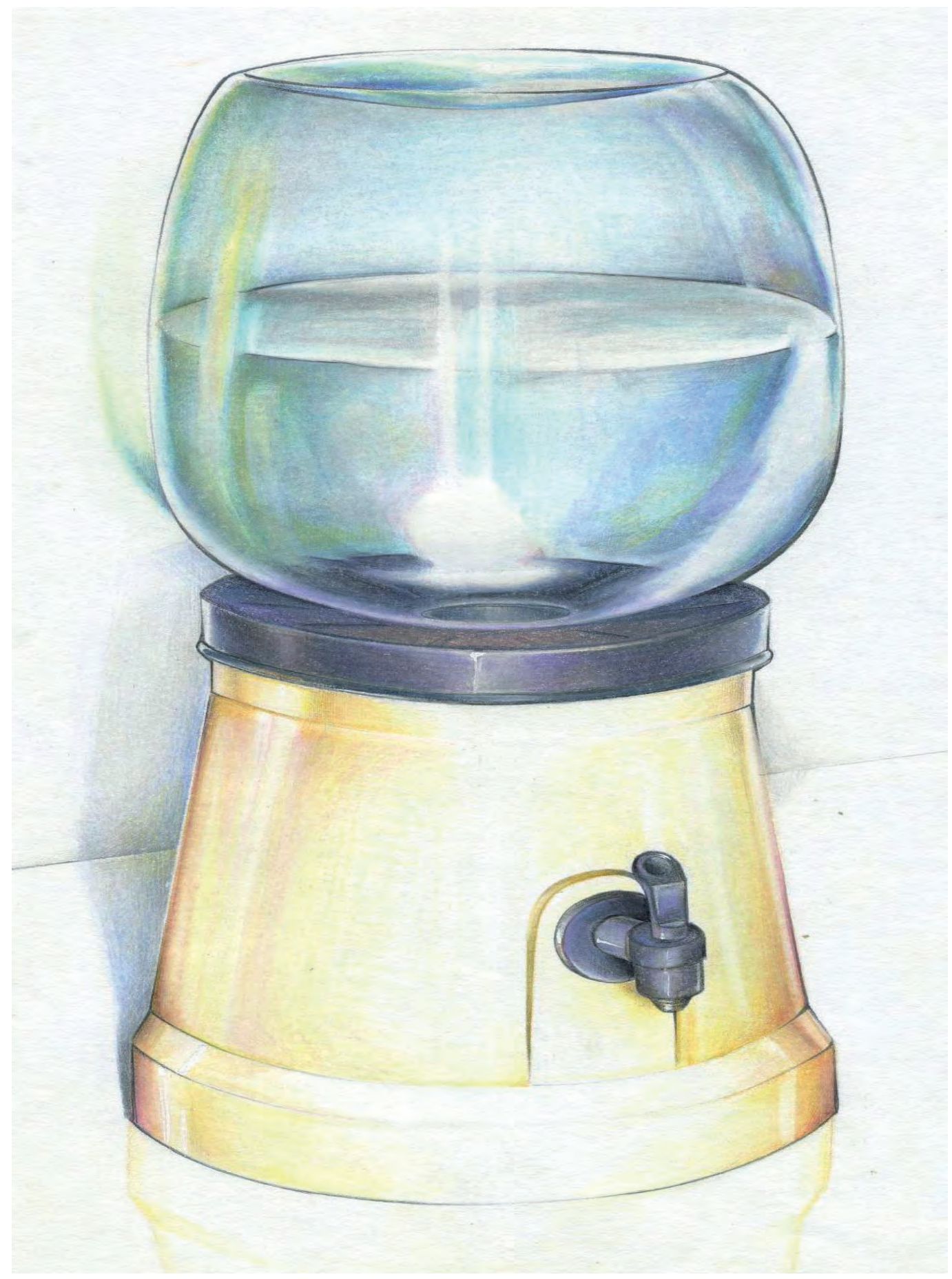

Realizado por Mario Fernández López 
BLOQUE 5

La figura humana
en el diseño industrial 
El diseñador introduce la figura humana en la presentación de sus proyectos por dos motivos fundamentales: mostrar las proporciones y escala del producto con relación al cuerpo humano y también para informar sobre la ergonomía y manejo del objeto.

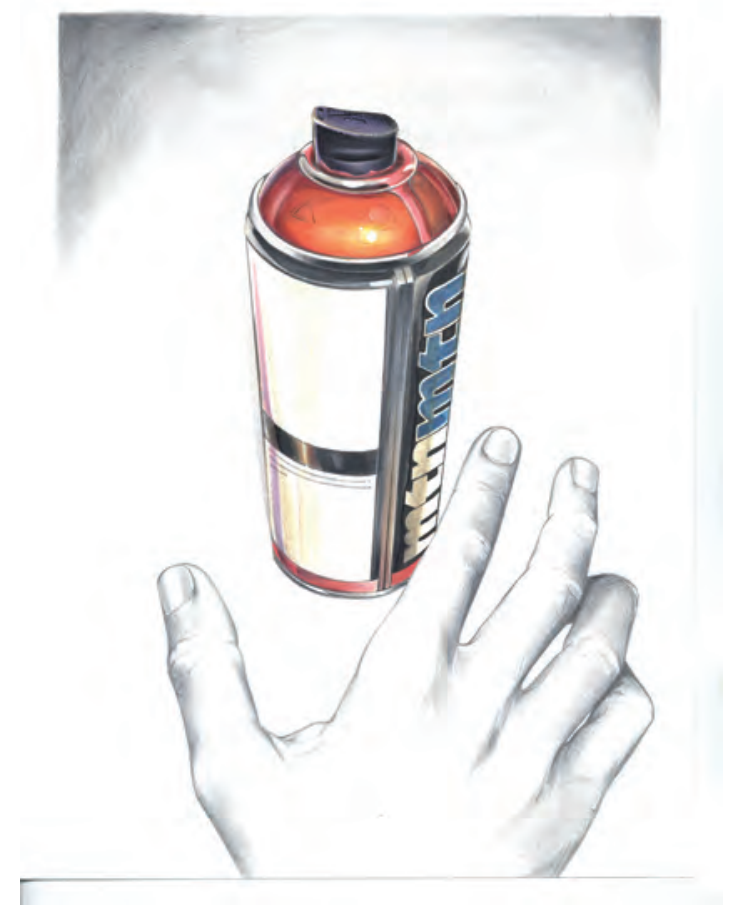

Renderizado realizado por Mario Fernández

Dominar la representación del cuerpo humano no es una tarea fácil, dada la complejidad anatómica a la que nos enfrentamos. Desde épocas clásicas la figura humana ha sido fruto de numerosas investigaciones para encontrar métodos gráficos que nos faciliten el trazado de poses, que sin entrar en grandes detalles, sean correctas en lo concerniente a proporción y movimiento.

En el siglo v a. C., Policleto estableció en su tratado El Canon unas reglas básicas para representar la anatomía humana que utilizaban la longitud de la cabeza como módulo que repetido siete veces en altura y dos en anchura permitía encajar las diferentes partes del cuerpo humano. Con el paso de la historia del Arte, los artistas fueron desarrollando este método y, según las modas reinantes en cada época, fueron variando el número de repeticiones de las cabezas dando lugar a los tres cánones fundamentales de la proporción:

- Canon de siete cabezas y media equivalente a las proporciones de una persona normal de estatura de entre 1,60 y $1,70 \mathrm{~m}$ de altura. 


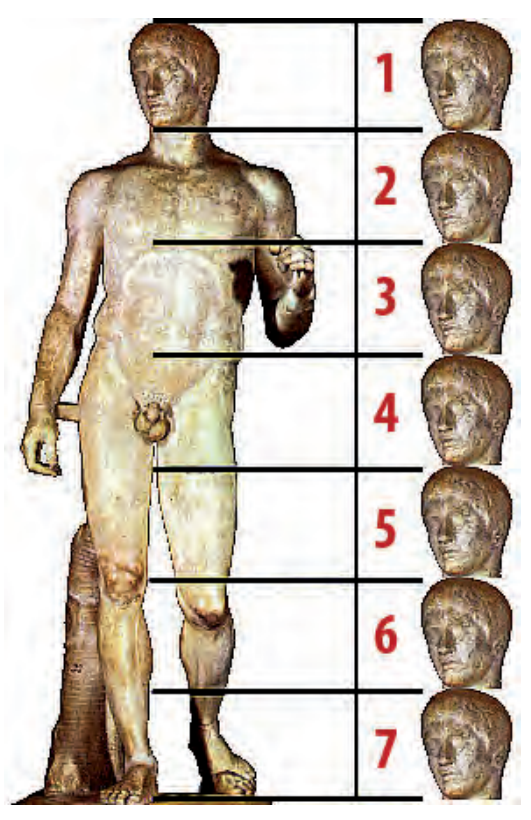

Canon de Policleto

- Canon de ocho cabezas correspondiente a las proporciones de una persona más alta y atlética con una estatura de $1,85 \mathrm{~m}$.
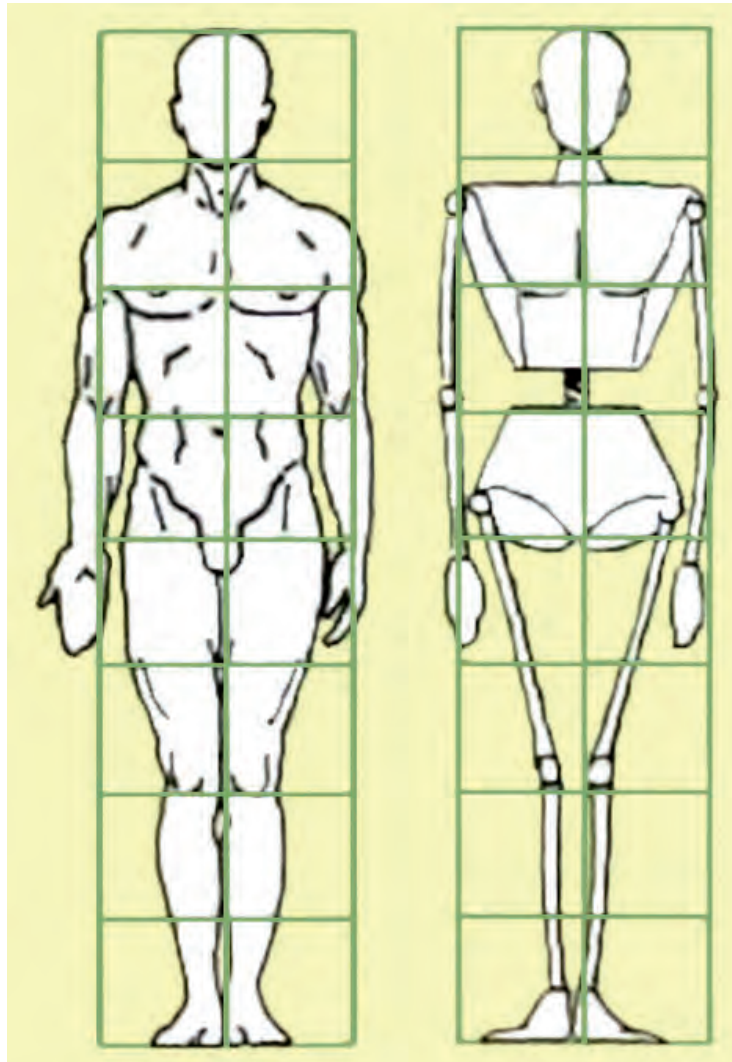

Encaje de la figura humana de ocho cabezas 
- Canon de nueve cabezas para personas muy esbeltas y con una estatura a partir de $1,85 \mathrm{~m}$.

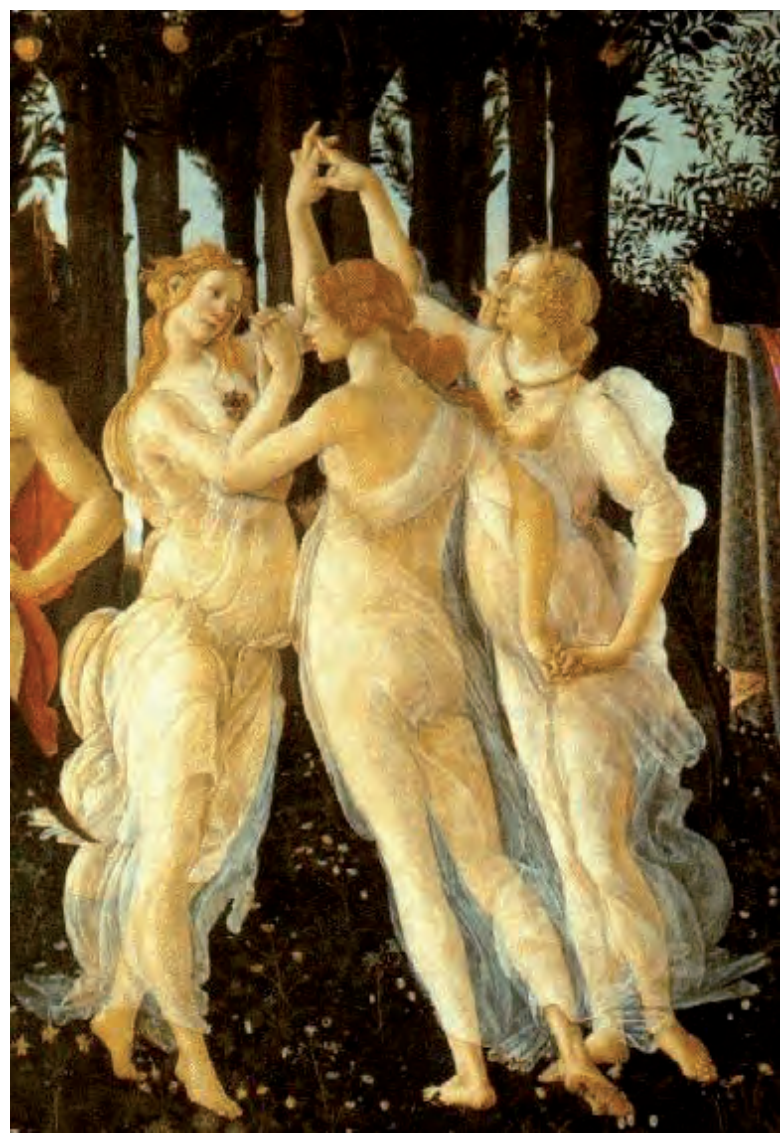

Las tres gracias, de Sandro Botticelli. En este cuadro el autor consigue mayor elegancia y esbeltez en las figuras utilizando el canon de nueve cabezas 


\section{Práctica 27 \\ La anatomía humana y el canon de proporción}

Es condición indispensable para representar gráficamente la figura humana estudiar su anatomía, tanto su estructura ósea como las articulaciones fundamentales y la musculatura principal.

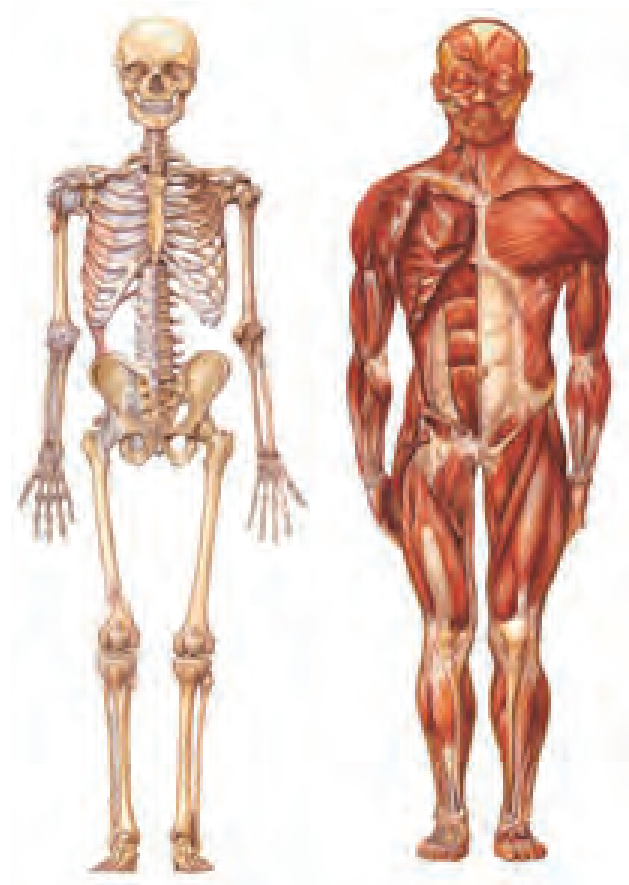

\section{A. Objetivos}

Esta práctica persigue dos objetivos fundamentales:

- Dibujar esquemáticamente el esqueleto humano.

- Dibujar la figura masculina y femenina utilizando el canon de las ocho cabezas.

B. Materiales

- Papel formato DIN A4

- Lápiz de dureza HB

- Goma de lápiz 


\section{Guía de ejecución}

\section{Planteamiento}

La práctica consistirá en realizar los dibujos que se describen a continuación:

- Un dibujo de frente del esqueleto de una persona adulta en el cual se deben plasmar de forma esquemática: el cráneo, la caja torácica, la columna vertebral, la pelvis y las extremidades superiores e inferiores.

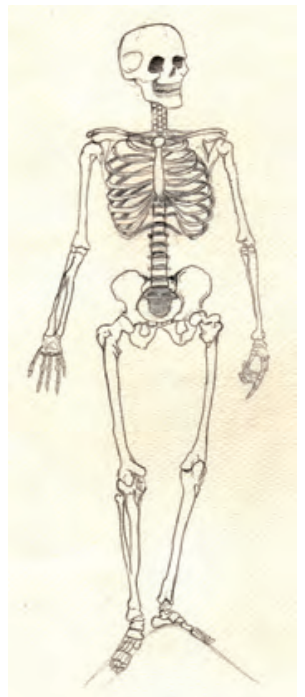

Realizado por Pamela Sánchez de las Matas

- Un dibujo de frente y de perfil de una figura masculina proporcionando cada una de las partes del cuerpo según el canon de ocho cabezas.

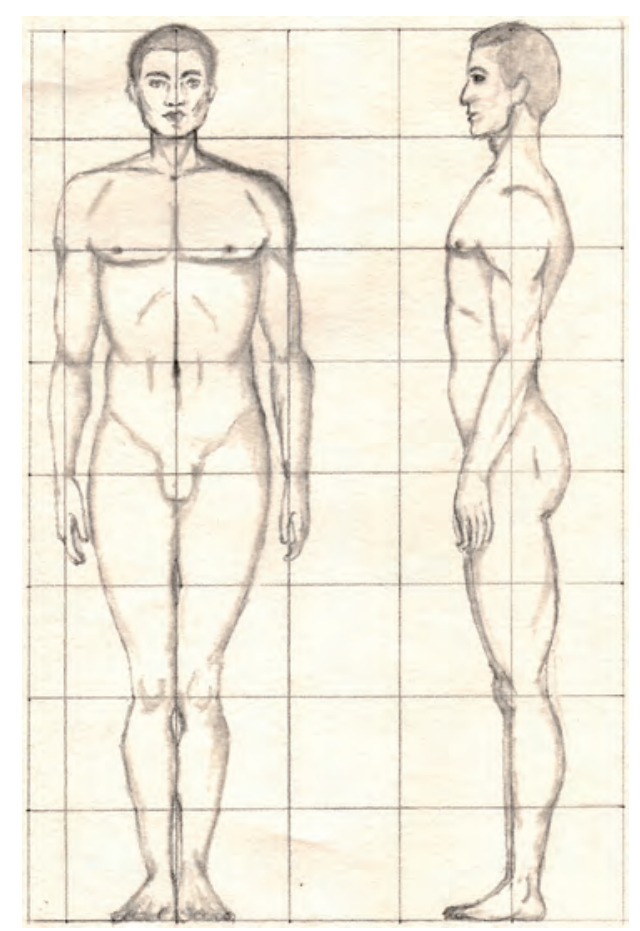

Realizado por Yasmin Moucharrafie Abdulsamad 
- Un dibujo de frente y de espaldas de una figura femenina proporcionando cada una de las partes del cuerpo según el canon de ocho cabezas.

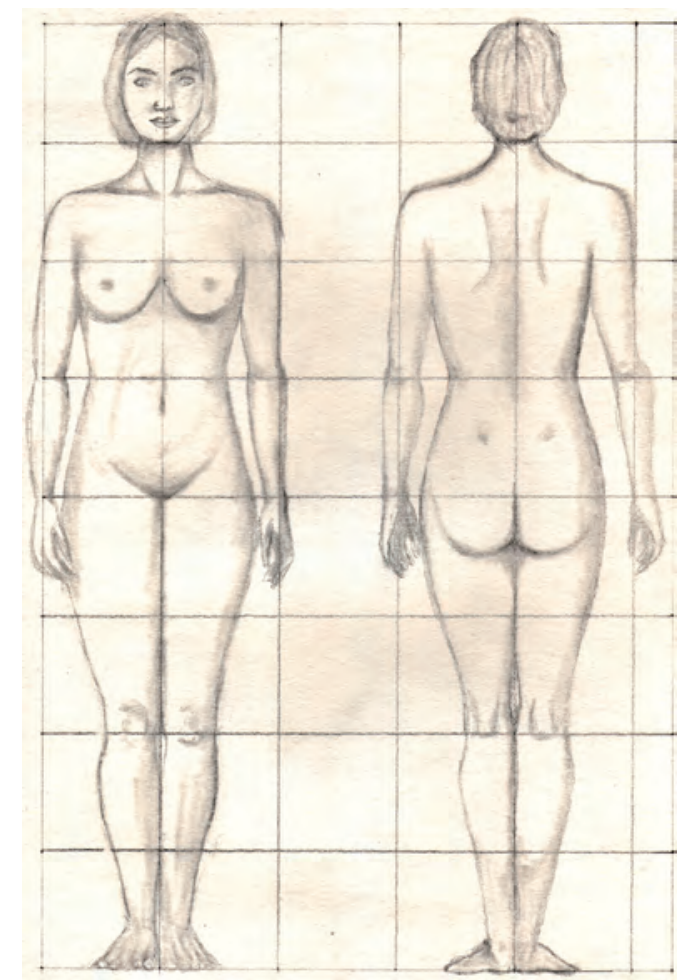

Realizado por Yasmin Moucharrafie Abdulsamad

\section{Proceso de ejecución del dibujo}

- Dibujar para cada uno de los cinco dibujos una cuadrícula de ocho cuadrados de altura y dos de anchura.

- Para dibujar cada una de las partes principales del cuerpo en cualquiera de los cinco dibujos, tendremos en cuenta las siguientes reflexiones sobre el uso del canon de ocho cabezas.

- La línea central de la cuadrícula será el eje de simetría de la figura.

- La cabeza ocupará el primer cuadrado superior.

- Los hombros se dibujarán más arriba de la mitad del segundo módulo.

- La línea del pectoral, por debajo del segundo cuadrado.

- La articulación del codo se encuentra al final del tercer módulo.

- El ombligo, en el inicio del cuarto cuadrado.

- El pubis se sitúa al final del cuarto módulo.

- Las manos se dibujan en al quinto módulo.

- Al final del sexto cuadrado se dibujará la articulación de la rodilla.

- Los pies descansarán sobre la línea final del último módulo. 
- Cada uno de los dibujos mostrará la volumetría de las partes principales del cuerpo humano: cabeza, tronco y extremidades.

- No es necesario ahondar en grades detalles pero sí cuidar al máximo la proporción.
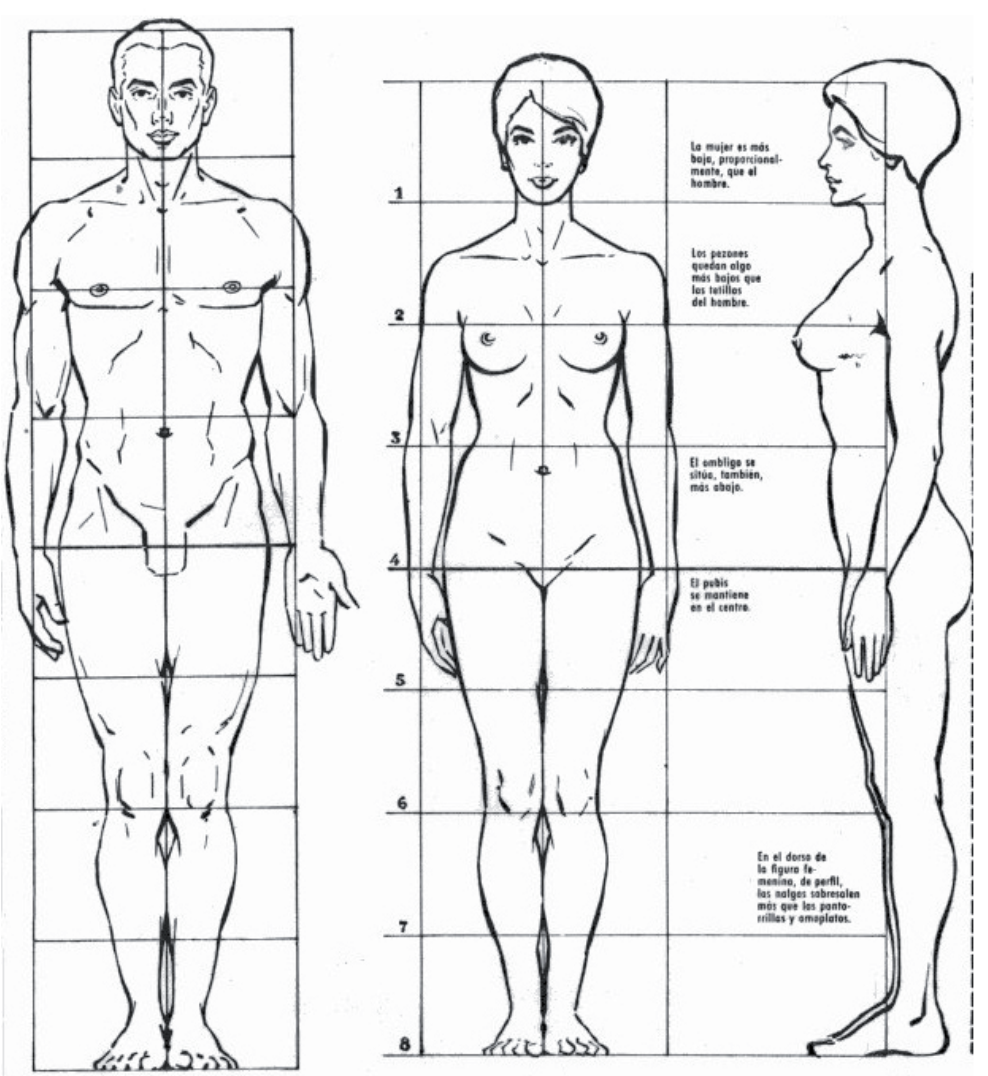

Dibujo extraído del libro Cómo dibujar la figura humana, colección Aprender haciendo, de José M. Parramón

\section{Guía de autocorrección}

- Una vez acabado cada dibujo es conveniente comprobar la simetría de la figura.

- Hay que detectar los errores de proporción más habituales: acortamiento de las extremidades inferiores, cabeza desproporcionada y manos mal posicionadas. 


\section{E. Ejemplos resueltos}

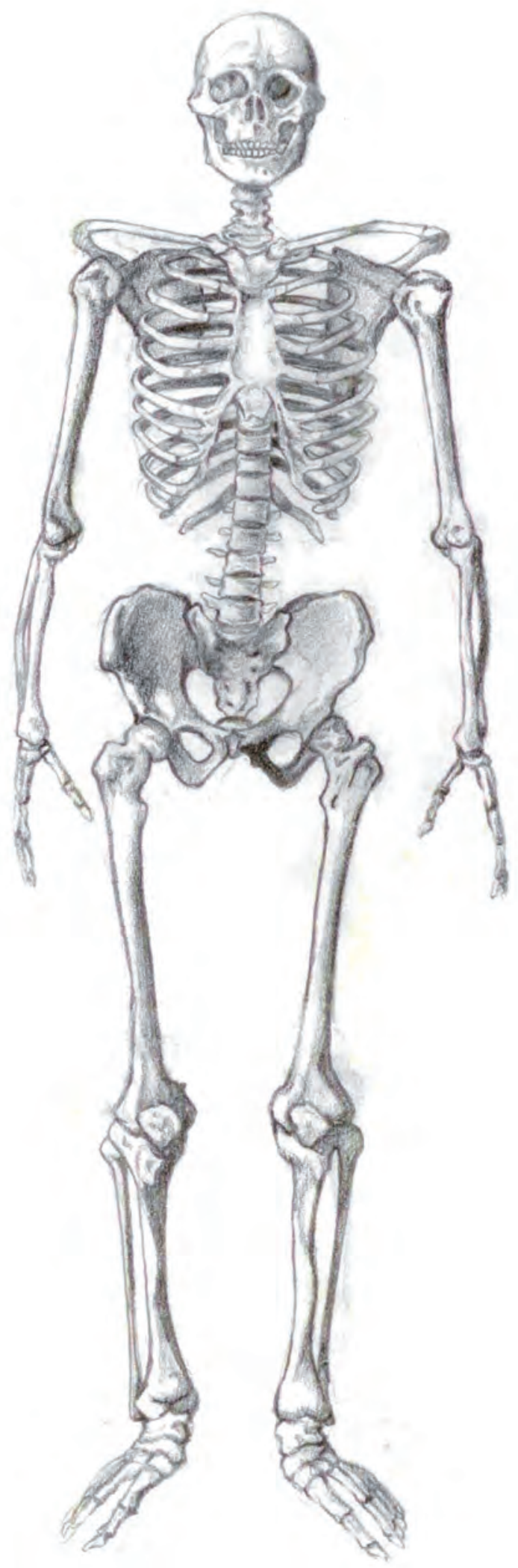

Realizado por Rocío Carreras Rubio 


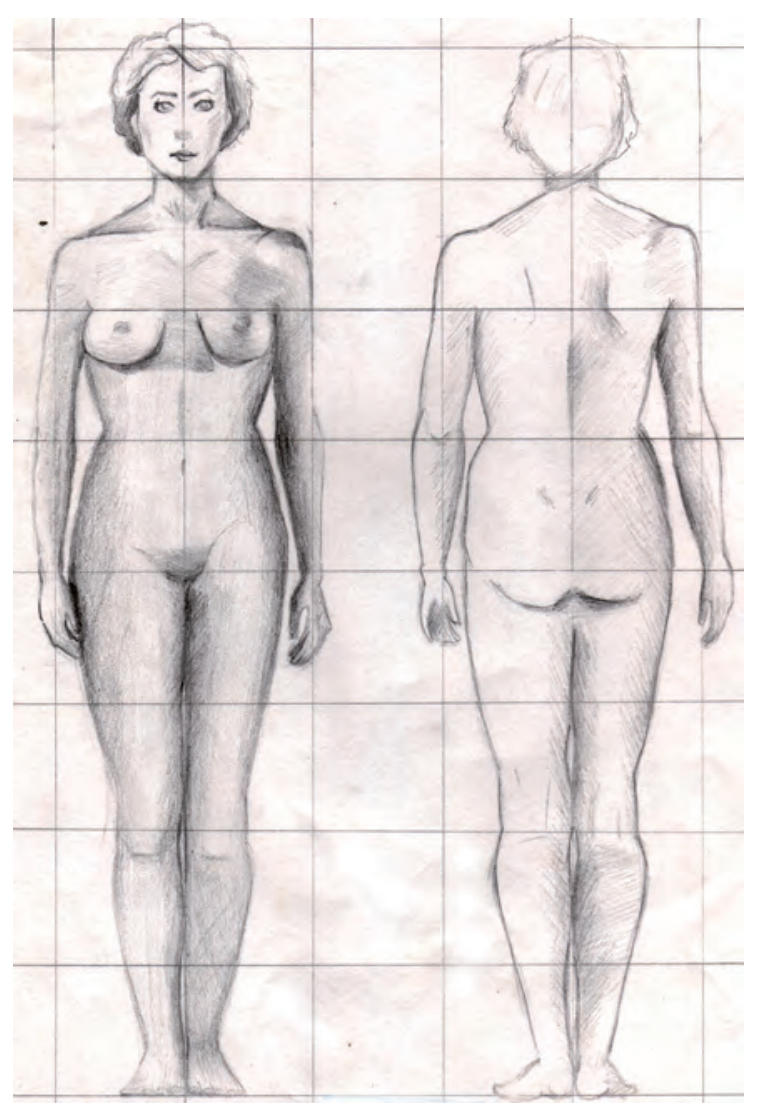

Realizado por Raquel Villanueva Hidalgo

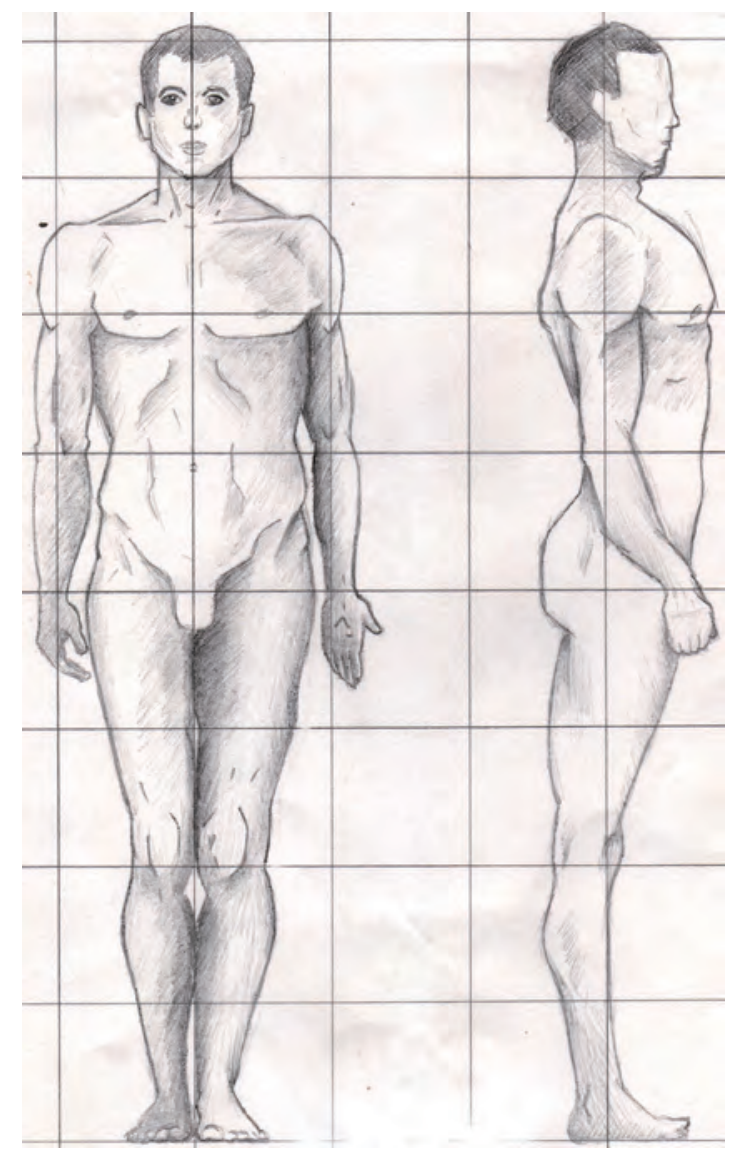

Realizado por Raquel Villanueva Hidalgo 


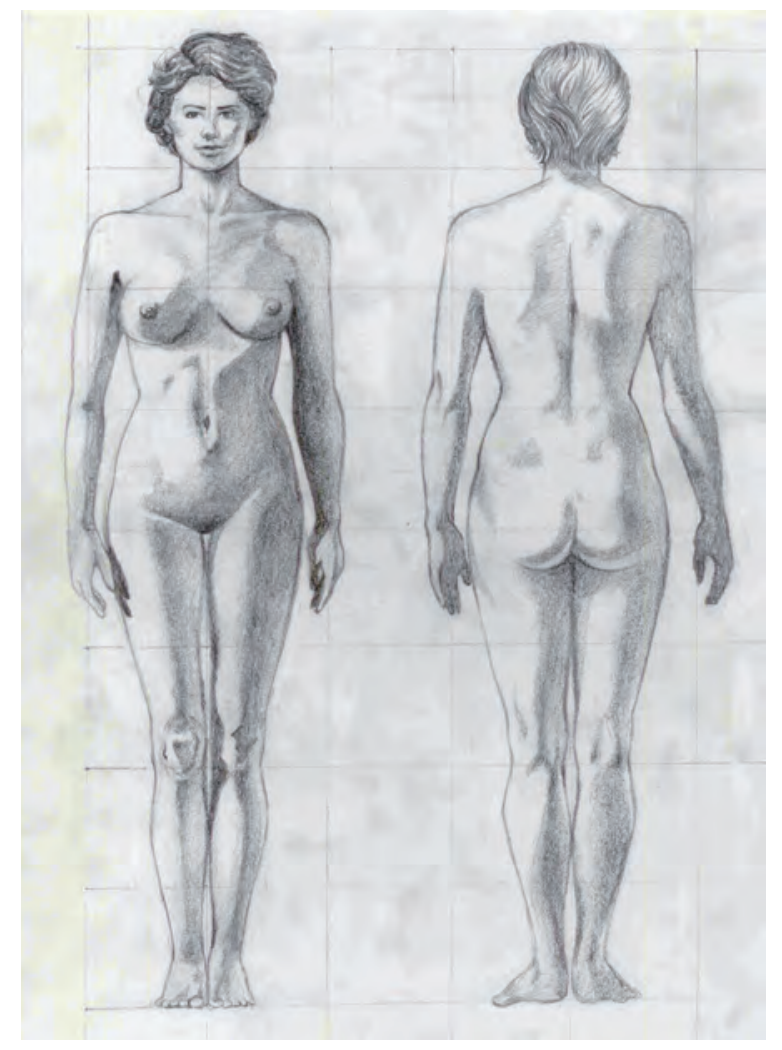

Realizado por Rocío Carreras Rubio

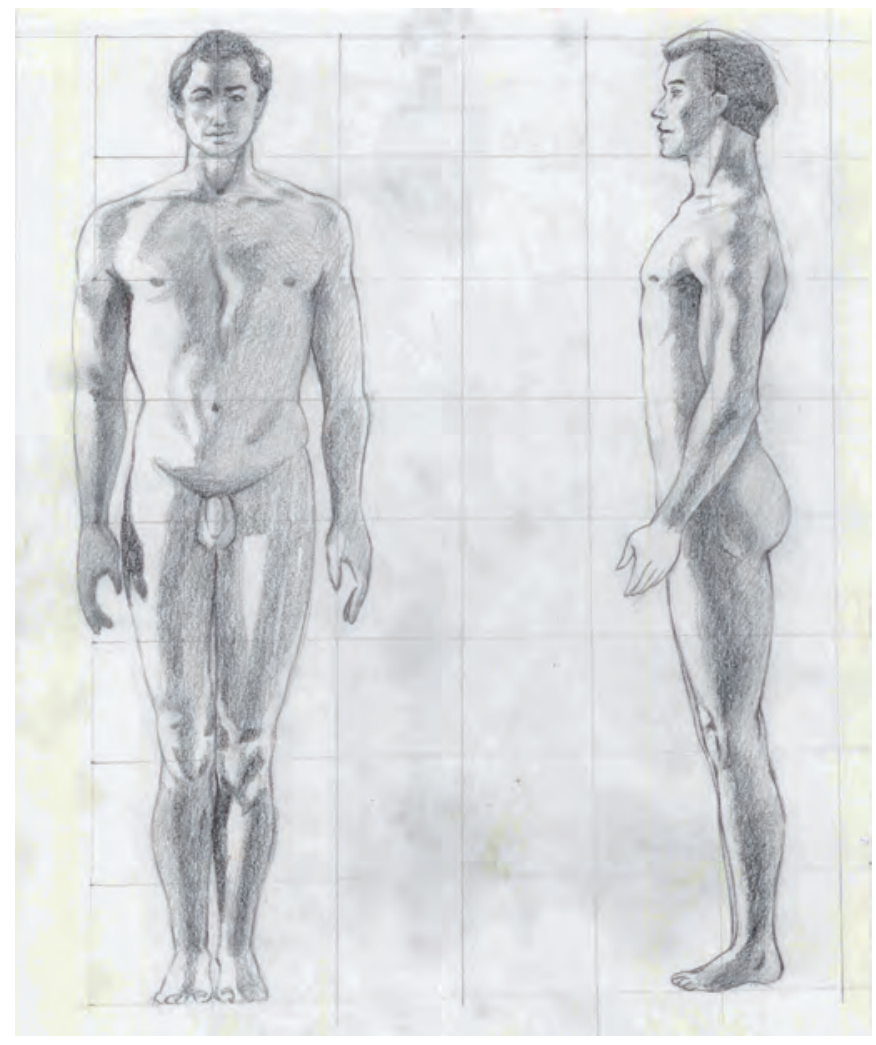

Realizado por Rocío Carreras Rubio 


\section{Práctica 28}

\section{Representación elemental de la figura humana}

Otro sistema para resolver la representación de la figura humana consiste en recurrir a maniquís articulados para comprender las proporciones del cuerpo y también toda su movilidad.

Los maniquís resumen las principales partes del cuerpo en una serie de piezas articuladas, que comprenden las proporciones primordiales de la figura por bloques geométricos, si dominamos el dibujo de estas piezas dominaremos a su vez el dibujo del cuerpo humano:

1. La cabeza, el tronco y la cadera son los tres bloques principales.

2. Las extremidades se representan como piezas tronco-cónicas.

3. Las articulaciones se dibujan como esferas insertadas en los otros elementos del cuerpo.

4. Los pies se resumen como prismas con una base más estrecha que es la correspondiente a la zona de los dedos.

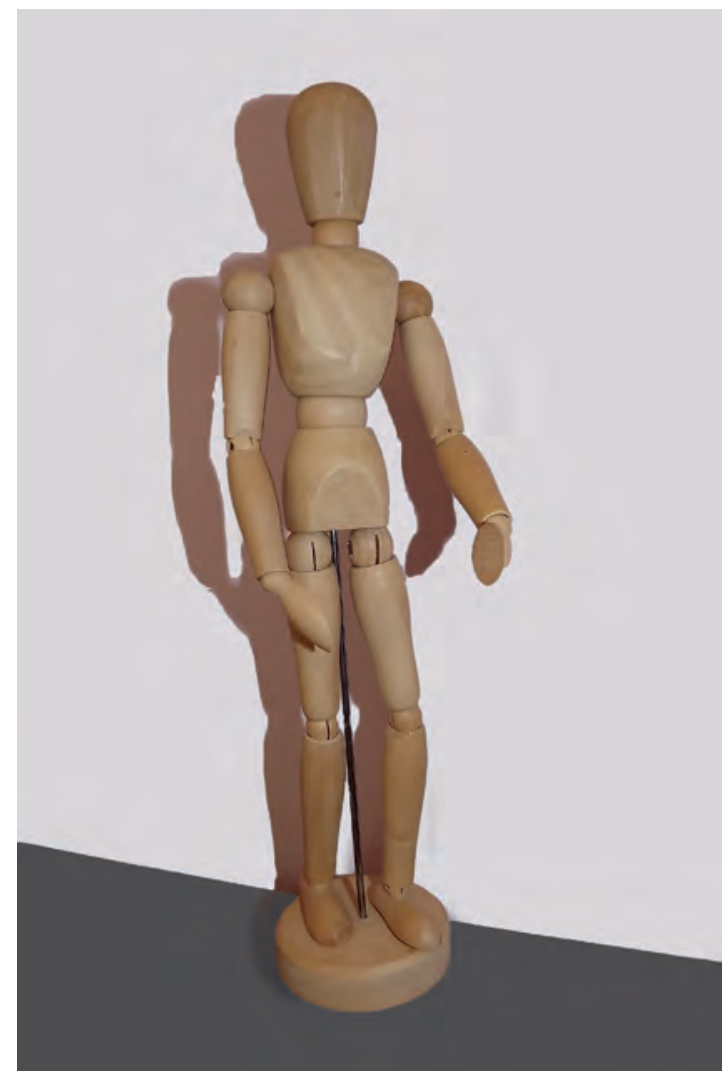

Maniquí articulado de madera.

Fotografía realizada por Lucía Ribelles Santos 


\section{A. Objetivos}

Realizando esta práctica alcanzaremos los siguientes objetivos:

- Dominar la proporción de la figura humana.

- Dibujar el cuerpo humano en movimiento.

- Estudiar las articulaciones fundamentales de la anatomía humana.

\section{B. Materiales}

- Papel formato DIN A4

- Lápiz de dureza HB

- Goma de lápiz

\section{Guía de ejecución}

\section{Planteamiento}

La práctica consistirá en realizar varios dibujos del maniquí en diferentes poses.

\section{Proceso de ejecución del dibujo}

- Es aconsejable realizar dibujos por separado de las piezas principales del maniquí para entender mejor la volumetría del cuerpo y sus articulaciones principales.

- A continuación, ya se puede dibujar el maniquí completo. Para realizar este dibujo comenzaremos haciendo un esbozo esquemático de la pose, en el cual estudiaremos la posición de la cabeza, la curvatura de la columna, la colocación de la caja torácica, el movimiento de la cadera, así como las articulaciones de las extremidades.

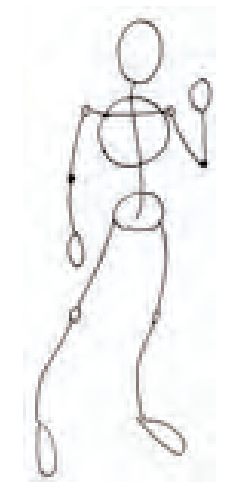

Realizado por Lucía Ribelles Santos 
- Sobre el esquema anterior se va concretando el dibujo de las partes del maniquí, la proporción de la figura y el movimiento de la pose.

\section{Guía de autocorrección}

- Una vez acabado cada dibujo es conveniente verificar las siguientes cuestiones:

- Direcciones del espacio: inclinación del tronco respecto de la vertical y perpendiculares a dicha inclinación con las dimensiones de la cabeza y del tronco.

- Longitudes generales y direcciones en el espacio.

- Grosor del tronco.

- Longitud del fémur. Situación de las rodillas y orientación del movimiento.

- Articulaciones del maniquí.

- Situación de los hombros y la cabeza del fémur.

- Hay que detectar los errores de proporción más habituales: acortamiento de las extremidades inferiores, cabeza desproporcionada y manos mal posicionadas.

\section{E. Ejemplos resueltos}

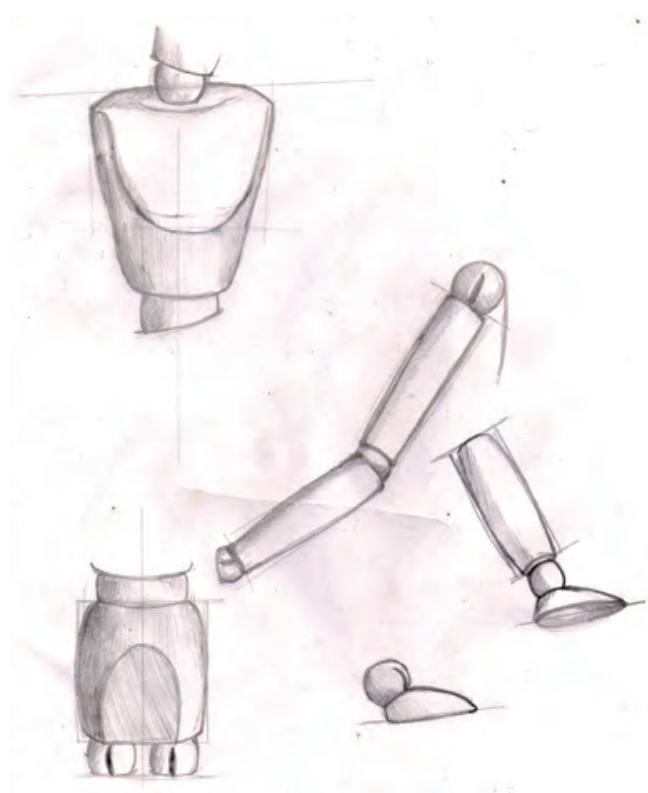

Realizado por Julia Badía Bellés
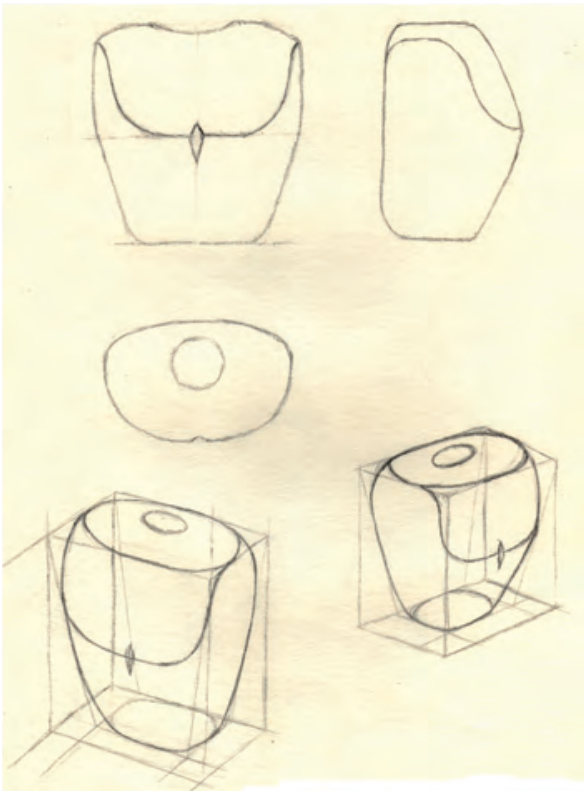

Realizado por Yasmin Moucharrafie Abdulsamad 


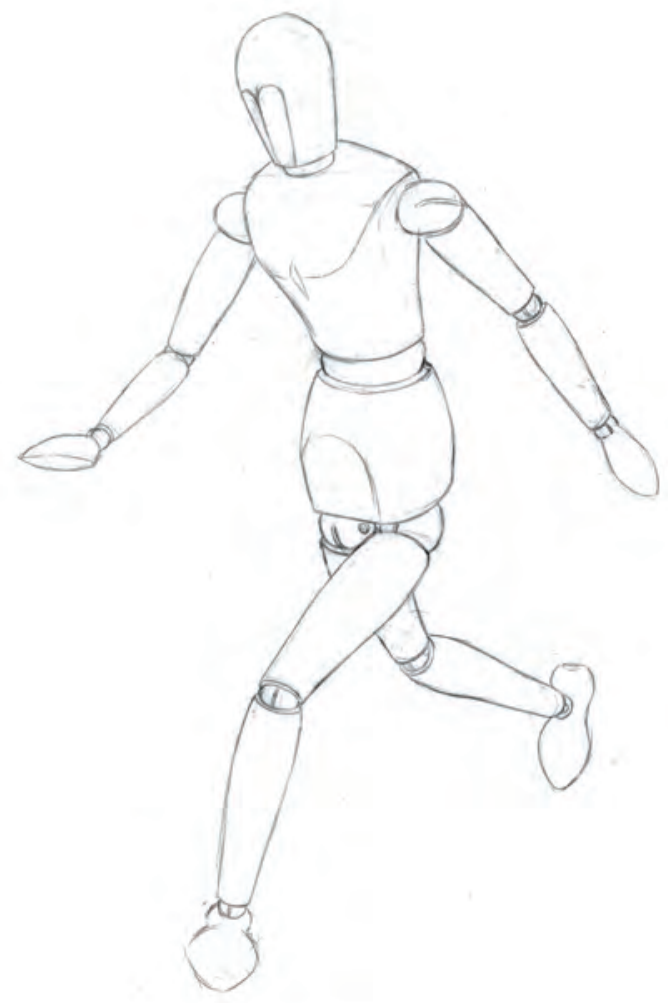

Realizado por Rocío Carreras Rubio

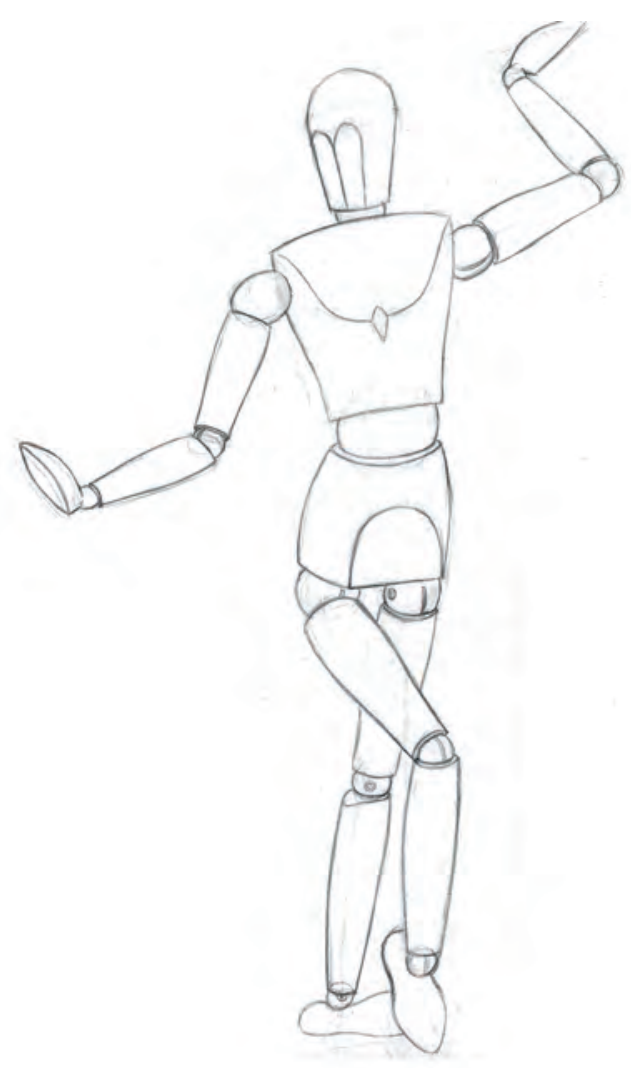

Realizado por Rocío Carreras Rubio 


\section{Práctica 29 \\ El factor humano en el producto}

La presencia de la figura humana contribuye a explicar mejor la relación de proporciones entre el producto y la escala humana, así como el manejo y la utilidad del objeto. Por ello es fundamental dominar la representación del cuerpo en movimiento. Generalmente, estos dibujos solo actúan como referente y no es necesario representarlos con grandes detalles. Un simple dibujo esquemático pero correcto de proporciones y movimiento será suficiente.
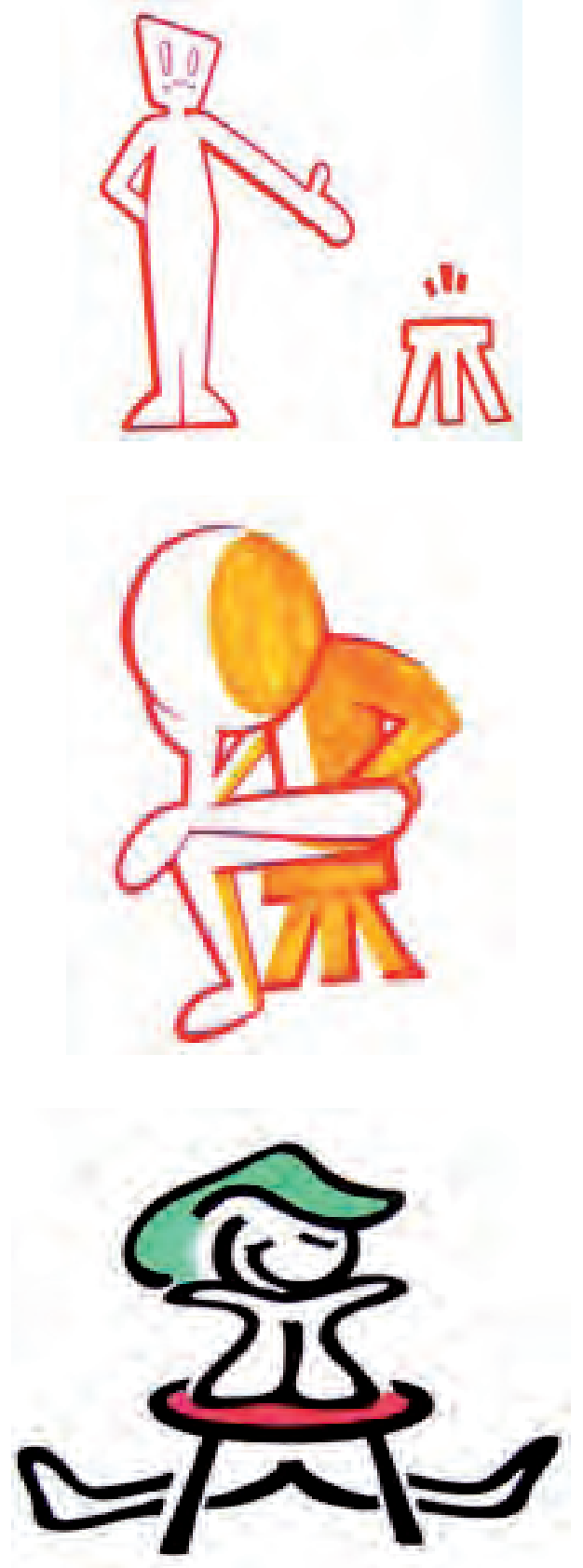
En el ámbito del diseño, muchas veces, la figura humana aparece representada dentro de un entorno espacial concreto e interactuando con objetos. El diseñador debe saber resolver gráficamente estas relaciones con dibujos sencillos pero correctos. Una de estas problemáticas más frecuente es resolver la figura humana vestida. Un acertado estudio gráfico de las prendas aporta movimiento y volumetría al dibujo del cuerpo humano. Por este motivo, es aconsejable practicar la representación de diferentes tipos de tejidos y realizar apuntes esquemáticos de personas con atuendos diversos.

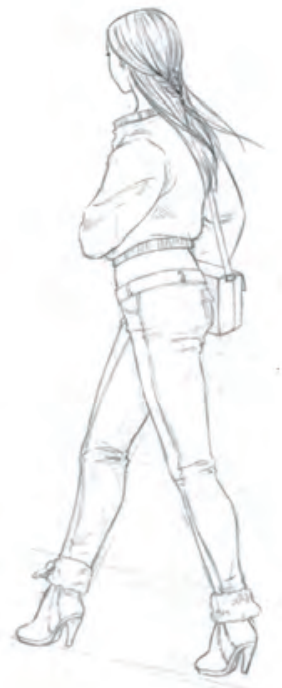

Realizado por Rocío Carreras Rubio

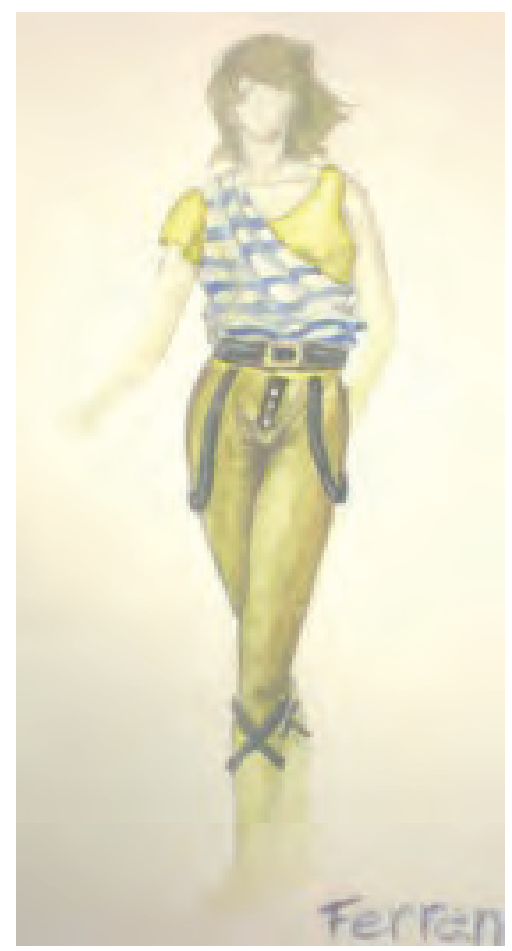

Realizado por Ferran Torres 


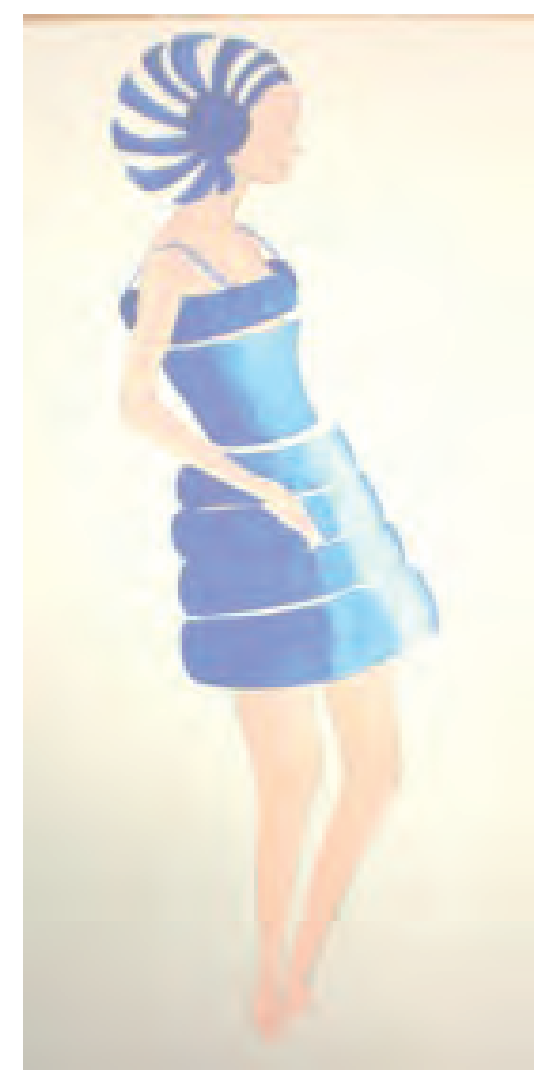

Realizado por María Serra

\section{A. Objetivos}

Con esta práctica alcanzaremos los siguientes objetivos:

- Dominar la proporción de la figura humana.

- Dibujar el cuerpo humano en movimiento.

- Estudiar las articulaciones fundamentales de la anatomía humana.

- Representar la figura humana interactuando con el entorno objetual: objetos, espacio interiores y exteriores, con prendas de vestir y complementos...

\section{B. Materiales}

- Papel formato DIN A4

- Lápiz de dureza HB

- Goma de lápiz 


\section{Guía de ejecución}

\section{Planteamiento}

- La práctica consistirá en realizar varios dibujos de personas en diferentes poses.

- Los dibujos se realizarán a línea y se aplicará un ligero claroscuro para mostrar la volumetría del cuerpo.

\section{Proceso de ejecución del dibujo}

- Se realizará un dibujo esquemático del cuerpo adaptado a la pose del modelo.

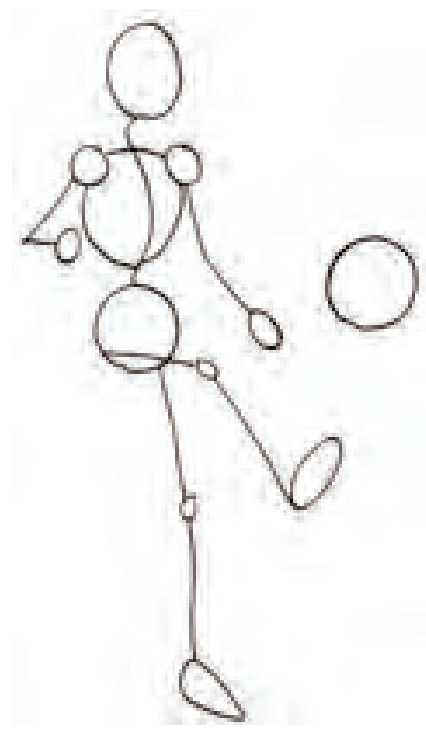

- A continuación, se dibujará sobre él la figura volumétrica prestando especial atención a la articulación del movimiento y la correcta representación de la anatomía.

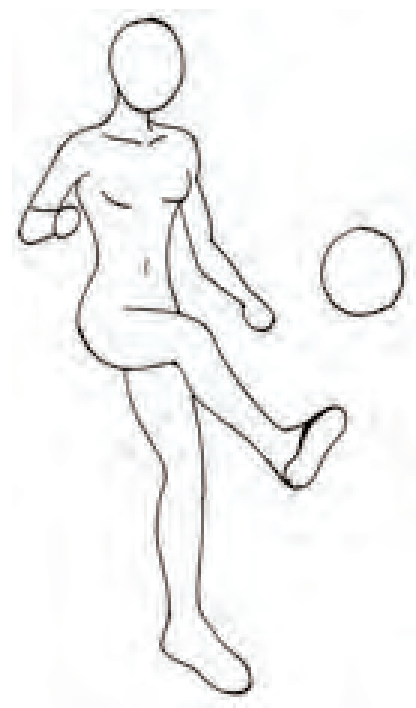


- Es recomendable realizar estudios previos de dibujo y claroscuro de telas de diferentes tejidos y estampados, con la finalidad de adquirir la praxis necesaria para representar posteriormente la figura humana vestida.

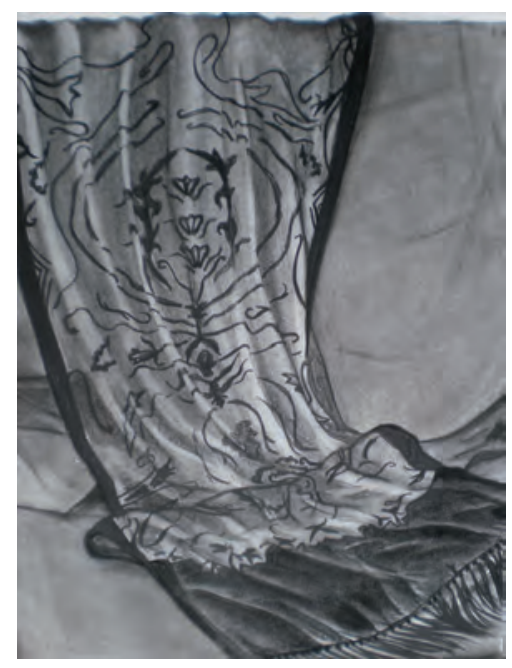

Dibujo realizado con carbón comprimido y difuminos por Lara Ordóñez

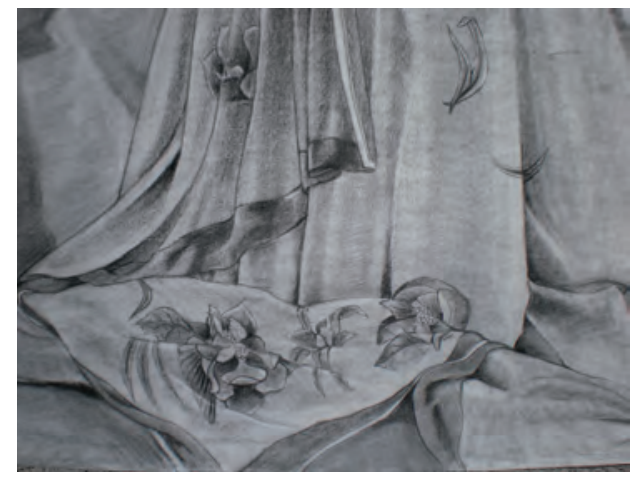

Dibujo realizado con carbón comprimido y difuminos por Rocío Carreras

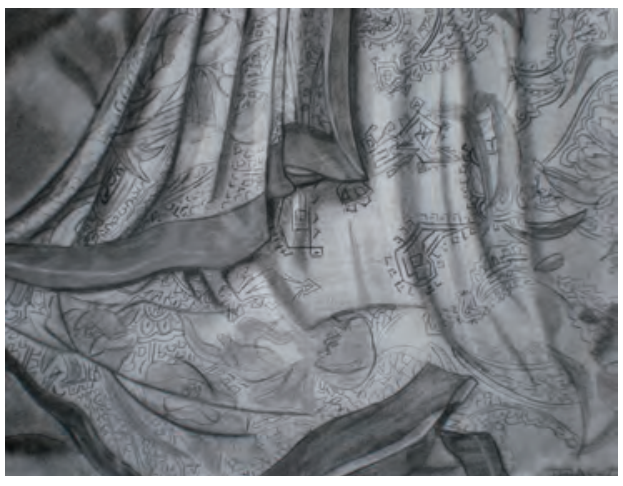

Dibujo realizado con carbón comprimido y difuminos por Iván Pérez 


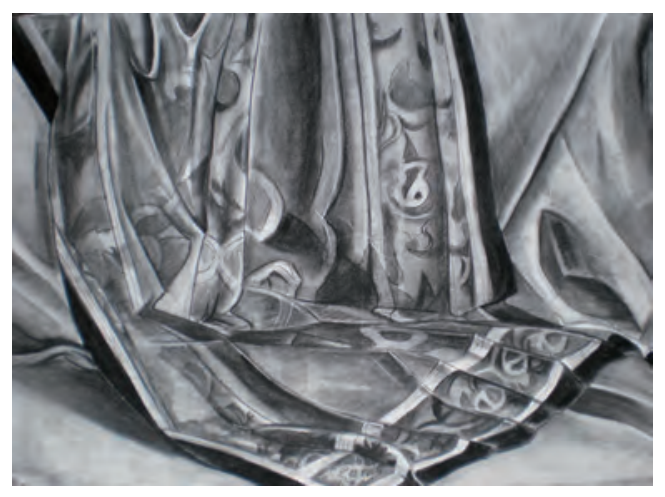

Dibujo realizado con carbón comprimido y difuminos por Sara Gómez

- Finalmente, se añaden los detalles necesarios según el grado de iconicidad que se pretenda.

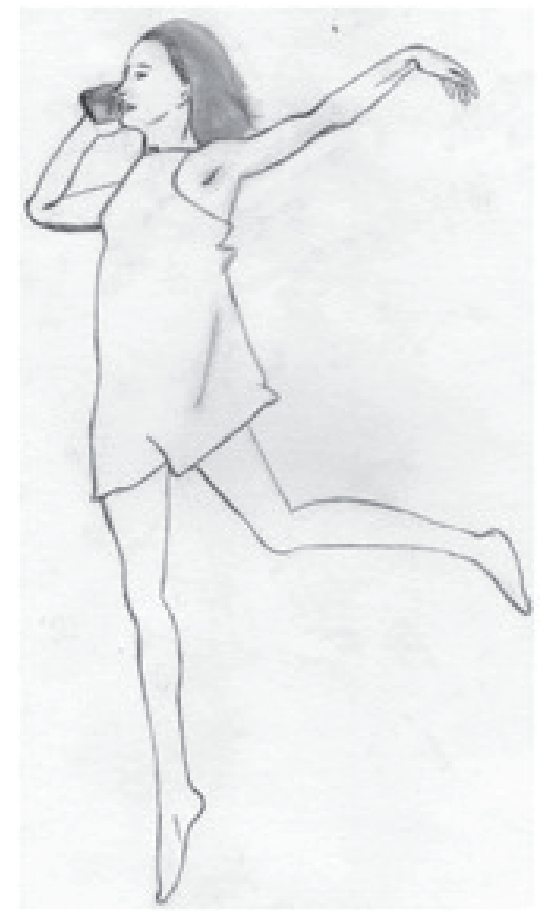

Realizado por Virginia Fuente

\section{Guía de autocorrección}

- Una vez acabado cada dibujo es conveniente comprobar la proporción de cada una de las partes principales del cuerpo.

- Hay que detectar los errores de perspectiva de la cabeza, tronco y extremidades.

- Las articulaciones principales de cabeza, hombros, codos, cadera y rodillas deben reproducir de forma lógica la pose de la figura. 


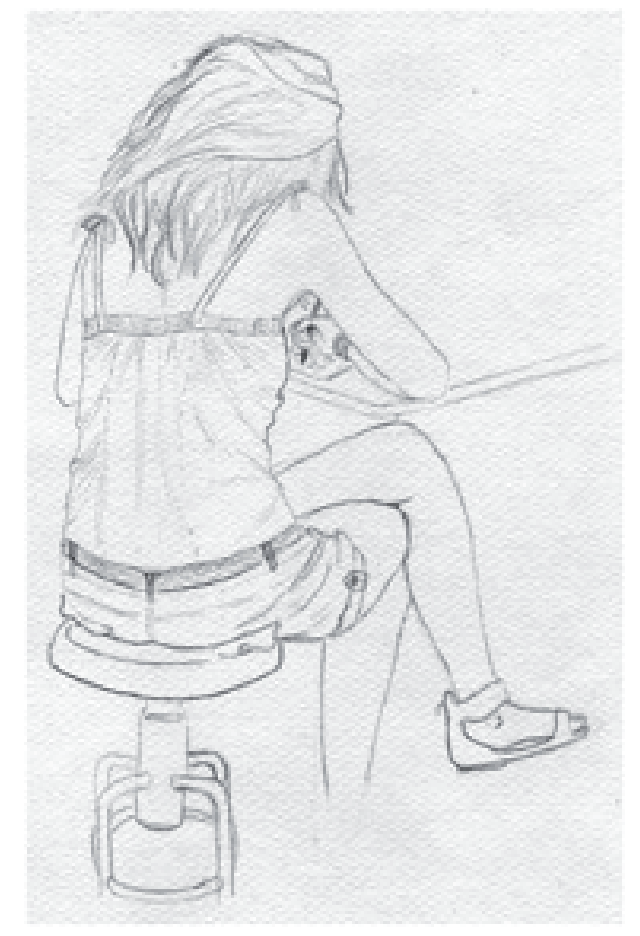

Realizado por Pamela Sánchez de las Matas

\section{E. Ejemplos resueltos}

En estos ejemplos podemos observar los dos tipos de representación del cuerpo humano, las primeras con un tratamiento más figurativo de la pose y las últimas, esquematizando la figura humana para una aplicación directa en el dibujo de producto.

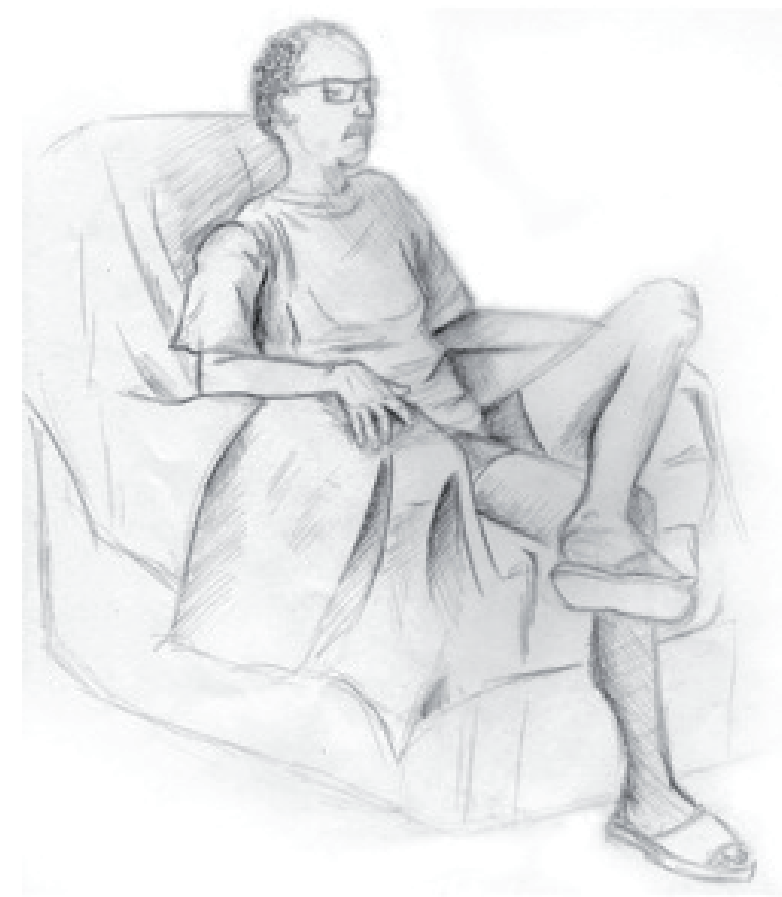

Realizado por Raquel Villanueva Hidalgo 


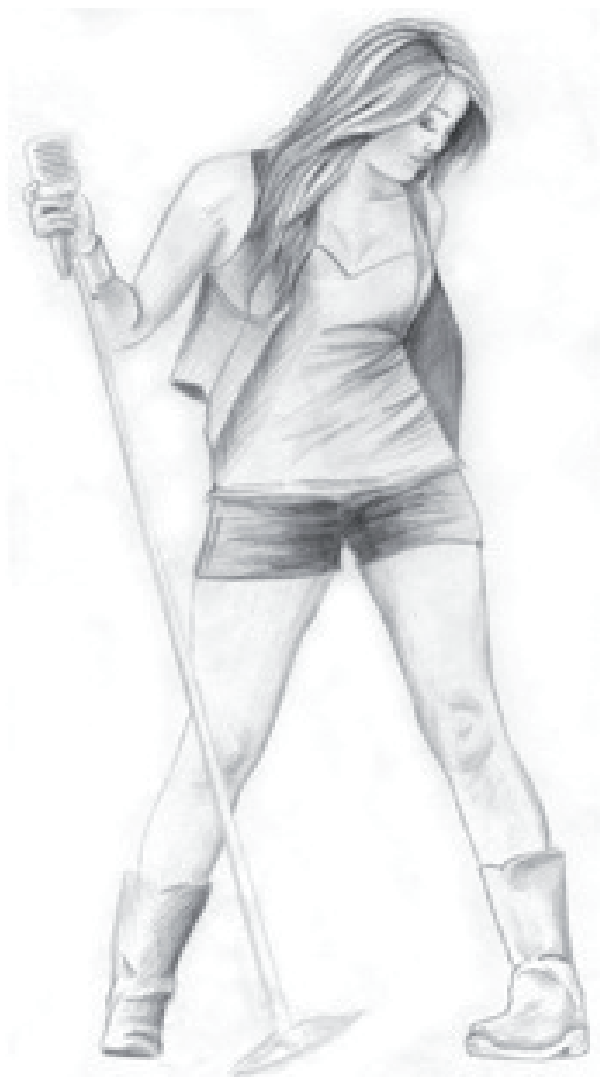

Realizado por Raquel Villanueva Hidalgo

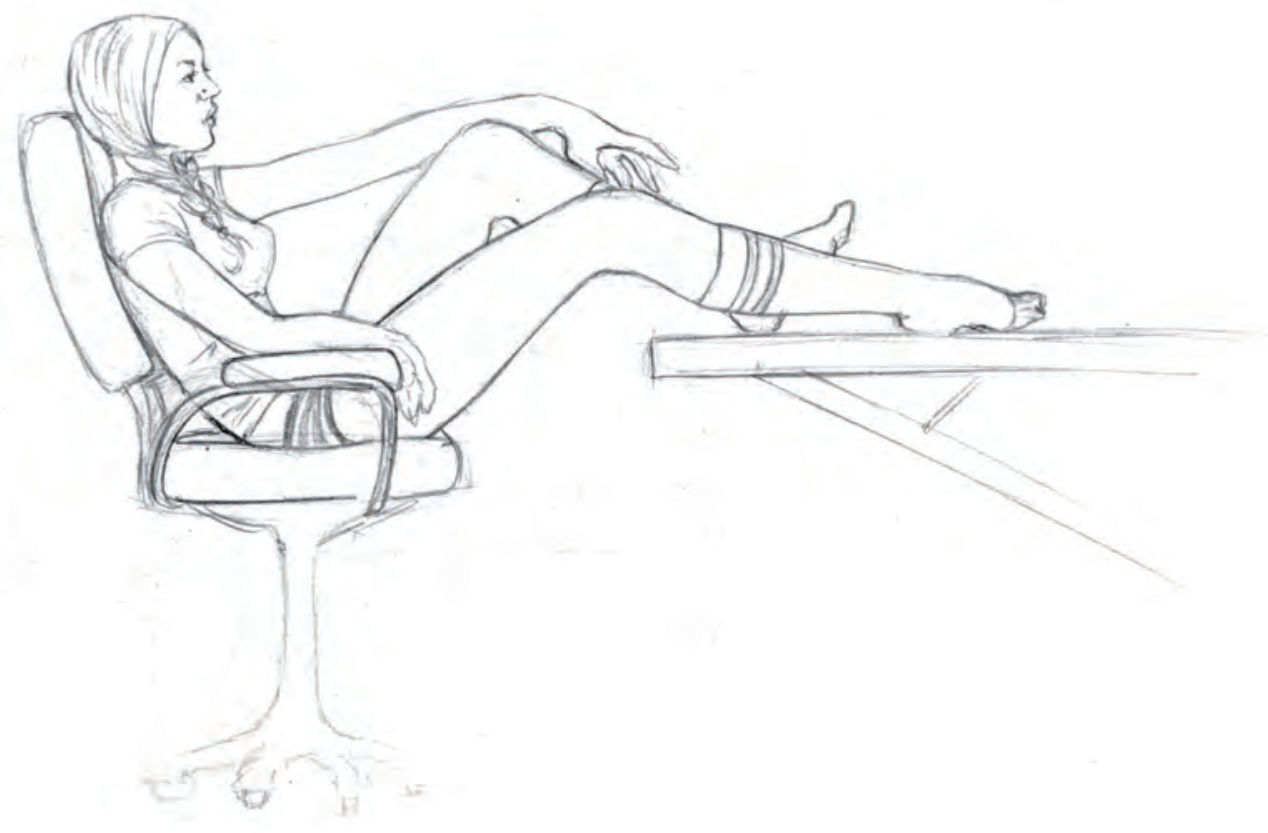

Realizado por Rocío Carreras Rubio 


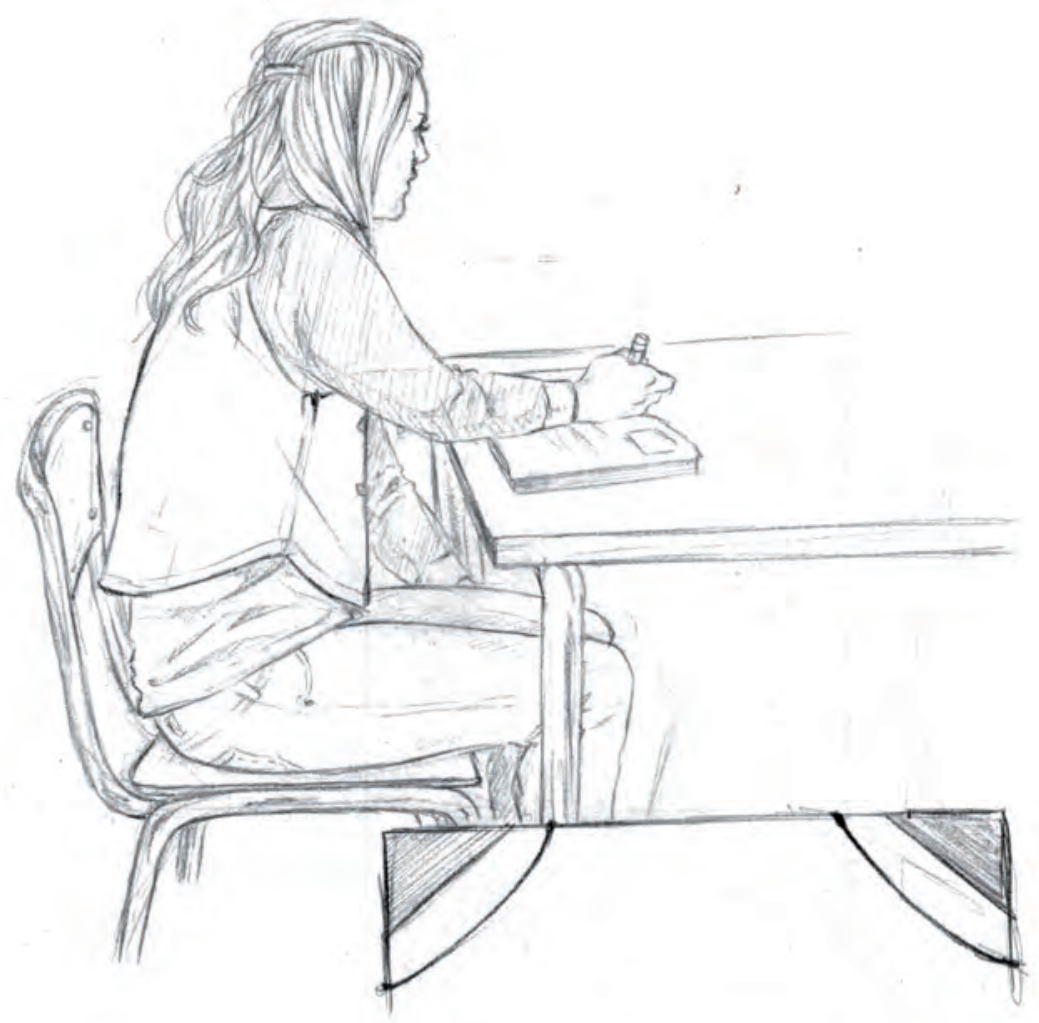

Realizado por Rocío Carreras Rubio

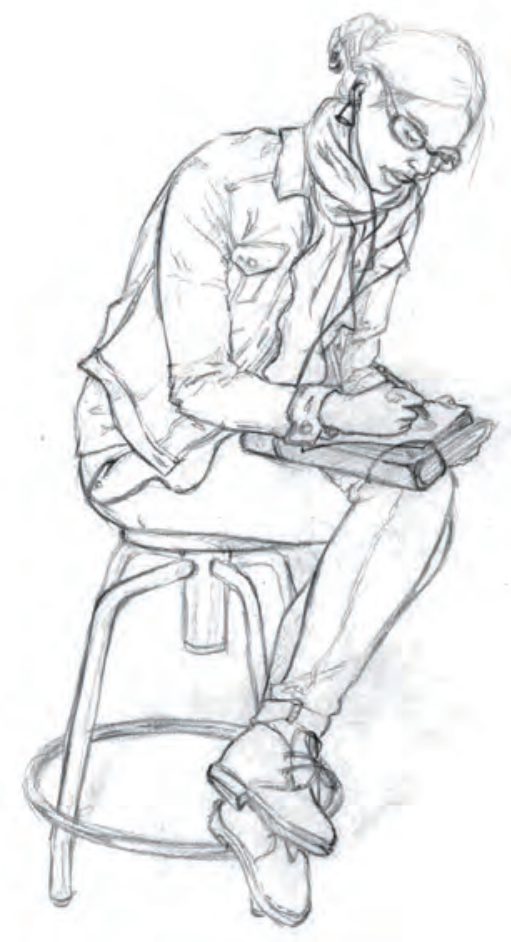

Realizado por Rocío Carreras Rubio 


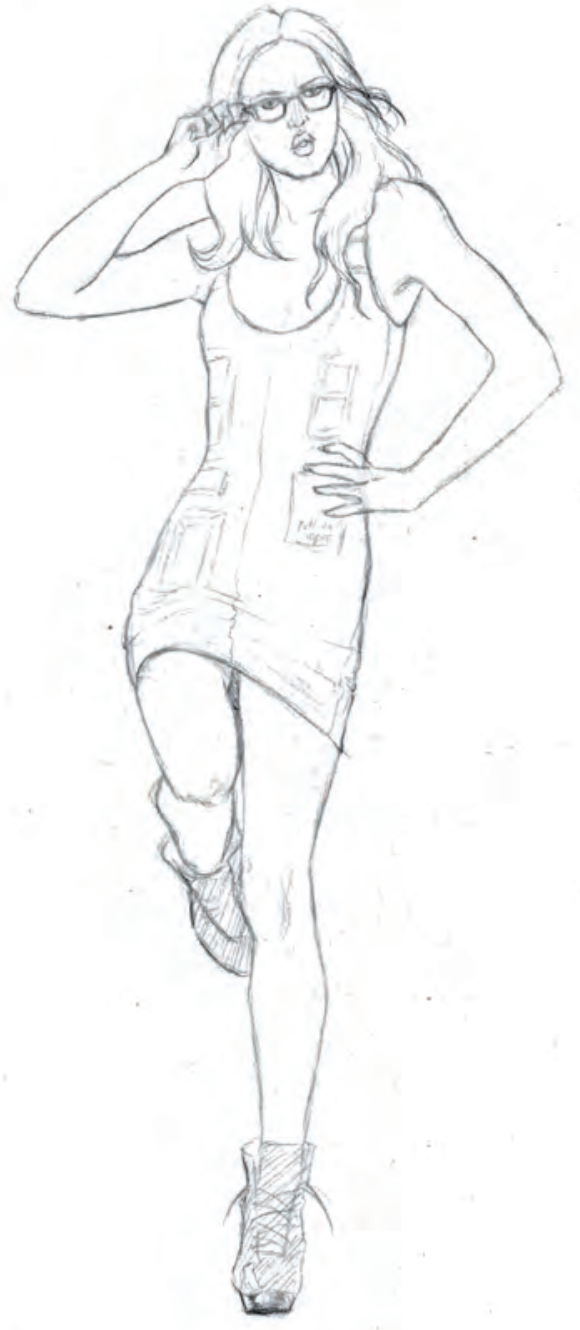

Realizado por Rocío Carreras Rubio 

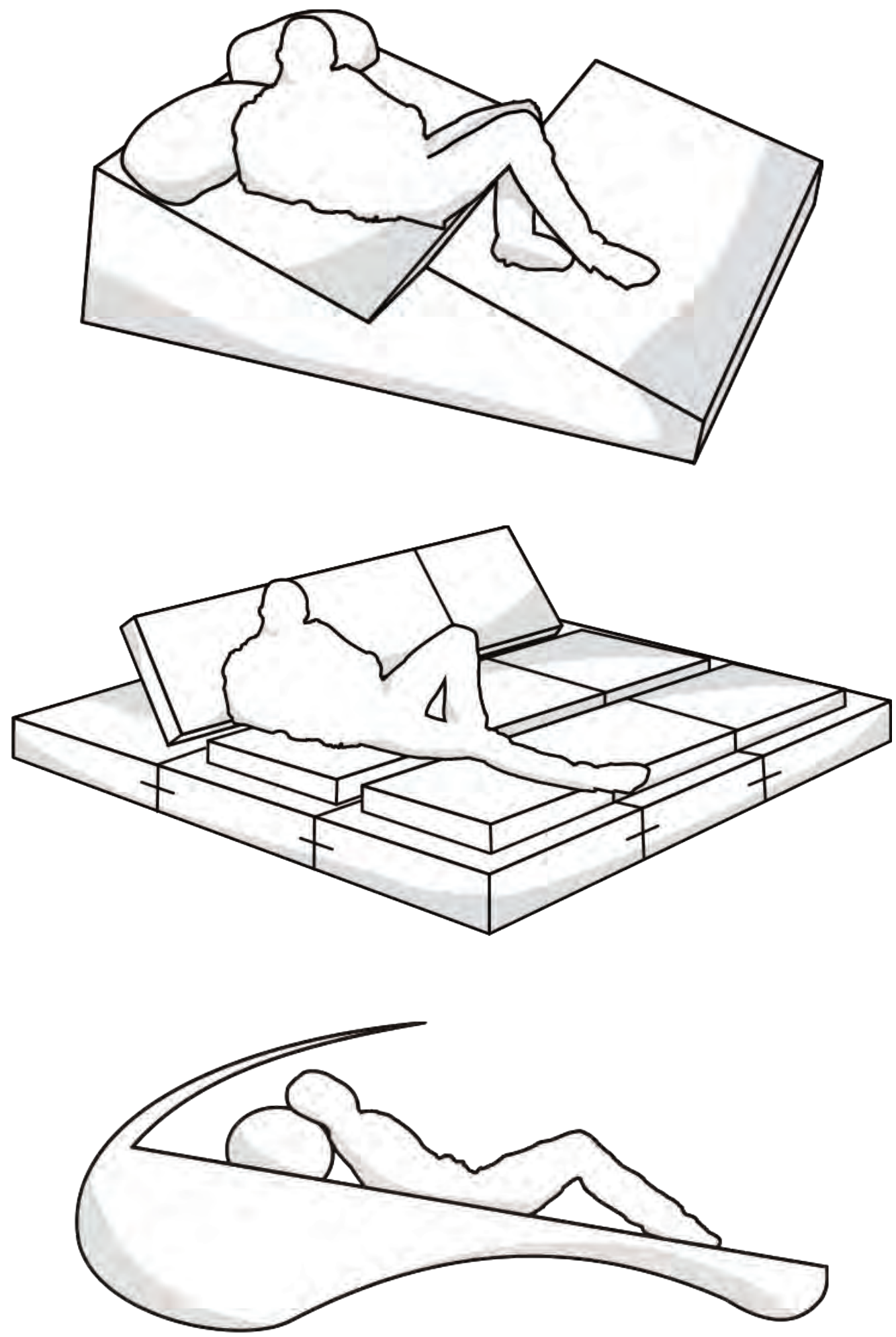

Ejemplos de dibujos esquemáticos de figura humana interactuando con un objeto. Realizado por Carlos García 


\section{Práctica 30 Las manos}

Después del rostro, la parte del cuerpo más compleja y variada es la mano, ya que tiene una disposición funcional diferente según se encuentre abierta o cerrada y también porque existen muchas tipologías: rudas, finas, manos de niños, de ancianos, etc.

En el diseño, la representación de la mano tiene un protagonismo especial porque acompaña a los objetos para mostrar su funcionamiento: asir, pinzar, estirar, enroscar, etc. Existiendo campos del diseño como el Packaging donde es especialmente importante mostrar la relación ergonómica entre el diseño del producto y la mano.

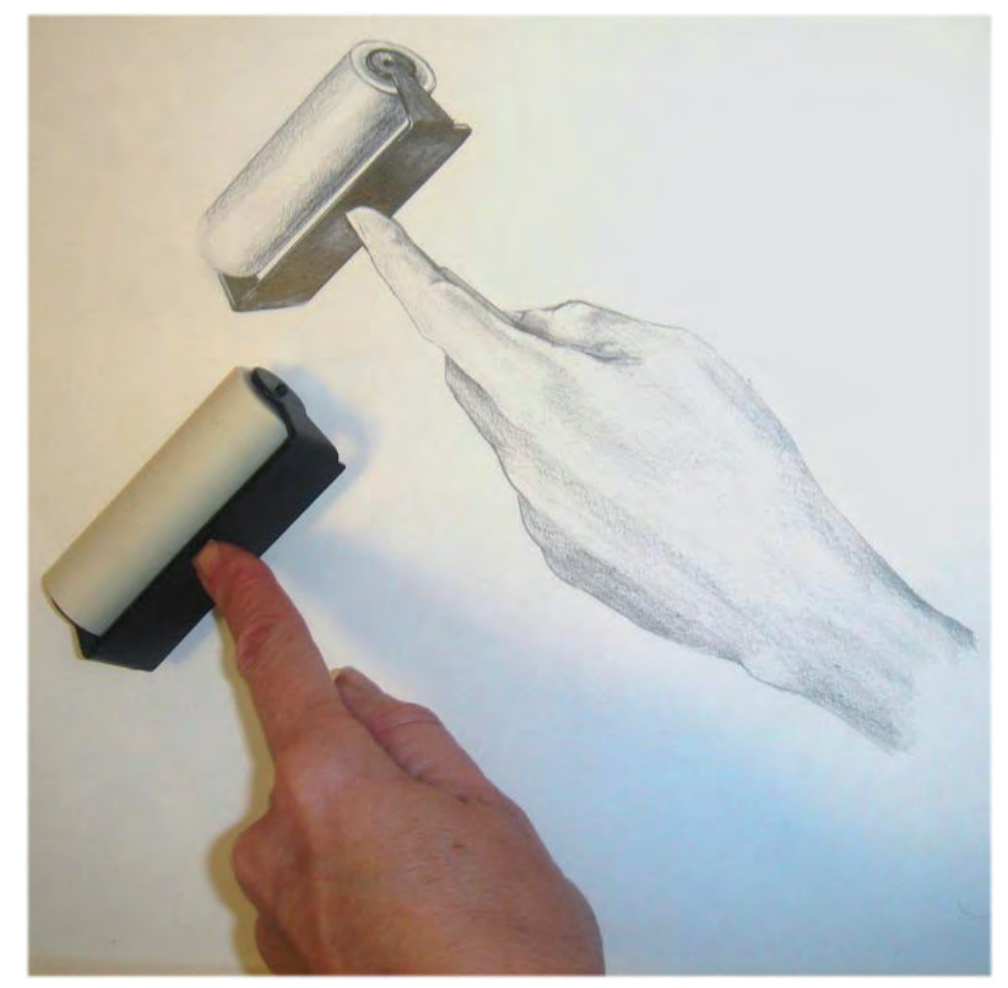

Realizado por Carmen Pesudo

En el dibujo de las manos es imprescindible conocer su estructura. La mano se divide en dos partes fundamentales:

- El esqueleto de la palma de la mano tiene forma de trapecio curvado.

- Y los dedos que parten de manera radial desde la palma de la mano. Es importante observar el ángulo que se forma entre los dedos y la palma de la mano. 


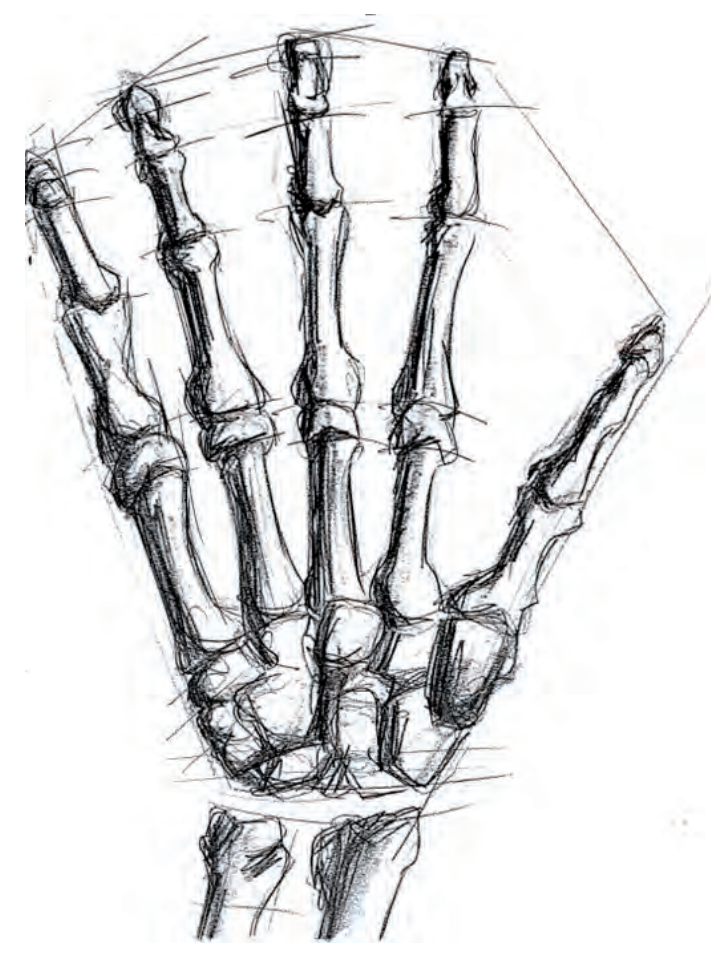

Esqueleto de la mano

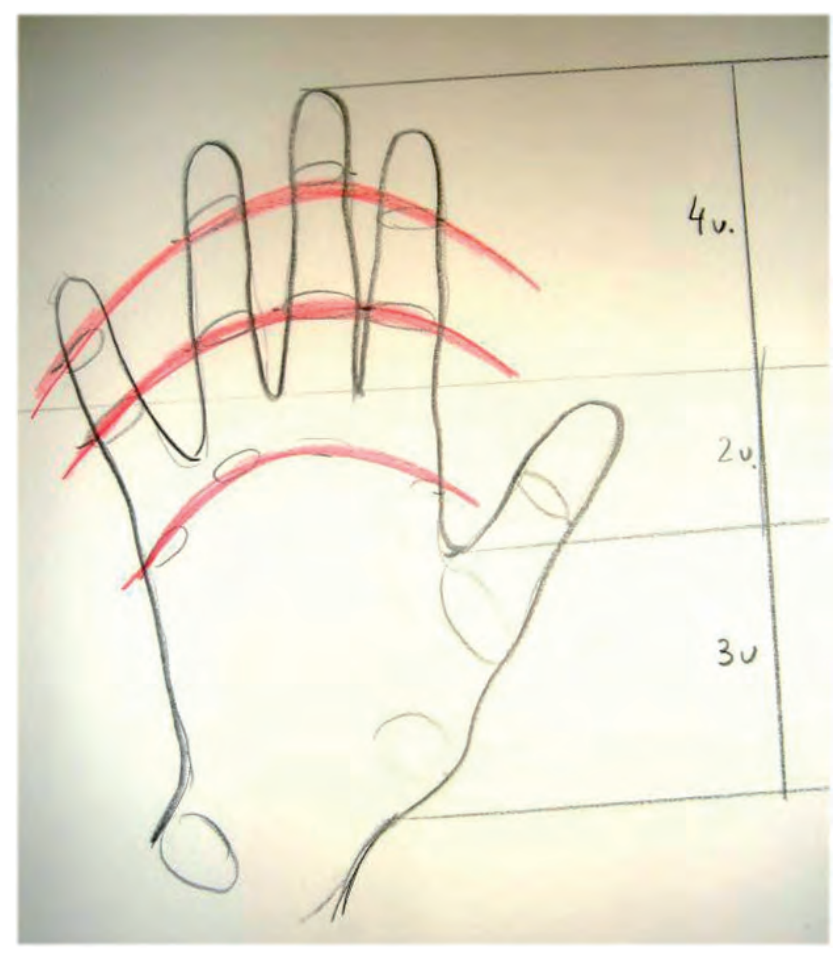

Realizado por Carmen Pesudo 


\section{A. Objetivos}

Con esta práctica alcanzaremos los siguientes objetivos:

- Conocer la proporción de la mano.

- Dibujar correctamente la mano en cualquier posición.

- Representar la mano sujetando o manipulando un objeto.

\section{B. Materiales}

- Papel formato DIN A4

- Lápiz de dureza HB

- Goma de lápiz

\section{Guía de ejecución}

\section{Planteamiento}

- La práctica consistirá en realizar varios dibujos de una mano interactuando con diversos objetos.

- Los dibujos se realizarán a línea y se aplicará un ligero claroscuro para mostrar la volumetría de la mano.

- No deben señalarse demasiados detalles. Únicamente se representarán arrugas y pliegues fundamentales.

\section{Proceso de ejecución del dibujo}

- Representación esquemática de la estructura de la mano.

a) Comenzamos dibujando la palma de la mano como un trapecio.

b) A continuación, situamos los dedos de forma radial y trabajando con arcos concéntricos la disposición de las articulaciones de las falanges y la longitud de los dedos.

- Representación concreta del contorno y detalles de la mano.

a) Sobre el esquema que hemos dibujado comenzamos a concretar los detalles y forma de la mano, sin excedernos en la cantidad de pliegues y arrugas. 
b) Es importante visualizar cada dedo como un cilindro.

c) Las uñas deben ser representadas en perspectiva según el movimiento de cada dedo.

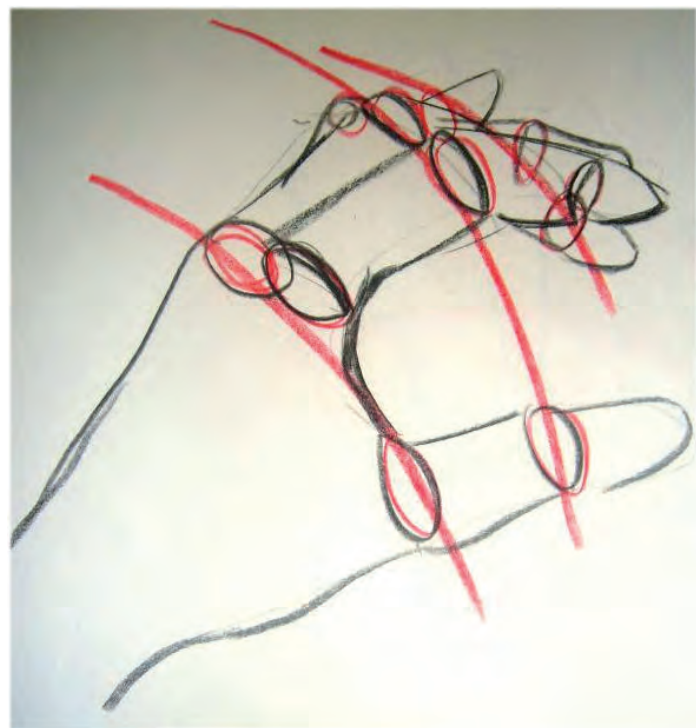

Realizado por Carmen Pesudo

- Representación del claroscuro.

a) El claroscuro debe aplicarse de forma simplificada.

b) Debe acentuar las sombras que se generan en los huecos y rehundidos de los pliegues fundamentales.

c) Es importante visualizar cada dedo como un cilindro y aplicar consecuentemente su gradiente de claroscuro.

\section{Guía de autocorrección}

- Se comprueba la correcta disposición de las partes principales de la mano: proporciones, tamaños y direcciones espaciales.

- Revisar la disposición radial de las falanges y la longitud correcta de los dedos.

- La mano y el objeto deben guardar una coherencia formal: mismas proporciones, adecuación a la forma...

- Comprobar que el claroscuro acentúa las sombras que se generan en los huecos y rehundidos de los pliegues fundamentales de la mano.

- Es importante visualizar cada dedo como un cilindro y aplicar consecuentemente su gradiente de claroscuro. 
- Controlar que el objeto se representa con la máxima objetividad en relación a las proporciones y su funcionalidad.

- Comprobar que el acabado del dibujo aporta verismo, concreción formal y calidad en la aplicación de la técnica.

\section{E. Ejemplos resueltos}

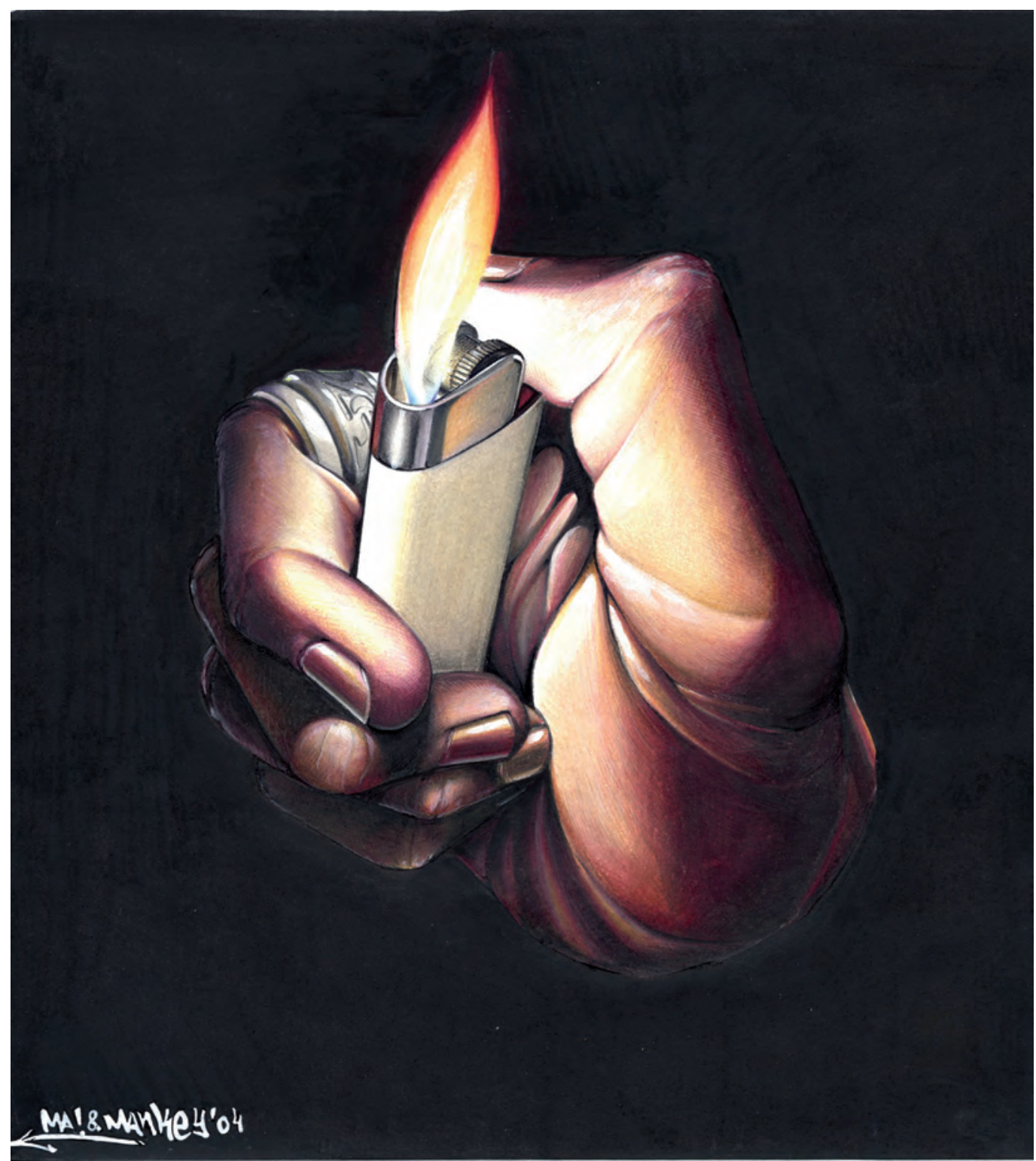

Realizado por Mario Fernández 


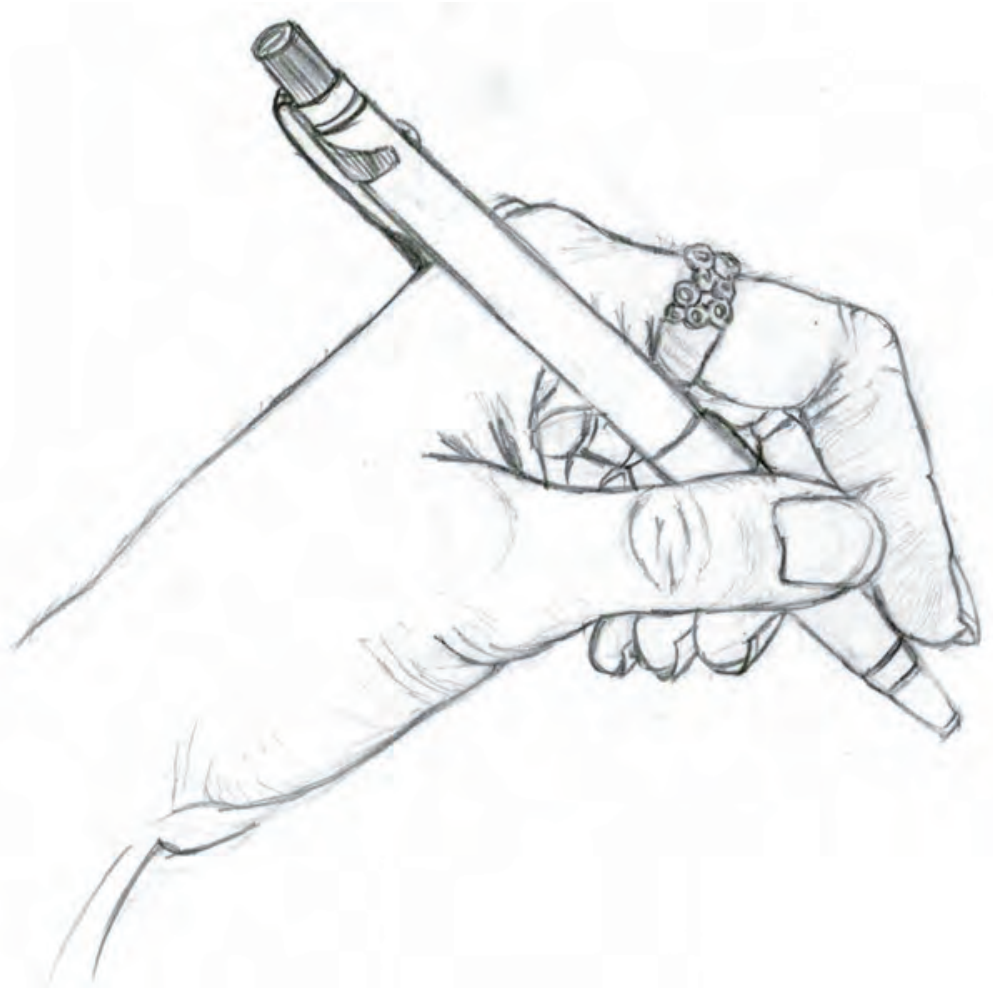

Realizado por Sara Tirado

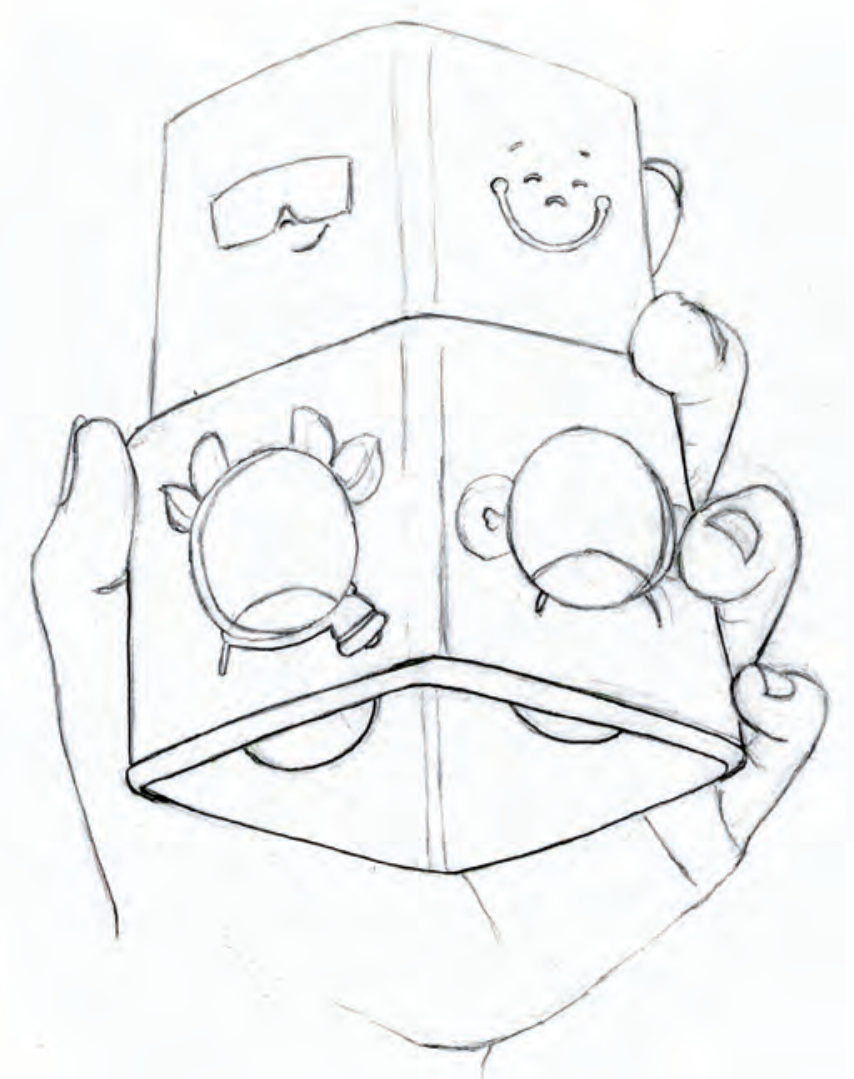

Realizado por Natalia Sanchís 

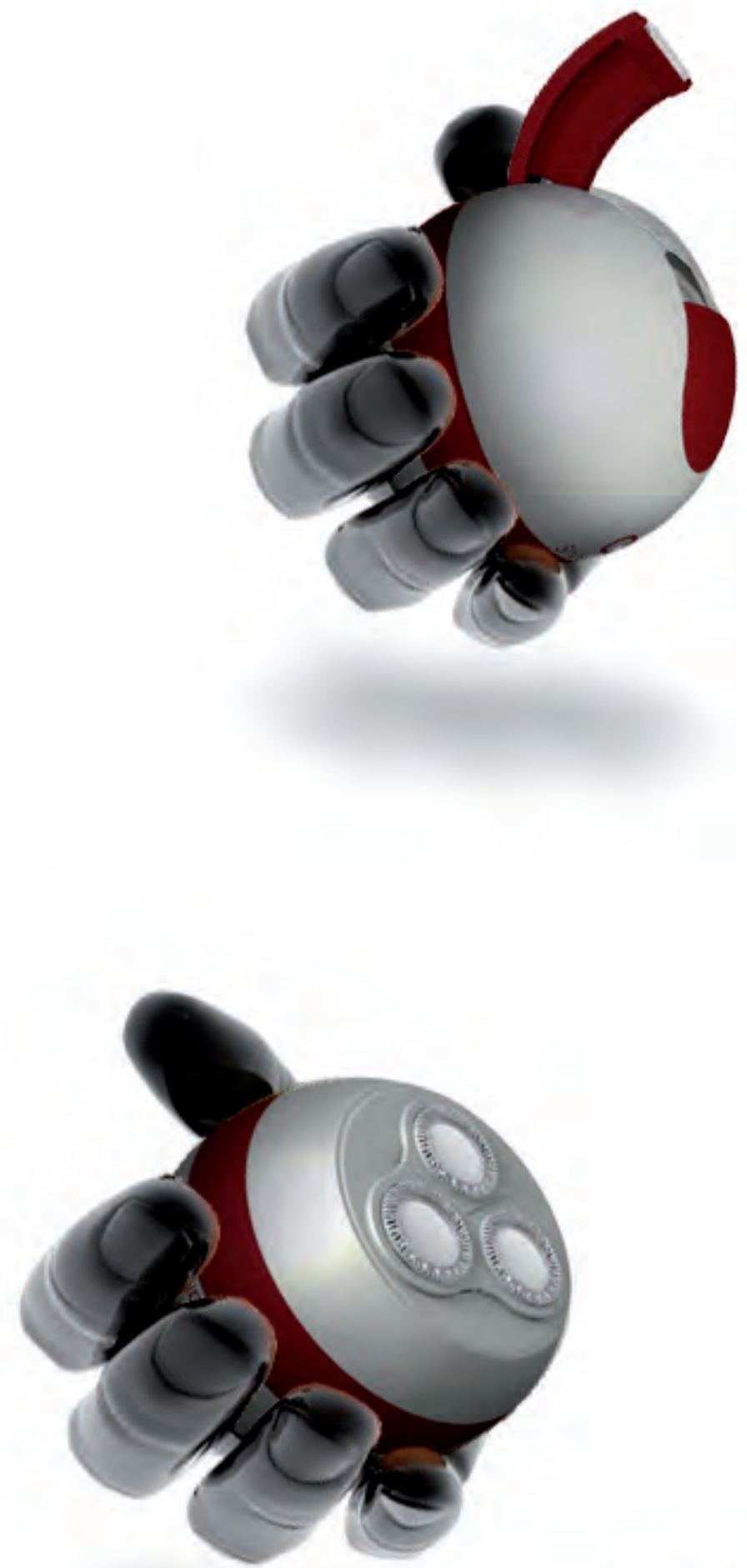

Renderizado realizado por Javier Bastán, Carlos García, Javier Gascó y Tarsio Valero 
BIBLIOGRAFÍA 
Albarracín, J.; Julián, F.: Dibujo para diseñadores industriales. Parramón Ediciones, Barcelona, 2005.

AlBers, J.: La interacción del color. Alianza, Madrid, 1984.

Bann, D., Gargan J.: Cómo corregir pruebas en color. Gustavo Gili. Serie Manuales de Diseño, Barcelona, 1990.

Barcsay, J.: Anatomía artística del cuerpo humano. Daimon, Budapest, 1968.

Buchan, J.: Escuela de arte paso a paso: Aerografía. Blume, Barcelona, 1991.

CAmpos, C.: Diseño de productos. Maomao Publicaciones, Barcelona, 2006.

CAmpos, J.: Dibujo Técnico: dibujo geométrico, sistemas de representación y análisis de formas. Madrid, Campos, 1978.

Dondis, D. A.: La sintaxis de la imagen. Gustavo Gili, Barcelona, 1976.

Droste, M.: Bauhaus 1919-1933. Bauhaus-Archiv Museum für Gestaltung, Berlín, 1993.

EDWARds, B.: Aprender a dibujar. Hermann Blume, Madrid, 1988.

Germani, R., Fabris, A.: Fundamentos del proyecto gráfico. Don Bosco, Barcelona, 1981.

GARAU, A.: Las armonías del color. Paidós, Barcelona, 1986.

GiBILIsCo, S.: Ilusiones ópticas. Rompecabezas, paradojas y enigmas. McGrawHill, Madrid, 1984.

Gómez-Senent, E.: Diseño industrial. Publicacions de la Universitat Politècnica de València, Valencia, 1986.

HAYes, C.: Guía completa del dibujo y la pintura. Técnicas y materiales. Tursen/ Hermann Blume, Madrid, 1986.

Henry, K.: Dibujo para diseñadores de producto. De la idea al papel. Promopress, Barcelona, 2012.

JoHn, L.: Cómo preparar diseños para la imprenta. Gustavo Gili, Barcelona, 1989.

Jones, J. Ch.: Diseñar el diseño. Gustavo Gili, Barcelona, 1984.

Koren, L., Meckler, R.: Recetario de diseño gráfico. Gustavo Gili, Barcelona, 1992.

LöBach, B.: Diseño industrial. Gustavo Gili, Barcelona, 1976.

MaAgnus, G. H.: Manual para dibujantes e ilustradores. Gustavo Gili, Barcelona, 1991.

MAIER, M.: Procesos elementales de proyección y configuración. Curso Básico de la Escuela de Artes Aplicadas de Basilea (4 volúmenes). Gustavo Gili, Barcelona, 1982.

Magnus, G. H.: Manual para dibujantes e ilustradores. Una guía para el trabajo práctico. Gustavo Gili, Barcelona, 1980.

Maldonado, T.: El diseño industrial reconsiderado. Gustavo Gili, Barcelona, 1991.

Maltese, Corrado: Las técnicas artísticas. Madrid. Manuales Arte Cátedra. pp. 479, Madrid, 1990.

Parramón, J. M. et al.: Colección «Aprender haciendo». Parramón Ediciones, Barcelona.

PiPes, A.: Dibujo para diseñadores. Blume, Barcelona, 2008.

Porter, T., Goodman, S.: Manual de técnicas gráficas para arquitectos (4 volúmenes). Gustavo Gili, Barcelona, 1984.

—: Manual de diseño para arquitectos, diseñadores gráficos y artistas. Gustavo Gili, Barcelona, 1990. 
Powell, D.: Técnicas de presentación. Guía de dibujo y presentación de proyectos $y$ diseños. Tursen-Blume, Madrid, 1986.

RaYness, J.: Human anathomy for the artist. The Hamlyn Publishing Group, Londres, 1979.

Russell, D.: Biblioteca del color: blanco y negro. Amarillo. Rojo y Azul. Colores Pasteles (5 volúmenes). Gustavo Gili, Barcelona, 1990.

Sмith, R.: Manual del artista. Hermann Blume, Madrid. 1990.

TeIssig, K.: Las técnicas del dibujo. Libsa, Madrid, 1990.

Sмiтн, S.: Dibujar y abocetar, Blume, Madrid, 1983.

Wong, W.: Principios del diseño en color. Gustavo Gili, Barcelona, 1991.

—: Fundamentos del diseño bi-tridimensional. Gustavo Gili, Barcelona, 1991.

\section{Selección de títulos comentados}

Albarracín, J., Julián, F.: Dibujo para diseñadores industriales. Parramón Ediciones, Barcelona, 2005.

Este libro de centra en un aspecto fundamental del proceso creativo del producto: la utilización del dibujo a mano alzada en las primeras fases del diseño del objeto. Tras una presentación en los medios e instrumentos de dibujo y de los conceptos básicos detrás de los primeros trazos, se explican las técnicas para que el diseñador pueda plasmar y transmitir su pensamiento gráfico, sus ideas creativas. La obra también incide en aspectos complementarios, como la importancia del factor humano o el posible escenario donde convivirán los nuevos diseños. Por último, incluye un capítulo sobre el estudio técnico, que constituye una parte esencial de la descripción del proyecto, del lenguaje necesario para su realización.

SмIтн, S.: Dibujar y abocetar, Blume, Madrid, 1983.

Guía esencial de dibujo y boceto al alcance de todos. Incluye diversos capítulos que se ocupan paso a paso de la figura, el paisaje, el retrato y la naturaleza muerta, así como del acabado y enmarcado. Contiene 176 páginas rebosantes de información práctica. Texto claro y explícito, junto con la descripción de procedimientos ilustrados paso a paso y ejemplos de obras acabadas.

Powell, D.: Técnicas de presentación. Guía de dibujo y presentación de proyectos y diseños. Tursen-Blume, Madrid, 1986.

Este libro contiene más de 300 ilustraciones en color y en blanco y negro, convirtiéndose en una magnifica guía para presentar ideas de forma atractiva y veraz.

Campos, C.: Diseño de productos. Maomao Publicaciones, Barcelona, 2006.

Este volumen muestra el presente de los diseños industriales y elabora un extenso catálogo de productos que marcarán la línea por la que discurrirá el diseño industrial de los próximos años. 